\title{
CONTRIBUTION OF CROSS LAMINATED TIMBER PANELS TO ROOM FIRES
}

\author{
A thesis submitted to \\ the Faculty of Graduate and Postdoctoral Affairs \\ in Partial Fulfillment of the requirements for the degree \\ Masters of Applied Science in Civil Engineering \\ by \\ Cameron James $\mathbf{M}^{\mathfrak{c}}$ Gregor \\ BEng Mechanical (Hons) \\ Department of Civil and Environmental Engineering \\ Carleton University \\ Ottawa-Carleton Institute of Civil and Environmental Engineering \\ January 2013
}

(C)2013 Cameron McGregor 
Library and Archives

Canada

Published Heritage

Branch

395 Wellington Street

Ottawa ON K1A ON4

Canada
Bibliothèque et

Archives Canada

Direction du

Patrimoine de l'édition

395 , rue Wellington

Ottawa ON K1A ON4

Canada
Your file Votre référence

ISBN: 978-0-494-94267-3

Our file Notre référence

ISBN: $978-0-494-94267-3$
NOTICE:

The author has granted a nonexclusive license allowing Library and Archives Canada to reproduce, publish, archive, preserve, conserve, communicate to the public by telecommunication or on the Internet, loan, distrbute and sell theses worldwide, for commercial or noncommercial purposes, in microform, paper, electronic and/or any other formats.

The author retains copyright ownership and moral rights in this thesis. Neither the thesis nor substantial extracts from it may be printed or otherwise reproduced without the author's permission.
AVIS:

L'auteur a accordé une licence non exclusive permettant à la Bibliothèque et Archives Canada de reproduire, publier, archiver, sauvegarder, conserver, transmettre au public par télécommunication ou par l'Internet, prêter, distribuer et vendre des thèses partout dans le monde, à des fins commerciales ou autres, sur support microforme, papier, électronique et/ou autres formats.

L'auteur conserve la propriété du droit d'auteur et des droits moraux qui protege cette thèse. $\mathrm{Ni}$ la thèse ni des extraits substantiels de celle-ci ne doivent être imprimés ou autrement reproduits sans son autorisation.
In compliance with the Canadian Privacy Act some supporting forms may have been removed from this thesis.

While these forms may be included in the document page count, their removal does not represent any loss of content from the thesis.
Conformément à la loi canadienne sur la protection de la vie privée, quelques formulaires secondaires ont été enlevés de cette thèse.

Bien que ces formulaires aient inclus dans la pagination, il n'y aura aucun contenu manquant. 


\section{Abstract}

This thesis describes a series of 5 tests that were conducted at Carleton University Fire Research Laboratory to assess the contribution of Cross Laminated Timber (CLT) panels to the development, duration and intensity of room fires. The tests were conducted in rooms constructed from $105 \mathrm{~mm}$ thick 3 -Ply CLT panels and measured $3.5 \mathrm{~m}$ wide by $4.5 \mathrm{~m}$ long by $2.5 \mathrm{~m}$ high. Propane and furniture fires were used with the CLT panels in protected and unprotected configurations. Data was collected on Heat Release Rate (HRR), room temperatures and charring rates. In protected configurations, no noticeable contribution was observed from the CLT panels, however in unprotected configurations, the CLT panels contributed to the fire load and increased fire growth rates and energy release rates. When charring advanced to the interface between the CLT layers, the polyurethane based adhesive failed resulting in delamination. Delaminated members contributed to the fire load and exposed uncharred timber which increased the intensity and duration of the fire. When delamination occurred, the fire in unprotected rooms continued to burn at high intensity well after the combustible contents in the room were consumed by the fire. These fires were extinguished as they could have resulted in structural failure of the test rooms. 


\section{Acknowledgements}

Firstly I would like to acknowledge my partner, Ruth, without whom I would unlikely have embarked on this journey. Her support and inspiration has been unwavering throughout this process. I'd like to thank my family, who has supported me in many different ways and to Rob who has been with me right the way through.

I would like to thank my co supervisors, Professor George Hadjisophocleous and Professor Steve Craft. Their guidance, advice and direction throughout this process has been invaluable and essential to reaching this point. To Carleton University and the National Research Council of Canada for making available the research facilities and answering all of my questions.

My gratitude to the Natural Sciences and Engineering Research Council of Canada, FPInnovations, Natural Resources Canada and the NEWBuildS network for providing the opportunity, support and the funding to conduct this research. Also to the team at Nordic Engineered Wood who have provided the CLT panels for testing, the technical assistance on design drawing and construction guidance.

To Arthur Turcot, for his patience and countless hours spent on the testing and to Ba Lam-Thien for his technical advice and for facilitating all of my requests.

Lastly a big thank you to all my friends, colleagues and associates who have attended the tests and listened with interest to my stories of burning rooms. 


\section{Contents}

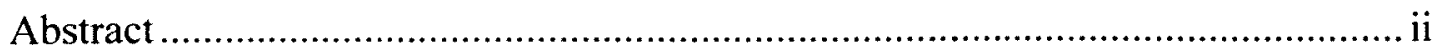

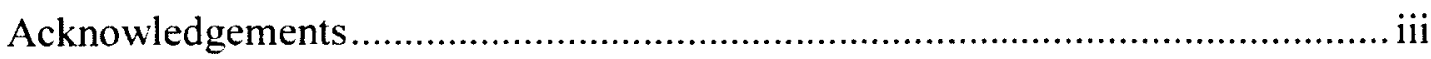

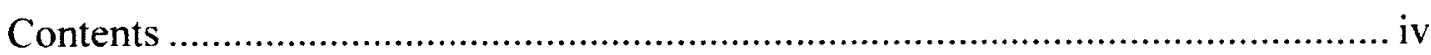

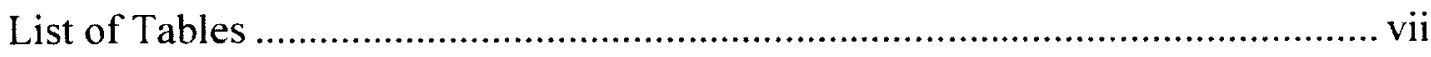

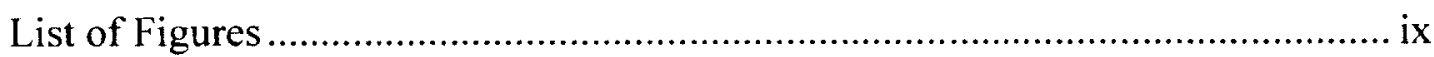

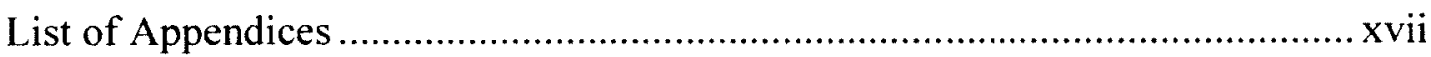

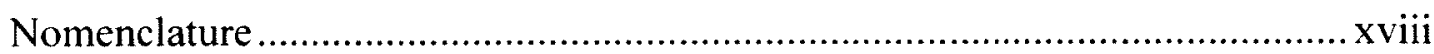

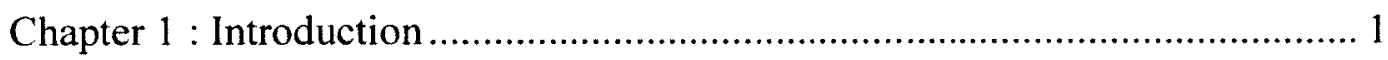

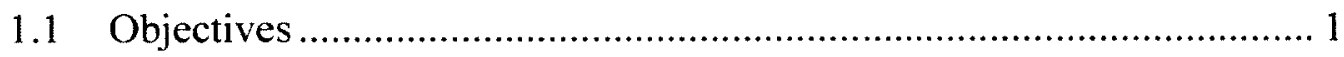

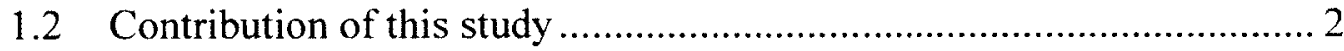

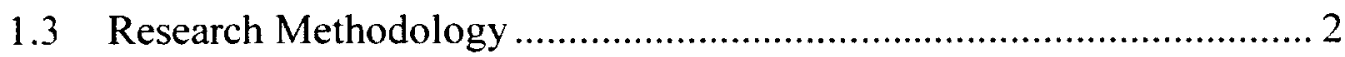

1.4 Cross Laminated Timber ........................................................... 3

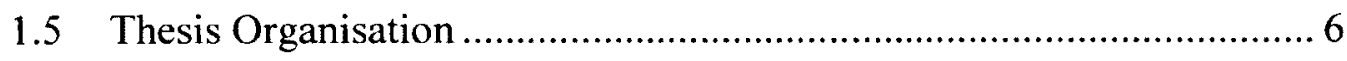

Chapter 2 : Literature Review...................................................................... 7

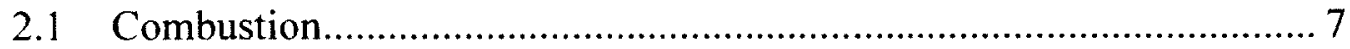

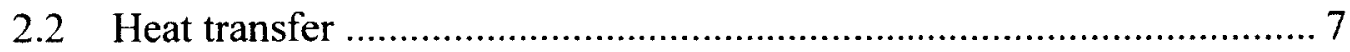

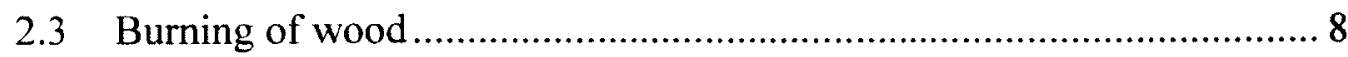

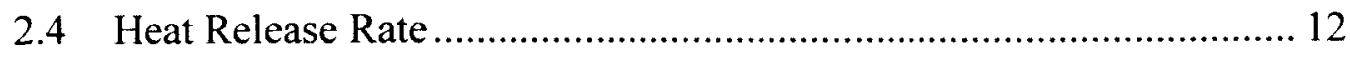

2.5 Temperature 


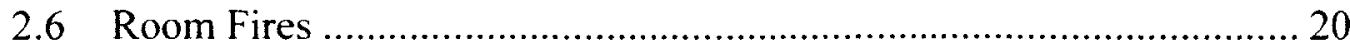

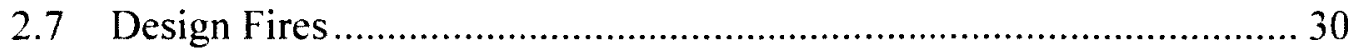

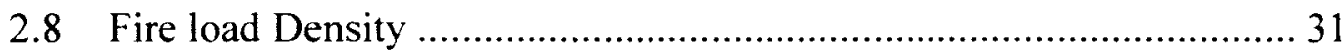

2.9 Previously Conducted Room Tests................................................... 33

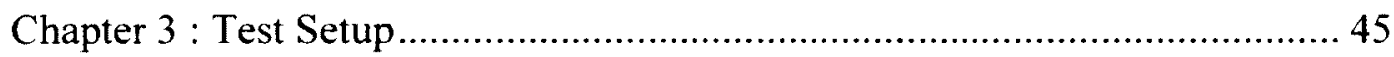

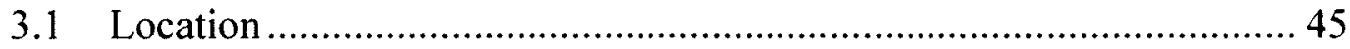

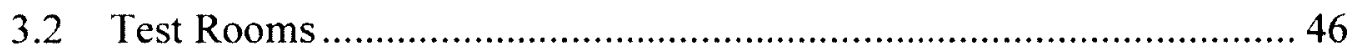

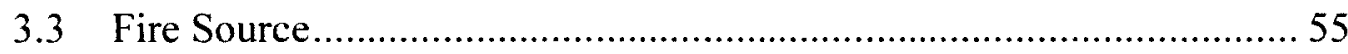

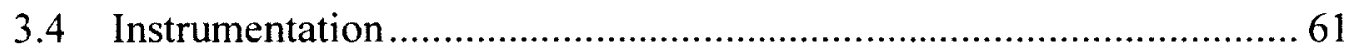

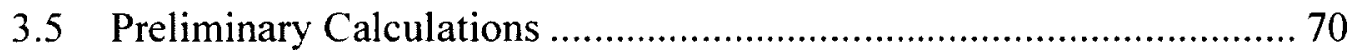

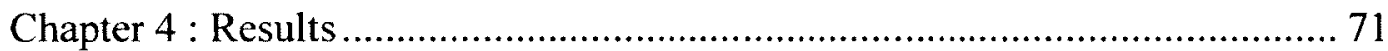

4.1 Test 1 - Protected room with propane fire ……………………….... 71

4.2 Test 2 - Protected room with furniture fire ………............................ 88

4.3 Test 3 - Unprotected room with propane fire...................................... 93

4.4 Test 4 - Protected room with furniture fire ……............................. 104

4.5 Test 5 - Unprotected room with furniture fire …………................ 115

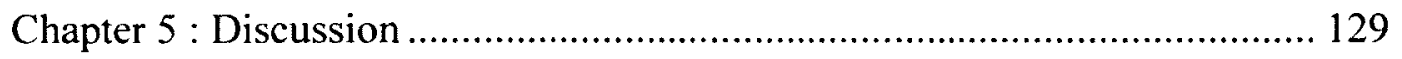

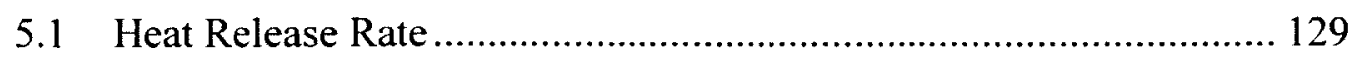

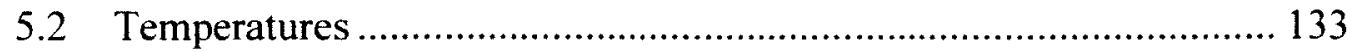

5.3 Fire load and energy released ...................................................... 140 


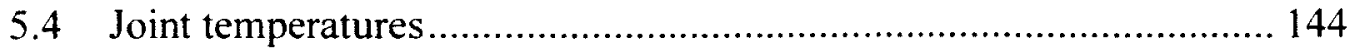

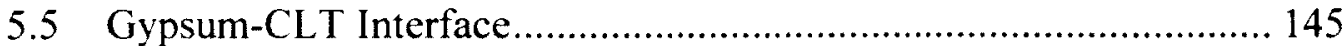

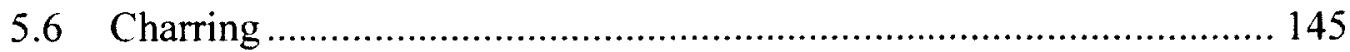

5.7 Fire Detection and Protection ......................................................... 153

Summary

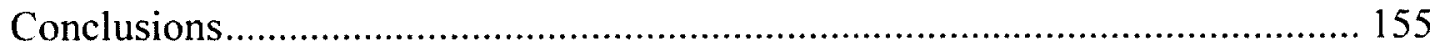

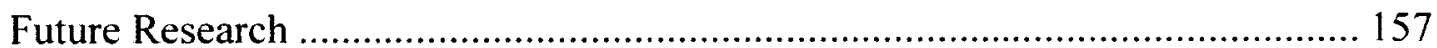

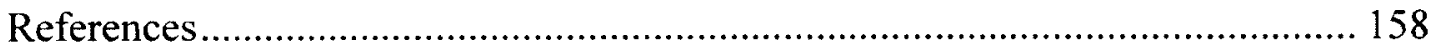




\section{List of Tables}

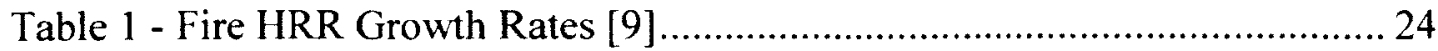

Table 2 - Summary of tests - Hakkarainen [38] ............................................. 34

Table 3 - Temperature and heat flux data for tests - Hakkarainen [38]............... 35

Table 4 - Charring data from tests - Hakkarainen [38]..................................... 36

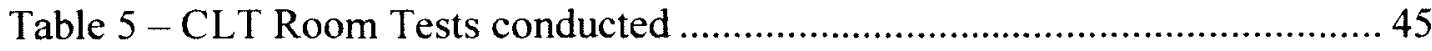

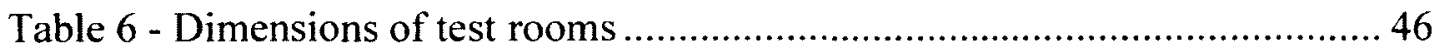

Table 7 -Fire loads for tests with furniture ………………….......................... 59

Table 8 - Thermocouple depths from inside surface of CLT panels $(\mathrm{mm})$..........69

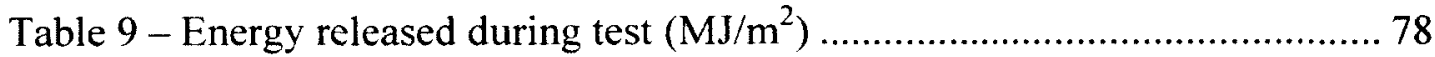

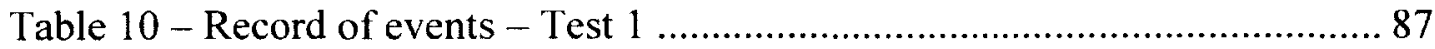

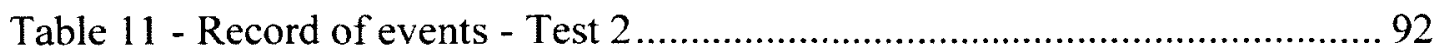

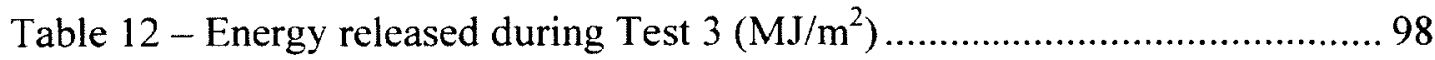

Table 13 - Record of events - Test 3 ............................................................... 104

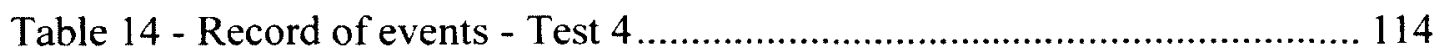

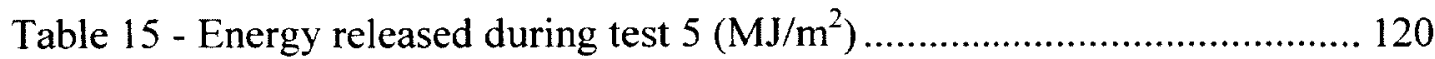

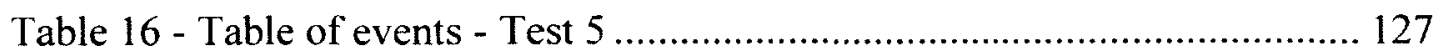

Table 17- Observed heat release rate development phase and corrections applied

Table 18 - Peak temperatures observed in tests $\left({ }^{\circ} \mathrm{C}\right)$........................................ 139

Table 19 - Test fire loads and measured energy released $\left(\mathrm{MJ} / \mathrm{m}^{2}\right) \ldots \ldots \ldots \ldots \ldots \ldots \ldots \ldots 1$

Table 20 - Original times and corrections applied to match energy release curves

to $1.055 \mathrm{MW}$ at 150 seconds. 142 
Table 21 - Combustion properties of European beech [51] ............................. 161

Table 22 - Maximum potential contribution from CLT in fire ........................ 163

Table 23 - HRR (MW) - Total and air limited ............................................ 165 


\section{List of Figures}

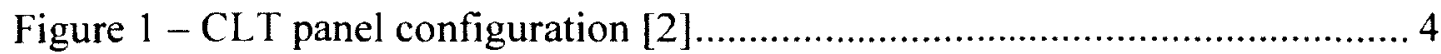

Figure 2 - Pre-fabricated CLT panels during construction [2] ............................. 5

Figure 3 - Graphite apartments - London, UK [2] .......................................... 5

Figure 4 - 1-dimensional charring rates for unprotected and protected timber

(charring occurs after protection falls off) [13]................................................ 10

Figure 5 - 1 dimensional charring rates for unprotected and protected timber

(charring begins before protection falls off) [13] ............................................. 11

Figure 6 - Eurocode 5 [13] charring rate for parametric fires............................ 12

Figure 7 - Schematic of a full scale fire test combustion system [19] ................. 14

Figure 8 - Schematic of Carleton University Laboratory facility [20] ................. 16

Figure 9 - Schematic of Carleton University HRR measurement system [20] .... 17

Figure 10 - Exposed wire thermocouple (after exposure to fire) ......................... 18

Figure 11 - Sheathed thermocouple types [23] ……….................................... 19

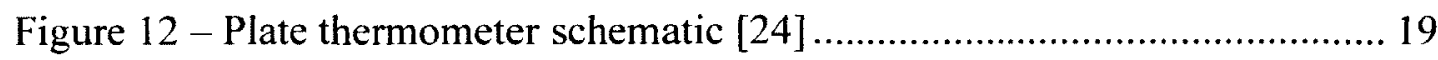

Figure 13 - Enclosure effect on mass loss rate [16] ......................................... 20

Figure 14 - Stages of fire development in room without suppression [26] -

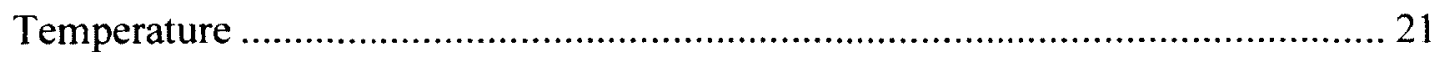

Figure 15 - Stages of fire development in room without suppression [27] - HRR

Figure $16-t$ squared fire growth following incipient phase (modified from [28])

Figure 17 - Energy release rates for different growth rates [30] .......................... 24 
Figure 18 - Vent flows for well mixed room with uniform temperature where

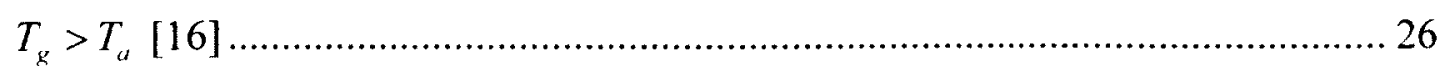

Figure 19 - Swedish Fire Curves developed by Magnusson and Thelanderson [35]

Figure 20 - Example of a simple fire curve [16] ............................................ 30

Figure 21 - Fire load densities for various rooms [27] ....................................... 33

Figure 22 - Schematic of test room - Hakkarainen [38] ................................... 34

Figure 23 - Geometry and location of fire test room - Tsukuba [39].................. 37

Figure 24 - Cross section of walls and floors of the fire room - Tsukuba (modified

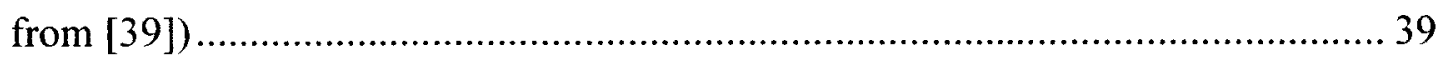

Figure 25 - Temperatures measured in the middle of the room - Tsukuba [39].. 40

Figure 26 - Room layouts used in full scale rooms tests by Chen [40] f............... 41

Figure 27 - HRR design curves - Chen Test 1 .................................................. 42

Figure 28 - HRR design curves - Chen [40] Test 2 ........................................ 43

Figure 29 - Average temperatures measured at the ceiling - Chen [40] tests ...... 43

Figure 30 - Tunnel test facility and schematic ................................................... 46

Figure 31 - X-Lam (105-s3) panel layup (modified from [42]) …...................... 47

Figure 32 - X-Lam (105-s3) Panel cross section (modified from [42]) ............... 47

Figure 33 - Top and Floor elevations [43] ..................................................... 48

Figure 34 - North, East and West Side elevations [43] ...................................... 49

Figure 35 - South Side and Erected ISO elevations [43] ................................ 50

Figure 36 - Longitudinal joints in walls, ceilings and floors (5-Ply drawing shown) [44] 


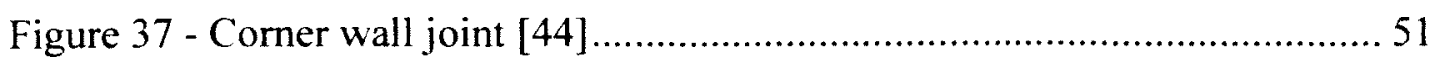

Figure 38 - Wall to floor joints (modified from [43]) ........................................5 52

Figure 39 - Lifting panels using gantry cranes .................................................53

Figure 40 - Imperfections in construction....................................................... 53

Figure 41 - Gypsum board and fibreglass protection installed - Test 1 ................ 55

Figure 42 - Hardwood flooring installed - Test 5 .............................................. 55

Figure 43 - Propane burner layout and installation - Test 1 and Test 3 .............56

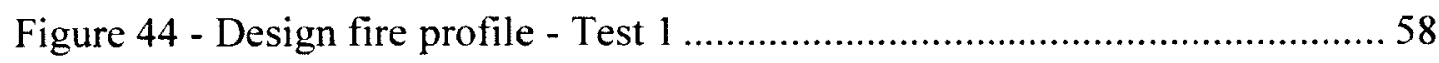

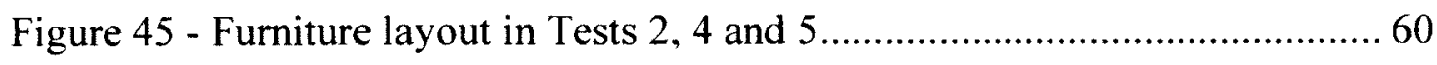

Figure 46 - Square burner used for ignition source in furniture tests .................... 61

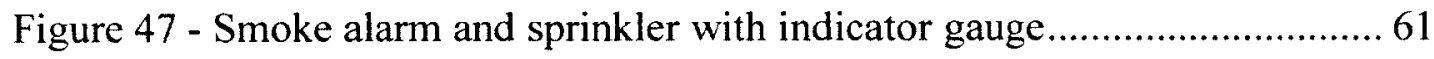

Figure 48 - Oxygen calorimetry tests - Carleton fire lab - 4 Apr $12 \ldots \ldots \ldots \ldots \ldots \ldots . . .62$

Figure 49 - Heat release rates from calibration tests - April $42012 \ldots \ldots \ldots \ldots \ldots \ldots . . .63$

Figure 50 - National Instruments chassis connected to laptop to display and record

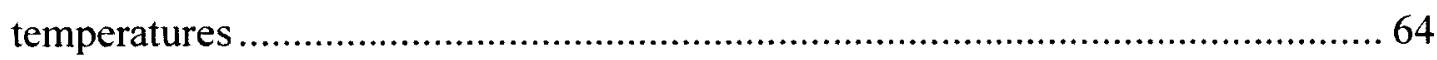

Figure 51 - Location of thermocouple trees and plate thermometer (PT) - All tests

Figure 52 - Unshielded thermocouples before (left) and after test with fibreglass protection (centre) and after test with fibreglass removed (right)......................... 66

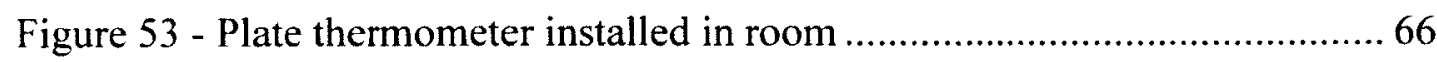

Figure 54 - Embedded thermocouples installed in CLT panels............................67

Figure 55 - Embedded thermocouple locations - Plan view................................. 68

Figure 56 - Embedded thermocouple locations - Side elevation ..........................68 
Figure 57 - Embedded thermocouple locations - Side wall (exterior view) ....... 69

Figure 58 - Removal of char layer to measure final char depth...................... 70

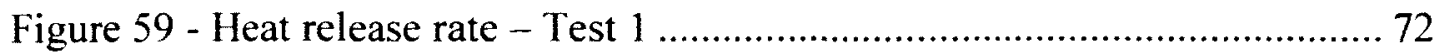

Figure 60 - Flaming and black smoke outside room - Test 1 ....................... 73

Figure 61 - Gases escaping through ceiling joint and walls - Test $1 \ldots \ldots \ldots \ldots \ldots . . . . .74$

Figure 62 - Fire subsides after propane flow reduced - Test 1 ....................... 75

Figure 63- The fire reflashes as the CLT panels delaminates exposing unburned

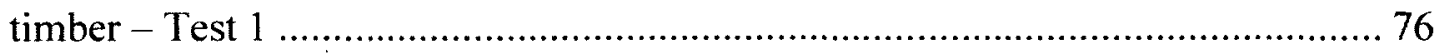

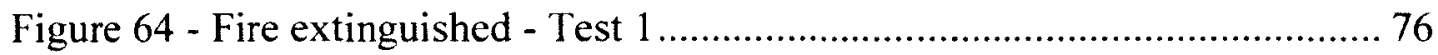

Figure 65 - Comparison of room temperatures and HRR - Test 1 .................. 79

Figure $66-$ Thermocouple tree average temperatures - Test $1 \ldots \ldots \ldots \ldots \ldots \ldots \ldots \ldots . \ldots . \ldots . \ldots$

Figure 67 - Thermocouple Tree 1 temperatures - Test 1 .............................. 82

Figure 68 - Thermocouple Tree 2 temperatures - Test $1 \ldots \ldots \ldots \ldots \ldots \ldots \ldots \ldots \ldots \ldots 2$

Figure 69 - Thermocouple Tree 3 temperatures - Test 1 ................................83

Figure 70 - Thermocouple Tree 4 temperatures - Test $1 \ldots \ldots \ldots \ldots \ldots \ldots \ldots \ldots \ldots \ldots . \ldots . \ldots \ldots$

Figure 71- Temperatures at interface of gypsum board protection and CLT panels

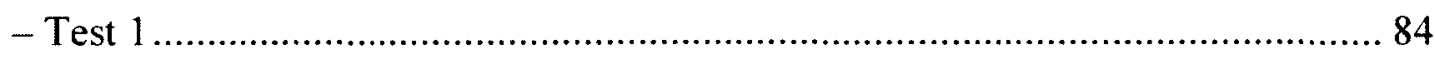

Figure 72 - Charring discovered when removing gypsum lining $>1 \mathrm{hr}$ after end of

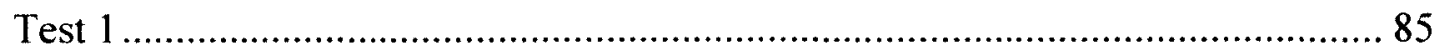

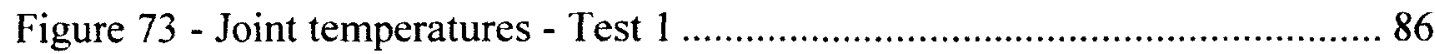

Figure 74 - Fire development in furniture fire - Test 2 ..............................89

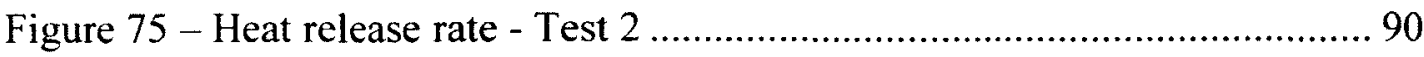

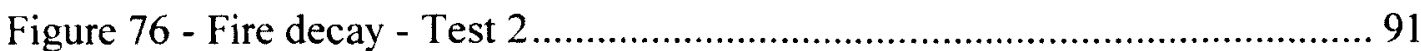


Figure 77 - Heat release rate - Test 3

Figure 78 - CLT panels became involved in the fire initiating flashover - Test 3

Figure 79 - Glowing combustion observed as flaming ends (left) and as the room

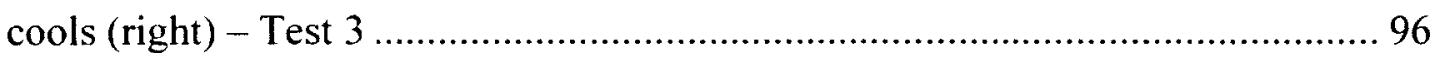

Figure 80 - Thermocouple Tree 1 temperatures - Test 3 .................................... 97

Figure 81 - Plate Thermometer and Average room temperatures showing HRR -

Test 3 99

Figure 82 - Thermocouple Tree 2 temperatures - Test $3 \ldots \ldots \ldots \ldots \ldots \ldots \ldots \ldots \ldots \ldots \ldots \ldots . . .100$

Figure 83 - Thermocouple Tree 3 temperatures - Test $3 \ldots \ldots \ldots \ldots \ldots \ldots \ldots \ldots \ldots \ldots \ldots \ldots \ldots . . .100$

Figure 84 - Thermocouple Tree 4 temperatures - Test $3 \ldots \ldots \ldots \ldots \ldots \ldots \ldots \ldots \ldots \ldots \ldots \ldots \ldots \ldots . .101$

Figure 85 - Exterior faces of walls remained safe to touch throughout Test 3 .. 102

Figure 86 - Thermocouple tree average temperatures - Test $3 \ldots \ldots \ldots \ldots \ldots \ldots \ldots \ldots \ldots . . .102$

Figure 87 - Temperatures at joints and W4 measuring position - Test 3........... 103

Figure 88 - Descending Smoke layer and burning material dripping from mattress

- Test 4

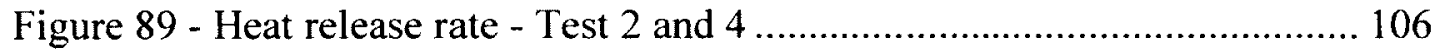

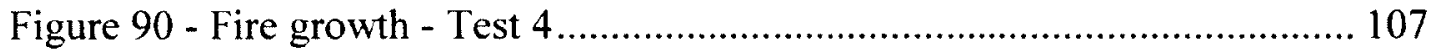

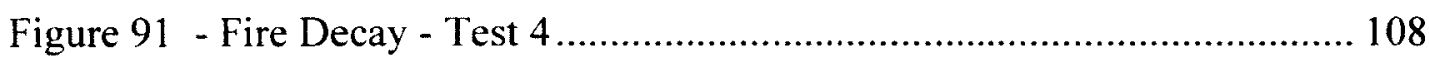

Figure 92- Plate thermometer and Average room temperatures showing HRR -

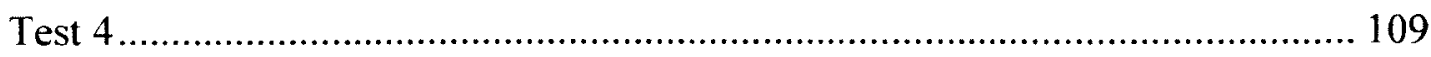

Figure 93 - Thermocouple Tree 1 temperatures - Test 4 ................................ 110

Figure 94 - Thermocouple Tree 2 temperatures - Test 4 ................................... 110 
Figure 95- Thermocouple Tree 3 temperatures - Test $4 \ldots \ldots \ldots \ldots \ldots \ldots \ldots \ldots \ldots \ldots \ldots \ldots \ldots . . .111$

Figure 96- Thermocouple Tree 4 temperatures - Test 4 ................................... 111

Figure 97 - Average thermocouple tree temperatures - Test 4 ........................... 112

Figure 98 - Temperatures at interface of CLT panels and Gypsum Board

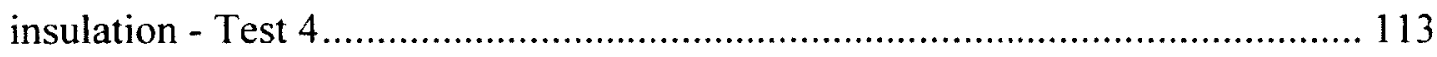

Figure 99 - Temperatures at the joints and embedded $24 \mathrm{~mm}$ from surface at

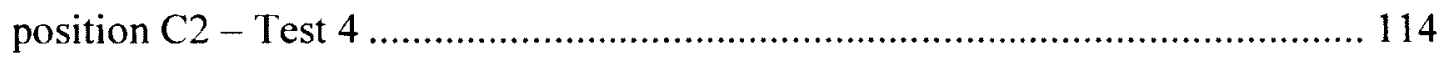

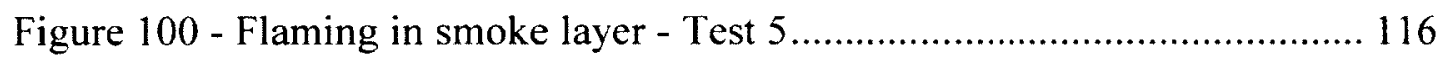

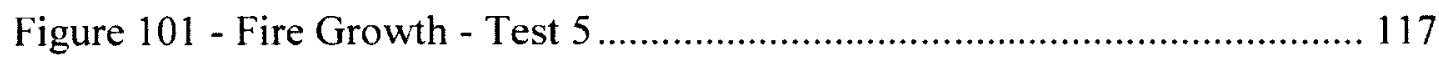

Figure 102- Heat release rate showing estimated contributions from CLT panels

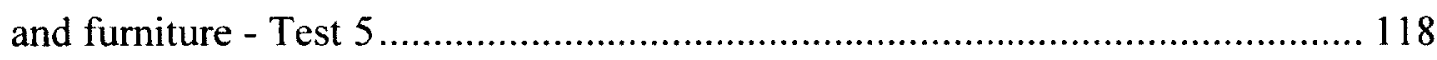

Figure 103 - Structure burning after most of furniture and hardwood flooring

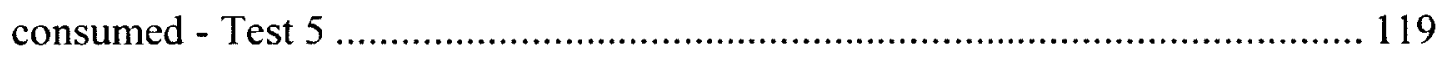

Figure 104 - Plate thermometer and Average room temperatures showing HRR -

Test 5 .

Figure 105 - Average temperatures at thermocouple tree positions - Test $5 \ldots . . .122$

Figure 106 - Thermocouple Tree 1 temperatures - Test 5................................ 123

Figure 107 - Thermocouple Tree 2 temperatures - Test 5................................ 123

Figure 108- Thermocouple Tree 3 temperatures - Test 5................................. 124

Figure 109- Thermocouple Tree 4 temperatures - Test 5................................... 124

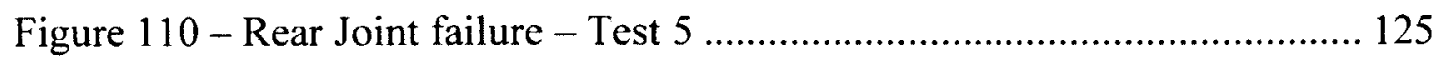

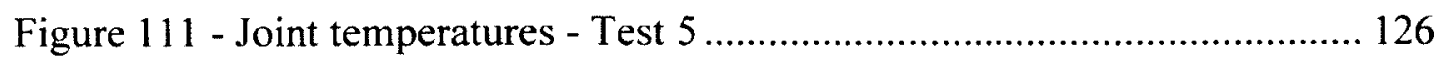


Figure 112 - Flaming from insufficiently sealed penetrations and gases escaping through ceiling joint.

Figure 113 - Comparison of HRR growth rates for propane tests ............... 130

Figure 114 - Comparison of HRR growth phase of furniture tests

Figure 115 - Temperatures of embedded thermocouples at position W2 showing the temperature drops - Test 3 134

Figure 116 - Psychrometric chart showing wet and dry bulb temperatures [49] 134

Figure 117 - Temperature increases observed in propane fires - Tests 1 and 3137

Figure 118 - Temperature growth rates of furniture fires - Tests 4 and $5 \ldots \ldots \ldots 138$

Figure 119 - Comparison of Average TCT room temperatures (second start only for Test 1) 139

Figure 120 - Comparison of total energy released for all tests (corrected to 1.055

MW at 150 seconds). 142

Figure 121 - Newly exposed layer following delamination........................ 143

Figure 122 - Gaps between non-structural middle layer members ................. 144

Figure 123 - Example of prepared char test measurement position................. 146

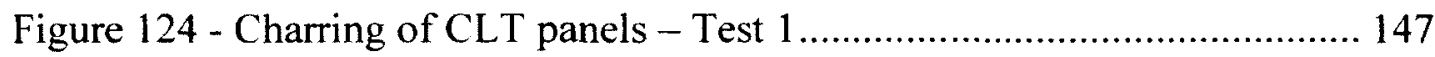

Figure 125 - Gypsum panels remaining in place following release of chemically

bound water - Test 1 148

Figure 126 - Charring at the gypsum/CLT interface 1 hour after fire extinguished

- Test 1 148

Figure 127 - Final Char Depths (mm) - Test 1 149

Figure 128 - Charring of CLT panels - Test 3. 150 


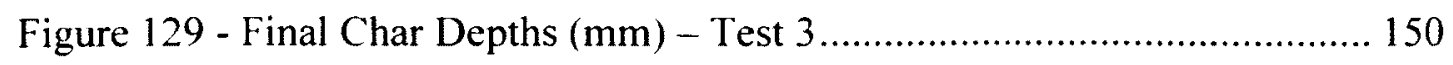

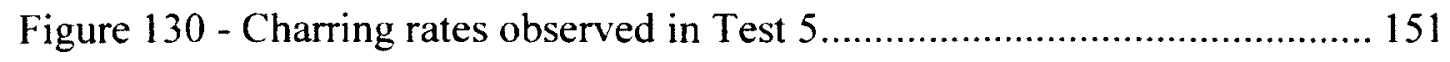

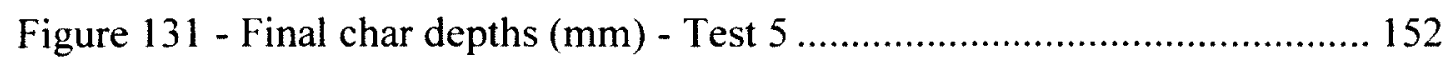

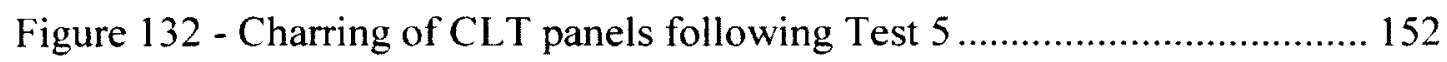




\section{List of Appendices}

Appendix A - Preliminary Calculations.

161 


\section{Nomenclature}

\begin{tabular}{|c|c|}
\hline$A$ & area $\left(m^{2}\right)$ \\
\hline$A_{f}$ & area of floor $\left(\mathrm{m}^{2}\right)$ \\
\hline$A_{0}$ & area of opening $\left(\mathrm{m}^{2}\right)$ \\
\hline$A_{T}$ & total internal surface area of room $\left(\mathrm{m}^{2}\right)$ \\
\hline$C_{d}$ & opening flow coefficient (ratio) \\
\hline$E$ & energy released $\left(k J g^{-1}\right)$ \\
\hline$F_{0}$ & opening factor $\left(\mathrm{m}^{0.5}\right)$ \\
\hline$g$ & acceleration due to gravity $\left(\mathrm{kg} \mathrm{m}^{-2)}\right.$ \\
\hline$h$ & height (m) \\
\hline$h_{1}$ & height of neutral plane $(\mathrm{m})$ \\
\hline$\Delta h_{c}$ & effective heat of combustion $\left(k J g^{-1}\right)$ \\
\hline$\Delta H_{c}$ & complete heat of combustion $\left(k^{J} g^{-1}\right)$ \\
\hline$L_{1}$ & Heat of gasification $\left(k J \mathrm{~g}^{-1}\right)$ \\
\hline$\dot{m}$ & mass flow rate $\left(k g s^{-1}\right)$ \\
\hline$\dot{m}^{\prime \prime}$ & mass loss per unit area $\left(k g s^{-1} m^{-2}\right)$ \\
\hline$M$ & molecular weight $\left(g \mathrm{~mol}^{-1}\right)$ \\
\hline$M L R$ & mass loss rate $\left(\mathrm{kg} \mathrm{s}^{-1}\right)$ \\
\hline$r h$ & relative humidity $(\%)$ \\
\hline$\dot{Q}_{F}^{\prime \prime}$ & heat flux supplied by the flame $\left(k W \mathrm{~m}^{-2}\right)$ \\
\hline$\dot{Q}_{L}^{\prime \prime}$ & heat flux lost through surface $\left(k W m^{-2}\right)$ \\
\hline$t$ & time (seconds/minutes/hours) \\
\hline$t_{0}$ & virtual ignition time (seconds) \\
\hline$T$ & temperature $\left({ }^{\circ} \mathrm{C}\right)$ \\
\hline$W$ & width of opening $(\mathrm{m})$ \\
\hline
\end{tabular}


X measured mole fraction (ratio)

$z \quad$ number of standard deviations from the mean

Greek Letters

$\begin{array}{ll}\alpha & \text { fire growth rate coefficient }\left(\mathrm{kW} \mathrm{s} \mathrm{s}^{-2}\right) \\ \beta_{0} & \text { charring rate }(\mathrm{mm} / \mathrm{min}) \\ \rho & \text { density }\left(\mathrm{kg} \mathrm{m}^{-3}\right) \\ \chi & \text { burning efficiency (ratio) } \\ \gamma & \text { expansion factor (oxygen calorimetry) } \\ \sigma & \text { standard deviation } \\ \mu & \text { mean } \\ \phi & \text { Oxygen depletion factor (ratio) }\end{array}$

Subscripts/superscripts

$\begin{array}{ll}a & \text { air } \\ g & \text { gas } \\ A & \text { exhaust gas } \\ a m b & \text { ambient } \\ \mathrm{DF} & \text { design fire } \\ \mathrm{FO} & \text { flashover } \\ \mathrm{max} & \text { maximum } \\ \mathrm{O} & \text { incoming air } \\ \mathrm{N}_{2} & \text { Nitrogen } \\ \mathrm{O}_{2} & \text { Oxygen } \\ \mathrm{CO} & \text { Carbon Dioxide } \\ \mathrm{CO} & \text { Carbon Monoxide } \\ w b & \text { wet bulb }\end{array}$




\section{Chapter 1 : Introduction}

The introduction of objective-based building codes in Canada in 2005 [1], and elsewhere have allowed opportunities for designers to use new products where prescriptive-based codes had previously incorporated a bias towards concrete and steel construction. New methods, materials and systems can now be used in Canada provided they are equivalent to 'Acceptable Solutions', which represent the minimum level of performance that can satisfy the objectives of the National Building Code of Canada (NBCC). For example, where the NBCC previously limited the use of combustible construction materials, fire safety design, through the use of fire modelling and other performance based techniques, can be used to demonstrate equivalency [2].

These changes provide flexibility for the designer and engineer to innovate to match the changing needs of clients. With an increasing desire to use innovative products which are sustainable and eco-friendly, the development and use of engineered wood products has grown in popularity over recent decades. This trend developed in Europe and is now spreading with interest and product development increasing in North America and Oceania. Traditional ideas and construction limitations on the use of wood and combustible materials are now being challenged and a demand for knowledge is driving innovation. One of the products gaining popularity is Cross Laminated Timber (CLT) panels.

\subsection{Objectives}

The research presented in this thesis is part of an NSERC Forest Sector R\&D initiative, a government and industry collaboration between the Natural Sciences and Engineering Research Council of Canada (NSERC), FPInnovations and Natural 
Resources Canada (NRCan). The NEWBuildS network, comprising researchers from FPInnovations, National Research Council (NRC-IRC), the Canadian Wood Council and 11 Canadian universities is collaborating in the investigation and promotion of new applications for the use of traditional and new engineered wood products. The Vision of the network is:

- 'To increase the use of wood products in mid-rise buildings for use in residential and non-residential purposes in Canada and other markets'.

NEWBuildS research currently encompasses 4 themes. The research presented in this thesis is part of Theme 3-Building Systems, Project T3-3-C7 - Fire Behaviour of Cross Laminated Timber (CLT) Panels. The objective of this research is to develop the understanding of fire behaviour of CLT Panels by experiments and computer modelling. Specifically, the objective of the research in this thesis was to conduct room tests to study the contribution of CLT panels to the growth, duration and intensity of room fires.

\subsection{Contribution of this study}

This research aimed to develop specific knowledge of the fire performance characteristics of CLT panels which will be used to develop and validate computer models used to predict the performance of CLT panels when exposed to fires.

\subsection{Research Methodology}

A series of 5 tests was conducted at the Carleton University Fire Research Laboratory where rooms were constructed from CLT panels and exposed to fire using different fuels and different passive protection configurations. Data was collected on temperature, Heat Release Rate (HRR), charring and other physical observations using 
permanent and temporary installations at the laboratory. This thesis discusses the results of those observations and the potential implications to future use of the product.

\subsection{Cross Laminated Timber}

CLT is an engineered wood product developed in Switzerland in the early 1990's and further developed in Austria and Germany. Since the early 2000's interest and use in construction has increased dramatically through a number of drivers including the green building movement, changes in code and improved business initiatives. Interest in use of the product has developed in North America with a number of manufacturing plants already producing the product and mid-rise CLT buildings already constructed in Quebec and British Columbia.

CLT is manufactured in layers using solid sawn wood members, $38 \times 89 \mathrm{~mm}$ members are commonly used however dimensions can vary depending on manufacturer and application. The individual members in each of the layers are finger joined, where necessary, to provide the required lengths for uninterrupted construction and layers are stacked perpendicular to each other at a 90 degree offset which can be seen in Figure 1.

In construction, the members in each layer are pressed together and the faces of the layers are then bonded, most commonly using an adhesive although it is possible to use dowels or nails. Multiple layers are used to create thick panels of typically 3-9 layers. Generally the structural characteristics of these layers are determined by one of the two planes, for example calculations may use properties of the longitudinal direction and the transverse layers are assumed to have no structural input. The transverse layers also tend to use a lower grade of wood. Kiln dried wood which has a moisture content of less than 
$12 \%$ is used producing a product that is dimensionally stable minimizing shrinkage.

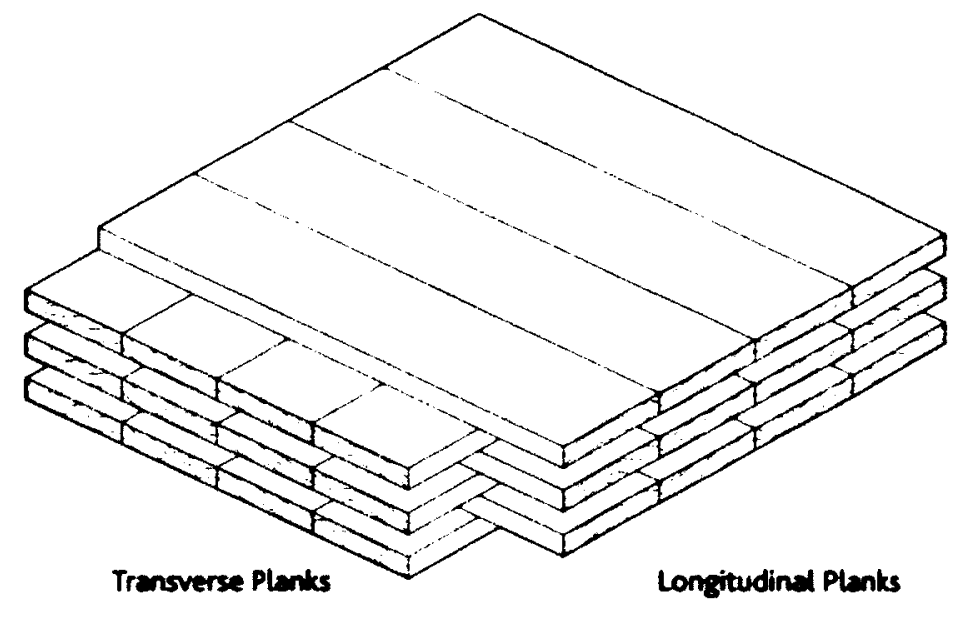

Figure 1-CLT panel configuration [2]

Panels are constructed at the factory to high tolerance and size is generally limited only by production and delivery capability. Nordic Engineered Wood for example, is currently able to construct panels of up to $2.4 \times 19.5 \times 0.381 \mathrm{~m}$ thick. Any features such as windows, doors and other penetrations are incorporated at the factory, shown in Figure 2 , with the use of high precision computer numerical control routers helping to reduce the time of onsite production. Depending on the application of the panel, the faces can be finished in the factory or even have a cladding installed prior to delivery.

At the production site, the pre-fabricated panels are lifted into place as shown in Figure 2 and generally fitted with dowel or bearing type mechanical fasteners. This allows rapid and efficient construction with small crews and low equipment demands. One example of this is the Graphite Apartments in London, UK which is a 9 story building shown in Figure 3 that was constructed at a rate of 3 days per floor (873 sqft/day) with 4 carpenters [3]. The development of construction techniques continues to improve with a building of 10 stories nearing completion in Australia [4] and some projecting future wood buildings as high as 30 storeys [5]. 


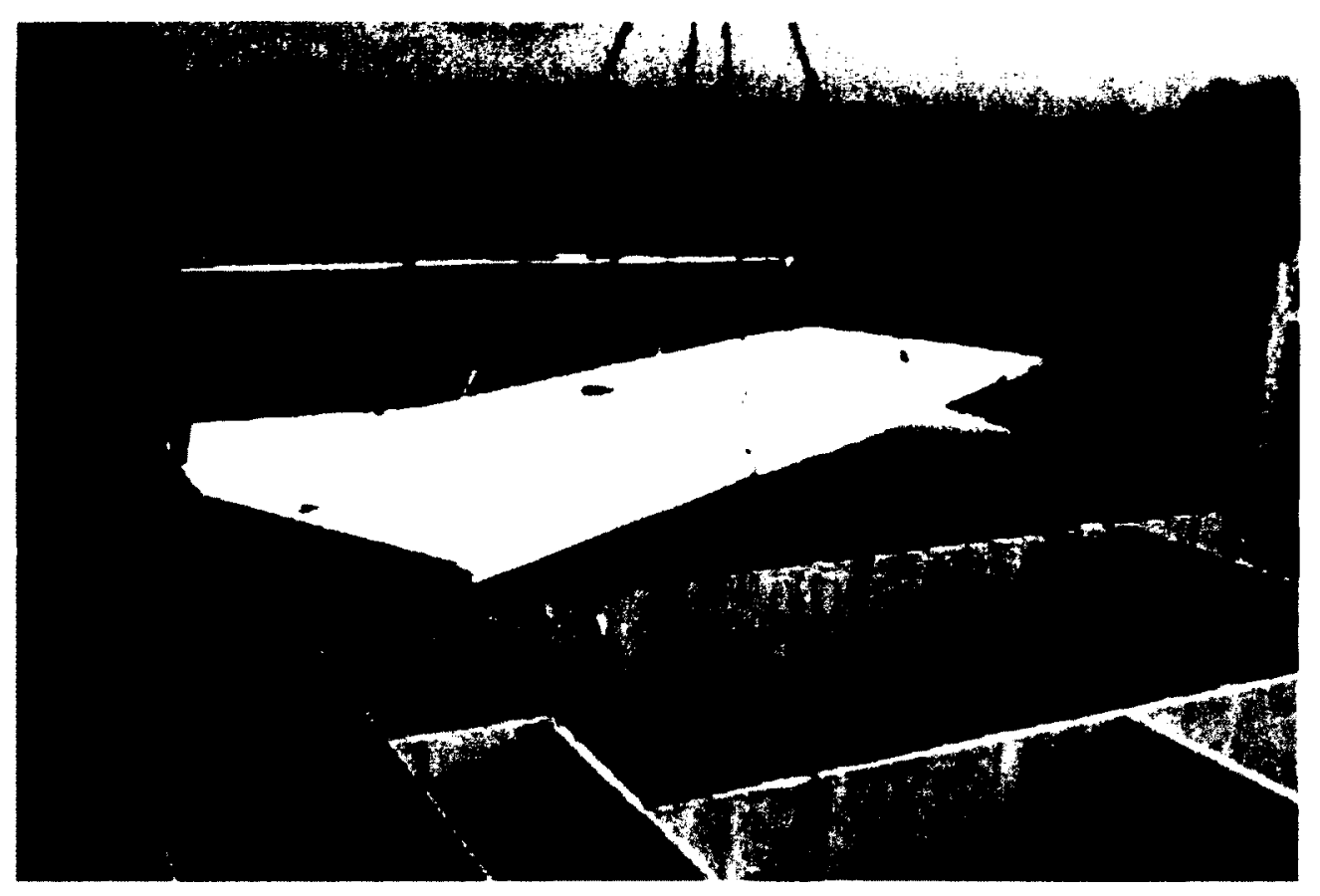

Figure 2 - Pre-fabricated CLT panels during construction [2]

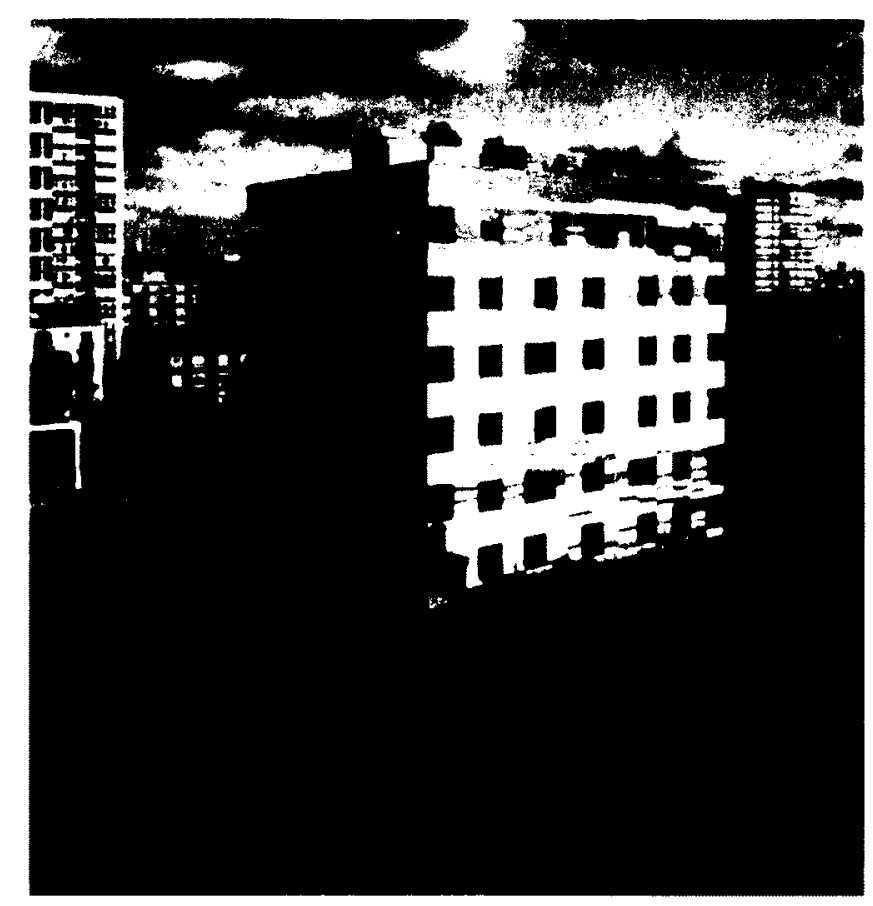

Figure 3 - Graphite apartments - London, UK [2] 


\subsection{Thesis Organisation}

This thesis is organized into 5 chapters.

- Chapter 1 gives an introduction to the research and discusses the objectives and methodology.

- Chapter 2 provides a review of the theory used in development and analysis of the test results for this research.

- Chapter 3 discusses the test parameters and preparation for this research.

- Chapter 4 presents the individual results of each of the 5 tests conducted.

- Chapter 5 discusses the overall observations from the series of tests and what the implications may be. 


\section{Chapter 2 : Literature Review}

\subsection{Combustion}

In its simplest definition, combustion is an exothermic reaction where fuel is oxidized producing heat and combustion products. Most products in building fires are hydrocarbons that release heat in the combustion process and form into $\mathrm{H}_{2} \mathrm{O}$ and $\mathrm{CO}_{2}$, an example of which is represented simply by the chemical reaction for propane in Eq 1 .

$$
\mathrm{C}_{3} \mathrm{H}_{8}+5 \mathrm{O}_{2} \Rightarrow 3 \mathrm{CO}_{2}+4 \mathrm{H}_{2} \mathrm{O}+\mathrm{Heat} \quad \mathrm{Eq} \mathrm{l}
$$

In reality there is a far more complex set of intermediate reactions which occur, as well as incomplete combustion, resulting in other products such as $\mathrm{CO}$ and $\mathrm{C}$ which can appear as smoke. Combustion is called a chain reaction as heat acts as a catalyst but is also a product [6]. There are two types of combustion that occur:

\subsubsection{Flaming combustion}

This occurs when the fuel is a gas, a liquid which has evaporated or a solid which has pyrolyzed to produce a flammable vapor [6]. An external heat source is generally required initially to start combustion; and

\subsubsection{Smouldering combustion}

This is a slower, lower temperature and flameless form of combustion which occurs as oxygen directly reacts with the surface of condensed phase fuel [7] such as char or a cigarette. This reaction can occur over many hours and can produce toxic gases which may be particularly hazardous as they can occur without sufficient heat or noise to wake sleeping occupants who may be overcome.

\subsection{Heat transfer}

During combustion, heat transfer occurs in 3 possible modes: 


\subsubsection{Conduction}

This occurs in solid materials and depends on the material properties such as density, specific heat and thermal conductivity. Some materials are good conductors whilst others are not.

\subsubsection{Convection}

This involves heat transfer due to the movement of fluids which transfer heat away from a source or heat transfer from a fluid to a solid surface [8]. The rate of heat transfer between a fluid and a solid surface depends on the temperature difference between the surface and the fluid or gas, and a heat transfer coefficient which can vary depending on geometry, thickness and flow characteristics at the interface. In a fire situation, the heat transfer is usually from the gas to the solid or liquid.

\subsubsection{Radiation}

This is the main mechanism of heat transfer from flames to a surface and is the transfer of energy through electromagnetic waves [8]. This can occur through a vacuum or a translucent solid, liquid or gas. This mode of heat transfer is largely influenced by distance and relative orientation.

\subsection{Burning of wood}

Wood is a complex mixture of different polymers which can be broken down into three main constituents when considering combustion. Their common compositions in wood, by weight, are hemicellulose (25\%), cellulose (50\%) and lignin $(25 \%)$ [9]. As wood increases in temperature these constituents decompose at different temperatures releasing volatiles in the ranges: 


$\begin{array}{lll}\text { Hemicellulose - } & 200-260^{\circ} \mathrm{C} \\ \text { Cellulose } & - & 240-350^{\circ} \mathrm{C} \\ \text { Lignin } & - & 280-500^{\circ} \mathrm{C}\end{array}$

As wood burns, approximately $15-25 \%$ remains as a char, much of this from the lignin of which only about $50 \%$ volatilizes [9]. The amount of the hemicellulose and cellulose that remains as char varies.

The governing equation in order for decomposition to remain at a steady state is given by $\mathrm{Eq} 2$ [9].

$$
\dot{m}^{n}=\frac{\dot{Q}_{l}^{\prime \prime}-\dot{Q}_{i}^{n}}{L_{l}}
$$

$$
\dot{m}^{n}=\text { rate of burning }\left(\mathrm{kg} \mathrm{s}^{-1} \mathrm{~m}^{-2}\right)
$$

Where $\quad \dot{Q}_{l}^{\prime \prime}=$ Heat flux supplied by the flame $\left(k W m^{-2}\right)$

$\dot{Q}_{i}^{\prime \prime}=$ heat flux lost through surface $\left(k W \mathrm{~m}^{-2}\right)$

$L_{1}=$ Heat of gasification $\left(k J \mathrm{~g}^{-1}\right)$

Research conducted by Tewarson and Pion [10] determined that for Douglas Fir $\dot{Q}_{l}^{n} \approx \dot{Q}_{l}^{n}$, where heat transfer from the flame is theoretically just sufficient to match the heat losses from the sample [9], and Petrella [11] found that $\dot{Q}_{l}^{n}<\dot{Q}_{l .}^{n}$ for several species of wood demonstrating that wood clearly requires the influence of an imposed heat flux to burn [9] (This does not apply to thin pieces of wood which can continue to burn). As char builds up at the surface it shields the wood below the char resulting in higher surface temperatures of the char and increased losses from the surface.

A steep thermal gradient exists between the surface of the char and the unburned wood. The exposed char is at roughly the temperature of the fire and the temperature at the boundary of the char and wood is at approximately $300^{\circ} \mathrm{C}$. Below the char, the layer 
of wood above $200^{\circ} \mathrm{C}$ is called the pyrolysis zone. Cracks in the char layer increase the penetration of heat into the pyrolysis layer and a constant charring rate is commonly assumed for timber structures in fire [12].

Eurocode 5 [13] specifies a charring rate of $\beta_{0}=0.65 \mathrm{~mm} / \mathrm{min}$ to be used in fire design for one dimensional charring of unprotected members, shown by line 1 in Figure 4. In the cases where protection is in place, two scenarios are presented for charring which includes periods of charring rates slower and faster than standard rates:

\subsubsection{Charring which starts when protection falls off}

This scenario assumes that no charring of the protected member occurs until a time when the protection falls off entirely. The surface is protected by a cladding that delays the start of charring until the protection falls off at time $t_{f}$. Charring is assumed to occur at twice the rate of the unprotected surface from $t_{f}$, the increased rate of charring is assumed until the timber develops a level of char which would be expected in initially unprotected timber, for which the depth of $25 \mathrm{~mm}$ is adopted.

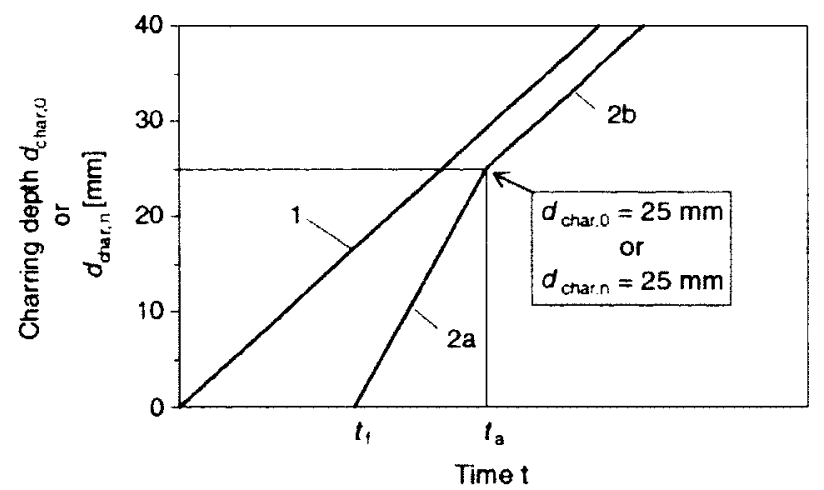

Key:

1 Relationship for members unprotected throughout the time of fire exposure for charring rate $\beta_{n}$ (or $\beta_{0}$ ).

2 Relationship for initially protected members after failure of the fire protection:

$2 a$ After the fire protection has fallen off at time $t_{f}$. charring starts at increased rate.

$2 b$ After char depth exceeds $25 \mathrm{~mm}$ at time $t_{a}$, the charring rate reduces to the rate shown by curve 1 .

Figure 4-1-dimensional charring rates for unprotected and protected timber (charring occurs after protection falls off) [13] 


\subsubsection{Charring which starts before protection falls off}

The timber surface is protected by a layer that delays the start of charring until time $t_{c i}$, shown in Figure 5, and provides some protection for a period before falling off. This results in a charring rate of $50 \%$ of that for unprotected wood until the protection falls off completely at time $t_{t}$. After this the charring occurs at twice the normal rate until reaching a depth of $25 \mathrm{~mm}$ when the charring rate reverts back to that for initially unprotected timber.

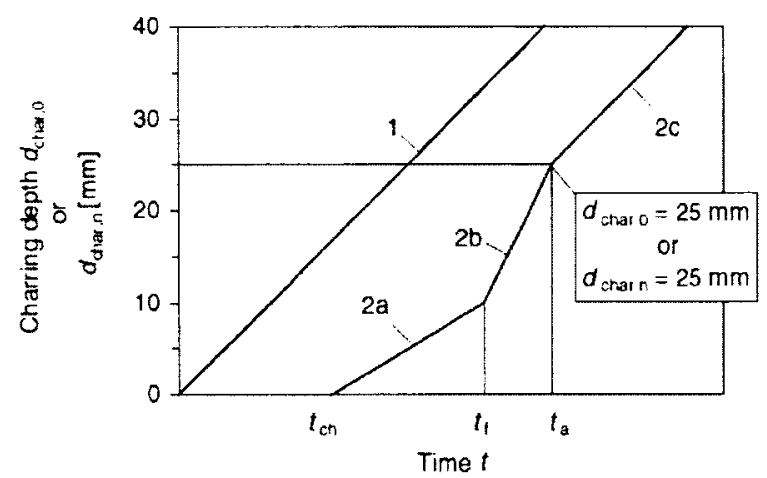

Key:

I Relationship for members unprotected throughout the time of fire exposure for charring rate $\beta_{\mathrm{n}}$ (or $\beta_{0}$ ).

2 Relationship for initially protected members where charring starts before failure of protection:

2a Charring starts at $t_{\mathrm{ch}}$ at a reduced rate when protection is still in place.

2b After protection has fallen off at time $t_{f}$. charring starts at increased rate.

$2 \mathrm{c}$ After char depth exceeds $25 \mathrm{~mm}$ at time $t_{\lrcorner}$, the charring rate reduces to the rate shoun by curve 1

Figure 5 - 1 dimensional charring rates for unprotected and protected timber (charring begins before protection falls off) [13]

Parametric design fires, which attempt to provide a realistic prediction of

temperature based on observations from previous tests, go through a period of continuous heating before entering a decay period. In parametric fires, the charring rate is considered constant until the start of the decay period at $t_{0}$ shown in Figure 6. After this, the charring rate is assumed to decay linearly reaching zero at $3 t_{0}$. 


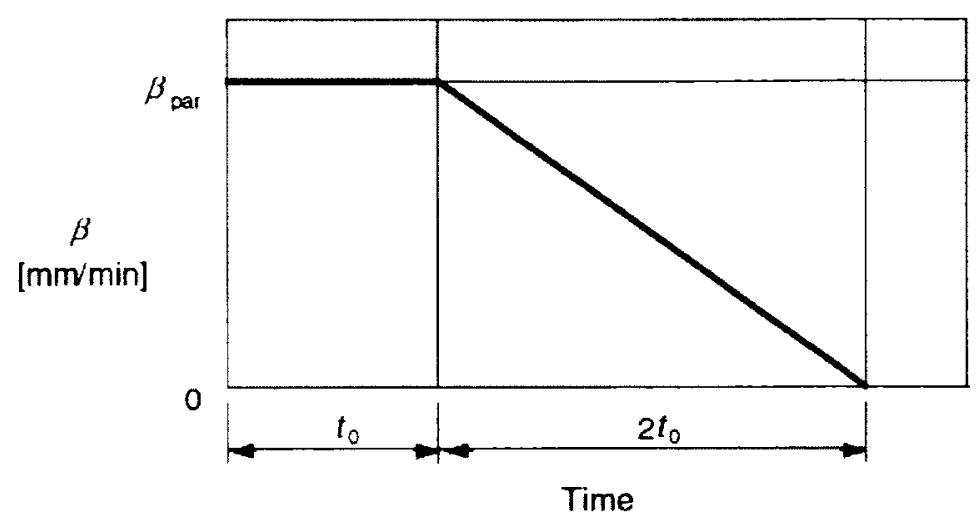

Figure 6 - Eurocode 5 [13] charring rate for parametric fires.

\subsection{Heat Release Rate}

Heat Release Rate (HRR) or Energy Release Rate has been described as the single most important variable in characterizing, and the best predictor of, fire hazard [14]. It is the rate at which combustion reactions produce heat [15] (measured in watts (W), kilowatts (kW) or megawatts (MW)) and controls to a considerable extent the environmental consequences of a fire [16].

The HRR $(\dot{Q})$ can be calculated from the mass loss rate and is expressed as:

$$
\dot{Q}=M L R \Delta h_{c}
$$

Where $\quad M L R=$ mass loss rate $\left(k g s^{-1}\right)$

$$
\Delta h_{\mathrm{c}}=\text { effective heat of combustion }\left(\mathrm{kJ} \mathrm{kg}^{-1}\right)
$$

This is often expressed in terms of horizontal burning area where $\mathrm{Eq} 3$ becomes:

$$
\dot{Q}=A_{f} \dot{m}^{\prime \prime} \Delta h_{c}
$$

$\mathrm{Eq} 4$

Where $\quad A_{f}=$ Area of floor $\left(m^{2}\right)$

$$
\dot{m}^{\prime \prime}=\text { mass loss per unit area }\left(k g s^{-1} m^{-2}\right)
$$


The effective heat of combustion is derived from free burn experiments and is related to the complete heat of combustion by the burning efficiency given in Eq 5:

$$
\chi=\frac{\Delta h_{c}}{\Delta H_{c}}
$$

Where $\quad \Delta H_{c}=$ complete heat of combustion $\left(k^{\prime} \mathrm{g}^{-1}\right)$

$\Delta H_{c}$ is the determined from bomb calorimetry [9] where samples are completely combusted under pressure in pure oxygen.

\subsubsection{Oxygen Consumption Calorimetry}

The most common method for measuring HRR is oxygen consumption calorimetry. This method is based on the principle, originally proposed by Thornton [17] in 1917 , that for any burning item the same amount of energy or heat is released for the amount of oxygen consumed (Thornton's Rule or the oxygen consumption principle). The determination of the HRR by measurement of a single parameter, oxygen, is particularly useful in large scale testing where many items are involved in the fire, of which a room fire is a good example. In tests conducted by Huggett [18] in 1980, he concluded that the amount of energy released for a fire involving conventional organic solids is $13.1 \mathrm{~kJ} \pm 5 \%$ per gram of oxygen consumed. The relationship for HRR based on oxygen consumption is presented in Eq 6 .

$$
\dot{Q}=E\left(\dot{m}_{O_{2}}^{()}-\dot{m}_{O_{2}}\right)
$$

Where

$$
\begin{aligned}
& E=13.1 \pm 5 \%\left(\mathrm{~kJ} \mathrm{~g}^{-1}\right) \\
& \dot{m}_{\mathrm{O}_{2}}^{\prime}=\text { mass flow rate of } O_{2} \text { in the incoming air }\left(\mathrm{kg} \mathrm{s}^{-1}\right) \\
& \dot{m}_{\mathrm{O}_{2}}=\text { mass flow rate of } \mathrm{O}_{2} \text { in the exhaust air }\left(\mathrm{kg} \mathrm{s}^{-1}\right)
\end{aligned}
$$


In 1991 Janssens [19] proposed a series of equations, developed specifically for full-scale fire tests where it is assumed that it is not possible to measure the air flow rate into the system. The basic requirement for the test is that all of the combustion products are collected and measured downstream at a sufficient distance for adequate mixing. At a minimum the oxygen can be measured, however the accuracy is increased by measuring the concentrations of $\mathrm{CO}, \mathrm{CO}_{2}$ and $\mathrm{H}_{2} \mathrm{O}$ in the gas stream which account for incomplete combustion. The schematic of the full scale fire test combustion system is presented in Figure 7.

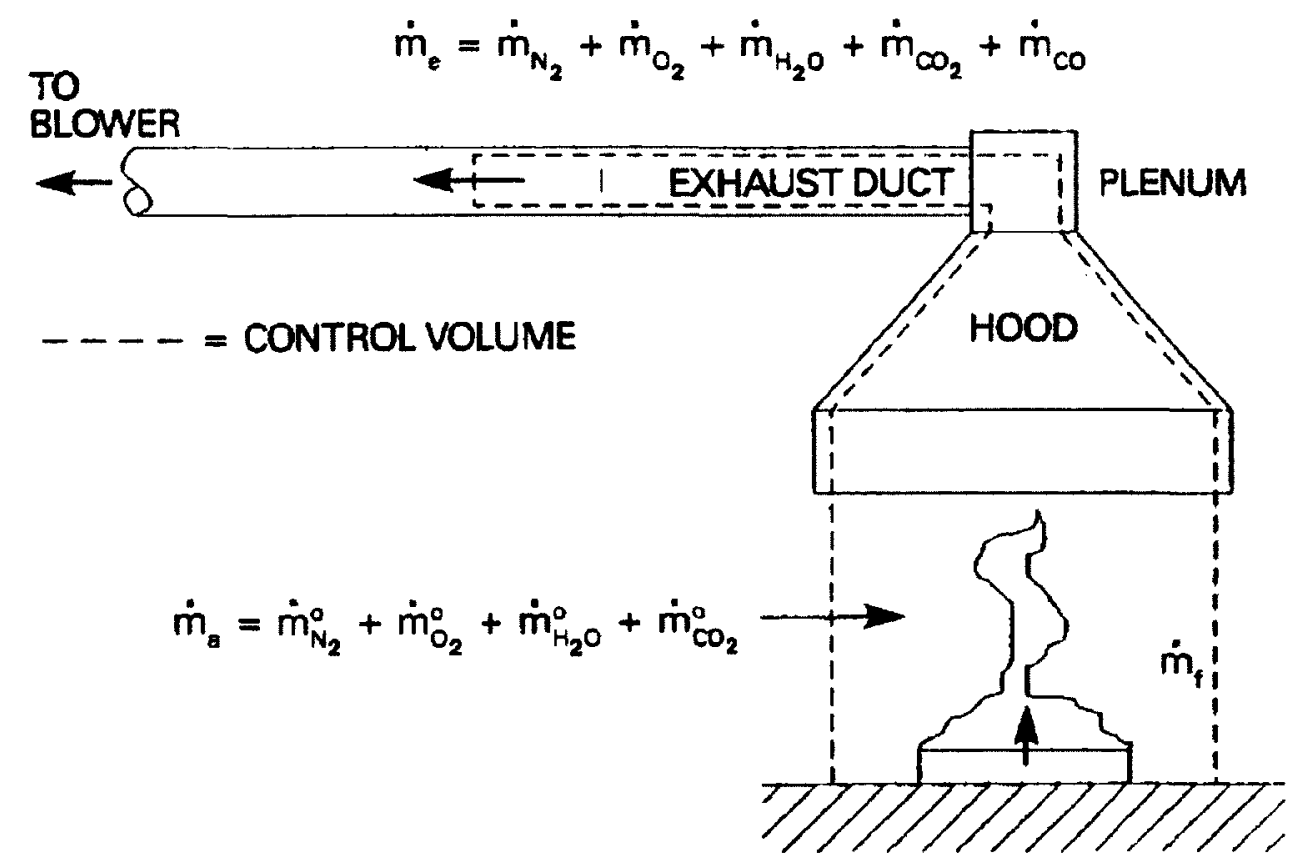

Figure 7 - Schematic of a full scale fire test combustion system [19] Janssens [19] set of equations for calculating HRR measuring $\mathrm{O}_{2}, \mathrm{CO}$ and $\mathrm{CO}_{2}$ are presented in $\mathrm{Eq} 7$ and $\mathrm{Eq} 8$.

$$
\dot{q}=\left(E \phi-\left(E_{(O)}-E\right) \frac{(1-\phi) X_{(O)}^{A}}{2 X_{O_{2}}^{A}}\right) \frac{\dot{m}_{e}}{1+\phi(\gamma-1)} \frac{M_{O_{2}}}{M_{a}}\left(1-X_{H_{2} O}^{0}\right) X_{O_{2}}^{A^{0}}
$$




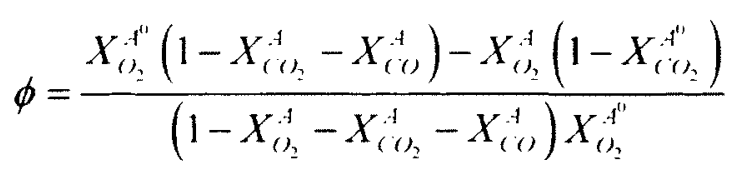

Where $\quad \dot{m}_{\mathrm{c}}=$ mass flow rate in duct $\left(\mathrm{kg} \mathrm{s}^{-1}\right)$

$E_{(\prime)}=$ Net heat release per unit mass of $O_{2}$ consumed for combustion

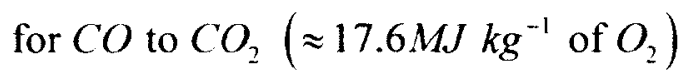

$\gamma=$ expansion factor (value of 1.105 suggested for most fire tests)

$M_{\mathrm{O}_{2}}=$ Molecular weight of $\mathrm{O}_{2}\left(\mathrm{~kg} \mathrm{kmol}^{-1}\right)$

$M_{o}=$ Molecular weight of air $\left(\mathrm{kg} \mathrm{kmol}^{-1}\right)$

$X_{\mathrm{H}_{2} \mathrm{O}}^{0}=$ Mole fraction of $\mathrm{H}_{2} \mathrm{O}$ in the incoming air

$\phi=$ Oxygen depletion factor

$X_{C O_{2}}^{A}=$ Measured mole fraction of $\mathrm{CO}_{2}$ in the exhaust air

$X_{C O}^{A}=$ Measured mole fraction of $\mathrm{CO}$ in the exhaust air

$X_{\mathrm{O}_{2}}^{A}=$ Measured mole fraction of $\mathrm{O}_{2}$ in the exhaust air

$X_{O_{2}}^{t^{\mathrm{N}}}=$ Measured mole fraction of $\mathrm{O}_{2}$ in the incoming air

$X_{C O_{2}}^{A^{\mathrm{n}}}=$ Measured mole fraction of $\mathrm{CO}_{2}$ in the incoming air

\subsubsection{Carleton University full-scale tunnel facility}

The Carleton University full-scale tunnel test facility features a system for measuring HRR using oxygen consumption developed by Ko [20]. This system calculates the HRR using the set of equations of Janssens [19] and has been calibrated in tests up to 13 MW [21]. A schematic of the tunnel is presented in Figure 8 showing the dimensions of the tunnel. 


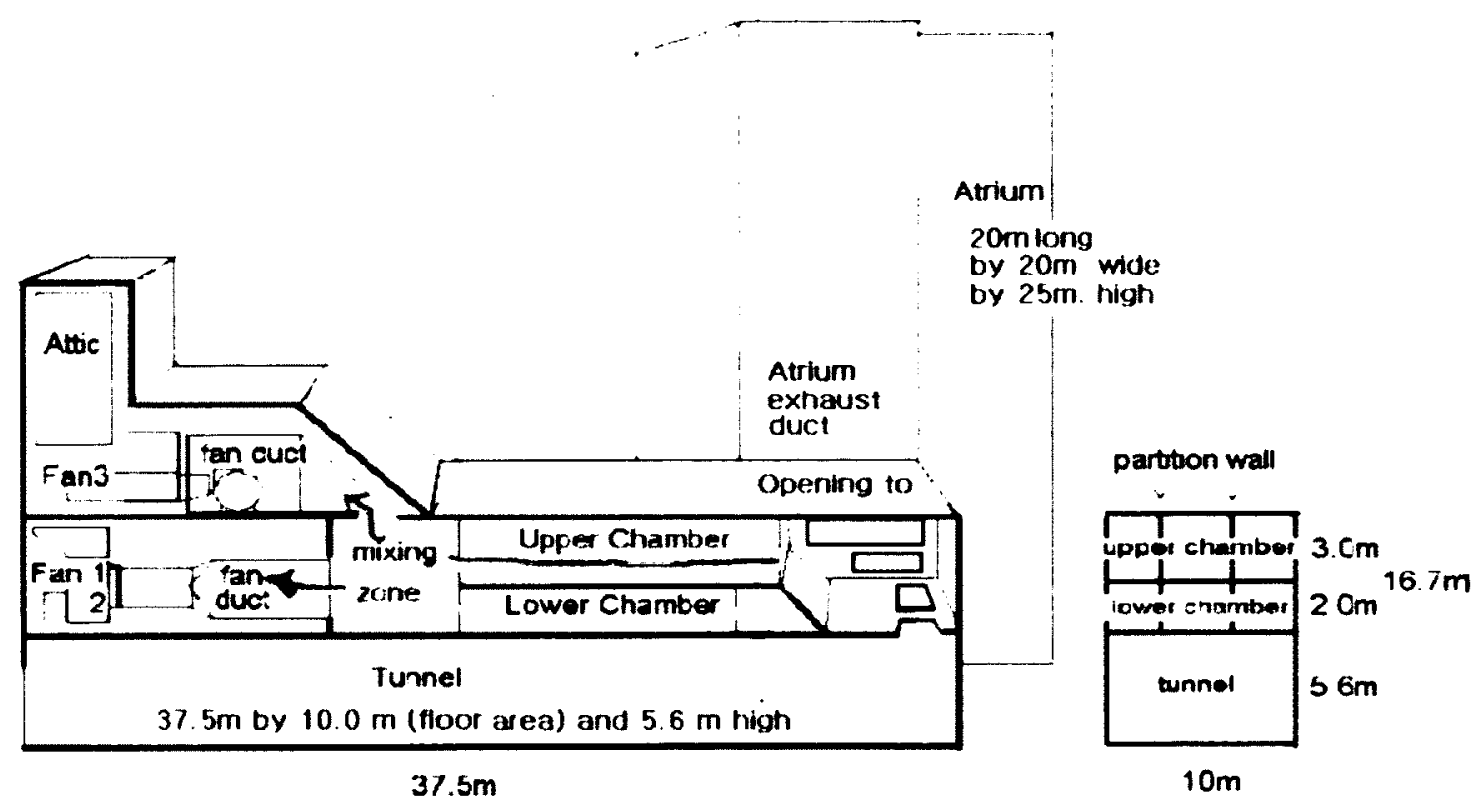

Figure 8 - Schematic of Carleton University Laboratory facility [20]

Exhaust fans draw the products of combustion through the chambers where they pass through instrumentation that measures the concentrations of $\mathrm{CO}_{2}, \mathrm{CO}$ and $\mathrm{O}_{2}$ as well as measuring velocity and temperature of the products. The measurement system, presented in Figure 9, provides real time measurement data on the HRR in the tunnel which can be compared to the other inputs such as fuel flow rate to the fire.

The results of the calibration tests showed that the system is suitable for fires from 2.5 MW and upwards, however is more suited for large fires that last a long time. A calibration factor is required to adjust for an overestimation in flow rates from flow deflection near the walls. The factor ranged from 0.83 to 0.85 for HRR's of 2.4 to 5.6 MW [21]. 


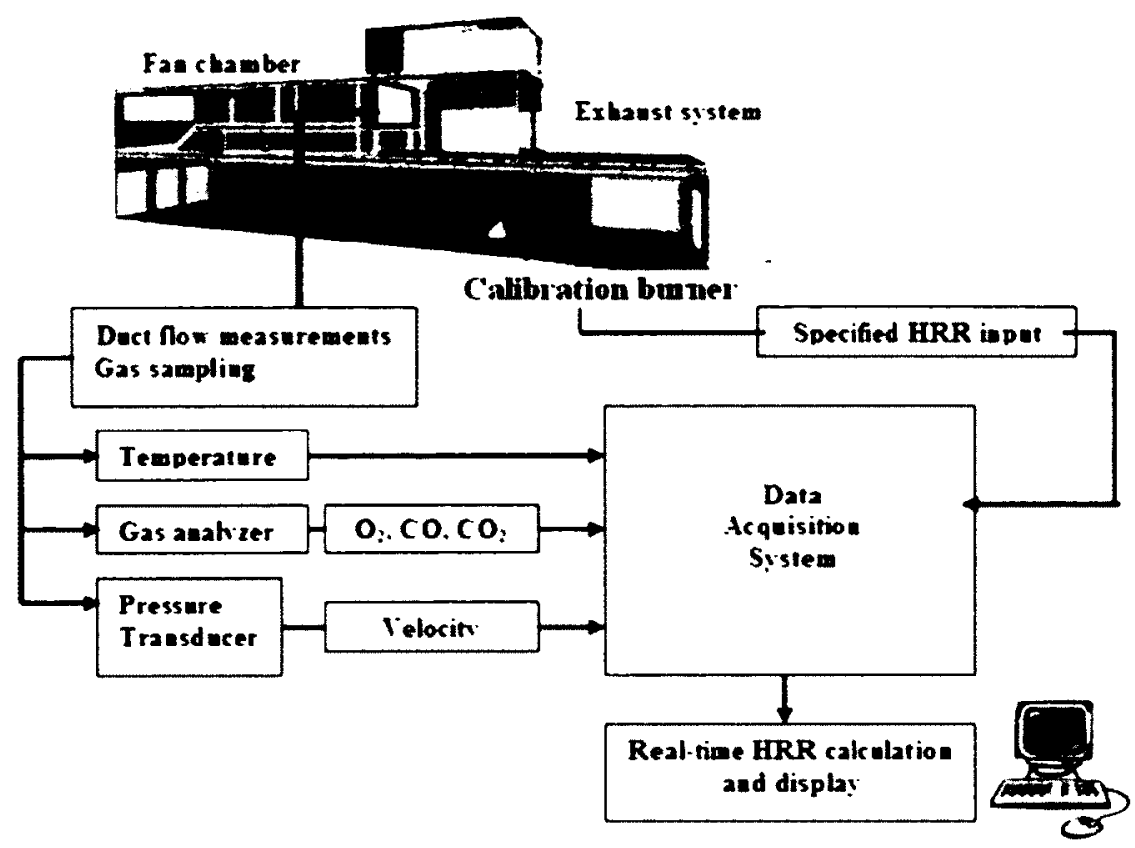

Figure 9 - Schematic of Carleton University HRR measurement system [20]

\subsection{Temperature}

One of the most important measurements in fires is that of temperature. It can be used to distinguish between different regimes of fire, predict hazardous conditions, burning rates and the onset of flashover (discussed in Section 2.6). Thermocouples are commonly used to measure the temperature which is achieved by taking advantage of a phenomenon known as the Seebeck effect [22]. When two ends of a wire are at different temperatures, an electrical potential is created, this is characterized by a property known as the Seebeck coefficient $\left(\mu \mathrm{V} \cdot \mathrm{K}^{-1}\right)$. When two wires with different Seebeck coefficients are joined together at the ends, the temperature can be derived from the voltage running through the circuit. This effect works best when the difference in Seebeck coefficients is large and in opposite directions (positive and negative) [22]. K-Type thermocouples are the most commonly used which employ wires of Chromel and Alumel with Seebeck coefficients of $21.8 \mu \mathrm{V} . \mathrm{K}^{-1}$ and $-17.7 \mu \mathrm{V} . \mathrm{K}^{-1}$ respectively. K-Type thermocouples have a 
range of measurement from $-200^{\circ} \mathrm{C}$ to $1250^{\circ} \mathrm{C}$. Three typical configurations for thermocouples commonly used in fire tests are:

\subsubsection{Exposed wire thermocouple}

Consists of thermocouple wire where the two elements have been twisted and/or welded at the exposed end as shown in Figure 10. These are generally a good choice when measuring gas temperature as they have a fast response, however as they are exposed, they can be subject to corrosion or oxidation which can reduce their effective life. These thermocouples are generally useful for short term applications.

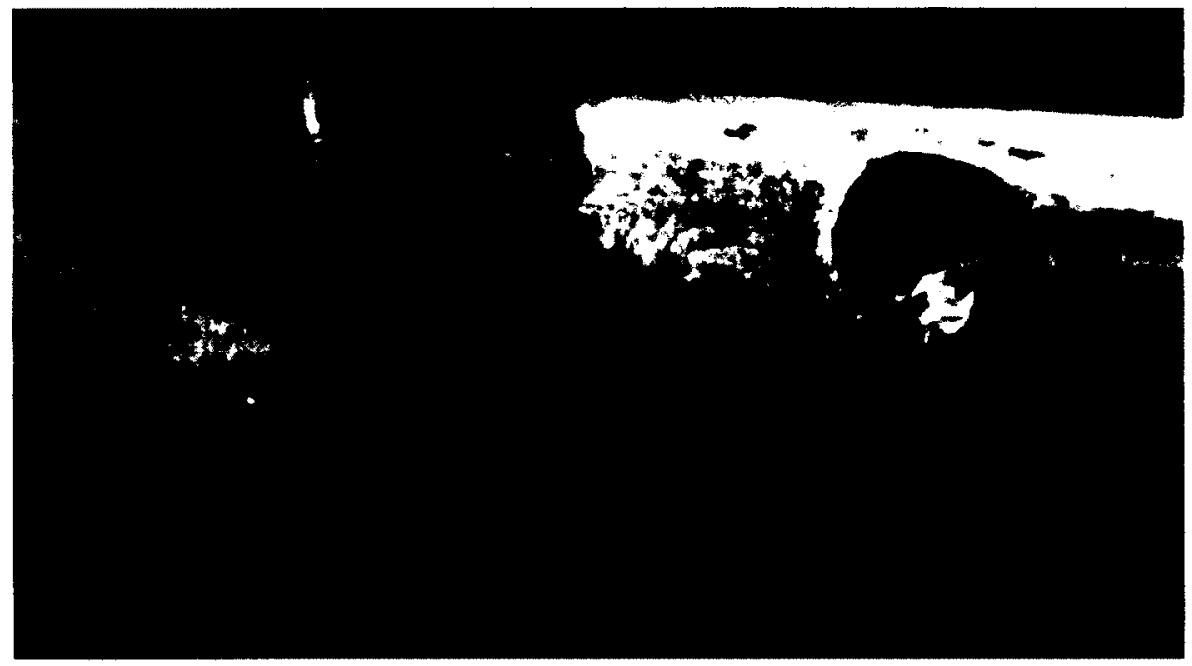

Figure 10 - Exposed wire thermocouple (after exposure to fire)

\subsubsection{Sheathed Thermocouple}

The thermocouple wires are housed inside a metallic tube, referred to as the sheath, which is commonly made of stainless steel or Inconel. The thermocouple wires are connected in a grounded, ungrounded or exposed configuration as shown in Figure 11. The thermocouple probe has a higher resistance to exposure and is suited to installation in solids and longer term or permanent installations. 

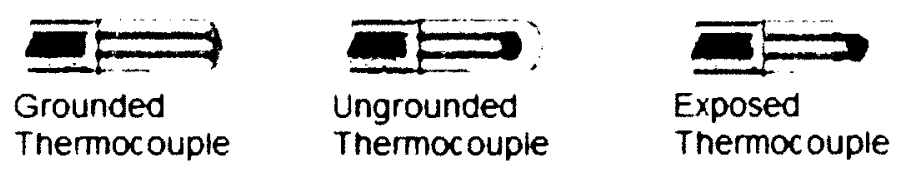

Figure 11 - Sheathed thermocouple types [23]

\subsubsection{Plate Thermometer}

The plate thermometer, shown in Figure 12, has a large surface area which is more sensitive to radiative heating than a standard thermocouple which has a small surface area and is more sensitive to local convective heat transfer. It is generally used in furnace testing where heat transfer depends primarily on radiant flux to a specimen rather than convection. It is installed in front of the specimen so that it receives the same amount of radiant exposure and is insulated behind so that it is not affected by the specimen [24]. As a result, the plate thermometer represents a reading of the adiabatic surface temperature of the plate which may differ from the surrounding gases significantly.

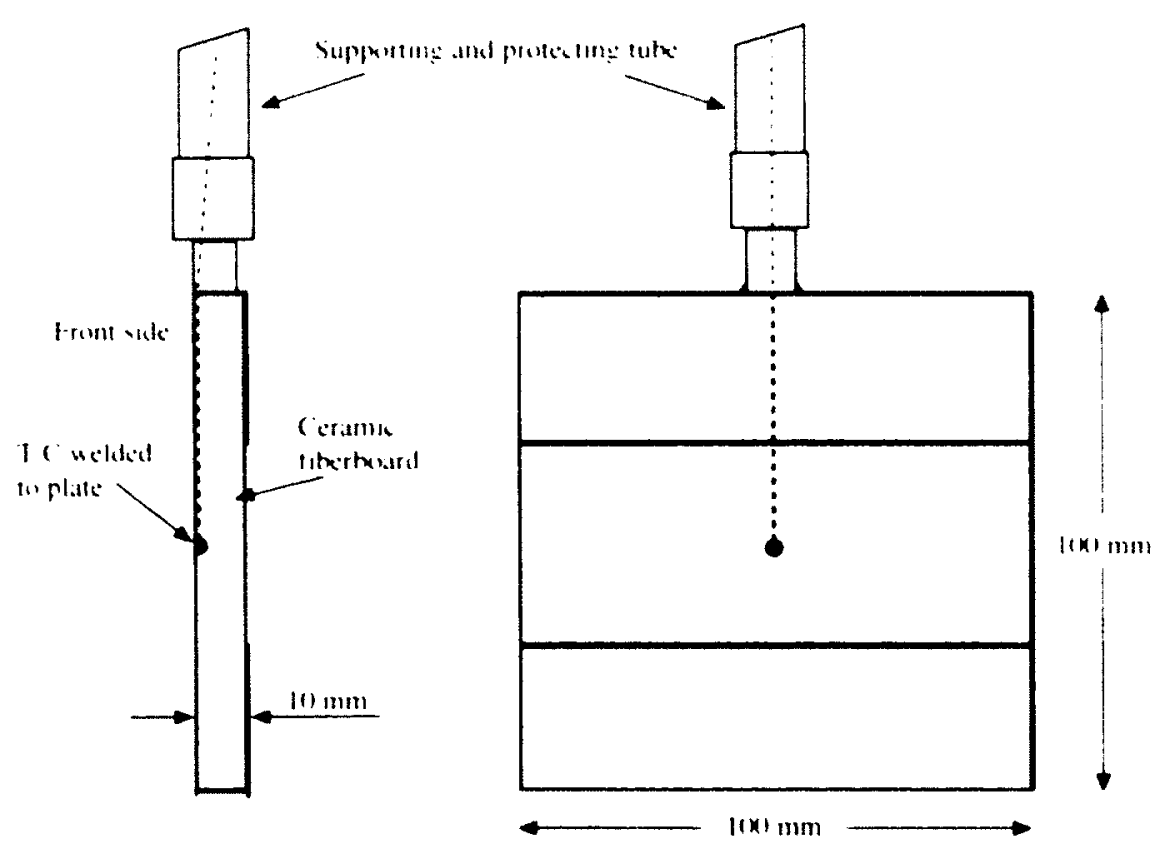

Figure 12 - Plate thermometer schematic [24] 


\subsection{Room Fires}

A room fire, often termed a compartment or enclosure fire, can occur in any confined space that controls the ultimate air supply and thermal environment [25]. These factors influence the energy release and burning rates making the fire perform differently to that of a fire in the open.

In a room fire the hot gases from combustion collect at the ceiling, developing a hot layer and heating the internal surfaces of the room. Together, these radiate heat back to the fuel enhancing the combustion process and increasing the burning rate which is demonstrated in Figure 13. The openings in the room however can limit the oxygen supply which can cause a decrease in the amount of fuel burnt and energy released which can ultimately decrease the burning rate. An expression which has been shown to be proportional to the burning rate in a room is termed the ventilation factor and is provided in $\mathrm{Eq} 9[16]$.

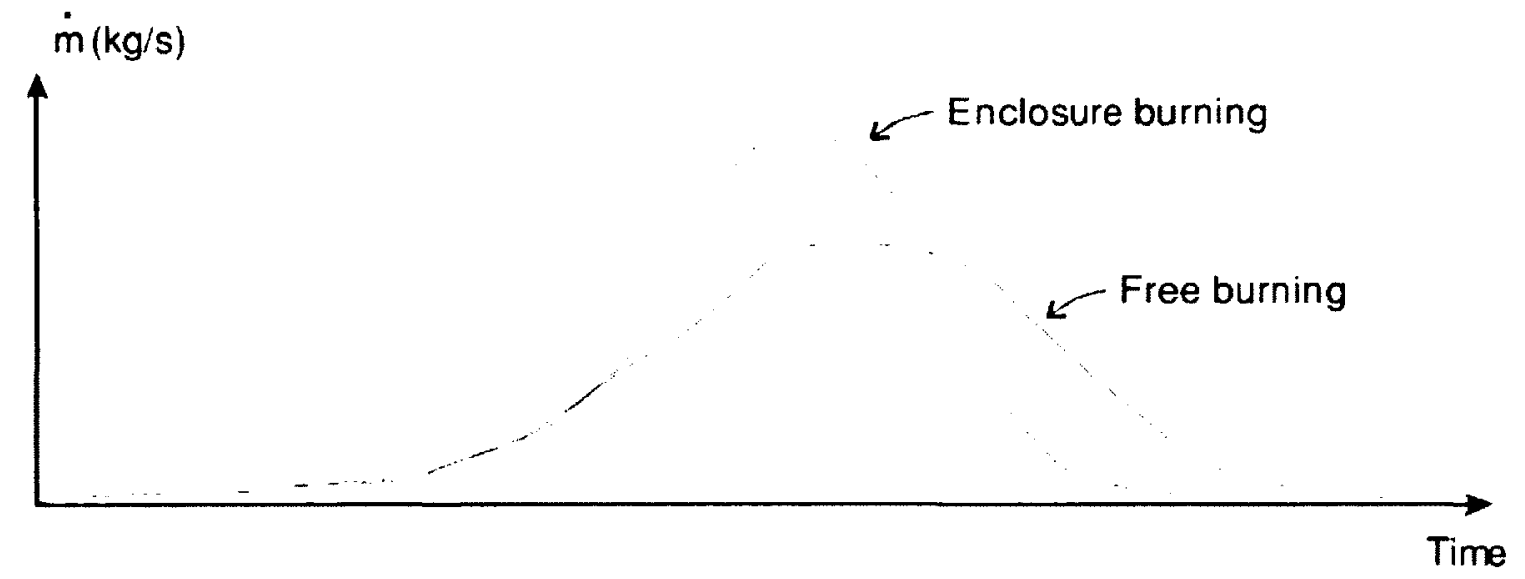

Figure 13 - Enclosure effect on mass loss rate [16]

$$
F_{O}=\frac{A_{O} \sqrt{H_{O}}}{A_{T}}
$$


Where $A_{\iota}=$ Area of opening $\left(\mathrm{m}^{2}\right)$

$$
\begin{aligned}
& H_{O}=\text { Height of opening }(\mathrm{m}) \\
& A_{t}=\text { Total internal surface area of room }\left(\mathrm{m}^{2}\right)
\end{aligned}
$$

Room fires generally consist of two main periods, the pre flashover fire and the post flashover fire [16]. The pre flashover period involves the growth stage of the fire, and is the period where fire safety design focuses on safety of humans [16]. The post flashover period is where the fire safety design focuses on structural stability, safety of fire fighters and measures to save property [16]. A more detailed description is provided by Walton and Thomas [26] which describes the fire in five stages relating to temperature, shown in Figure 14. A similar schematic for the five stages, relating to HRR, is presented in Figure 15. These stages are:

\section{Ignition}

2. Growth

3. Flashover

4. Fully Developed, and

5. Decay

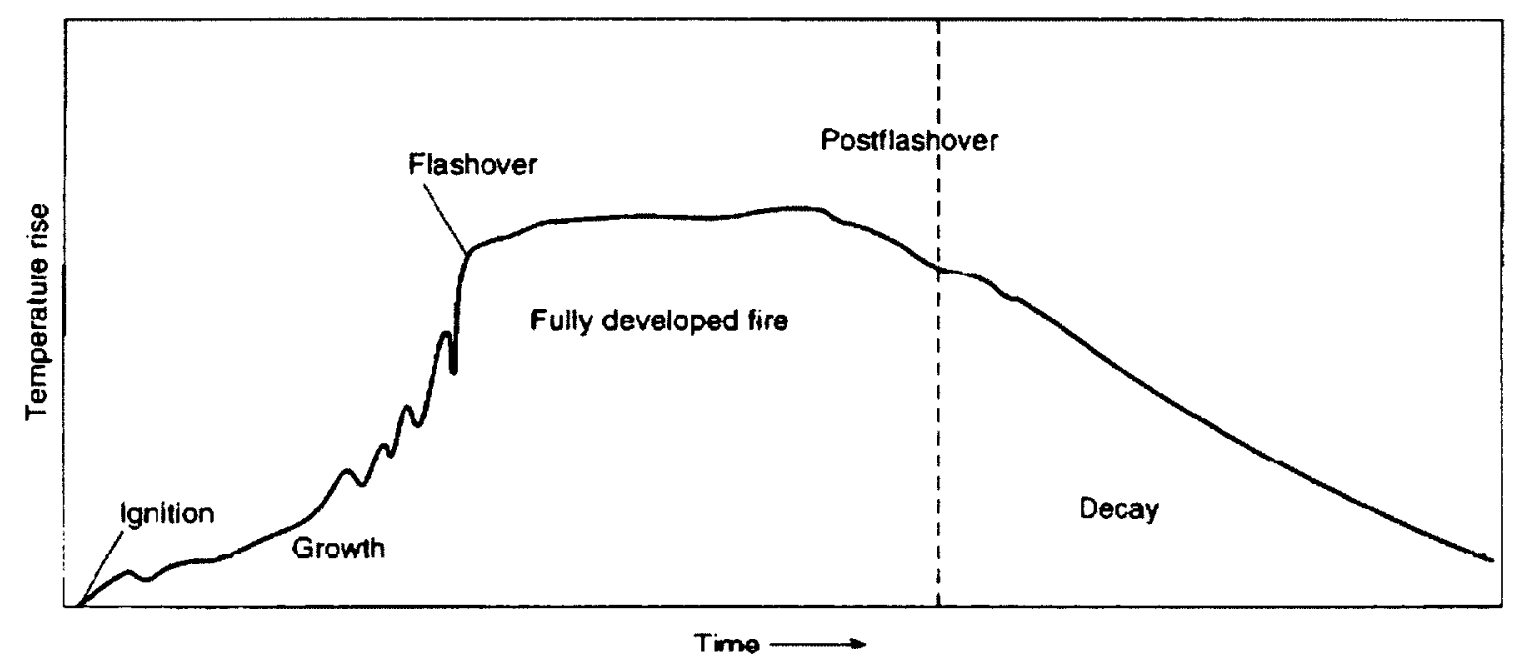

Figure 14 - Stages of fire development in room without suppression [26] Temperature 


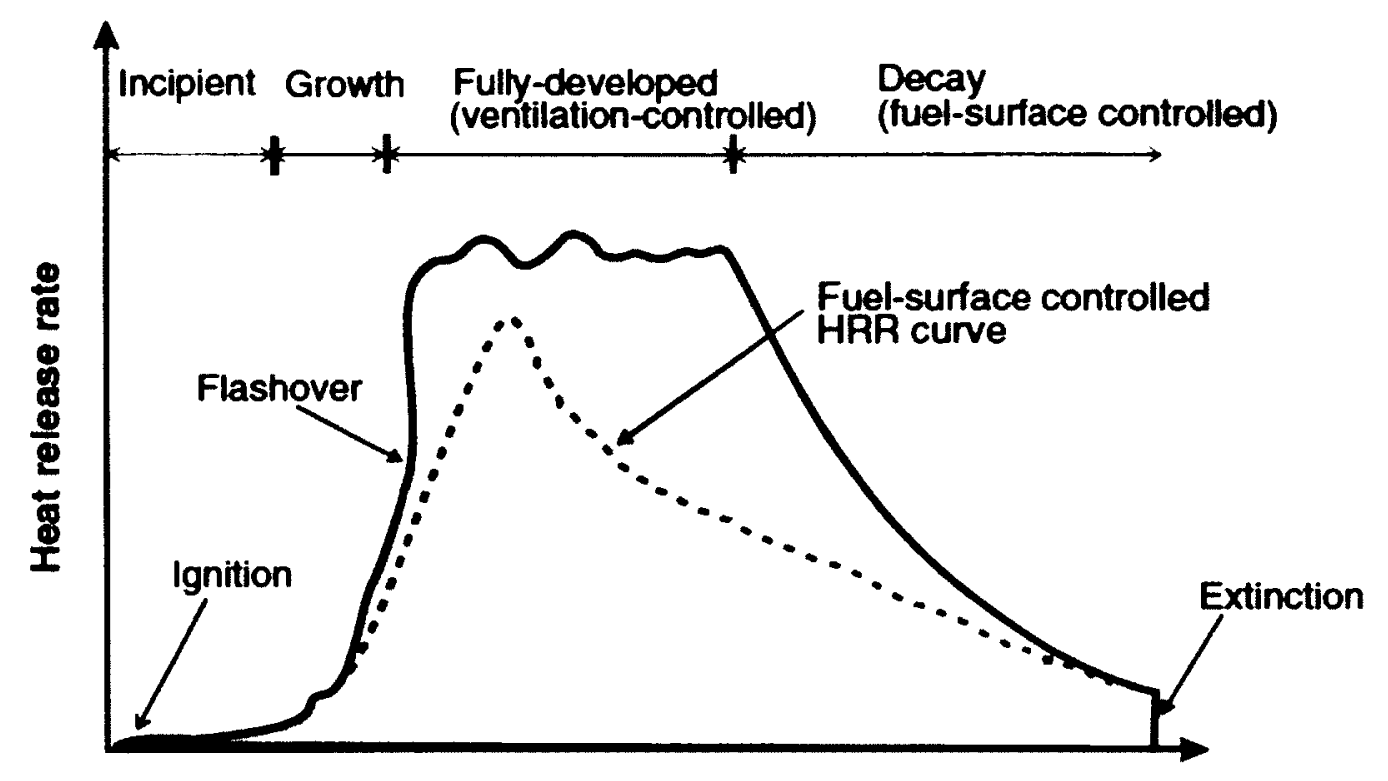

TIme

Figure 15 - Stages of fire development in room without suppression [27] - HRR

\subsubsection{Fire Stages}

\subsubsection{Pre-Flashover}

In the pre flashover fire, concern is for the safety of occupants and the most important measure is energy release rate vs time.

\subsubsection{Ignition}

Ignition is a process that produces an exothermic reaction that starts the combustion process. It can be through piloted ignition (spark, flame or other pilot source) or by spontaneous combustion (from an increase in heat in the fuel or radiant flux) [16].

\subsubsection{Growth}

Following ignition a fire undergoes an incipient period, shown in Figure 16, during which the fire grows very slowly until the confinement begins to influence the fire development. This period is difficult to quantify and can be influenced by various factors 
such as strength of ignition source, location of the burning items and the properties of the first item ignited [9].

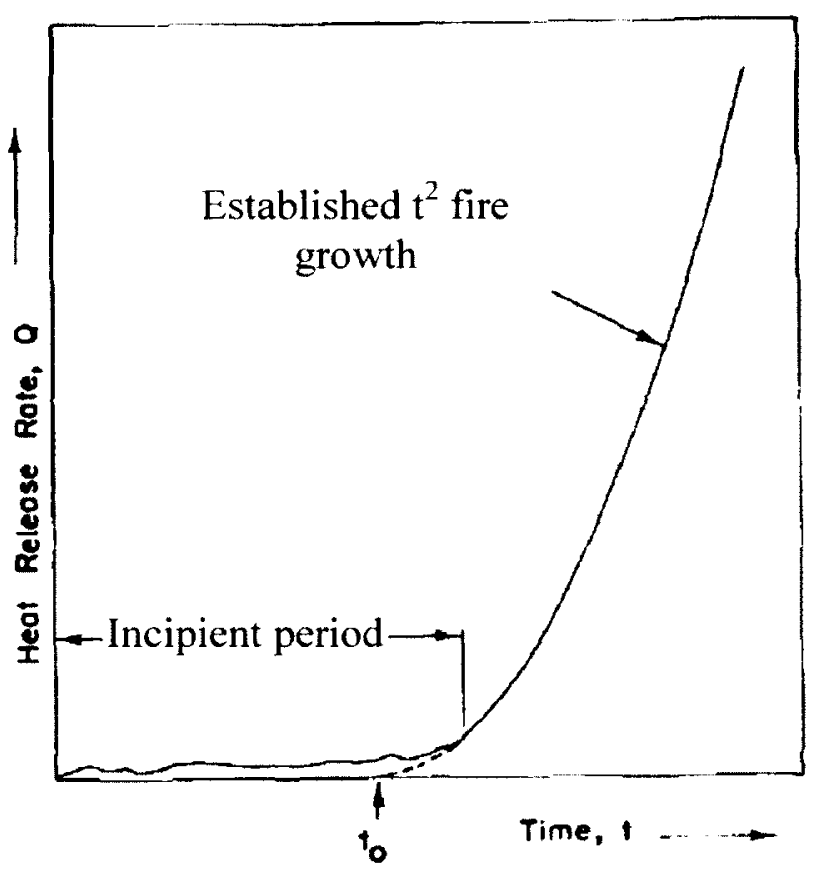

Figure $16-t$ squared fire growth following incipient phase (modified from [28]) In situations where there is sufficient fuel and ventilation the fire can progress to full room involvement and is said to be fuel controlled. The fire growth in this period can be characterized by the t-squared growth rate given in Eq 10[28]. A simpler form of the equation used for design fires, where an incipient period is ignored, is presented in Eq 11 .

$$
\dot{Q}=\alpha\left(t-t_{0}\right)^{2}
$$

Where

$$
\begin{aligned}
& \alpha=\text { growth rate coefficient }\left(k W s^{-2}\right) \\
& t_{0}=\text { virtual ignition time }(s) \\
& \dot{Q}=\alpha t^{2}
\end{aligned}
$$


The NFPA [16.29] recommended categories of fire growth in design fires, corresponding to the time it takes to reach $1055 \mathrm{~kW}$, are presented in Table 1 and graphically in Figure 17,

Table 1 - Fire HRR Growth Rates [9]

\begin{tabular}{|c|c|l|c|}
\hline & $\alpha\left(\mathrm{kW} / \mathrm{s}^{2}\right)$ & Typical Scenario & $\begin{array}{c}\text { Time }(\mathrm{s}) \text { to } \\
\text { reach 1055 kW }\end{array}$ \\
\hline Slow & 0.0029 & Densely packed paper products & 600 \\
\hline Medium & 0.012 & $\begin{array}{l}\text { Traditional mattress/boxspring } \\
\text { Traditional armchair }\end{array}$ & 300 \\
\hline Fast & 0.0469 & $\begin{array}{l}\text { PU mattress (horizontal) } \\
\text { PE pallets, stacked 1 m high }\end{array}$ & 150 \\
\hline Ultra-Fast & 0.1876 & $\begin{array}{l}\text { High-rack storage } \\
\text { PE rigid foam stacked 5 m high }\end{array}$ & 75 \\
\hline
\end{tabular}

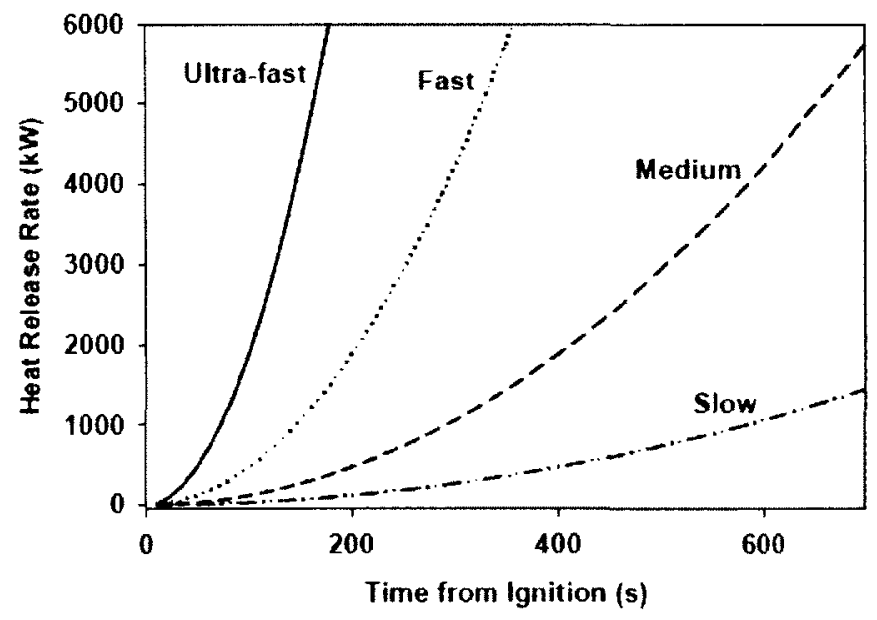

Figure 17 - Energy release rates for different growth rates [30]

\subsubsection{Post Flashover and Flashover}

\subsubsection{Flashover}

Flashover is generally defined as the transition from fire growth to a fully developed fire, at which point everything in the room becomes involved in the fire. This is not a precise term but is often defined in terms of heat flux of $20 \mathrm{~kW} / \mathrm{m}^{2}$ at floor level 
(Waterman's [31] criterion), ceiling temperatures of $500-600^{\circ} \mathrm{C}[26]$ or an observation of flame projecting from the compartment openings [32].

At flashover, the rapid rise in energy release and temperature make the environment untenable and focus shifts from safety of the occupants to structural integrity and safety of firefighting personnel. In this period the temperature in the room is of most concern [27]. A simple energy balance is used as the basis to predict the conditions in the room where the HRR of the fire, given by Eq 12 [33], is assumed to be delivered to the upper layer [33].

$$
\begin{aligned}
& \dot{m}_{g}=\dot{\hat{g}} \text { as flow out of opening }\left(\mathrm{kgs}^{-1}\right) \\
& c_{n}=\text { specific heat of gas }\left(k^{\prime} \mathrm{kg}^{-1} \mathrm{~K}^{-1}\right) \\
& \text { Whi } \left.T_{g}=\text { temperature of upper gas layer }\left({ }^{\circ} K\right)_{-1}\right) \\
& T_{a}=\text { ambient temperature }\left({ }^{\circ} \mathrm{K}\right) \\
& \begin{aligned}
\dot{q}_{\text {lows }}= & h_{k} A_{t}\left(T_{s}-T_{s}\right) \\
I_{a} & =\text { ambient temperature }\left({ }^{\circ} \mathrm{K}\right)
\end{aligned} \\
& \dot{q}_{\text {low }}=h_{k} A_{T}\left(T_{g}-T_{s}\right) \\
& =\text { net radiative and convective heat transfer from the upper gas layer }(\mathrm{kW}) \\
& h_{k}=\text { effective heat transfer coefficient of boundaries }\left(k W m^{-2} K^{-1}\right)^{1 / 2}
\end{aligned}
$$

To determine the mass flows in and out of the compartment, vent flow analysis can be used. Assuming the well mixed case, shown in Figure 18, and taking into account the burning rate in the room, Eq 13 and Eq 14 are generated [16]. 


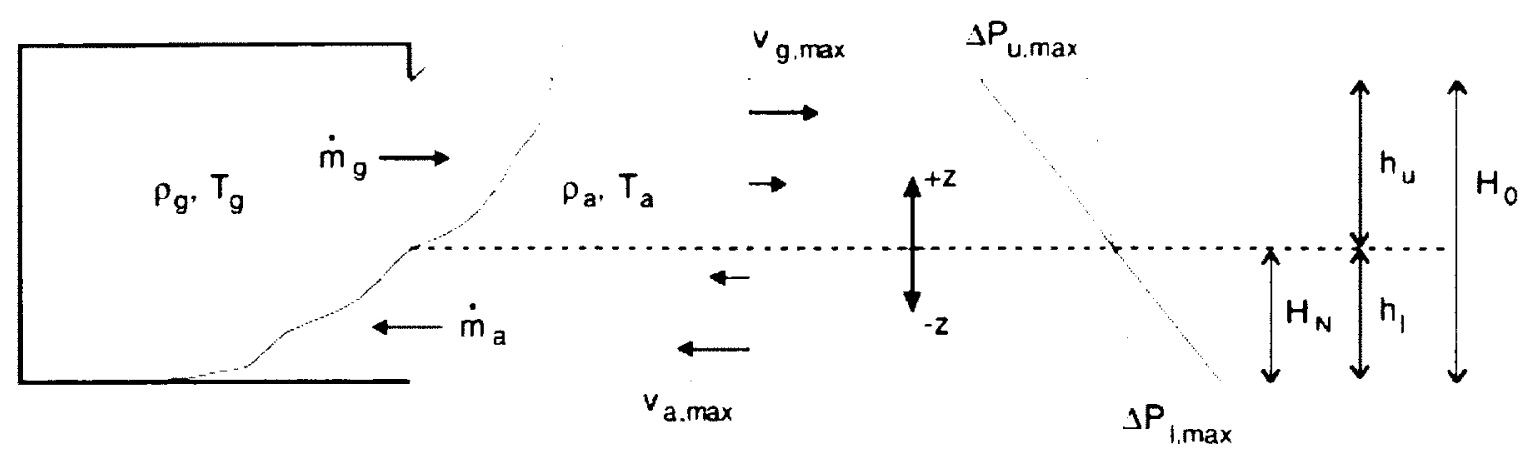

Figure 18 - Vent flows for well mixed room with uniform temperature where

$$
\begin{aligned}
T_{g} & >T_{a} \\
\dot{m}_{a}=\frac{2}{3} C_{d} W \rho_{a} \sqrt{\frac{2\left(\rho_{a}-\rho_{g}\right) g}{\rho_{a}}} h_{l}^{3 / 2} &
\end{aligned}
$$

Where

$$
\begin{aligned}
\dot{m}_{a} & =\text { gas flow into of opening }\left(\mathrm{kgs}^{-1}\right) \\
C_{d} & =0.7=\text { opening flow coefficient } \\
W & =\text { width of opening }(\mathrm{m}) \\
\rho_{a} & =1.2\left(\mathrm{~kg} \mathrm{~m}^{-3}\right)=\text { density of air } \\
\rho_{g} & =\text { density of gases leaving room }\left(\mathrm{kg} \mathrm{m}^{-3}\right) \\
g & =9.81\left(\mathrm{~m} \mathrm{~s}^{-2}\right)=\text { acceleration due to gravity } \\
h_{l} & =\text { height of neutral plane }(\mathrm{m})
\end{aligned}
$$

$$
\dot{m}_{g}=\dot{m}_{a}+\dot{m}_{b}=\frac{2}{3} C_{d} W \rho_{g} \sqrt{\frac{2\left(\rho_{a}-\rho_{g}\right) g}{\rho_{a}}} h_{u}^{3 / 2}
$$

Where

$$
\begin{aligned}
\dot{m}_{b} & =\text { burning rate }\left(\mathrm{kgs}^{-1}\right) \\
H_{N} & =h_{l}+h_{u}=\text { height of opening }(\mathrm{m})
\end{aligned}
$$

If the burning rate is known, $\mathrm{Eq} 13$ and $\mathrm{Eq} 14$ can be solved by iteration to determine the neutral plane from which the flow rates and temperatures can be determined.

McCaffrey, Quintiere and Harkleroad (MQH) [33] developed an expression to predict the minimum HRR required for flashover to occur, given by Eq 15 [33]. This 
method assumes a conservative increase in temperature of $500^{\circ} \mathrm{C}$ and replaces $\dot{m}_{g}$ with $\sqrt{g} \rho_{a} A_{,} \sqrt{H_{0}}$. A similar expression, given by Eq 16, was developed by Thomas [8].

$$
\begin{aligned}
& \dot{Q}_{t \cdot()}=610\left(h_{k} A_{t} A_{O} \sqrt{H_{O}}\right)^{12} \\
& \dot{Q}_{l \cdot()}=7.8 A_{T}+378 A_{O} \sqrt{H_{O}}
\end{aligned}
$$

\subsubsection{Fully developed}

Following flashover the HRR is the greatest and often more fuel is pyrolyzed than can be combusted within the room meaning that the size of the fire is controlled by the amount of air that is entering the room. The fire is termed fully developed and is said to be ventilation controlled. Drysdale [9] shows that the mass flow rate of air is given by Eq 17. The peak HRR is derived from Eq 18 using the assumption that energy released when air is consumed is $3 \mathrm{MJ} / \mathrm{kg}$, modified from the oxygen consumption principle presented in $\mathrm{Eq} 6$.

$$
\begin{aligned}
& \dot{m}_{a}=0.5 A_{O} \sqrt{H_{O}} \quad\left(k g s^{-1}\right) \\
& \dot{Q}_{\text {pcak }}=1.5 A_{O} \sqrt{H_{O}} \quad(M W)
\end{aligned}
$$

The concern for fire in this stage is for structural integrity and the most important measures are those of temperature and duration. Several methods are available to estimate the temperatures of post flashover fires. Law provides an empirical method to estimate the maximum temperature which is shown in Eq 19 [26].

$$
T_{g, \max }=6000 \frac{\left(1-e^{-0.1 \Omega}\right)}{\sqrt{\Omega}}
$$


Where $\quad \Omega=\frac{A_{l}-A_{l}}{A_{l} \cdot \sqrt{H_{l}}}$

$$
T_{g \cdot \max }=T_{y \cdot \max }=6000 \frac{\left(1-e^{-0.1 \Omega}\right)}{\sqrt{\Omega}}
$$

Perhaps the most widely used equations in design fires for temperature vs time are the Eurocode 1 [34] parametric equations. This method divides the fire development into two phases: heating and decay. The heating phase, developed from the 'Swedish' [9] fire curves shown in Figure 19, is provided in Eq 20. Each group of curves in Figure 19 represents a different ventilation factor where $Q$, represents the fire load density as a function of the total internal surface area of the room (whereas the floor area is referenced in this thesis).

$$
T_{y}=1325\left(1-0.324 e^{-0.2 i^{*}}-0.204 e^{-1.7 i^{*}}-0.472 e^{-19 i^{*}}\right)
$$

Where

$$
\begin{aligned}
& t^{*}=\Gamma_{\text {II:KGi }} \mathrm{t} \\
& \Gamma_{\text {II:KK }}=\frac{\left(F_{l} \cdot F_{r e f}\right)^{2}}{\left(b b_{r e f}\right)^{2}} \\
& F_{r c t}=0.04 \mathrm{~m}^{0.5} \\
& b=\sqrt{k \rho c_{p}}\left(\mathrm{Jm}^{-2} \mathrm{~s}^{-0.5} \mathrm{~K}^{-1}\right) \\
& \mathrm{b}_{r e f}=1160\left(\mathrm{Jm}^{-2} \mathrm{~s}^{-0.5} \mathrm{~K}^{-1}\right) \\
& k \rho c_{p}=\text { thermal inertia }\left(W^{2} \mathrm{sm}^{-4} \mathrm{~K}^{-2}\right)
\end{aligned}
$$

\subsubsection{Decay Phase}

The decay phase occurs as the fuel is consumed and the HRR begins to reduce. This is accompanied by a reduction in temperature and the fire changes from ventilation controlled back to fuel controlled. 
The decay phase of the Eurocode 1 [34] parametric fires is provided in Eq 21. This period is often identified by the temperature dropping to $80 \%$ of its peak [9] and changes from ventilation to fuel controlled.

$$
T_{g}=\left\{\begin{array}{ll}
T_{x, \max }-625\left(t^{*}-t_{d}^{*}\right) & t_{d} \leq 0.5 \\
T_{g, \max }-250\left(3-t_{d}^{*}\right)\left(t^{*}-t_{d}^{*}\right) & 0.5 \leq t_{d} \leq 2.0 \\
T_{g, \max }-250\left(t^{*}-t_{d}^{*}\right) & t_{d} \geq 2.0
\end{array}\right\}
$$

Where

$T_{g, \max }$ is the max temperature in the heating phase for $t^{*}-t_{d}^{*}$

$$
\begin{aligned}
t_{d}^{*} & =t_{d d}\left(\frac{F_{o}}{\sqrt{k \rho c_{p}}}\right)^{2}\left(\frac{b_{r c t}}{F_{v}}\right)^{2} ; \quad t_{d}=\frac{0.13 \times 10^{-3} Q_{t}^{n}}{F_{o}} \\
Q^{n} & =\text { fire load density }\left(M J m^{-2}\right. \text { total area) }
\end{aligned}
$$
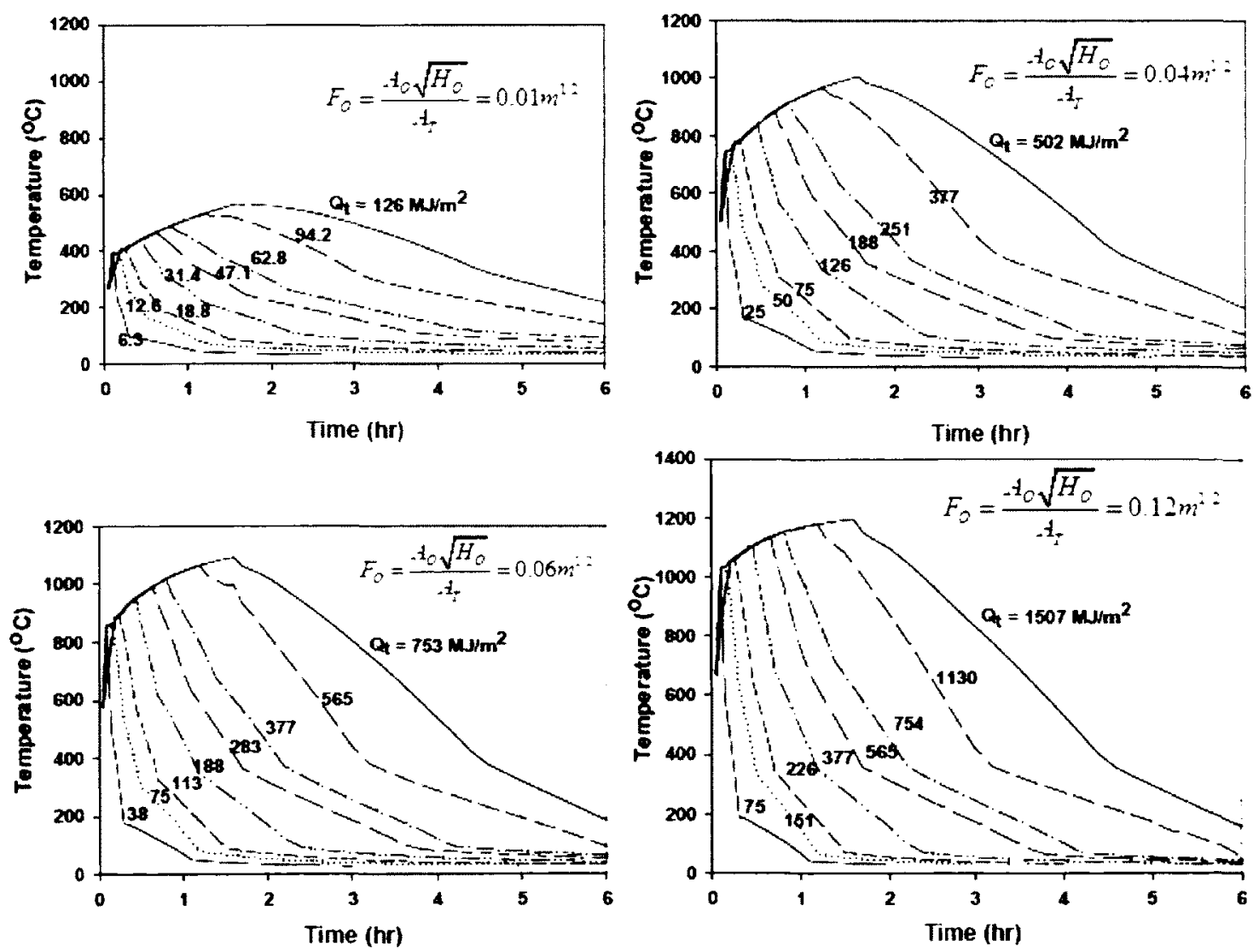

Figure 19 - Swedish Fire Curves developed by Magnusson and Thelanderson [35] 


\subsection{Design Fires}

Design fires are used by fire engineers to simulate design fire scenarios to demonstrate the performance in the context of fire regulations. The two main objectives to be met in the building regulations are life safety of the occupants and structural stability of the building.

As there is no exact methodology or procedure available to determine the design fire to be used in room fires, the engineer must use all available information on the building and fuels, and engineering judgement to determine an appropriate fire [16]. The design fire is expressed in terms of HRR vs time and, in the simple case, incorporates three phases: Growth, Steady burning and Decay. The $\mathrm{t}^{2}$ fires, discussed in Section 2.6, are commonly used to model the growth phase of the fire and can also be adjusted to represent the decay. An example of a simple design fire is presented in Figure 20.

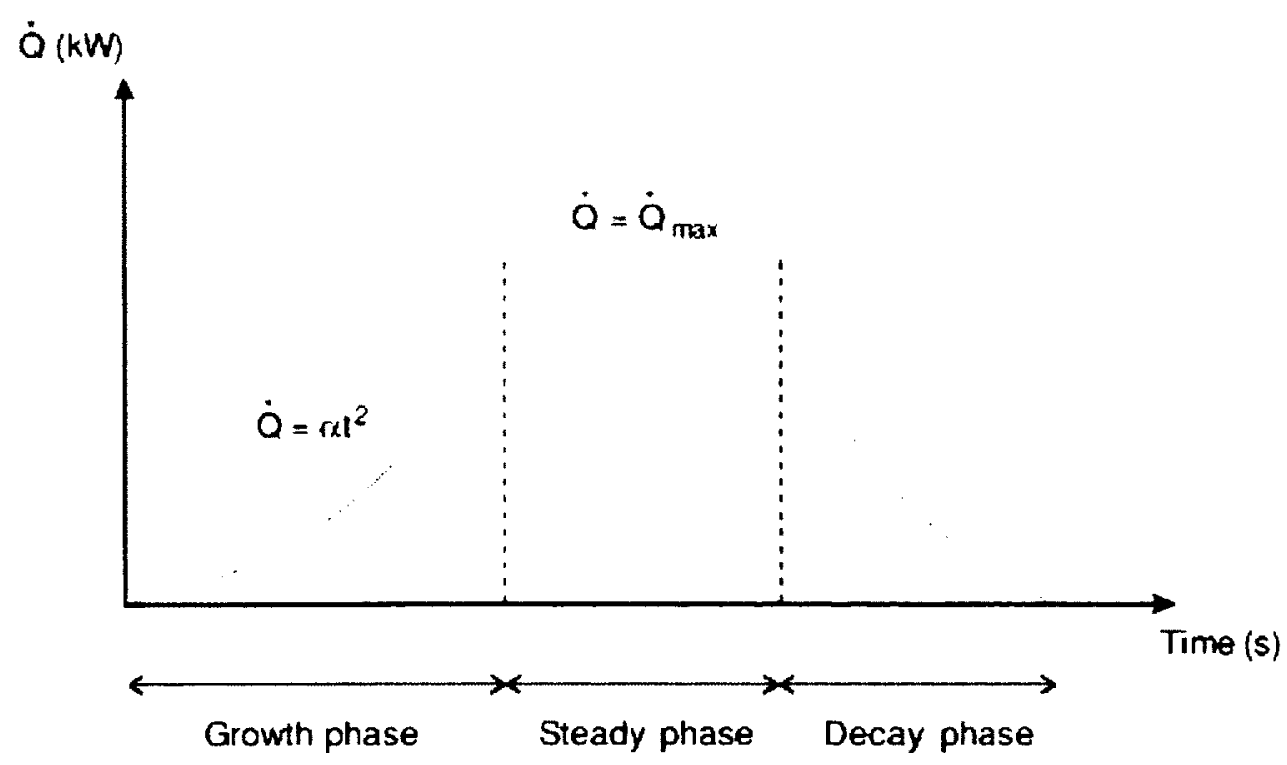

Figure 20 - Example of a simple fire curve [16] 


\subsection{Fire load Density}

Fire load, measured in megajoules (MJ), represents the potential heat energy in a room that can be released during combustion from both fixed and moveable items, generally any items that are not part of the basic structure. Fixed items can represent built in elements such as floor coverings, cupboards, doors, window frames etc; whereas movable items include anything that can be easily moved in and out of the room. Fire load (FL) is most often described as a fire load density (FLD), where it is expressed in terms of unit area $\left(\mathrm{MJ} / \mathrm{m}^{2}\right)$ which allows comparison with rooms of different sizes. A simple expression for fire load density is given in Eq 22 [8].

$$
Q^{\prime \prime}=\frac{E}{A_{f}} \quad\left(M J / \mathrm{m}^{2}\right)
$$

Where

$$
\begin{aligned}
E= & \text { the maximum possible energy that can be released by complete } \\
& \text { combustion }(M J) \\
A_{f}= & \text { floor area of room }\left(\mathrm{m}^{2}\right)
\end{aligned}
$$

When used in design, the fire load should be considered much like any other load in building design such as wind, snow or earthquake etc, and should represent an extreme case of the likely scenarios. Buchanan [8] recommends that this value should represent a less than $10 \%$ probability of occurrence in the 50 year life of the building, which, when using representative surveys is determined at the $90^{\text {th }}$ percentile [8]. Other recommendations for design fire load percentiles are $80^{\text {th }}$ or $95^{\text {th }}[36]$.

Depending on distribution of data in the surveys, this value can often exceed twice the average of the sample. Where using data that matches a normal distribution, the percentile required for design is calculated using Eq 24 [37]. 


$$
z=\frac{(x-\mu)}{\sigma}
$$

Where $\quad z=$ number of standard deviations from mean

$\sigma=$ standard deviation

$x=$ value

$\mu=$ mean

Which is rearranged for fire load in $\mathrm{Eq} 24$.

$$
Q_{\mathrm{o}_{\mathrm{o}}}^{n}=Q_{\mu}^{n}+\sigma z_{\mathrm{o}}
$$

Where

$$
z_{0_{\mathrm{o}}}=\mathrm{z} \text { value below which the } \% \text { of samples lie (given by table) }
$$

$$
z_{80}=0.84
$$

$z_{90}=1.28$

$z_{95}=1.64$

A survey conducted of Canadian multi-family dwellings [27] collected information using the traditional approach of visiting households, as well as estimations using photographs from online real estate listings, to gain information on dimensions, quantity, size, materials and other pertinent attributes of room contents. The data was compared to published data on heat of combustion and weight for common groups of items to determine the overall fire loads in each of the rooms. From each set of data an average was presented along with the value for the worst case scenario, specified as the $95^{\text {th }}$ percentile. The results from the survey are presented in Figure 21. 


\begin{tabular}{|c|c|c|c|c|c|c|c|}
\hline Room & $\begin{array}{c}\text { Mean } \\
\text { FLD } \\
\left(\mathrm{MJ} / \mathrm{m}^{2}\right)\end{array}$ & $\begin{array}{c}\text { Standard } \\
\text { Deviation } \\
\left(\mathrm{MJ} / \mathrm{m}^{2}\right)\end{array}$ & $\underset{\left(\mathrm{MJ} / \mathrm{m}^{2}\right)}{\operatorname{Minimum}}$ & $\begin{array}{c}\text { Maximum } \\
\left(\mathrm{MJ} / \mathrm{m}^{2}\right)\end{array}$ & $\begin{array}{c}95^{\text {th }} \\
\text { Percentile }\end{array}$ & $\begin{array}{c}\text { Sample } \\
\text { Size }\end{array}$ & $\begin{array}{c}\text { Mean FL } \\
\text { (MJ) }\end{array}$ \\
\hline Kitchen & 807 & 123 & 420 & 1244 & 940 & 515 & 7,908 \\
\hline $\begin{array}{l}\text { Secondary } \\
\text { bedroom }\end{array}$ & 594 & 146 & 107 & 1,000 & 846 & 129 & 6,237 \\
\hline $\begin{array}{l}\text { Primary } \\
\text { Bedroom }\end{array}$ & 534 & 125 & 249 & 920 & 753 & 347 & 8,864 \\
\hline Living Room & 412 & 127 & 106 & 897 & 610 & 397 & 7,251 \\
\hline Dining Room & 393 & 132 & 119 & 901 & 576 & 292 & 3,812 \\
\hline $\begin{array}{l}\text { Basement } \\
\text { Living Room } \\
\end{array}$ & 288 & 96 & 103 & 633 & 450 & 130 & 6,682 \\
\hline
\end{tabular}

Figure 21 - Fire load densities for various rooms [27]

\subsection{Previously Conducted Room Tests}

\subsubsection{Hakkarainen [38]}

Hakkarainen carried out 4 tests as part of the research project 'Fire Safe Wooden Buildings' (Brandsäkra Trähus - Massivträ) as part of a Nordic research program on wood technology (Nordic Wood).

\subsubsection{Objectives}

- To determine the temperature development for natural fires inside a room of heavy timber construction,

- To study the contribution of the timber construction to the fire load, and

- To evaluate the capability of gypsum plasterboard to protect the timber construction.

A brief review of temperature development in compartment fires and charring of timber structures was included. The dimensions of the room used in the tests, shown in Figure 22, were $4.5 \times 3.5 \times 2.5 \mathrm{~m}$ height. Opening dimensions were width $2.3 \times 1.2 \mathrm{~m}$ height. 


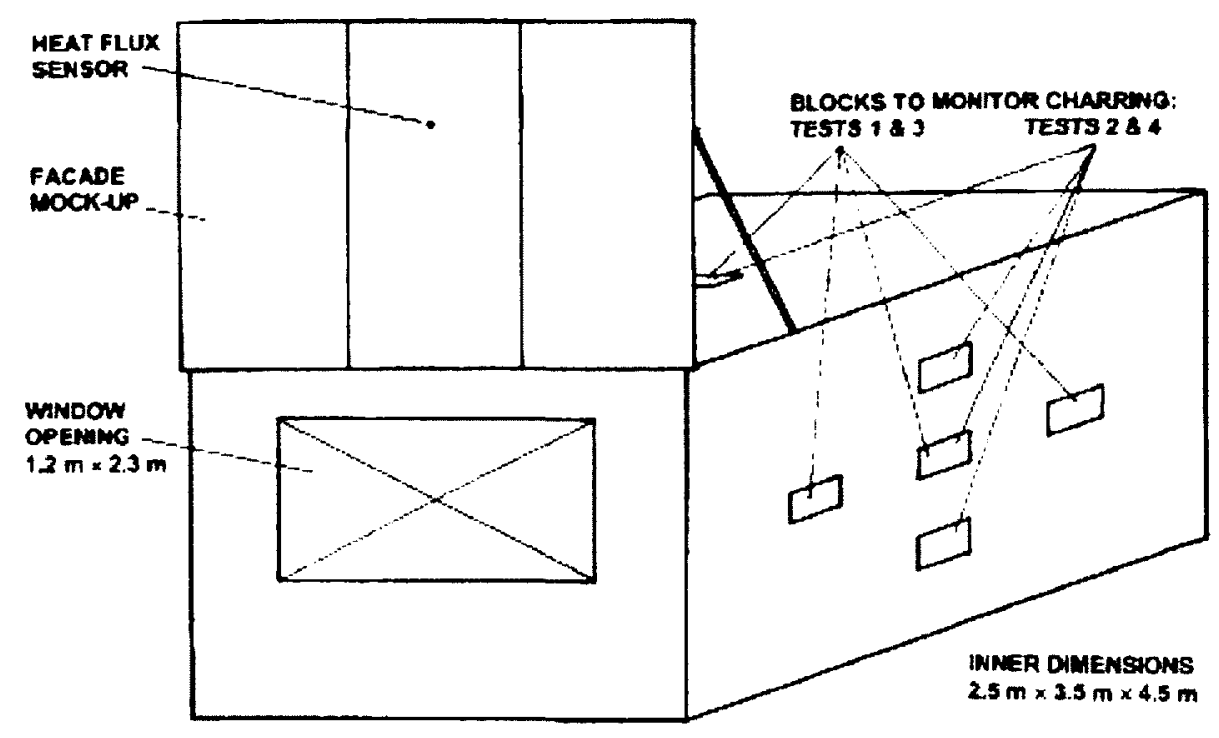

Figure 22 - Schematic of test room - Hakkarainen [38]

A summary of the tests conducted and configurations are presented in Table 2.

Table 2 - Summary of tests - Hakkarainen [38]

\begin{tabular}{|c|c|c|c|}
\hline Test no. & Date & Construction & $\begin{array}{c}\text { Gypsum } \\
\text { Plasterboard } \\
\text { Protection }\end{array}$ \\
\hline lest 1 & 25 Apnl 2001 & Heavy laminated timber & None \\
\hline lest 2 & 24 Jenuary 2001 & Heavy laminated timber & 1 teyer type A \\
\hline lest 3 & 5 June 2001 & Heavy laminated timber & 2 layers, type A t type t \\
\hline lest 4 & 18 January 2001 & $\begin{array}{l}\text { Wood studs with } \\
\text { mineral wool insulation }\end{array}$ & 2 kyers, type $A \cdot$ type 1 \\
\hline
\end{tabular}

The thickness of the heavy timber structure is not specified, however thermally thick expressions were used in calculations. Thermocouples were fitted within the structure at depths of $0,6,18,30,42$ and $54 \mathrm{~mm}$ from the inside surface. Temperatures in the room were measured using 3 thermocouple trees each with thermocouples at heights $0.1,0.5,0.9,1.3$ and $1.7 \mathrm{~m}$ from the ceiling. Heat flux was measured on the façade above the opening. The fire load in the room consisted of wood cribs and a tongue and groove particle board floor. The fire load density in each of the tests was estimated at $720 \mathrm{MJ} / \mathrm{m}^{2}$, 
this did not include the contribution of the heavy timber structure. Unfortunately all of the tests did not run to completion for various reasons, intensity appeared to increase for Tests 1 and 2 shortly before each test was ended and the decay phases were not observed. Decay phases were observed in Tests 3 and 4. Gas temperatures and heat flux data are presented in Table 3:

Table 3 - Temperature and heat flux data for tests - Hakkarainen [38]

\begin{tabular}{|c|c|c|c|c|c|c|c|c|c|c|}
\hline \multirow{3}{*}{ Test no. } & \multirow{3}{*}{$\begin{array}{l}\text { Time to } \\
\text { Flashover } \\
\text { (min:s) }\end{array}$} & \multicolumn{6}{|c|}{ Temperature (C) } & \multirow{3}{*}{$\begin{array}{l}\text { Maximum } \\
\text { Heat Flux } \\
\left(k W: m^{2}\right)\end{array}$} & \multicolumn{2}{|r|}{ End of Test } \\
\hline & & \multicolumn{2}{|c|}{ Front } & \multicolumn{2}{|c|}{ Centre } & \multicolumn{2}{|c|}{ Rear } & & \multirow{2}{*}{ Time (min) } & \multirow{2}{*}{ Reason } \\
\hline & & Typical & Max & Typical & $\operatorname{Max}$ & Typical & $\operatorname{Max}$ & & & \\
\hline iest 125 ADr 2001 & 450 & 700 & 1250 & 750 & 1100 & 700 & 1250 & 140 & 50 & Excesswe thang \\
\hline Test 2 (24 dariusy 2001 : & $4 \cdot 30$ & 800 & 1050 & 750 & 1500 & 600 & $8 X$ & 130 & 46 & Maitunctior of smake veming system \\
\hline iest 315 June 2001 ? & $6 x$ & 1500 & 1150 & 350 & 1200 & $7 x 0$ & 1150 & 140 & 169 & Feube ot ceting wall jont \\
\hline Test 4 (18 danuary 2501; & 6.10 & 1500 & 1250 & 1200 & 1200 & 750 & 1150 & 80 & 48 & Burnthough of celleg \\
\hline
\end{tabular}

The measured gas temperatures in the tests were $300-500^{\circ} \mathrm{C}$ lower than the temperatures predicted by the Eurocode 1 [34] parametric equations for Tests 1 and 2 but were much closer in Tests 3 and 4 in which the protection remained in place throughout. The lowest temperatures were attributed to the pyrolysis products from the walls and ceiling consuming energy during heating and gasification, and restricting the oxygen entering the compartment. This resulted in increased combustion occurring outside the compartment and excessive flaming in the case of unprotected heavy timber. Each layer of gypsum board applied provided approximately 20 minutes delay in the onset of charring. All fires were ventilation controlled and all predictions were on the safe side.

In general, high charring rates were observed at the onset of charring which reduced over time as the char layer increased providing a greater protective effect, these results are presented in Table 4. 
Table 4 - Charring data from tests - Hakkarainen [38]

\begin{tabular}{|c|c|c|c|c|c|c|c|c|c|c|}
\hline \multirow[b]{3}{*}{ Test no. } & \multirow{3}{*}{$\begin{array}{l}\text { Collacose d } \\
\text { trist GPB } \\
\text { byer irom } \\
\text { ceing imm; }\end{array}$} & \multicolumn{2}{|c|}{ Start of Olarng inm: } & \multicolumn{4}{|c|}{ Chanmg Rate imn:mn: } & \multicolumn{2}{|c|}{ Maxmum Ona: Depth (rm): } & \multirow{3}{*}{$\begin{array}{l}\text { Tome tor } \\
\text { Masinum } \\
\text { Ona Deptr = Enc } \\
\text { of Test imet }\end{array}$} \\
\hline & & \multirow[b]{2}{*}{ Comg } & \multirow[b]{2}{*}{$\begin{array}{l}\text { Mrodte } \\
\text { theynth } \\
\text { J Wats }\end{array}$} & \multicolumn{2}{|c|}{ Coing } & \multicolumn{2}{|c|}{ Wals } & \multirow[b]{2}{*}{ Coding } & \multirow[b]{2}{*}{ Walks } & \\
\hline & & & & $\begin{array}{l}\text { at the } \\
\text { Onsel of } \\
\text { Cranng }\end{array}$ & $\begin{array}{l}\text { n the } \\
\text { End Phase } \\
\text { of Iest }\end{array}$ & $\begin{array}{l}\text { at the } \\
\text { Orset } \\
\text { a Ctarng }\end{array}$ & $\begin{array}{l}\text { on the } \\
\text { End Priase } \\
\text { of Tesl }\end{array}$ & & & \\
\hline$i=1 \cdot 2540 \cdot 200^{\circ}$ & & 3 & 5 & $\cdot$ & 05 & 3.5 & $0.5 \rightarrow 7$ & 35 & 20 & 50 \\
\hline 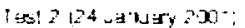 & $\cdot 5$ & 20 & 25 & 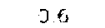 & & 9405 & & .4 & $2-3$ & $\angle 8$ \\
\hline 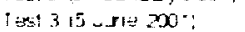 & 27 & 40 & 5 & 4 & 04 & 3. & 02 & 47 & $23-20$ & 5 \\
\hline 7 sot 41.5 wisury 2000 & 3 & 39 & & 3 & & & & 7 & $2-3$ & 48 \\
\hline
\end{tabular}

\subsubsection{Conclusions}

- Temperatures significantly lower than predicted using Eurocode 1 were observed for unprotected structures and single layer gypsum protection.

- The Eurocode 1 parametric temperature-time curves were useful in predicting the gas temperatures within the compartments with two layered gypsum protection,

- A reduction of charring rates were observed over time resulting from the increased protective effect of the char layer.

- Gypsum protection delays the onset of charring by approximately 20 minutes per layer.

\subsubsection{Frangi, Bochicchio, Ceccotti and Lauriola [39]}

As part of SOFIE, an extensive research project on the structural behaviour of cross laminated timber buildings, a natural fire test was conducted on a 3 story cross laminated timber building at the Building Research Institute in Tsukuba Japan in 2006. The aim of the SOFIE research project was to supply documentation and information on the use of CLT panels, particularly for residential multi storey buildings.

The fire room was located one floor above ground level in the building with dimensions $3.34 \times 3.34 \times 2.95$ high as shown in Figure 23. The floor and ceiling of the 
room were constructed from $142 \mathrm{~mm}$ CLT panels, the walls were constructed from 85 $\mathrm{mm}$ on 3 sides and $142 \mathrm{~mm}$ CLT panels on 1 side. The insulating and finishing materials varied with cross sections of each of the configurations as shown in Figure 24. The windows of the room were made of standard glass and opened $1 / 4$ width at the start of the test. All other windows in the building were either closed or sealed with gypsum plasterboards. The door, which had a 60 minute fire resistance rating, remained closed throughout the test.

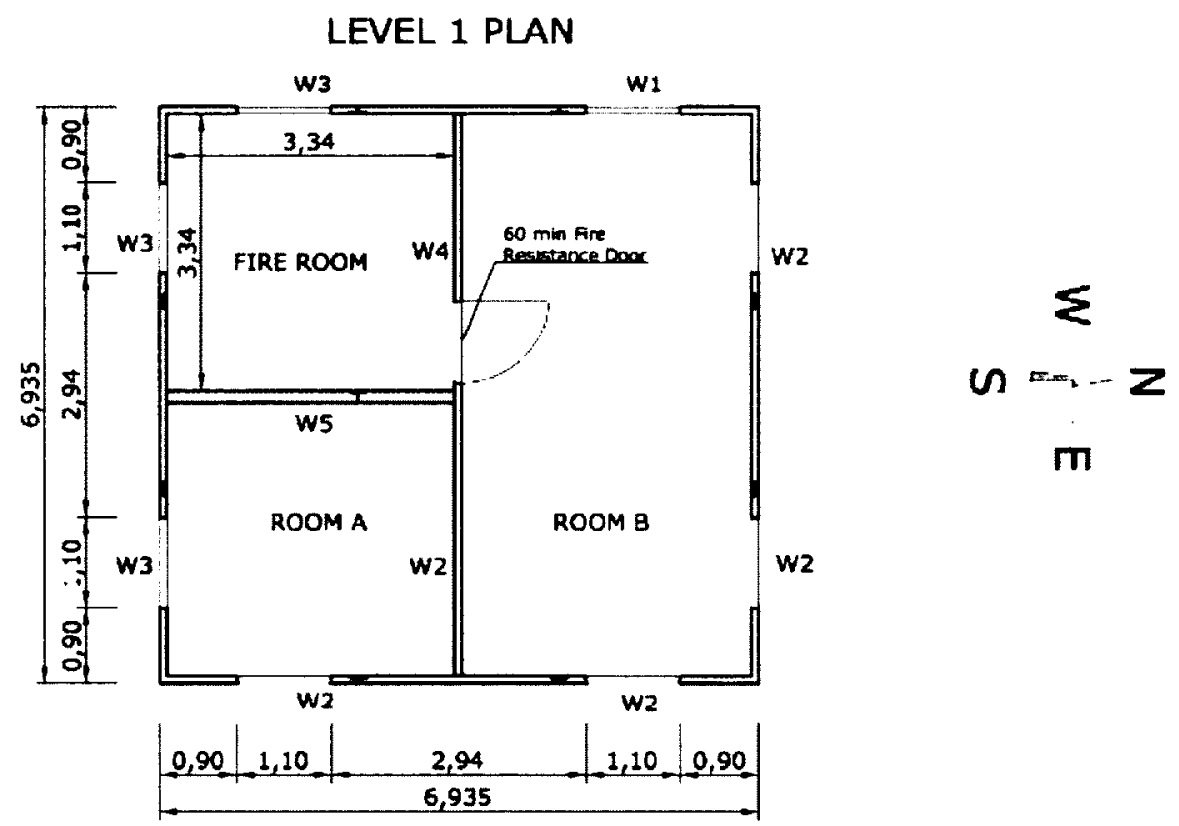

Figure 23 - Geometry and location of fire test room - Tsukuba [39]

The fire load in the test consisted of wood cribs, two single mattresses, several wood cribs and an assumed 50\% involvement of the wooden floor. The total fire load density calculated over the floor areas was $790 \mathrm{MJ} / \mathrm{m}^{2}$. This did not include the contribution of the XLAM panels which occurred after failure of the gypsum board and rock wool linings. 
Temperatures were measured at 100 different locations including positions in the room, at the room surface and within the structure. Inside the room, temperatures were measured by a thermocouple tree, installed at the centre of the room with thermocouples at heights $0.1,0.74,1.48,2.22$ and $2.85 \mathrm{~m}$ from the floor, and 8 plate thermometers installed close to the floor and ceiling of each wall at a distance of $0.1 \mathrm{~m}$ from the walls. Pressure transducers were installed in the windows to measure gas flow, $\mathrm{O}_{2}, \mathrm{CO}_{2}$ and $\mathrm{CO}$ concentrations were measured in the room, and heat flux measurements were taken outside the room $3 \mathrm{~m}$ from the windows.

The fire grew slowly initially until failure of the windows at 36 minutes after which the fire size increased and flashover was observed at 40 minutes. The door failed and fell off after 53 minutes and the fire size began to decline after 55 minutes. The fire was manually controlled and extinguished after 60 minutes as planned. Temperatures in the room, presented in Figure 25, showed a non-uniform distribution over the height of the room, highest at ceiling and lowest at floor, until flashover when they all increased confirming the intensity of the fire.

First indications of failure of the gypsum board layers in the north and south walls were indicated by sharp rises in temperature behind the gypsum board at 47 and 50 minutes respectively. Total failure, indicated by a rise above $600^{\circ} \mathrm{C}$ behind the layers of gypsum board, occurred at 57 and 53 minutes respectively. At the ceiling, where only 1 layer of gypsum board was installed, failure of the gypsum board probably occurred at 40 minutes. At the end of the test, all gypsum board layers had fallen off and charring was observed to be between 5 and $10 \mathrm{~mm}$ deep in most areas. 


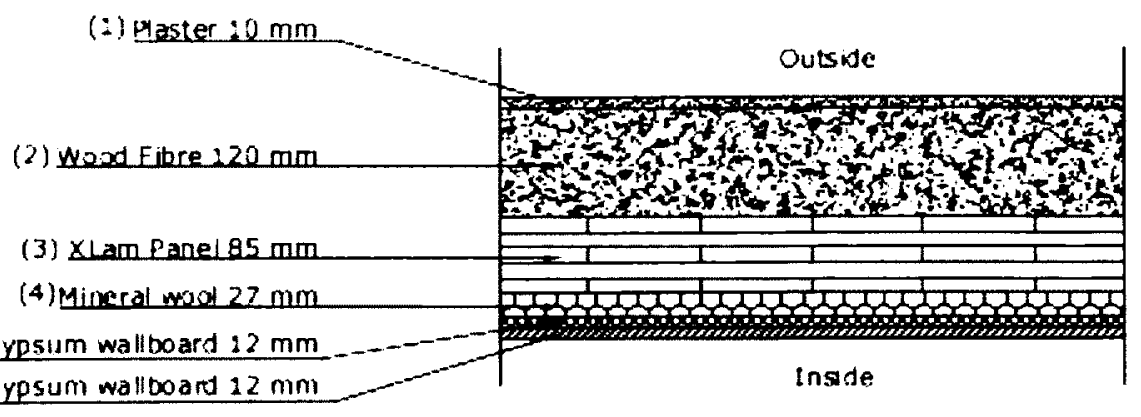

Wall $2 / 3$

(5) Standard gypsum wallboard $12 \mathrm{~mm}$

(6) Fire prool gypsum wallboard $12 \mathrm{~mm}$

(1) Fire proof gypsum wallboard $12 \mathrm{~mm}$

(2)

standard oypsum wall woard $12 \mathrm{~mm}$

(3) Mineral wool $27 \mathrm{~mm}$

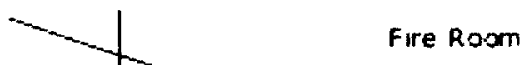

(4) $X \mathrm{lam}$ Pand $85 \mathrm{~mm}$

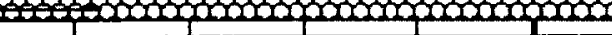

(5) Mineral wool $27 \mathrm{~mm}$

(6) Standard gypsum wallboard $12 \mathrm{~mm}$

(7) Fire proof pypsum wallboard $12 \mathrm{~mm}$

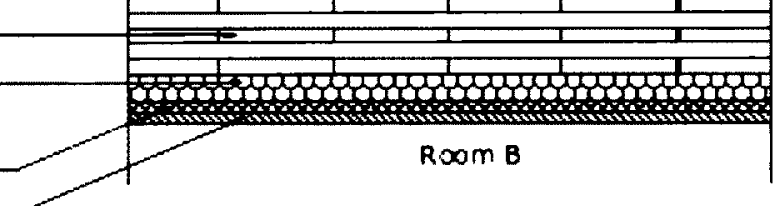

Wall 4

(1) Standard gypsum walboard $12 \mathrm{~mm}$

(2) Mineral wool $27 \mathrm{~mm}$ - - - Fire Rom

(3) XLam Panel $142 \mathrm{~mm}$

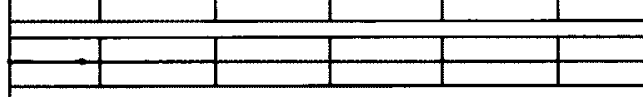

Wall 5

(4) Mineral wool $27 \mathrm{~mm}$

(5) Standard gypsum wallboard $12 \mathrm{~mm}$

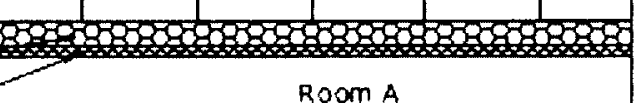

(1) Wood nooring $20 \mathrm{~mm}$

(2) Concrete topping $50 \mathrm{~mm}$

(3) Polyethylene sheet

(4) $50060 \mathrm{~mm}$

(5) Xlam Panel $142 \mathrm{~mm}$
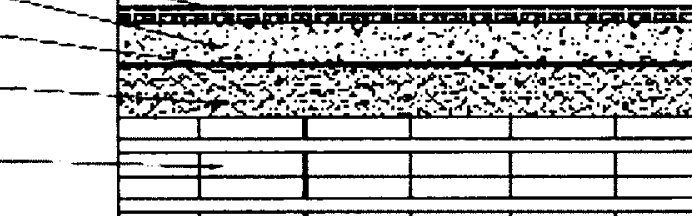

(6) Mineral wool $27 \mathrm{~mm}$

(1)

Floor and Ceiling

(7) rireproot gypsum wall baard $12 \mathrm{~mm}$

Figure 24 - Cross section of walls and floors of the fire room - Tsukuba (modified from [39]) 

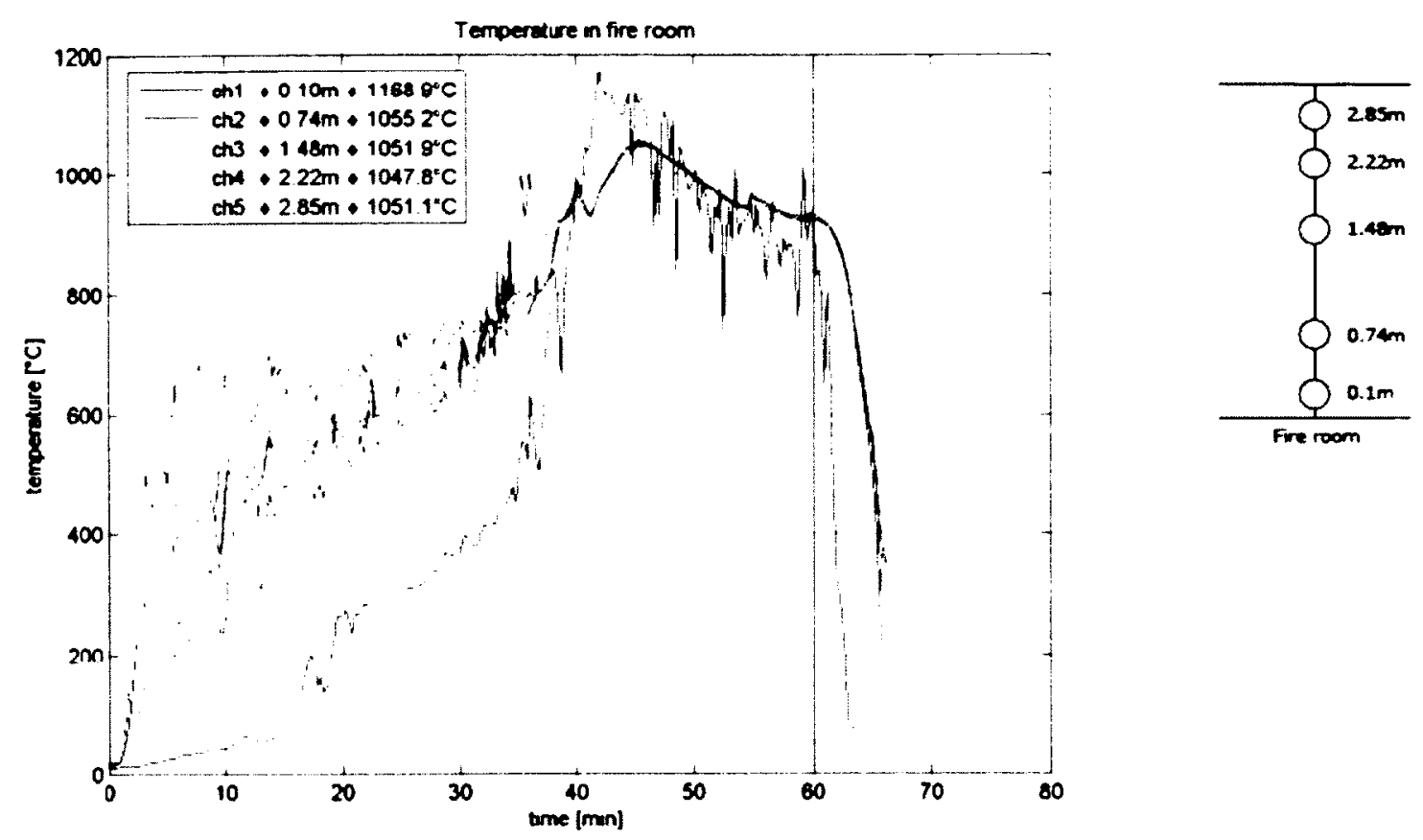

Figure 25 - Temperatures measured in the middle of the room - Tsukuba [39]

\subsubsection{Conclusions}

- It is possible to limit the fire spread to one room without active fire protection systems and with the use of structural measures only.

- No elevated temperatures or smoke was observed in the room above the fire, and

- Damage to the timber structure inside the room was relatively small as a result of using gypsum board protection.

\subsubsection{Chen [40]}

As part of Chen's research to develop appropriate design fires for hotels and motels, 10 motels and 12 hotels were surveyed to determine appropriate fire loads, two room tests were conducted at Carleton University Fire Research Lab in 2008 and computer modelling was used to simulate those room tests. 


\subsubsection{Objectives}

- Determine fire loads for motels and hotels, and

- Obtain data through full scale fire test and compare to the results of computer modelling.

Two tests were conducted in a room that measured $3.77 \times 4.17 \times 2.4 \mathrm{~m}$ high and had a single opening in the front wall of $1.5 \times 1.5 \mathrm{~m}$. Furniture was used as the fire load in each test and configured to represent two scenarios presented in Figure 26:

1. Bedroom with a single double bed with fire load density of $397.2 \mathrm{MJ} / \mathrm{m}^{2}$, and

2. Bedroom with two single beds with a fire load density of $366.1 \mathrm{MJ} / \mathrm{m}^{2}$.
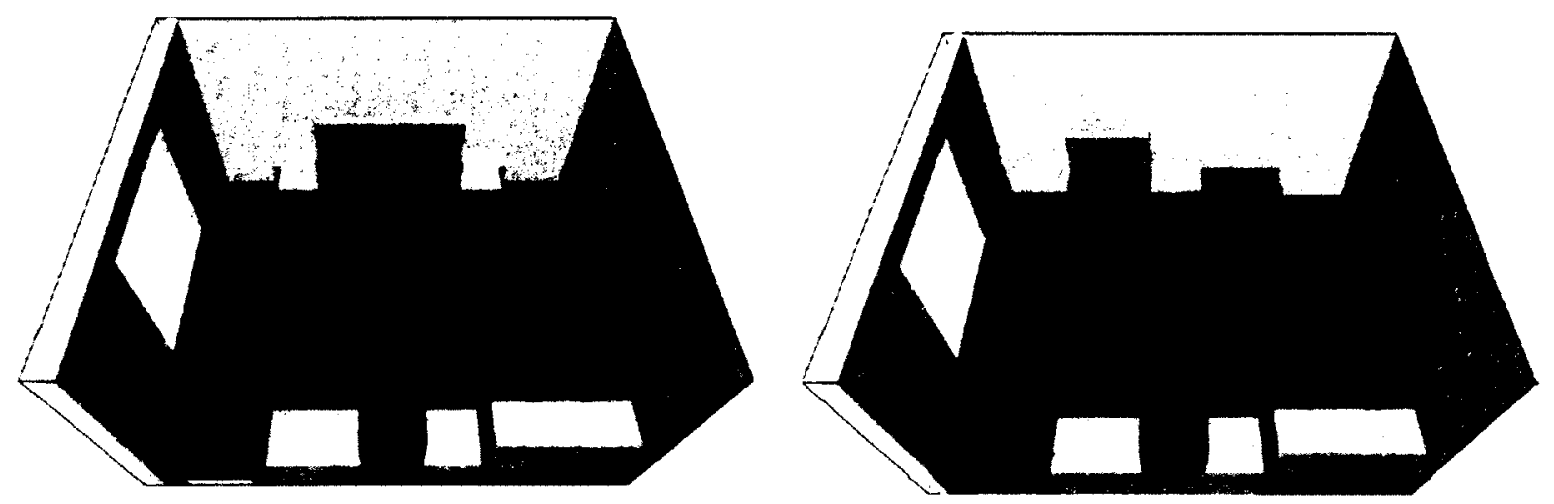

Figure 26 - Room layouts used in full scale rooms tests by Chen [40]

The rooms featured steel framing with 1 layer of $12.7 \mathrm{~mm}$ cement board under 1 layer of $15.7 \mathrm{~mm}$ Type-X gypsum board on the walls and two layers of $15.7 \mathrm{~mm}$ Type-X gypsum board on the ceiling. Temperatures were measured at multiple locations in the room, in the structure, in the opening and outside the room using thermocouple trees and single thermocouples. Heat flux, gas composition and flow rates in and out of the opening were also measured. HRR was also measured using oxygen consumption calorimetry. A propane burner was used as the ignition source in each of the tests. 


\subsubsection{Results}

Higher peaks and average HRR's were observed in Test 1 which reached a peak of 4.8 MW vs 3.7 MW for Test 2. From the results, Chen developed a number of possible designs curves for HRR which are presented in Figure 27 and Figure 28. For both of the tests, a curve was matched to the observed HRR and a conservative curve was generated by increasing the peak values by a safety factor of $15 \%$ and employing a linear decay.

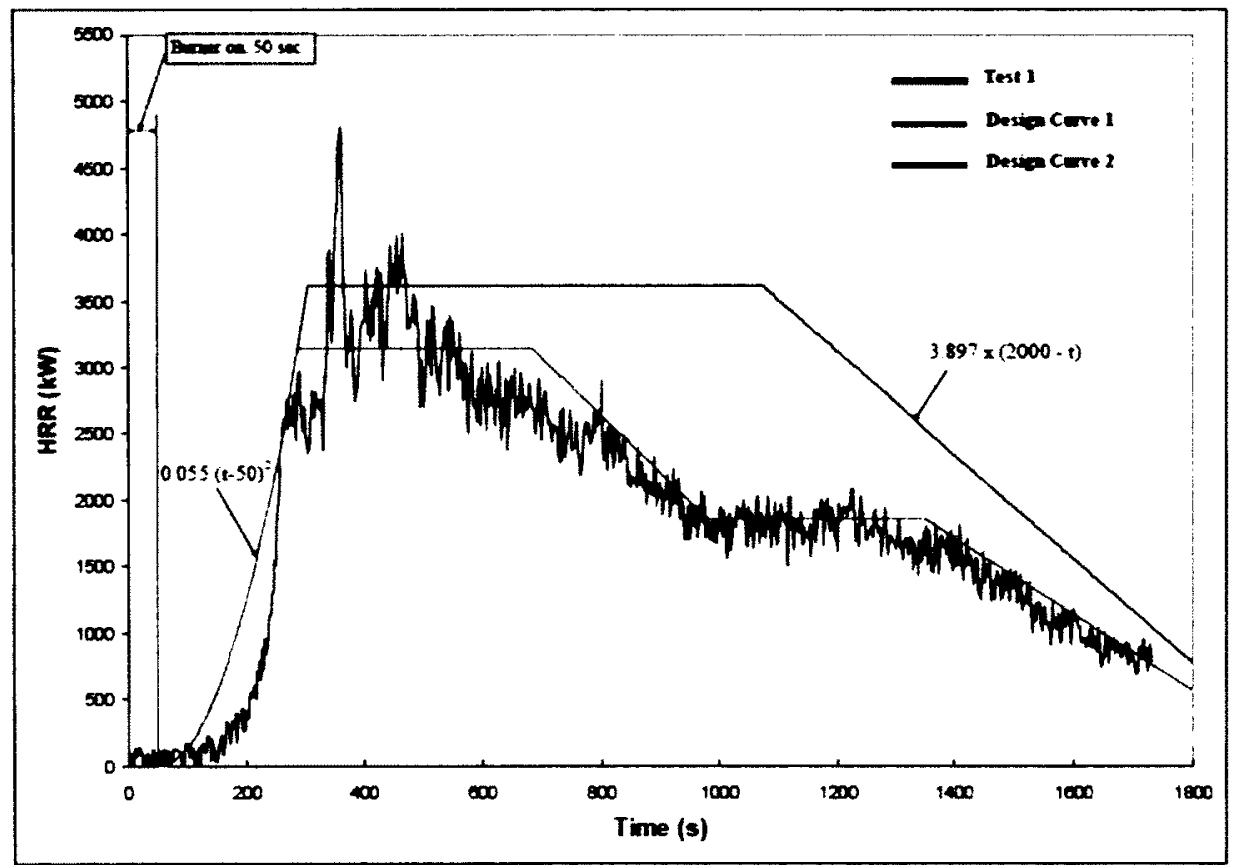

Figure 27 - HRR design curves - Chen Test 1

The average ceiling temperatures for Tests 1 and 2 are presented in Figure 29, which show peaks of approximately $990^{\circ} \mathrm{C}$. Localised peak temperatures of approximately $1200^{\circ} \mathrm{C}$ and $1100^{\circ} \mathrm{C}$ were observed for Tests 1 and 2 respectively. Peak heat flux measurements of $286 \mathrm{~kW} / \mathrm{m}^{2}$ and $234 \mathrm{~kW} / \mathrm{m}^{2}$ were recorded at the northeast corners (opposite the opening) for Tests 1 and 2 respectively. 


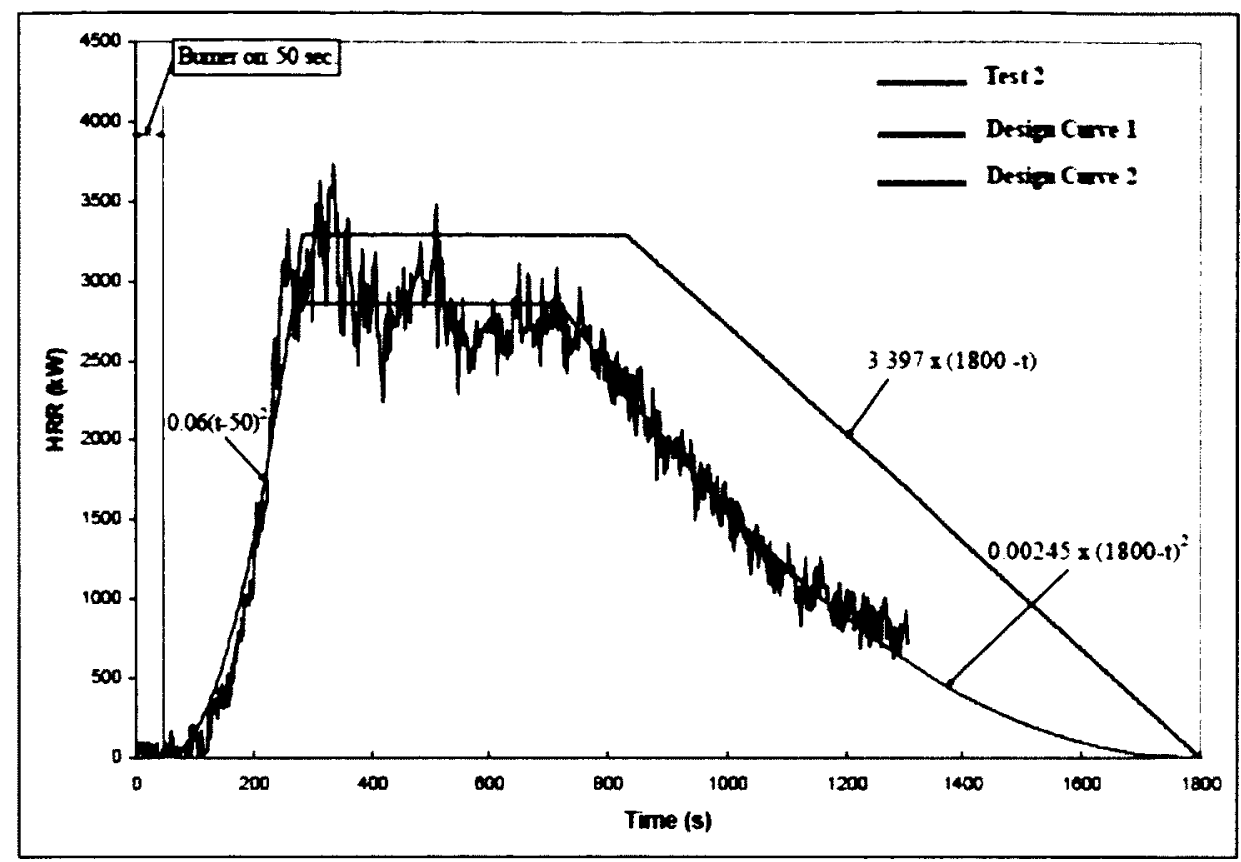

Figure 28 - HRR design curves - Chen [40] Test 2

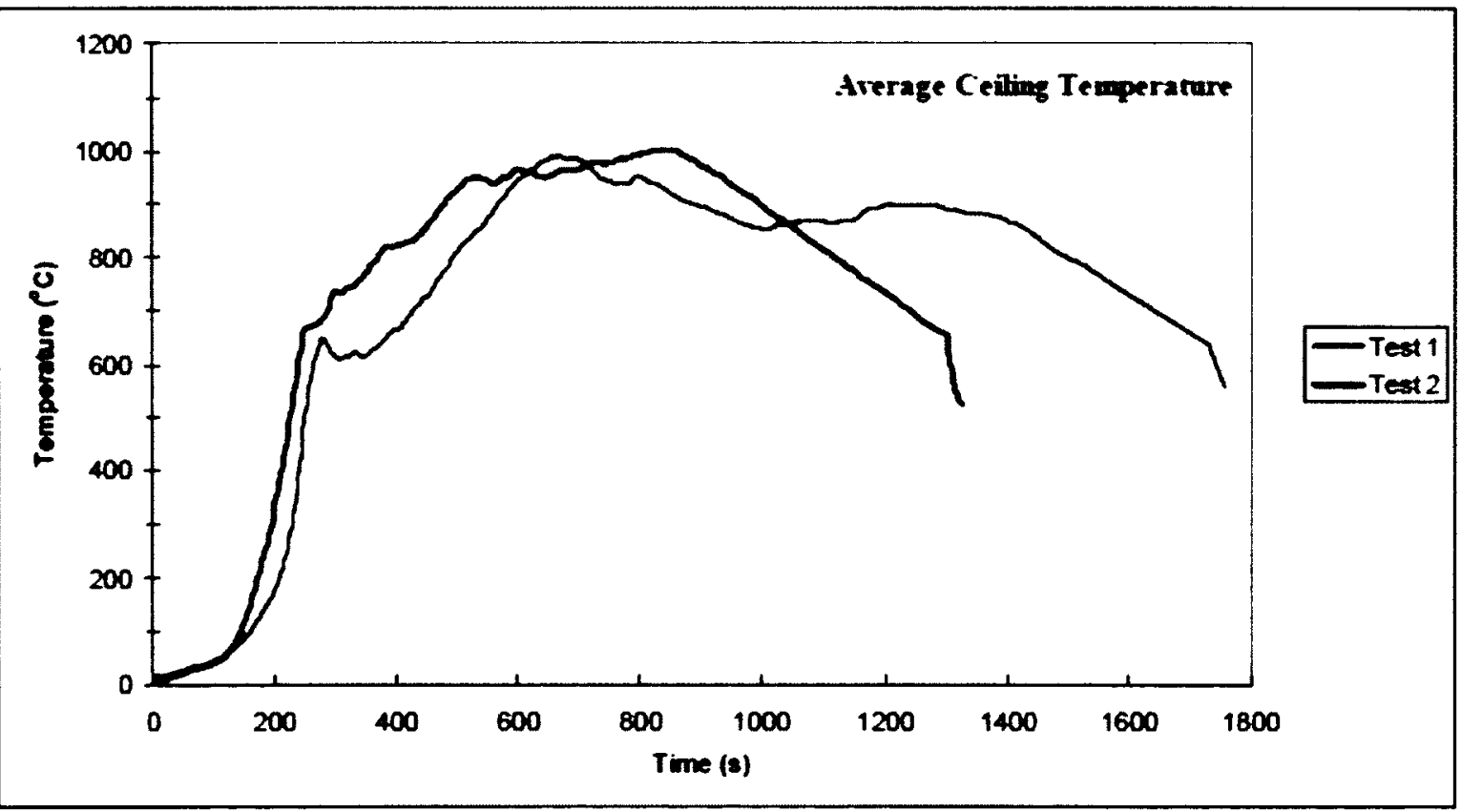

Figure 29 - Average temperatures measured at the ceiling - Chen [40] tests 
As well as the full scale room tests, Chen conducted fire modelling using the Fire Dynamics Simulator (FDS) [41] software. Best results were achieved with the use of propane gaseous fuel in the simulations.

\subsubsection{Conclusions}

- The average fire load density for hotels and motels surveyed was $550 \mathrm{MJ} / \mathrm{m}^{2}$,

- Design curves were developed which could be used as prescribed input files in FDS, and

- In FDS, propane can be used a virtual fuel to predict early stages of the fire. 


\section{Chapter 3 : Test Setup}

Five tests were carried out between 18 April 2012 and 25 Jul 2012 at the Carleton University Fire Research Lab to investigate the contribution of CLT construction to the development, duration and intensity of room fires. Fires using two different fuels, (propane and bedroom furniture) and two room lining configurations (protected and unprotected) were used. A summary of the tests conducted and the configurations are presented in Table 5. The configurations and effects of these are discussed in later sections.

Table 5 - CLT Room Tests conducted

\begin{tabular}{|c|c|c|c|c|c|}
\hline Test \# & 1 & 2 & 3 & 4 & 5 \\
\hline Date & $18-\mathrm{Apr}-12$ & $16-\mathrm{May}-12$ & $08-\mathrm{Jun}-12$ & $17-\mathrm{Jul}-12$ & $25-\mathrm{Jul}-12$ \\
\hline Ambient Temp & $5.5^{\circ} \mathrm{C}$ & $17.5^{\circ} \mathrm{C}$ & $16^{\circ} \mathrm{C}$ & $27^{\circ} \mathrm{C}$ & $21^{\circ} \mathrm{C}$ \\
\hline Protected & Yes & Yes & No & Yes & No \\
\hline Fire Load & Propane & Furniture & Propane & Furniture & Furniture \\
\hline Joints Sealed & No & Yes & Yes & Yes & Yes \\
\hline Smoke Detector & No & Yes & No & Yes & Yes \\
\hline Sprinkler Indication & No & Yes & No & No & No \\
\hline
\end{tabular}

\subsection{Location}

The tunnel test facility at the Carleton University Fire Research Lab was used to perform the tests. This facility is equipped with a system for measurement of HRR and is discussed in Section 2.2 [21]. Rooms were constructed inside the tunnel shown in Figure 30. 


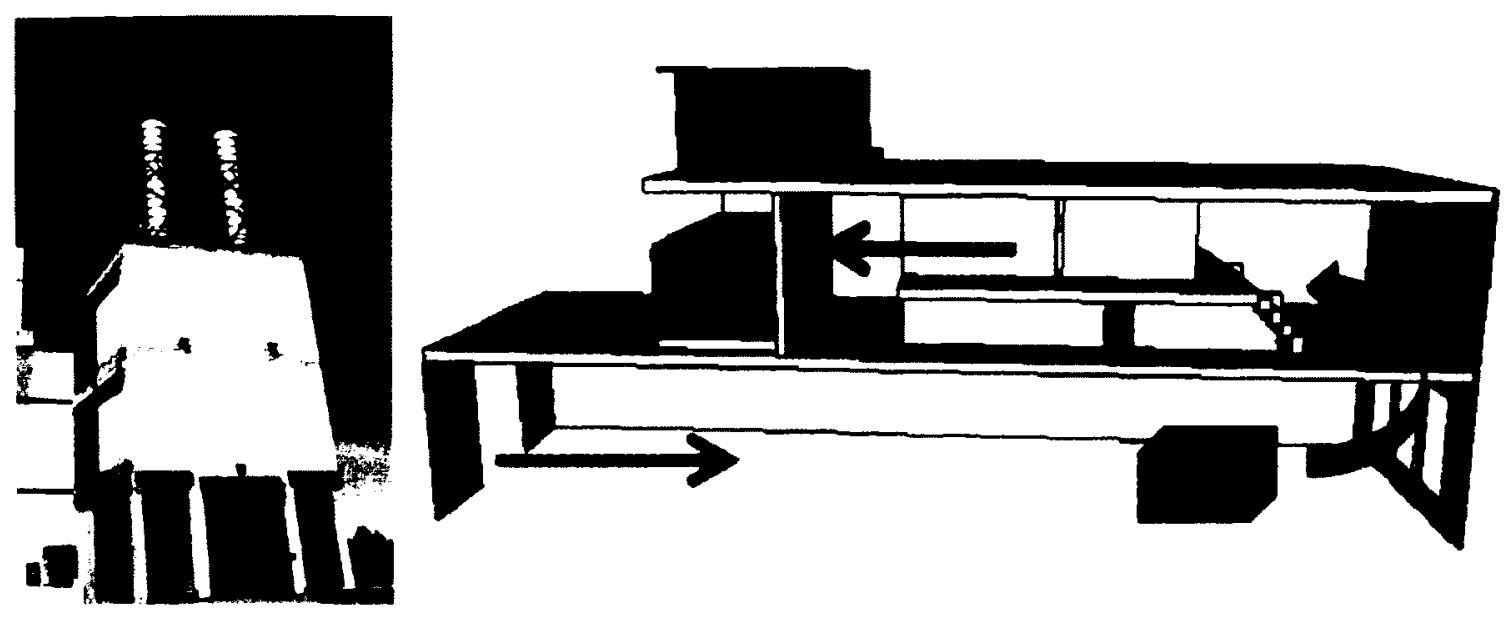

Figure 30 - Tunnel test facility and schematic

\subsection{Test Rooms}

\subsubsection{Room Size}

Internal dimensions of each room were set at $3.5 \times 4.5 \times 2.5 \mathrm{~m}$ high prior to installation of linings. These dimensions were chosen to allow comparison with results from tests conducted by Chen [40] and Hakkarainen [38]. The tests from Chen [40] involved lined, light timber frame rooms using furniture as a fuel source whereas the Hakkarainen [38] tests involved some heavy timber rooms with wood cribs as a fuel source. A comparison of dimensions for these series of tests is presented in Table 6 .

Table 6 - Dimensions of test rooms

\begin{tabular}{|l|l|l|l|l|l|l|}
\cline { 2 - 7 } \multicolumn{1}{c|}{} & \multicolumn{3}{c|}{ Room } & \multicolumn{2}{c|}{ Opening } & Opening \\
\cline { 2 - 7 } \multicolumn{1}{c|}{} & W & D & H & W & H & Factor \\
\hline Chen [40] & 3.77 & 4.17 & 2.37 & 1.5 & 1.5 & 0.0399 \\
\hline Hakkarainen [38] & 3.5 & 4.5 & 2.5 & 2.3 & 1.2 & 0.0423 \\
\hline McGregor & 3.5 & 4.5 & 2.5 & 1.07 & 2 & 0.0423 \\
\hline
\end{tabular}

A single opening in the front wall of dimensions $1.07 \times 2 \mathrm{~m}$ high was included giving an equivalent opening factor to that of Hakkarainen [38] calculated using Eq 25. 


$$
F_{i}=\frac{A_{l} \cdot \sqrt{H_{l}}}{A_{f}}
$$

\subsubsection{Construction materials}

All rooms were constructed from X-Lam (105-s3), 105mm thick 3 ply CLT panels provided by Nordic Engineered Wood. The outer (longitudinal) laminations were made from SPF 1950Fb MSR $35 \times 89 \mathrm{~mm}$ members with the centre (transversal) lamination made from S-P-F No 3/Stud $35 \times 89 \mathrm{~mm}$ at a $90 \mathrm{deg}$ offset orientation as shown in Figure 31 and Figure 32.

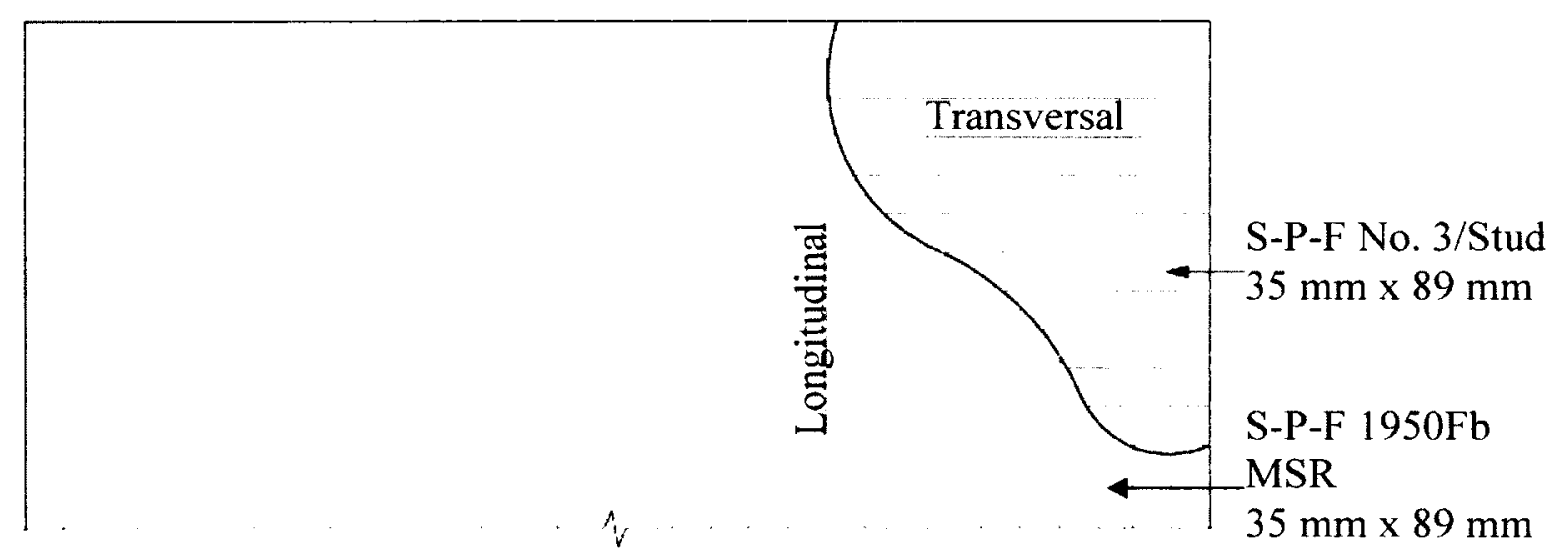

Figure 31 - X-Lam (105-s3) panel layup (modified from [42])

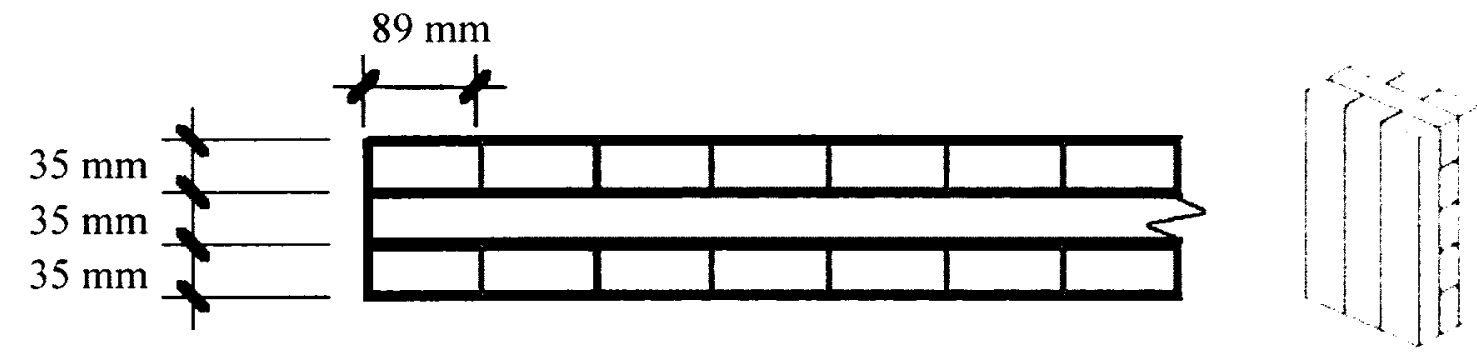

Figure 32 - X-Lam (105-s3) Panel cross section (modified from [42])

The panels were pre-fabricated by Nordic Engineered Wood in accordance with the erection drawings in Figure 33, Figure 34, and Figure 35 and delivered to the laboratory on 22 Feb 2012 where the rooms were assembled on site. 

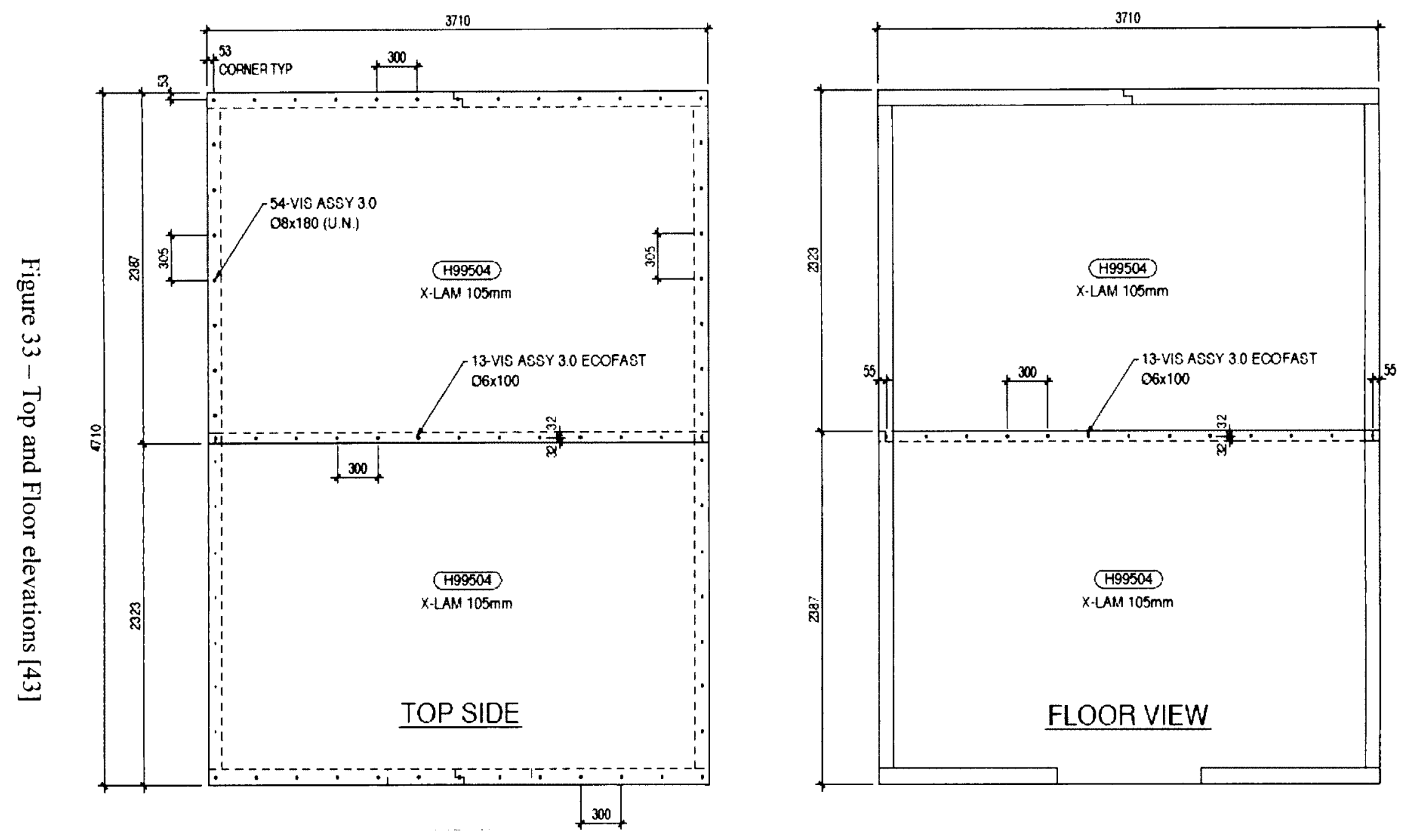

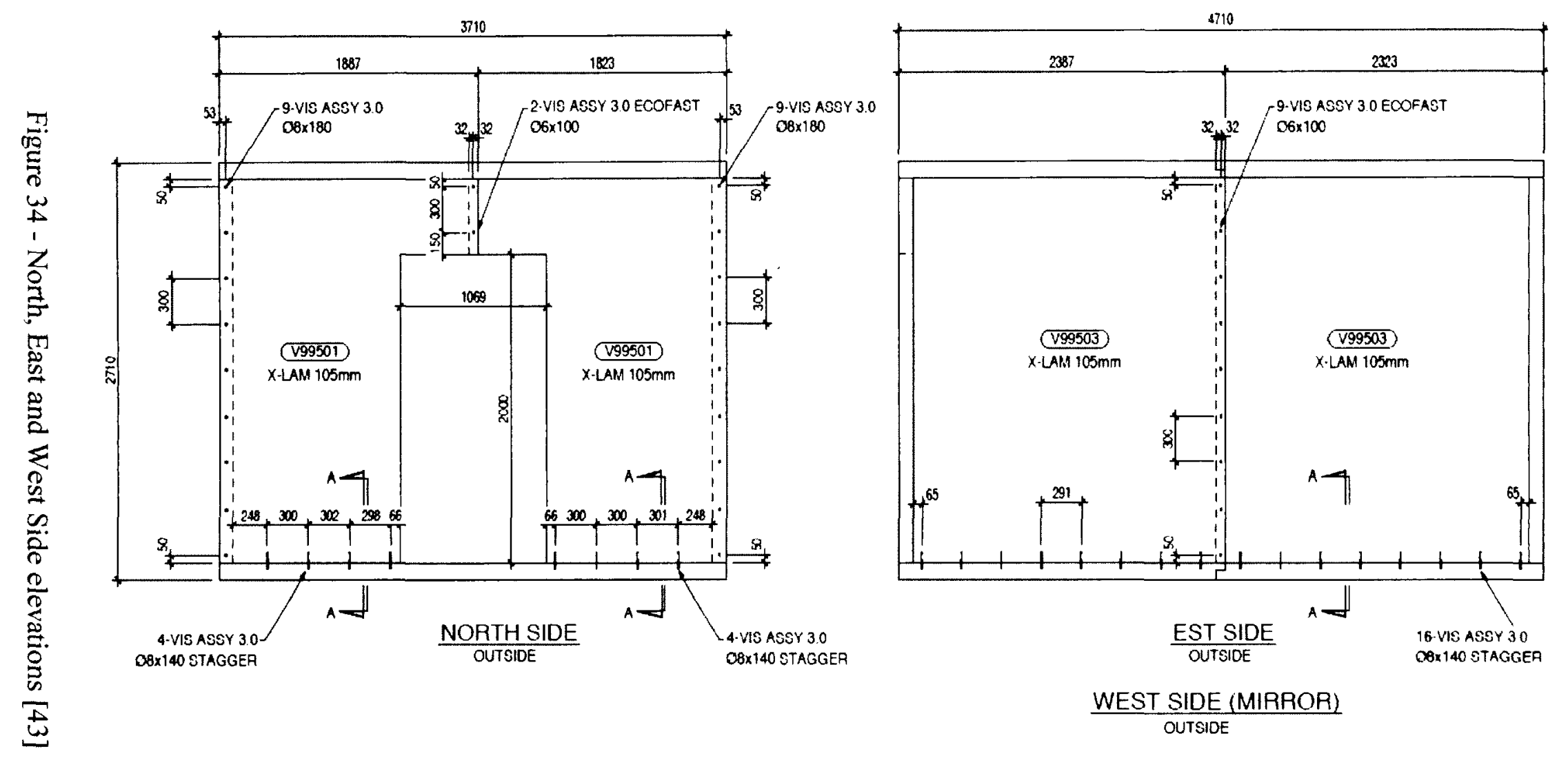


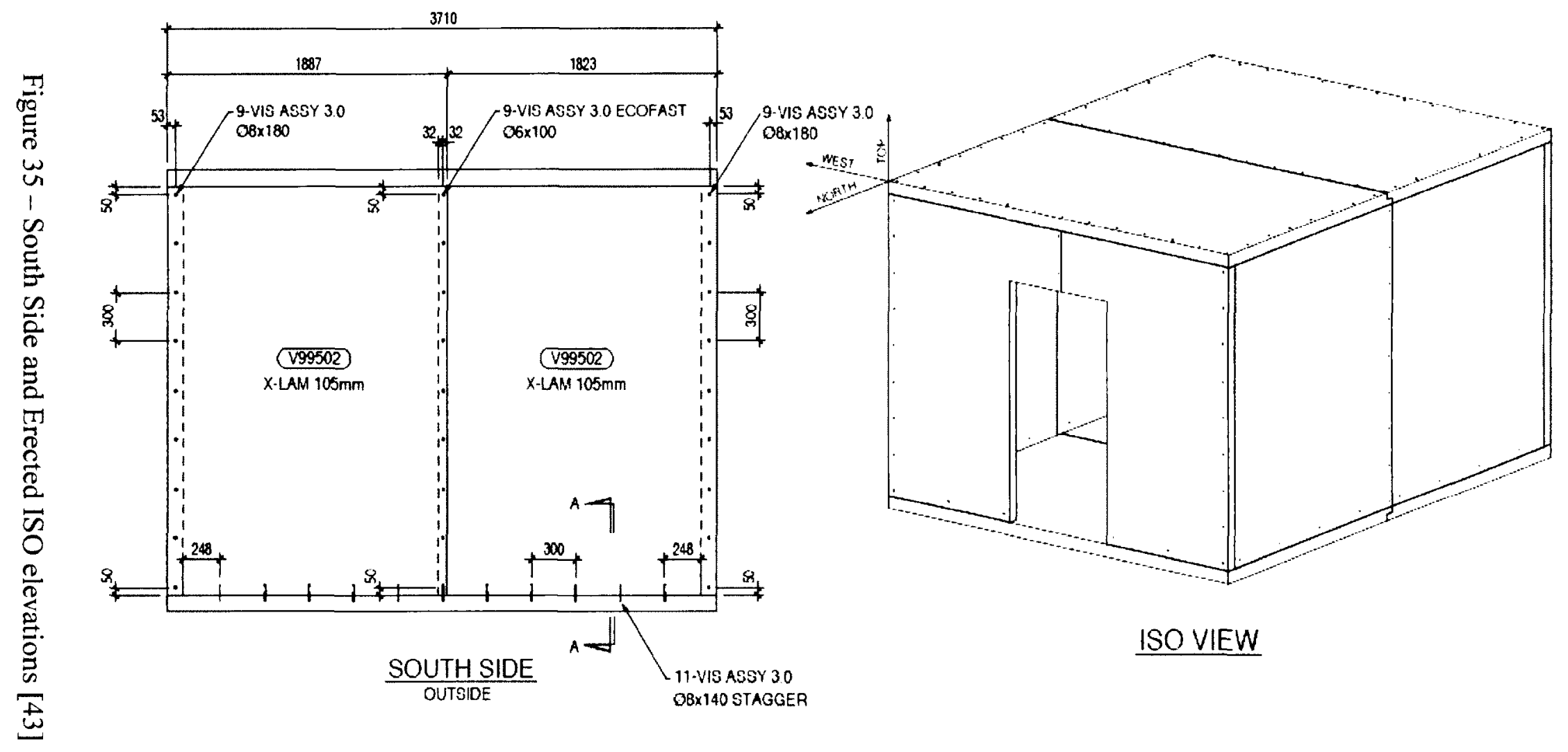


Three types of joints were used between the panels in the construction of the rooms. Lap joints connect panels longitudinally at the walls, ceiling and floor and were secured at $300 \mathrm{~mm}$ intervals with $ø 6 \mathrm{~mm} \times 100 \mathrm{~mm}$ self-tapping screws as shown in Figure 36.

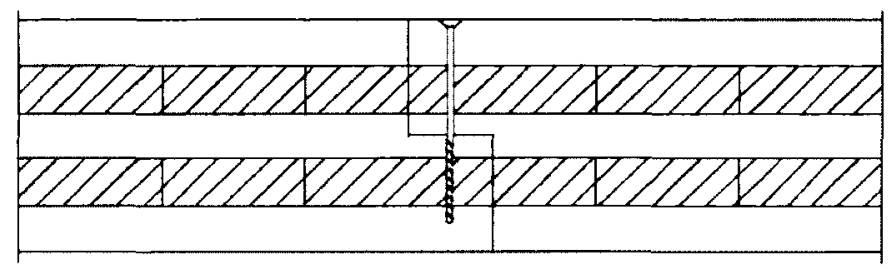

Figure 36 - Longitudinal joints in walls, ceilings and floors (5-Ply drawing shown) [44]

Wall to wall corner joints were secured at $300 \mathrm{~mm}$ intervals with $\varnothing 8 \mathrm{~mm} \times 180$ mm self-tapping screws as shown in Figure 37.

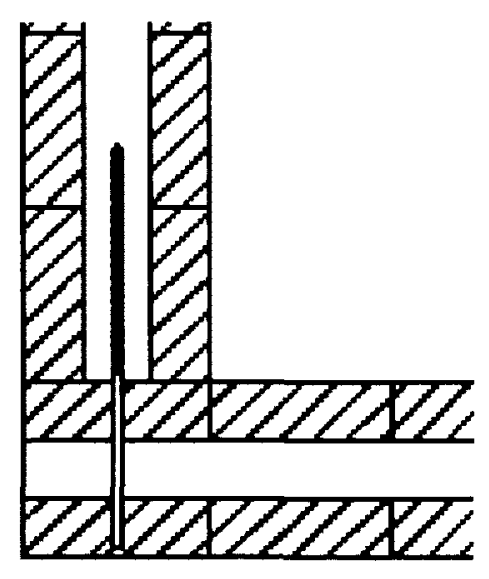

Figure 37 - Corner wall joint [44]

Wall to floor joints were secured at $300 \mathrm{~mm}$ intervals with $ø 8 \mathrm{~mm} \times 180 \mathrm{~mm}$ selftapping screws driven in at $45 \mathrm{deg}$ as shown in Figure 38. 


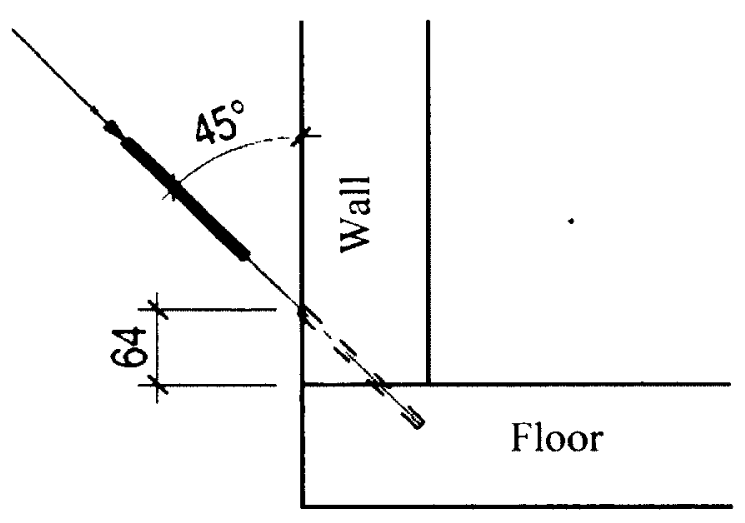

Figure 38 - Wall to floor joints (modified from [43])

After observing gases escaping from the panel joints in Test 1 , it was decided to use a silicon based fire rated sealant in Tests 2 to 5 to seal the joints and improve the resistance to the fire.

\subsubsection{Method of construction}

A levelled base, on which the rooms were assembled, was constructed from timber framing with a surface consisting of one layer of $12.7 \mathrm{~mm}$ cement board on top of a layer of $12.7 \mathrm{~mm}$ plywood. With the base installed, there was insufficient access in the tunnel to utilise a forklift for complete assembly of the room so two identical gantry cranes, shown in Figure 39, were designed and manufactured on site. The CLT panels, weighing between $200 \mathrm{~kg}$ and $500 \mathrm{~kg}$, were lifted into place using the gantry cranes enabling much of the room to be constructed by a single person. 


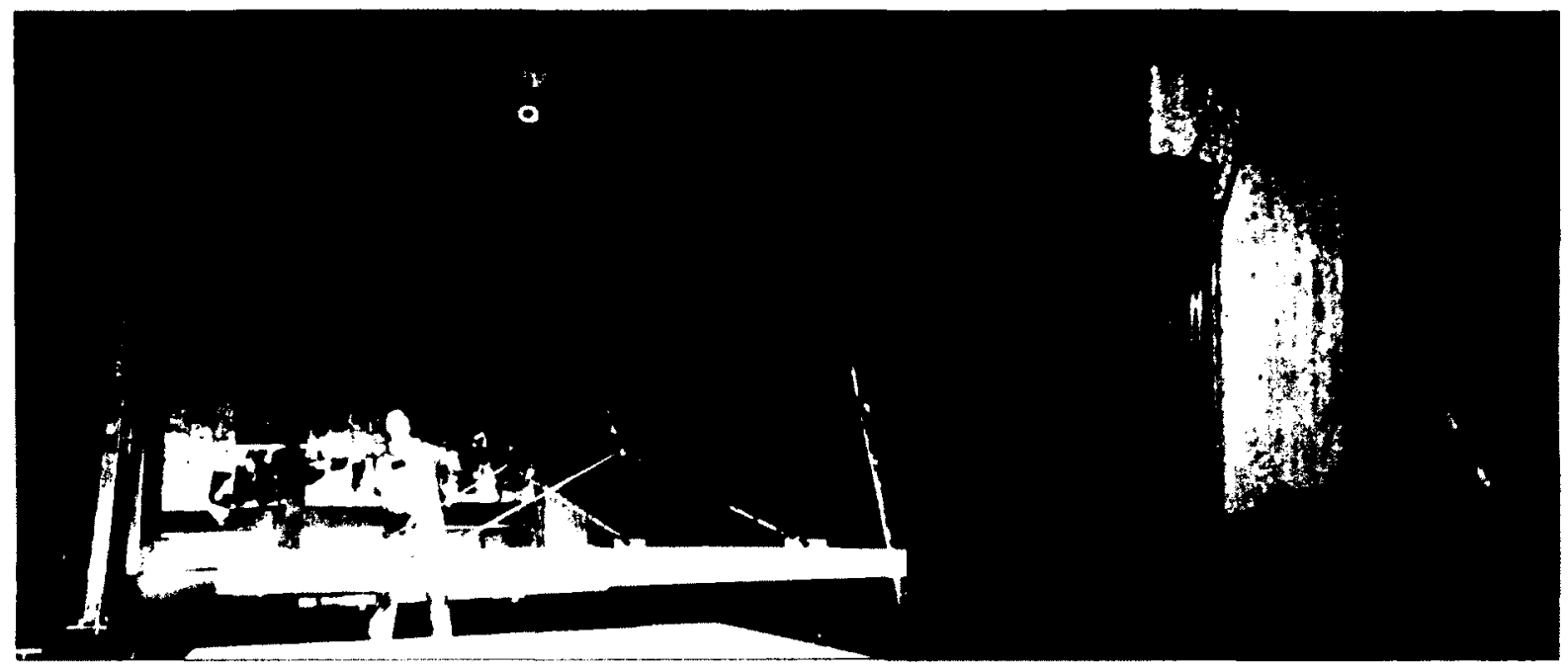

Figure 39 - Lifting panels using gantry cranes

Factory lifting holes, minor imperfections and some warping of the panels similar to those shown in Figure 40 were present during construction of all rooms. In most cases, these were filled using joint compound to prevent any passage of the fire. This was in addition to the fire rated silicon based sealant used in Tests 2-5.

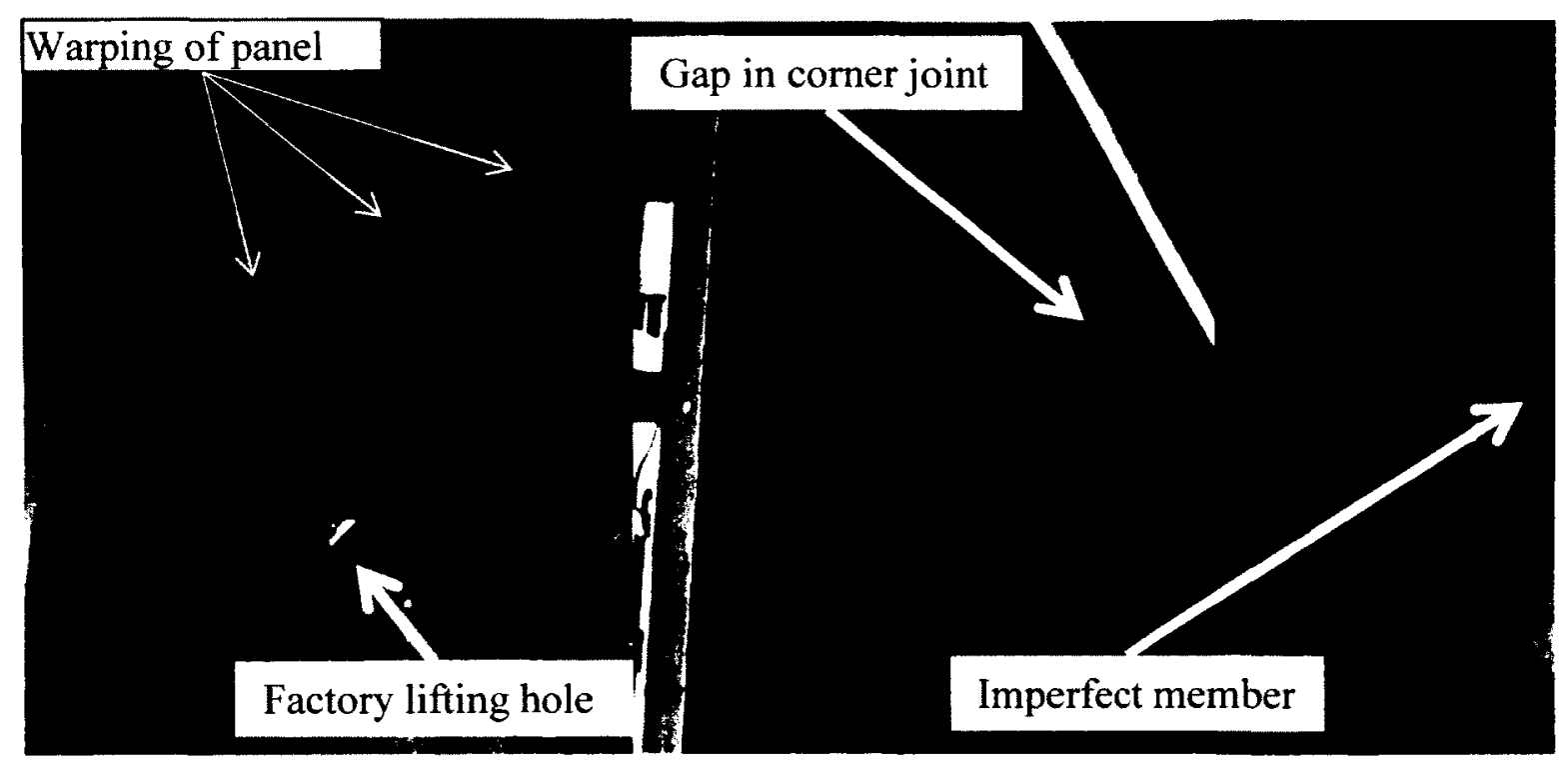

Figure 40 - Imperfections in construction 


\subsubsection{Fire protection}

Figure 41 shows the lining configuration used in Tests 1.2 and 4 . Two layers of $12.7 \mathrm{~mm}$ fire rated gypsum board were installed directly over the CLT panels on the walls and ceiling in the protected rooms, Tests 1,2 and 4. The first layer was secured using $35 \mathrm{~mm}$ drywall screws on grid at $300 \mathrm{~mm}$ intervals on the ceiling and $400 \mathrm{~mm}$ intervals on the walls. The second layer was installed at an offset, so that no joints were aligned with those in the next layer, using $55 \mathrm{~mm}$ drywall screws using the same grid system as the first layer. All screw heads, joints and corners in each layer of gypsum were taped and skimmed with building compound to provide a completed seal.

To ensure that no additional material contributed to the fire and the HRR measurements, the door frame, the external front wall and the external roof of the room were protected from the fire with $12.7 \mathrm{~mm}$ fire rates gypsum board. The doorframe had two layers and the external front of the room had a single layer. The gypsum board in these positions was then covered with $25 \mathrm{~mm}$ fibreglass blanket.

The floors in each room were protected with a layer of $15.9 \mathrm{~mm}$ fire rated gypsum with a layer of $12.7 \mathrm{~mm}$ cement board installed on top. Tests 2 and 3 had a second layer of concrete board. 


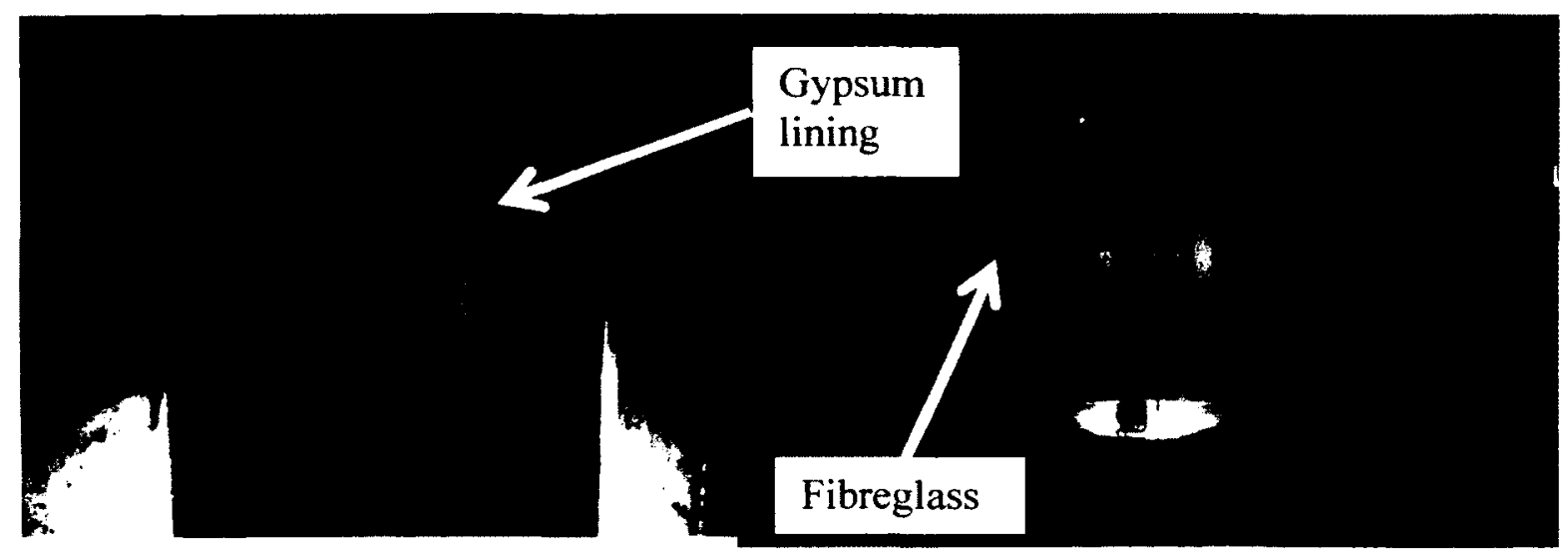

Figure 41 - Gypsum board and fibreglass protection installed - Test 1

For Tests 2, 4 and 5, with furniture, $19 \mathrm{~mm}$ hardwood tongue and groove maple flooring was installed over the concrete panel floor as shown in Figure 42.

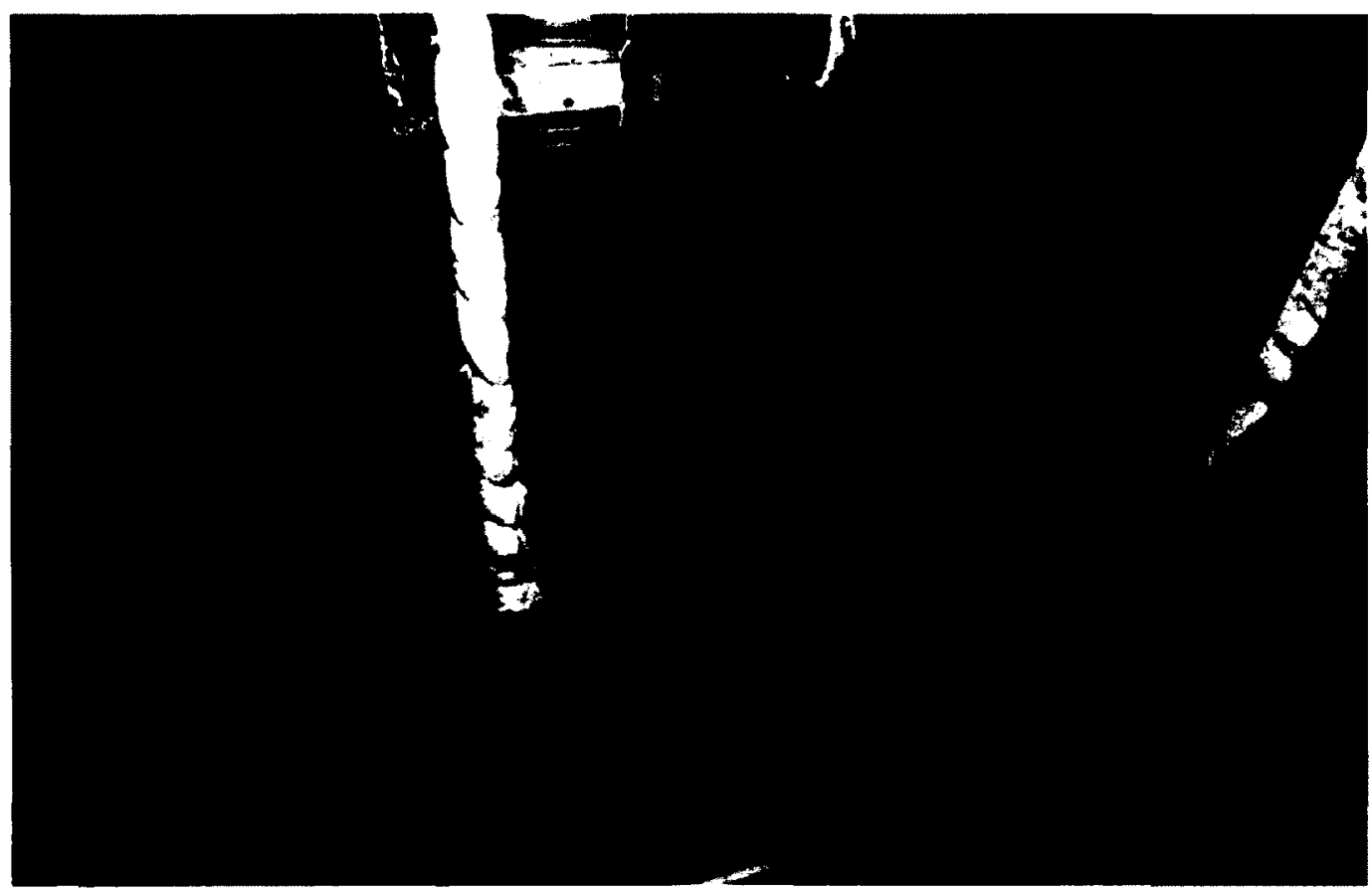

Figure 42 - Hardwood flooring installed - Test 5

\subsection{Fire Source}

\subsubsection{Propane Fires}

The purpose of the propane fire was to establish a reference against which the contribution from the CLT panels could be measured. Propane burners were constructed 
on site from heavy gauge $ø 50 \mathrm{~mm}$ steel tubing. Three $1.2-\mathrm{MW}$ burners were constructed and joined together on a common distribution manifold. Each burner had 2 lines and could be manually controlled, or isolated, with the use of a ball valve, however these were left open and the main line valve was used to control the overall flow. The construction and position of the burners is shown in Figure 43.

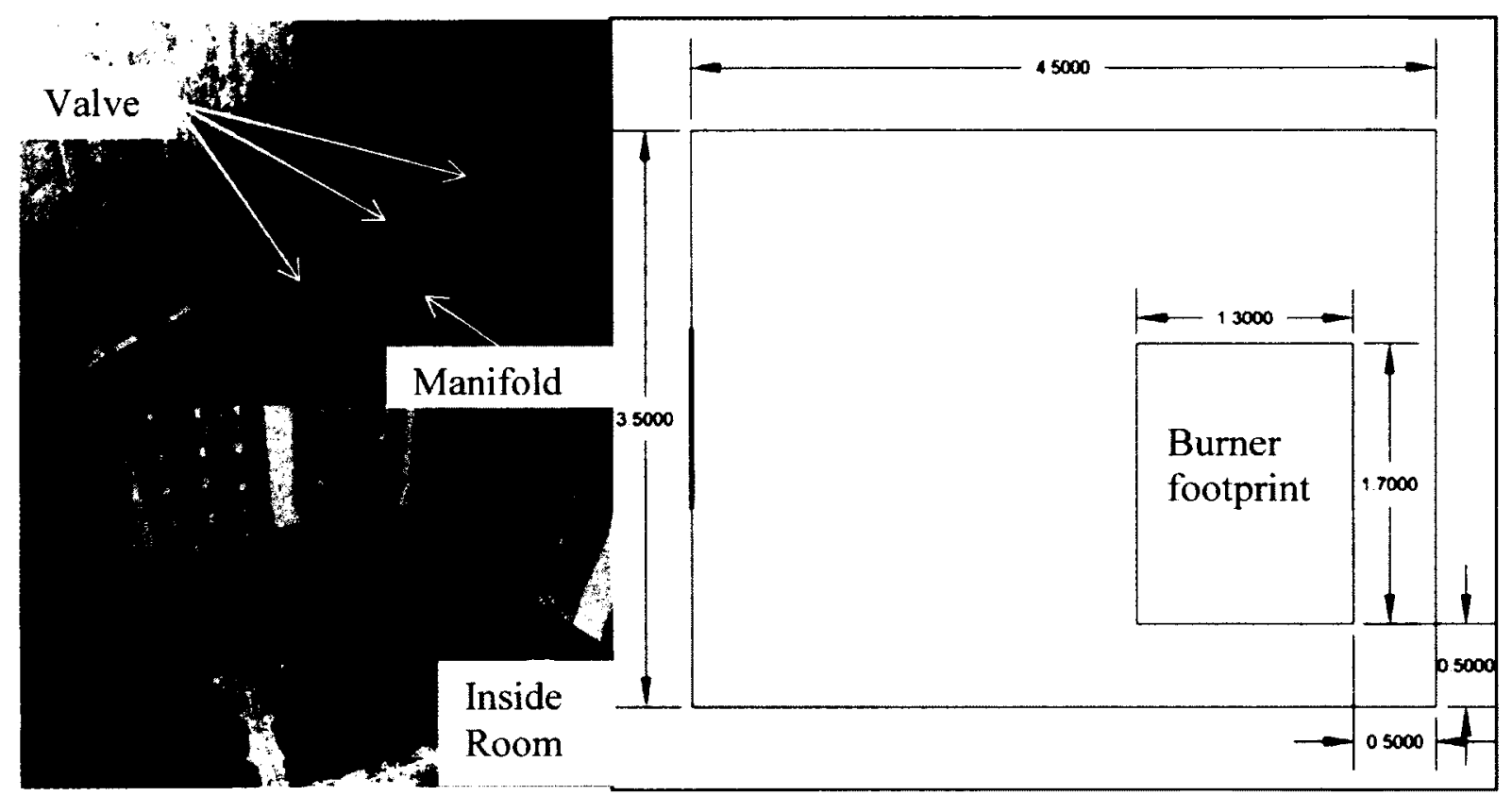

Figure 43 - Propane burner layout and installation - Test 1 and Test 3 During the test, LabVIEW [45] software was used to compare the intended design propane HRR with an actual input from a portable inline-flowmeter and the propane HRR was controlled manually using the main line control valve. 


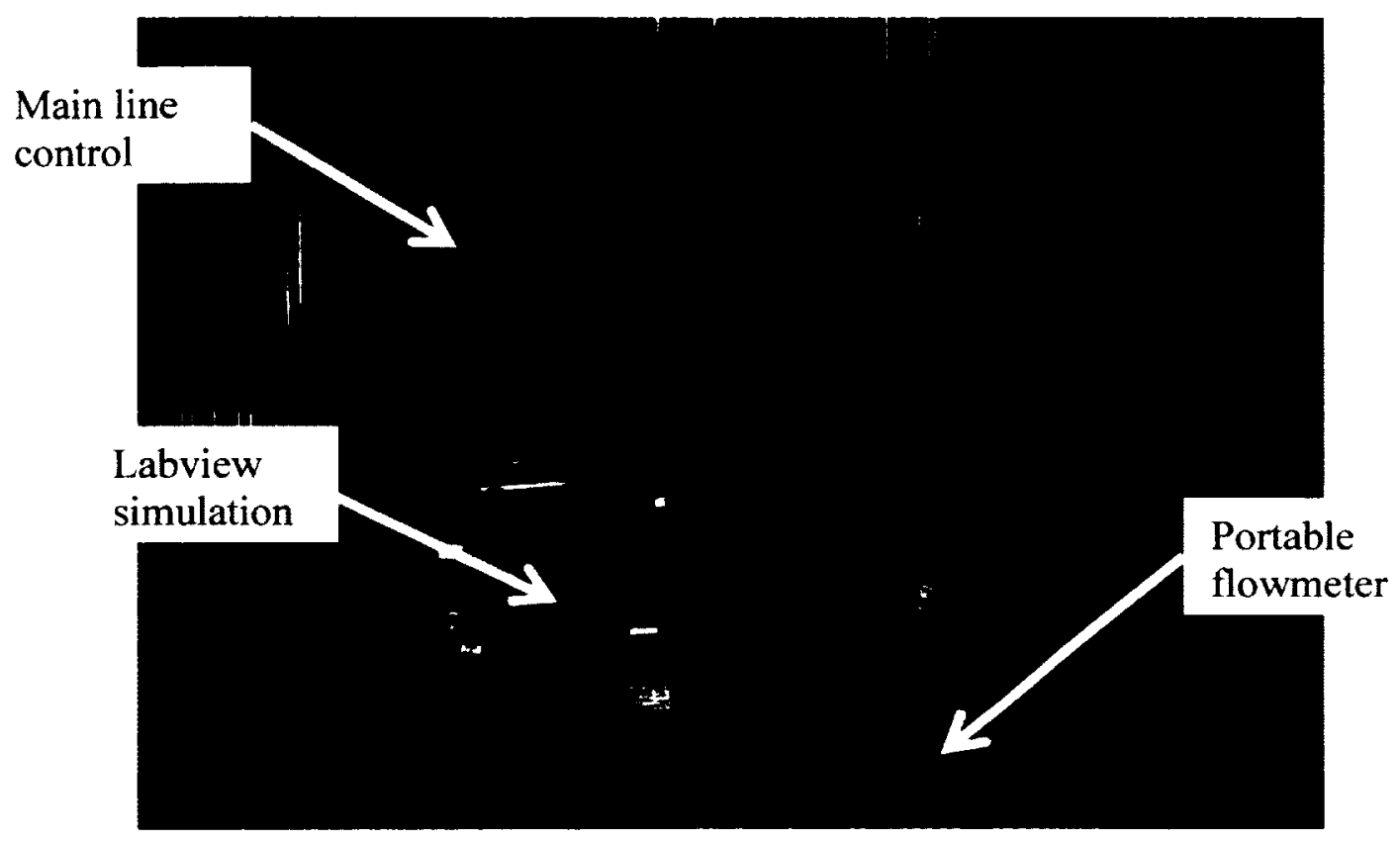

A portable flowmeter was used with a range of $7 \mathrm{~kg} / \mathrm{min}(\sim 5.1 \mathrm{MW})$. Calculation of the propane HRR was conducted using Eq 26:

$$
\begin{aligned}
\dot{Q} & =\dot{m} \Delta h_{c} \\
& =\left(7 \mathrm{~kg} \cdot \mathrm{min}^{-1} / 60\right) \times 43.7 \mathrm{~kJ} \cdot \mathrm{g}^{-1} \\
& =5.1 \mathrm{MW}
\end{aligned}
$$

Where: $\quad \dot{m}=$ mass flow rate of propane $\left(k g . s^{-1}\right)$

$$
\Delta h_{c}=\text { effective heat of combustion }\left(k J \cdot g^{-1}\right)
$$

\subsubsection{Design Fire}

A fire load density representing an extreme fire case was used for Test 1 . The value for primary bedrooms from survey results of Canadian multi-family dwellings [46] was selected, this had an average fire load density of $534 \mathrm{MJ} / \mathrm{m}^{2}$ and a $95^{\text {th }}$ percentile of $753 \mathrm{MJ} / \mathrm{m} 2$.

A simple design fire profile, presented in Figure 44, was adopted for propane HRR based on results of Chen [40] for a hotel room with a queen bed. The design fire comprised three phases: 


\subsubsection{Growth}

During which the HRR increases in a fast fire growth rate until it reaches the ventilation limited peak HRR calculated using Eq 27 (4.54 MW);

$$
\dot{Q}_{\max }=1500 A_{o} \sqrt{H_{o}}
$$

$\mathrm{Eq} 27$

\subsubsection{Steady burning}

At the peak HRR of $4.54 \mathrm{MW}$ until $60 \%$ of the fuel has been consumed; and

\subsubsection{Decay phase}

This section was proportional to the decay phase recommended by Chen [40]. A tsquare decay was used with a decay rate of $\alpha=9.72 \times 10^{-4} \mathrm{MJ} / \mathrm{s}^{2}$ giving an expected test duration of approximately 60 minutes.

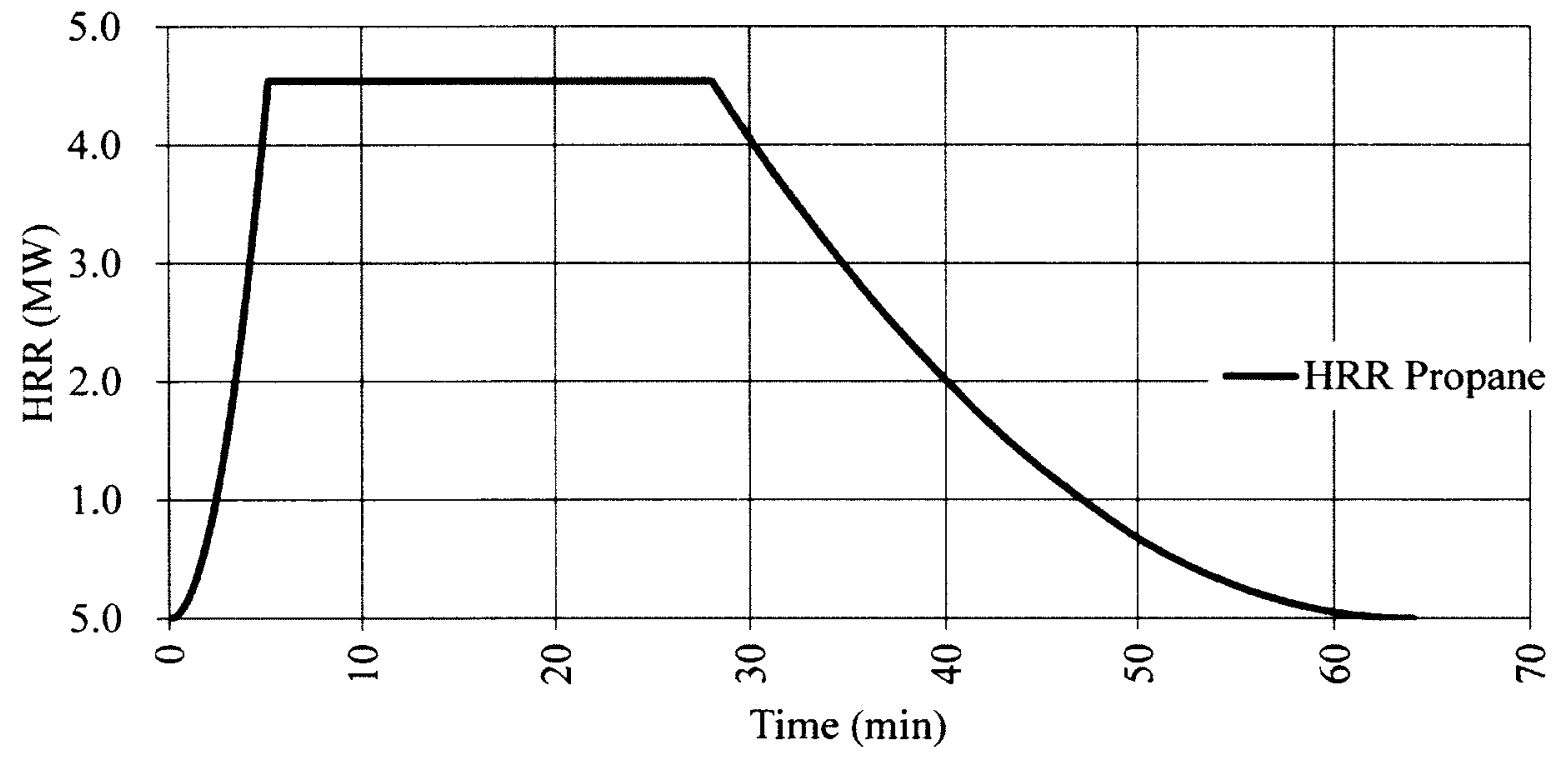

Figure 44 - Design fire profile - Test 1

The shape of the HRR ( $\mathrm{kW})$ curve is given in Eq 28.

$$
\dot{Q}_{D F}=\left\{\begin{array}{ll}
0.0469 t^{2} & 1<t<311 \\
4540 & 311<t<1385 \\
9.72 \times 10^{-4}(t-1345)^{2} & 1386<t<3857
\end{array}\right\}
$$


During Test 1, excessive flaming was observed outside the compartment and a revised peak HRR of $3 \mathrm{MW}$ was used in Test 3.

\subsubsection{Furniture Tests}

Furniture tests were conducted to observe the fire performance in a real situation and to provide comparison with the propane fires. Furniture was used as the fuel source in Tests 2, 4 and 5. Test 4 was a repeat of Test 2. The fire loads for each test are presented in Table 7, each of the items was weighed at the laboratory and heat of combustion values used were based on a survey of Canadian residential buildings conducted by Bwalya [46].

Table 7 -Fire loads for tests with furniture

\begin{tabular}{|c|c|c|c|c|c|c|c|}
\cline { 2 - 8 } \multicolumn{1}{c|}{} & \multicolumn{2}{c|}{} & \multicolumn{2}{c|}{ Test 2 - Protected } & \multicolumn{2}{c|}{ Test 4- Protected } & \multicolumn{2}{c|}{$\begin{array}{c}\text { Test 5 - } \\
\text { Unprotected }\end{array}$} \\
\cline { 2 - 8 } \multicolumn{1}{c|}{} & $\begin{array}{c}\Delta H_{c} \\
(\mathrm{MJ} / \mathrm{kg})\end{array}$ & $\begin{array}{c}\text { Weight } \\
(\mathrm{kg})\end{array}$ & $\begin{array}{c}\text { Fuel } \\
\text { Load } \\
\left(\mathrm{MJ} / \mathrm{m}^{2}\right)\end{array}$ & $\begin{array}{c}\text { Weight } \\
(\mathrm{kg})\end{array}$ & $\begin{array}{c}\text { Fuel } \\
\text { Load } \\
\left(\mathrm{MJ} / \mathrm{m}^{2}\right)\end{array}$ & $\begin{array}{c}\text { Weight } \\
(\mathrm{kg})\end{array}$ & $\begin{array}{c}\text { Fuel } \\
\text { Load } \\
\left(\mathrm{MJ} / \mathrm{m}^{2}\right)\end{array}$ \\
\hline $\begin{array}{c}\text { Headboard/ } \\
\text { footboard }\end{array}$ & 18 & 29.5 & 33.7 & 29.5 & 33.7 & 29.5 & 33.7 \\
\hline Mattress & 20 & 37 & 47.0 & 37 & 47.0 & 37 & 47.0 \\
\hline Boxspring & 20 & 10 & 12.7 & 10 & 12.7 & 10 & 12.7 \\
\hline Dresser & 18 & 46 & 52.6 & 46 & 52.6 & 46 & 52.6 \\
\hline Tallboy & 18 & 59 & 67.4 & 59 & 67.4 & 59 & 67.4 \\
\hline $\begin{array}{c}\text { Night } \\
\text { Tables }\end{array}$ & 18 & 24 & 27.4 & 24 & 27.4 & 24 & 27.4 \\
\hline Clothes & 20 & 10 & 12.7 & 10 & 12.7 & 20 & 25.4 \\
\hline Books & 18 & 17.1 & 19.5 & 20.3 & 23.2 & 0 & 0 \\
\hline Pillows & 20 & 2 & 2.5 & 2 & 2.5 & 2 & 2.5 \\
\hline Sheets & 20 & 2 & 3 & 2 & 2.5 & 2 & 2.5 \\
\hline Duvet & 20 & 2 & 2.5 & 2 & 2.5 & 2 & 2.5 \\
\hline Floor & 18 & 221 & 252.6 & 235.3 & 268.9 & 223.2 & 255.1 \\
\hline $\begin{array}{c}\text { Total Fuel } \\
\text { Load }\end{array}$ & & & & & & & \\
\hline MJ/m $\left.{ }^{2}\right)$ & & & 533 & & 553 & & 529 \\
\hline
\end{tabular}


The furniture/bedding sets and layout of the rooms, presented in Figure 45, were identical for each of these three tests. With the exception of the clothing and books, all items used in the tests were new.

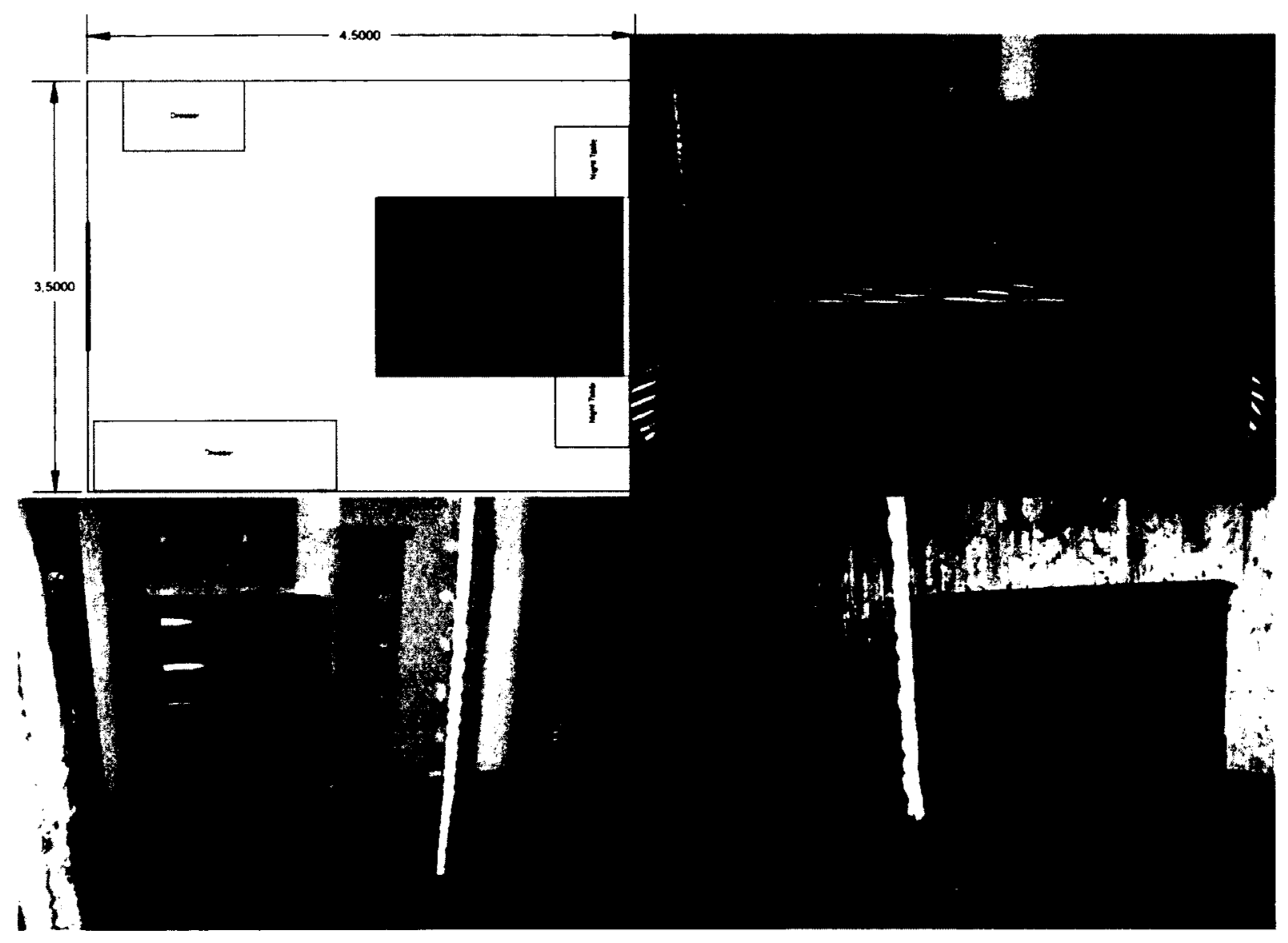

Figure 45 - Furniture layout in Tests 2, 4 and 5

The ignition source for the tests was a square propane burner [47]. The burner, shown in Figure 46, was positioned at the head of the bed and was removed once the fire began to spread. 


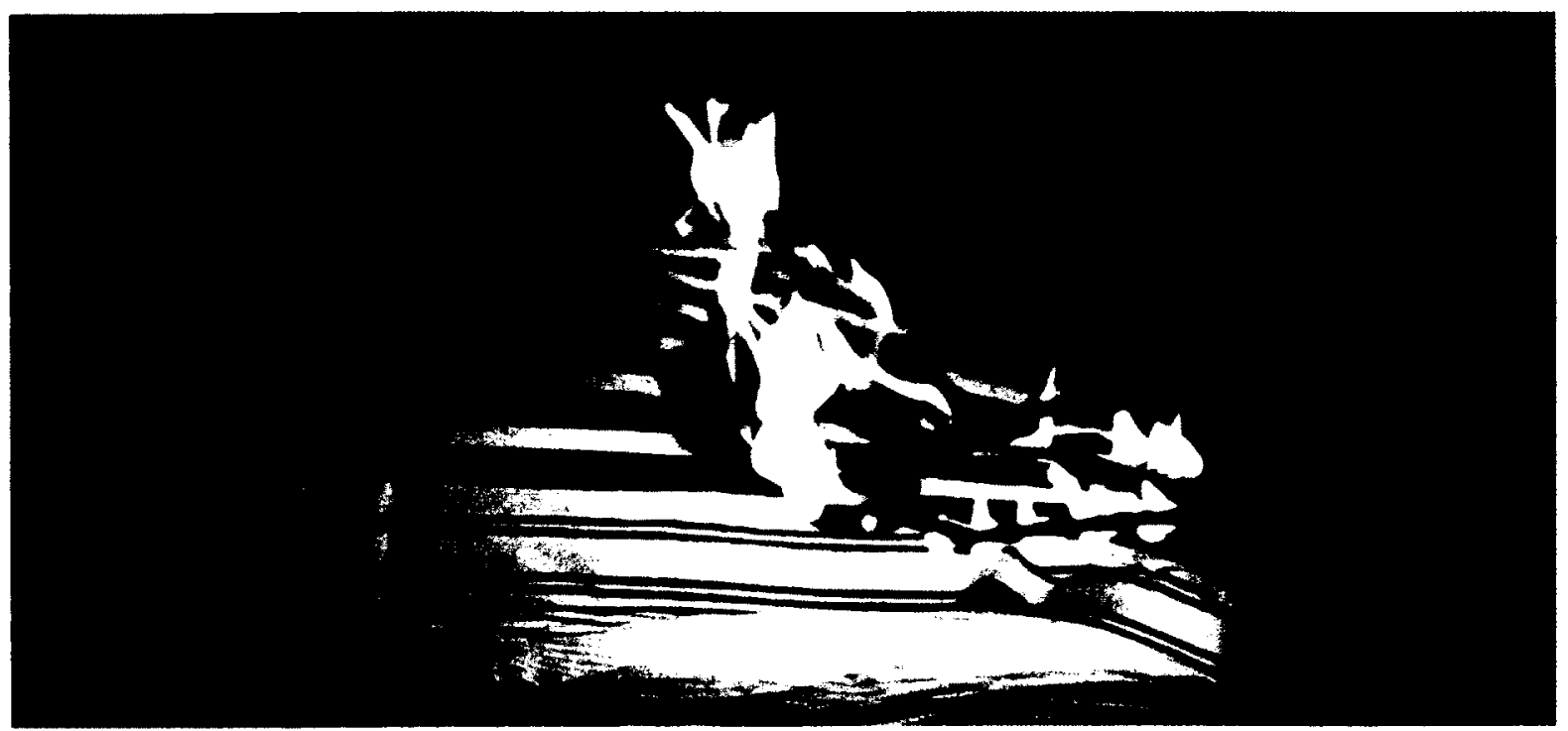

Figure 46 - Square burner used for ignition source in furniture tests

A smoke alarm and $60^{\circ} \mathrm{C}$ sprinkler head (Test 2 only) were installed in the centre of the ceiling in the room. The sprinkler head was connected to a pressurised line with a gauge to indicate activation and are shown in Figure 47.

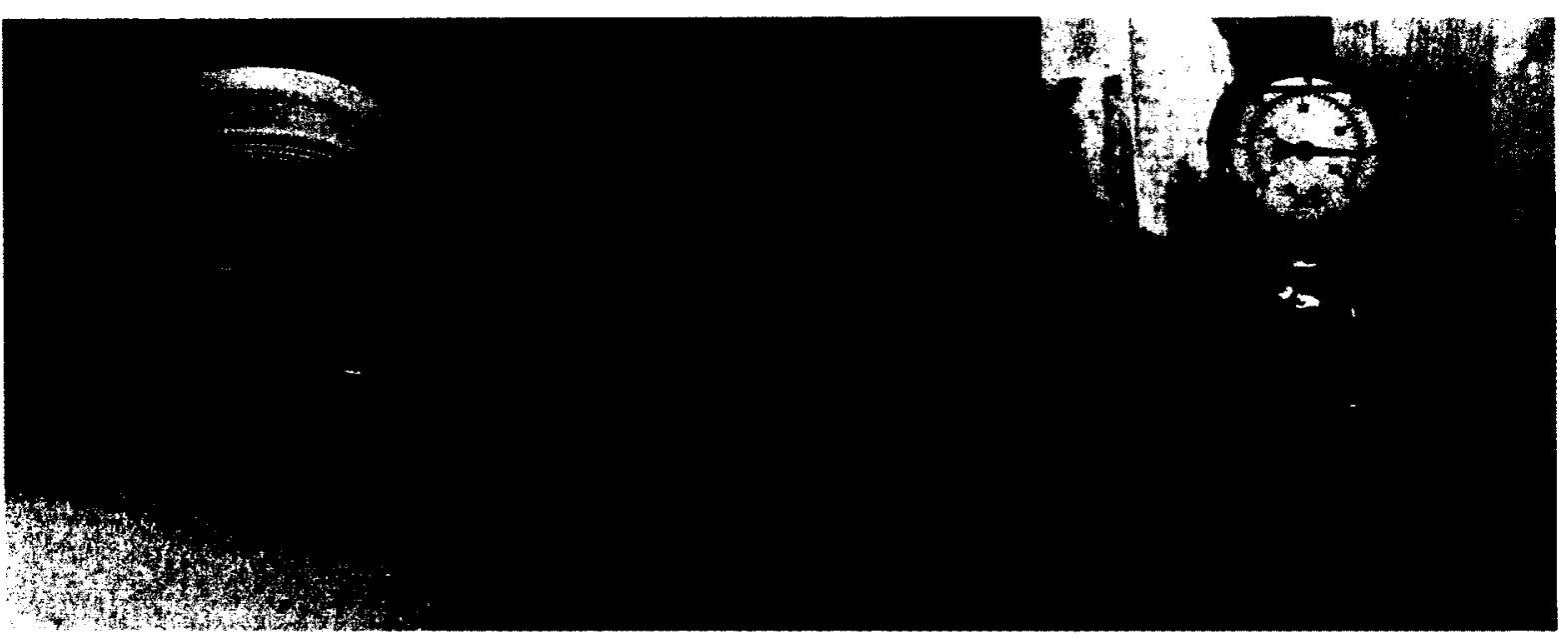

Figure 47 - Smoke alarm and sprinkler with indicator gauge

\subsection{Instrumentation}

Data was collected on the performance of the CLT panels in fire and was used to determine the HRR, room temperature and charring rates. In addition fire characteristics, 
notes, photographic and video data were used to compile lists of events for each of the tests.

\subsubsection{HRR}

HRR was recorded for each test using the Oxygen Consumption Calorimetry system installed in the tunnel described in Section 2.4. The tunnel had previously been calibrated for fires up to $13 \mathrm{MW}[21]$ and has also been used in fires up to $50 \mathrm{MW}$. The arrangement of the tunnel is shown in Figure 30.

The specified system calibration factor of 0.83 [21] was used for a series of calibration test conducted on 4 Apr 2012 prior to the construction of the first room. An unconfined fire using the propane burners was used for the calibration check shown in Figure 48.

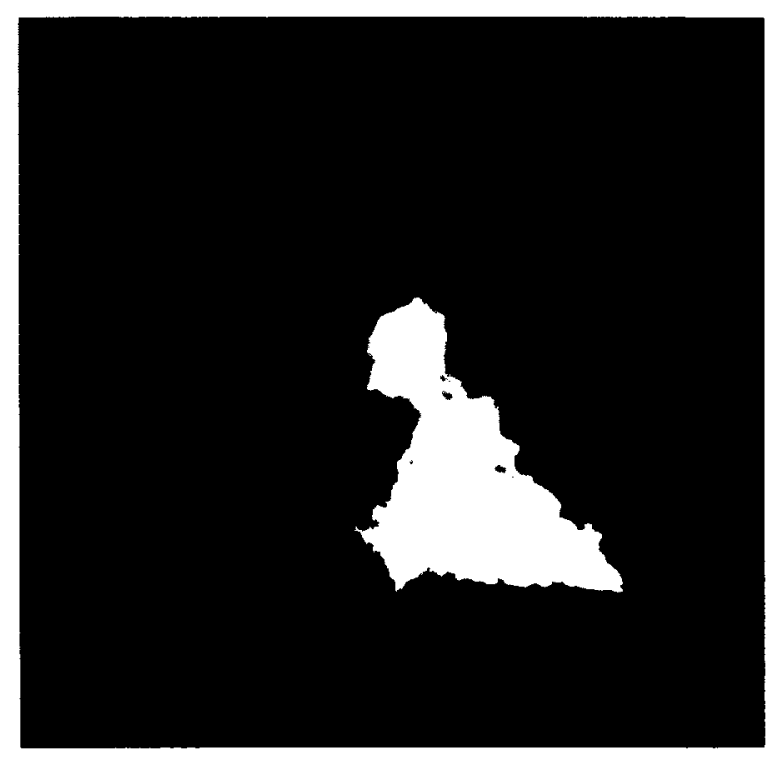

Figure 48 - Oxygen calorimetry tests - Carleton fire lab - 4 Apr 12

The results from the calibration check, presented in Figure 49, show a close correlation between the measured HRR and the calculated propane HRR. The test was considered successful and the adjustment factor of 0.83 was used throughout the testing. 
The spikes in HRR correlate to increases in air flow as the fan speeds were increased to clear smoke buildup in the tunnel and should be disregarded. The delay between propane HRR and measured HRR is due to transport time of the gases from the fire to the measurement point and through the measurement system.

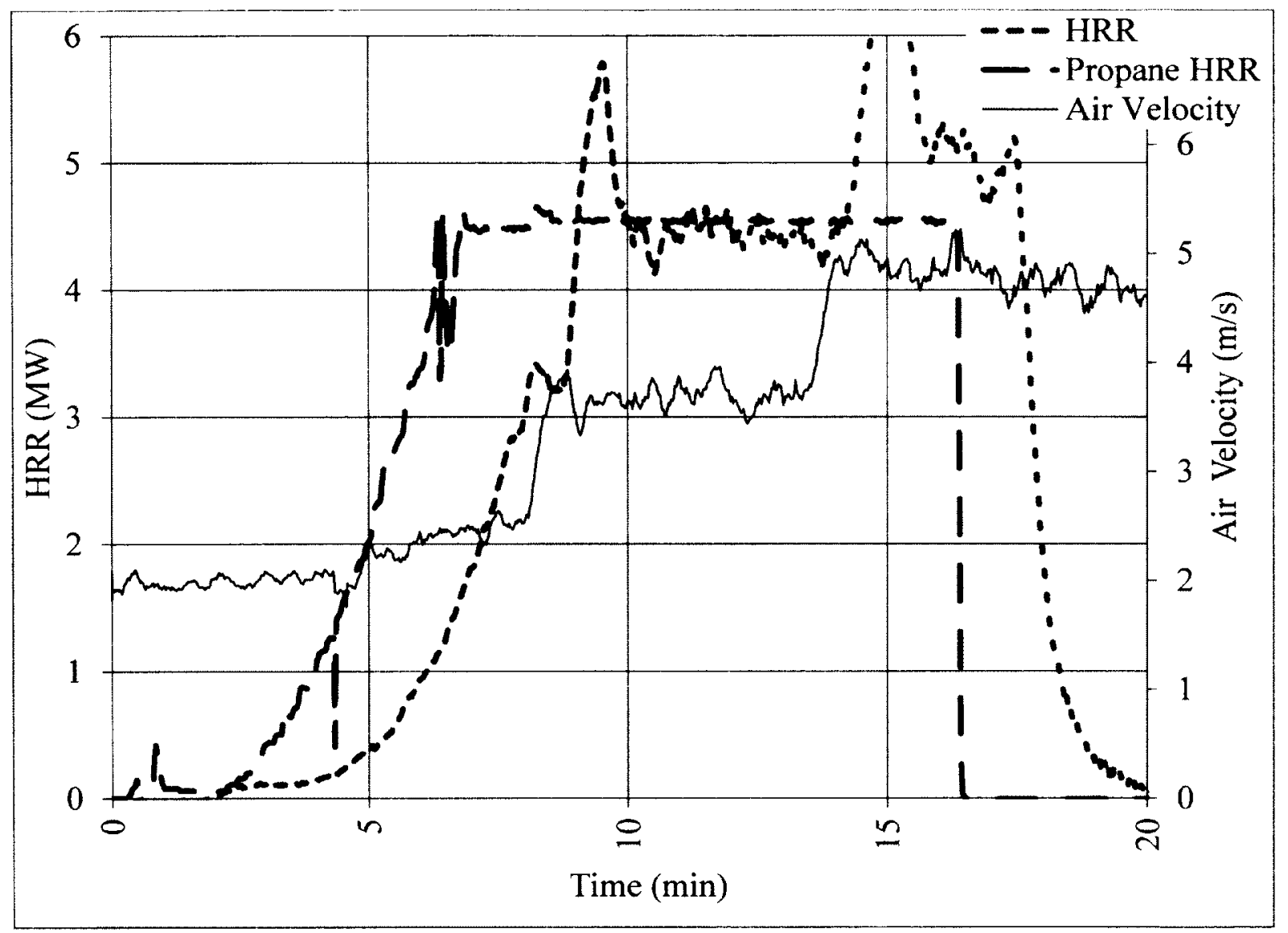

Figure 49 - Heat release rates from calibration tests - April 42012

\subsubsection{Temperatures}

For each test, temperatures were measured in the room, within the structure and the environment for reference purposes. The temperatures in the room were measured using thermocouple trees to observe the temperature differences with height and location, as well as a plate thermometer. Temperatures were also measured within the first layer of the CLT panels to measure the charring rates at different locations. 
Figure 50 shows the equipment setup used to record temperature measurements for the tests. Temperatures were recorded using National Instruments hardware consisting of temperature modules installed in a network enabled chassis. The chassis was connected to the laptop running LabVIEW [45] which was used to display all temperatures in real time and record the data.

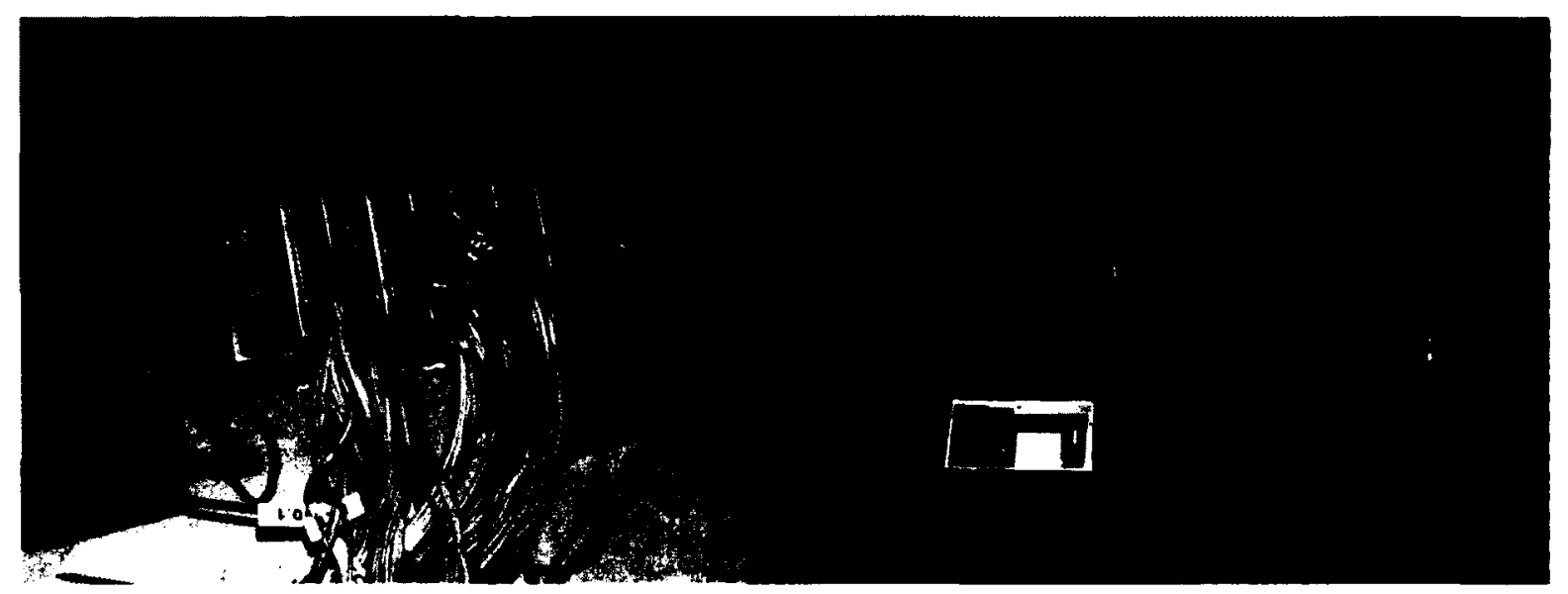

Figure 50 - National Instruments chassis connected to laptop to display and record temperatures

All thermocouples were tested before each test for calibration. A naked flame was exposed to thermocouples externally and embedded thermocouples were tested before installation in the panels.

\subsubsection{Room temperatures}

\subsubsection{Thermocouple trees}

Figure 51 shows the location thermocouple trees were positioned in each room. Each thermocouple tree included 6 thermocouples at heights at $0.4,0.8,1.2,1.6,2.0$ and 2.4 metres from the floor. Trees were located at the doorway, two near the centre of the room and one at the rear of the room. 


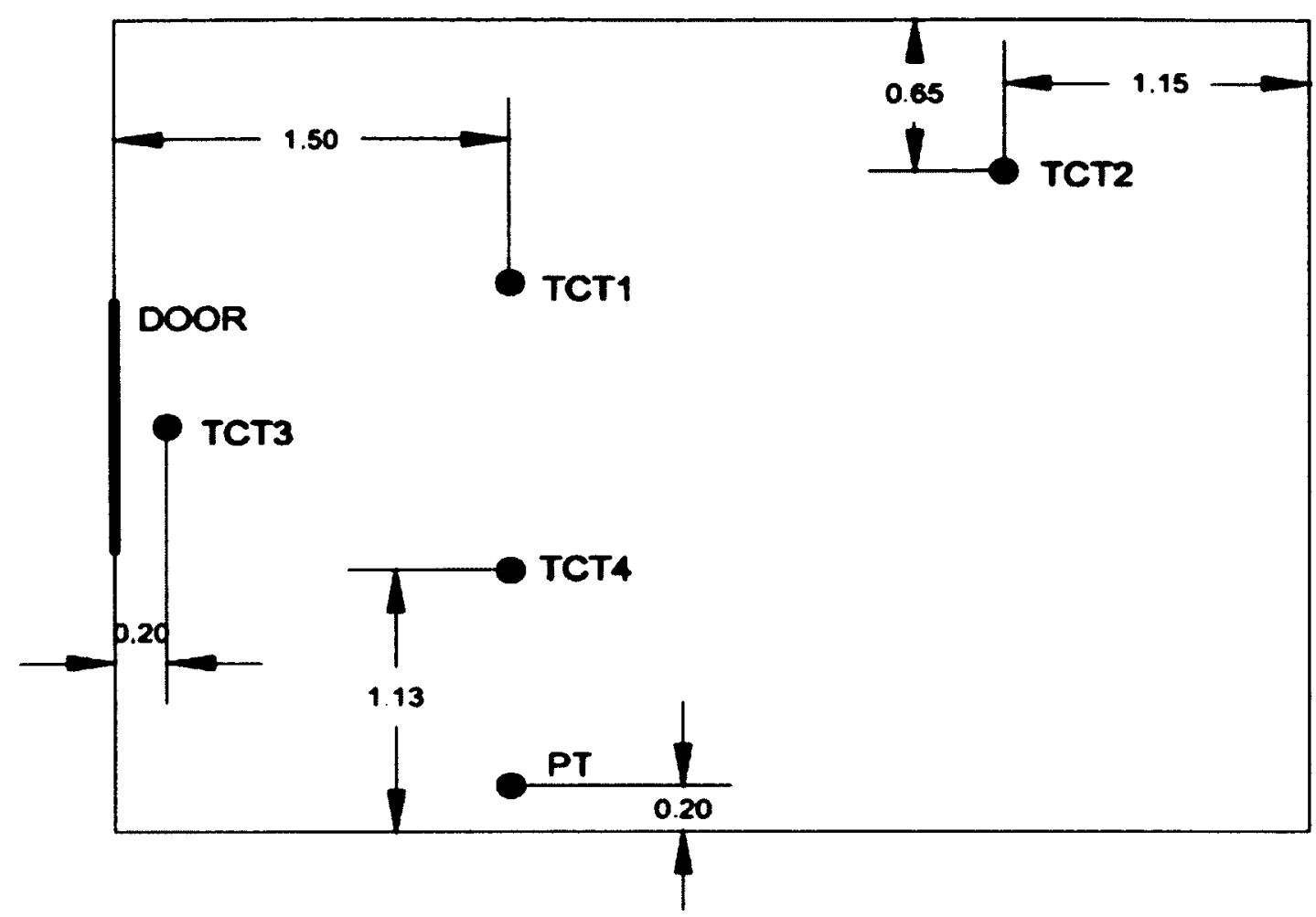

Figure 51 - Location of thermocouple trees and plate thermometer (PT) - All tests Thermocouple trees for Test 1 were constructed using shielded thermocouples connected to tensioned guide wires, however were destroyed during the test.

Thermocouple trees for Tests 2-5 were constructed from steel tube, shown in Figure 52, which was inserted through the ceiling of the room and fixed to the floor. Unshielded type $\mathrm{K}$ thermocouple wire was fed from the top of the trees and protruded through drilled holes at the specified heights. The thermocouple wire ends were twisted together to make the connection and the trees were covered with a $12.7 \mathrm{~mm}$ fibreglass insulation layer shown in Figure 52. 


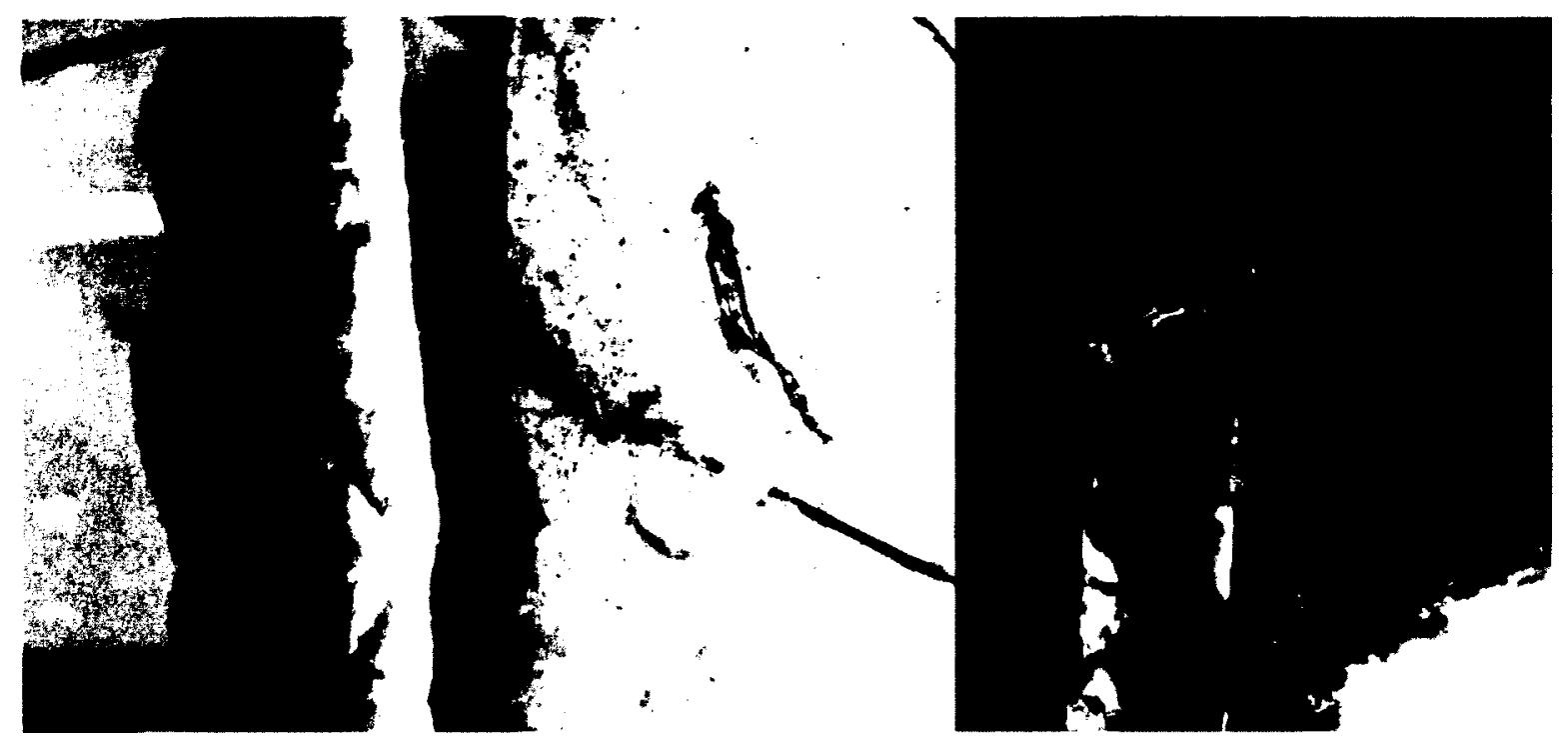

Figure 52 - Unshielded thermocouples before (left) and after test with fibreglass protection (centre) and after test with fibreglass removed (right)

A single plate thermometer was installed in each room at a height of $1.5 \mathrm{~m}$ as shown in Figure 51 and Figure 53.

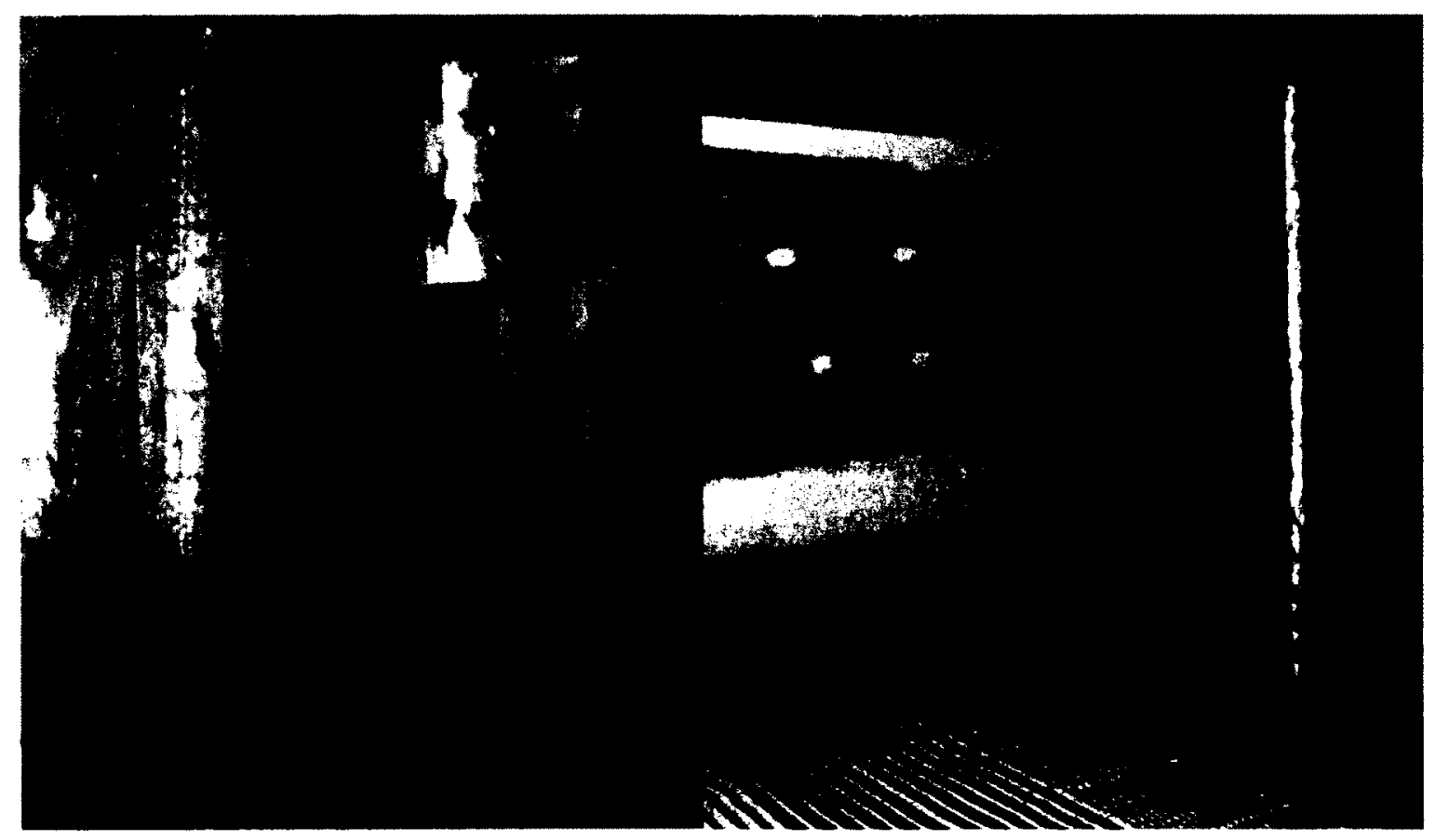

Figure 53 - Plate thermometer installed in room 


\subsubsection{Embedded Thermocouples}

Shielded thermocouples were embedded in the structure to measure advancement of the char front which is identified by the $300^{\circ} \mathrm{C}$ isotherm [9]. Thermocouples were inserted in the structure through $2.5 \mathrm{~mm}$ pilot holes drilled from the outside surface shown in Figure 54. These were bent at the surface with a radius, to avoid damaging the wires, and secured to the surface of the structure with staples to avoid any movement. The pilot holes were drilled to exact depth using a hand held drill press.

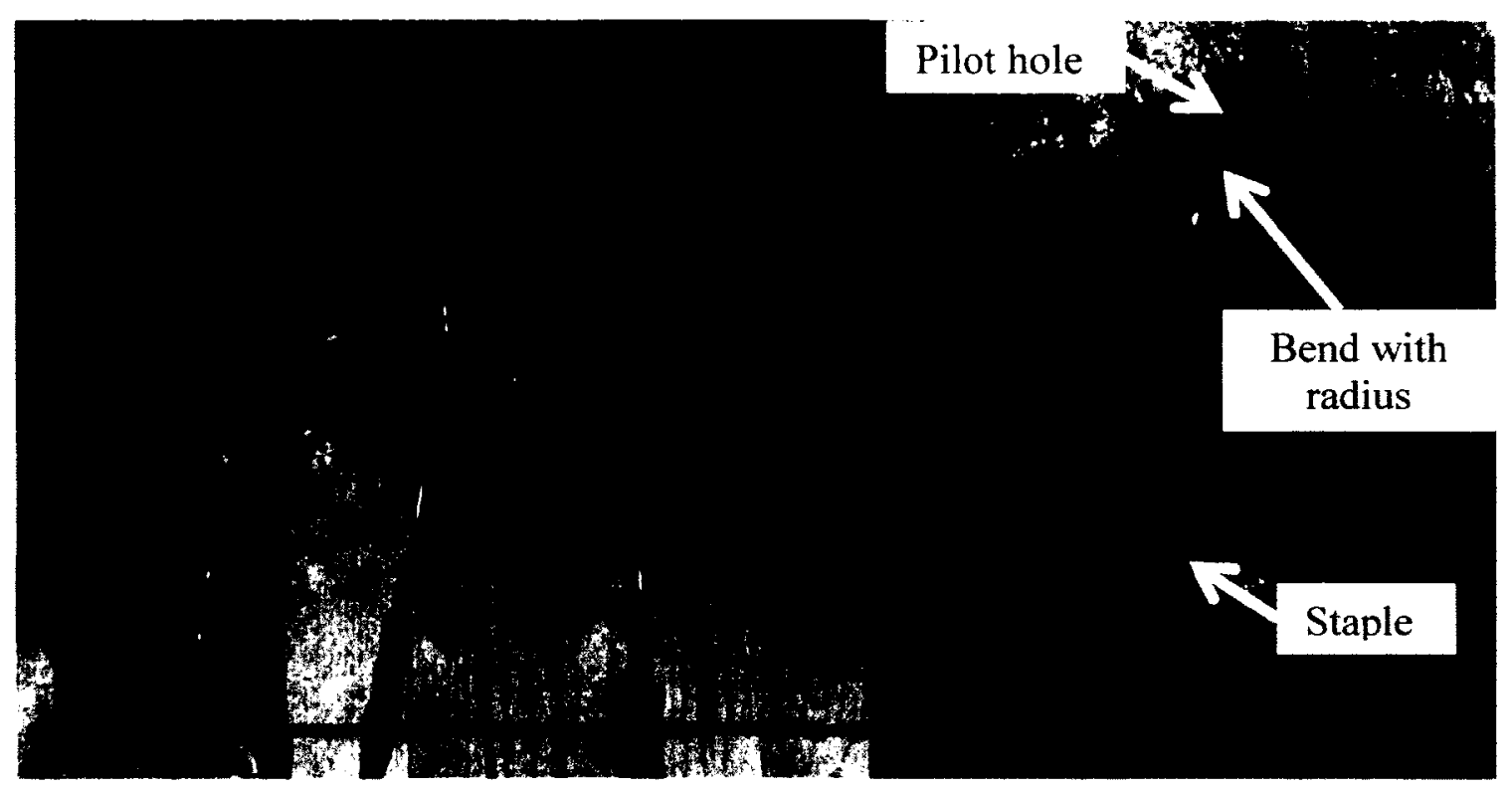

Figure 54 - Embedded thermocouples installed in CLT panels

Groups of six thermocouples were installed at 8 locations $(\mathrm{C} 1, \mathrm{C} 2, \mathrm{~W} 1, \mathrm{~W} 2, \mathrm{~W} 3$, W4, W5 and W6) shown in Figure 55, Figure 56 and Figure 57 to measure the charring rates. Table 8 provides details of the depths at which thermocouples were installed for each of the tests. 


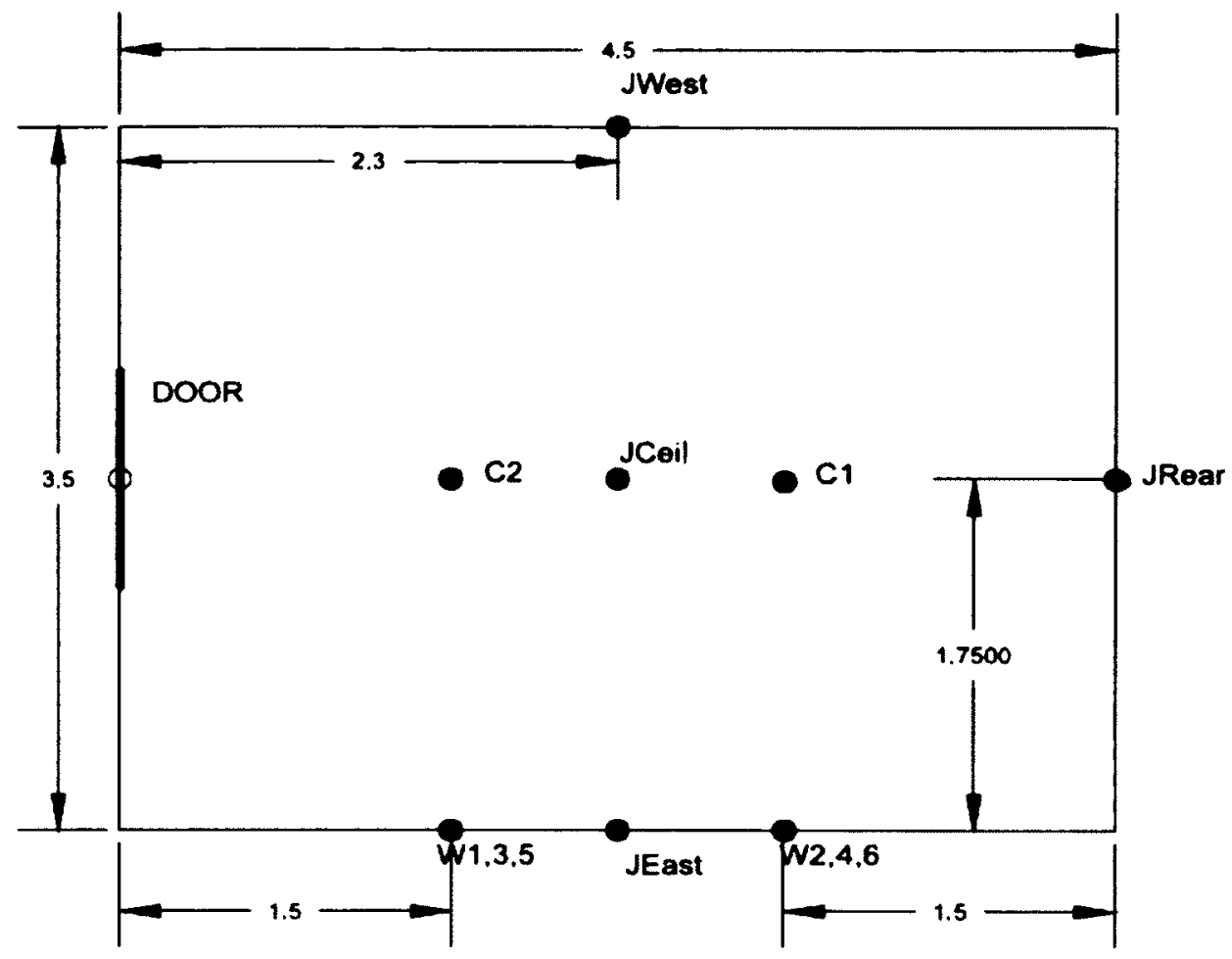

Figure 55 - Embedded thermocouple locations - Plan view

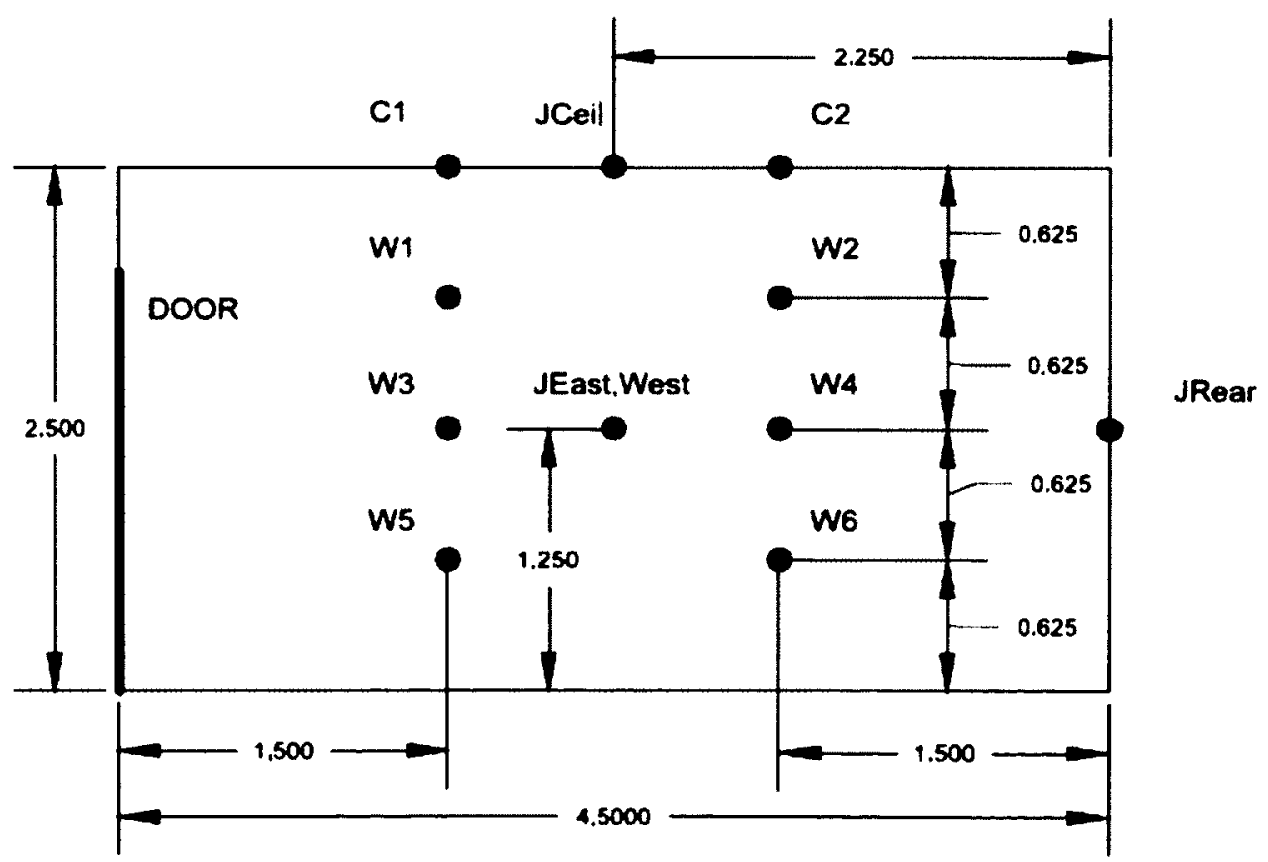

Figure 56 - Embedded thermocouple locations - Side elevation 


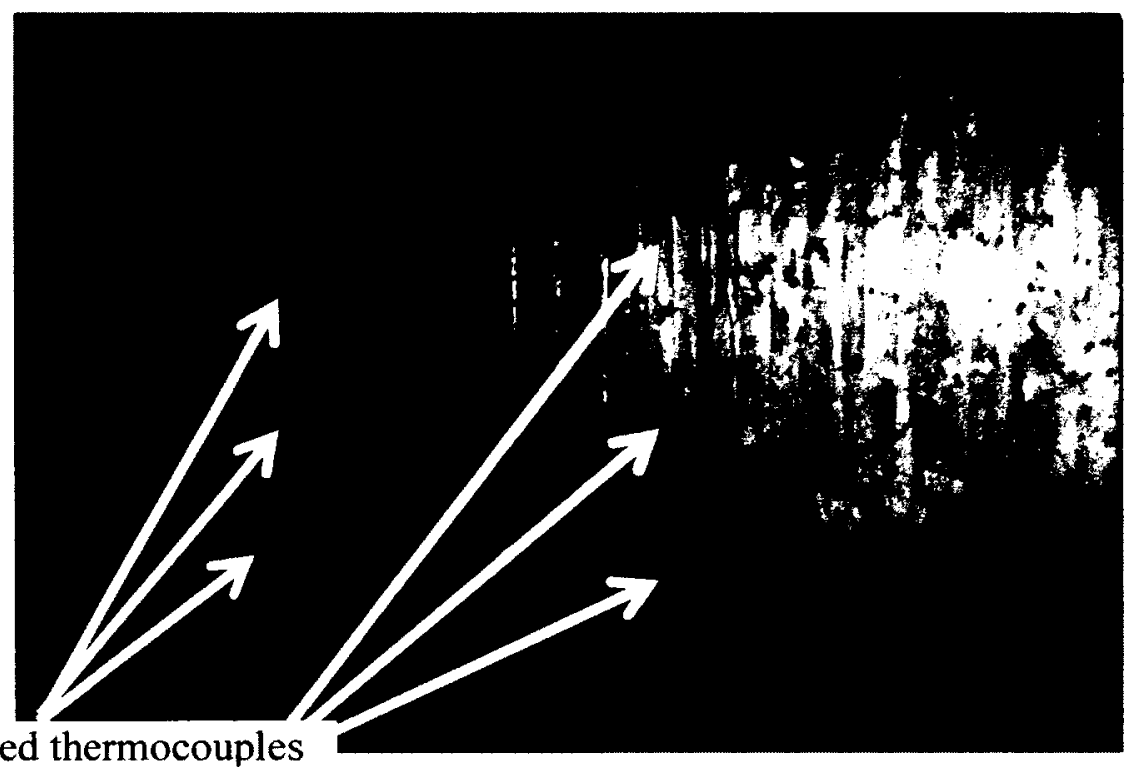

Embedded thermocouples

Figure 57 - Embedded thermocouple locations - Side wall (exterior view)

Table 8 - Thermocouple depths from inside surface of CLT panels (mm)

\begin{tabular}{|c|c|c|c|c|c|}
\hline TC \# & Test 1 & Test 2 & Test 3 & Test 4 & Test 5 \\
\hline 1 & Btwn Gyp & Btwn Gyp & 6 & Btwn Gyp & 3 \\
\hline 2 & $\begin{array}{c}\text { Interface } \\
(0)\end{array}$ & $\begin{array}{c}\text { Interface } \\
(0)\end{array}$ & 12 & $\begin{array}{c}\text { Interface } \\
(0)\end{array}$ & 6 \\
\hline 3 & 6 & 6 & 18 & 6 & 9 \\
\hline 4 & 12 & 12 & 30 & 12 & 12 \\
\hline 5 & 18 & 18 & 42 & 18 & 18 \\
\hline 6 & 24 & 24 & 54 & 24 & 24 \\
\hline
\end{tabular}

Gyp - Thermocouples installed between layers of gypsum board

Interface - Thermocouples installed at the interface between gypsum board and CLT panels. 


\subsubsection{Final Char depth readings}

Measurements were taken of final char depths using a grid with $300 \mathrm{~mm}$ spacing between measuring points. To obtain the final measurements the charred timber was taken back with a wire brush, shown in Figure 58, to expose solid timber.

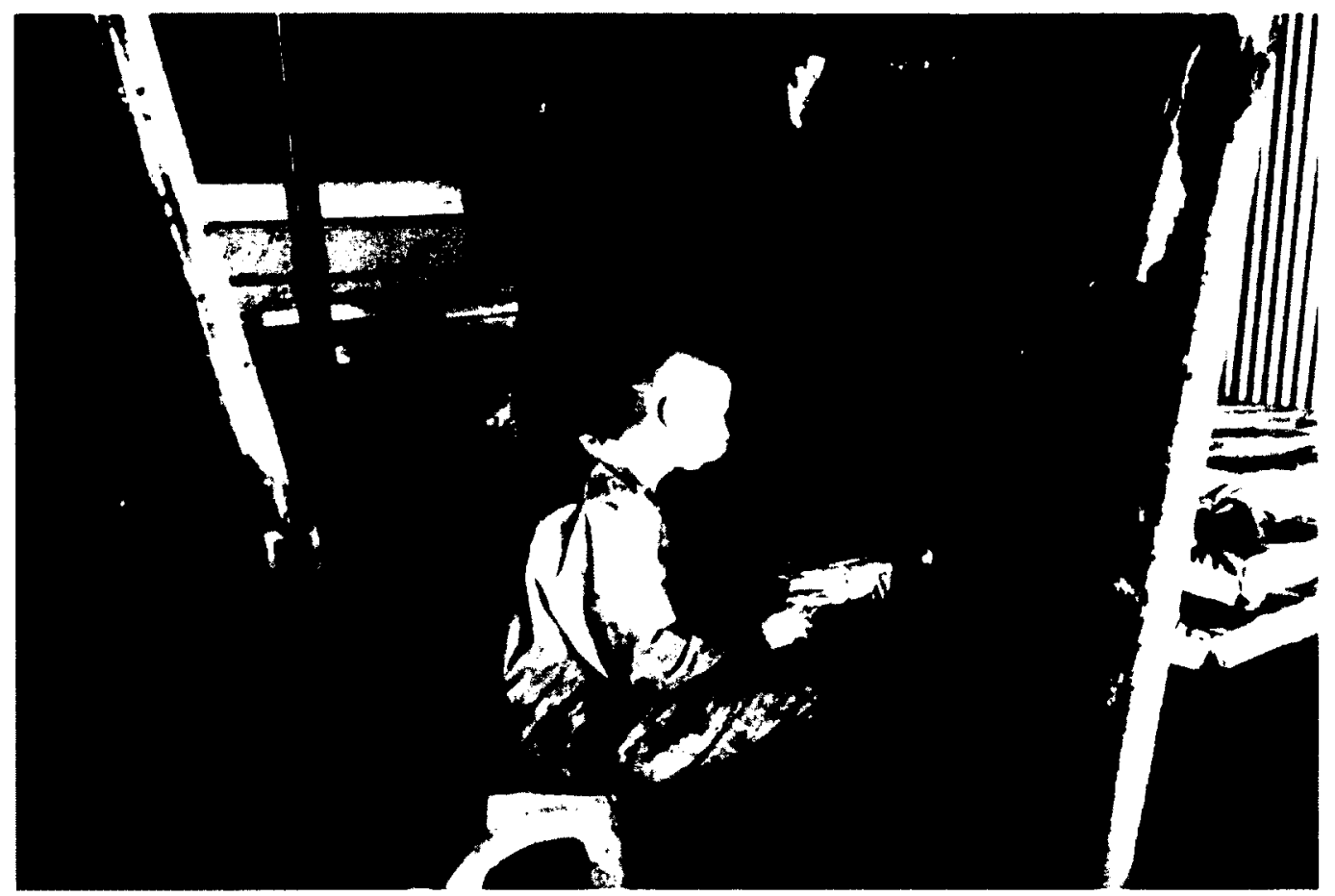

Figure 58 - Removal of char layer to measure final char depth

\subsubsection{Digital video and still Cameras}

Two video cameras were used to record each of the tests, one from the side and one from the front of the room. Still cameras were also used to record observations before, during and after each of the tests and during the preparation stages.

\subsection{Preliminary Calculations}

Some calculations were carried out prior to the tests to try to estimate the actions of the fire performance in the rooms. These are included in Appendix A. 


\section{Chapter 4 : Results}

Five tests were carried out between 18 April 2012 and 25 Jul 2012 at the Carleton University Fire Research Lab to investigate the contribution of CLT panels to the development, duration and intensity of room fires. Fires using two different fuels, propane and bedroom furniture and two room lining configurations (protected and unprotected) were used.

\subsection{Test 1 - Protected room with propane fire}

Test 1 was conducted on the morning of 18 April 2012. The aim of the test was to establish a reference fire and to observe the performance of the CLT panels in a protected room using propane to simulate a fire. The propane fire was designed to represent an extreme fire situation representing the 95 th percentile of the expected fire load for a primary bedroom in residential occupancies [46] as discussed in Section 2.8.

The propane burners were ignited at 11:50 AM with an ambient temperature of $5.5^{\circ} \mathrm{C}$. At 1 minute after the burners were ignited, the propane flow, presented in Figure 59, was increased at a 'fast' fire growth rate to the calculated peak HRR of 4.54 MW (Eq 27). The propane flow rate reached 1.055 MW after 3:40 minutes and flames were seen emerging from the room at 4:57 minutes, at which time the propane flow rate was 2.33 MW. The propane flow reached 4.54 MW at 6:17 minutes and much flaming and black smoke were observed outside the compartment indicating that there was insufficient oxygen within the compartment to combust all of the propane. A failure in the HRR measurement was discovered and the burners were shut off after 8 minutes. 


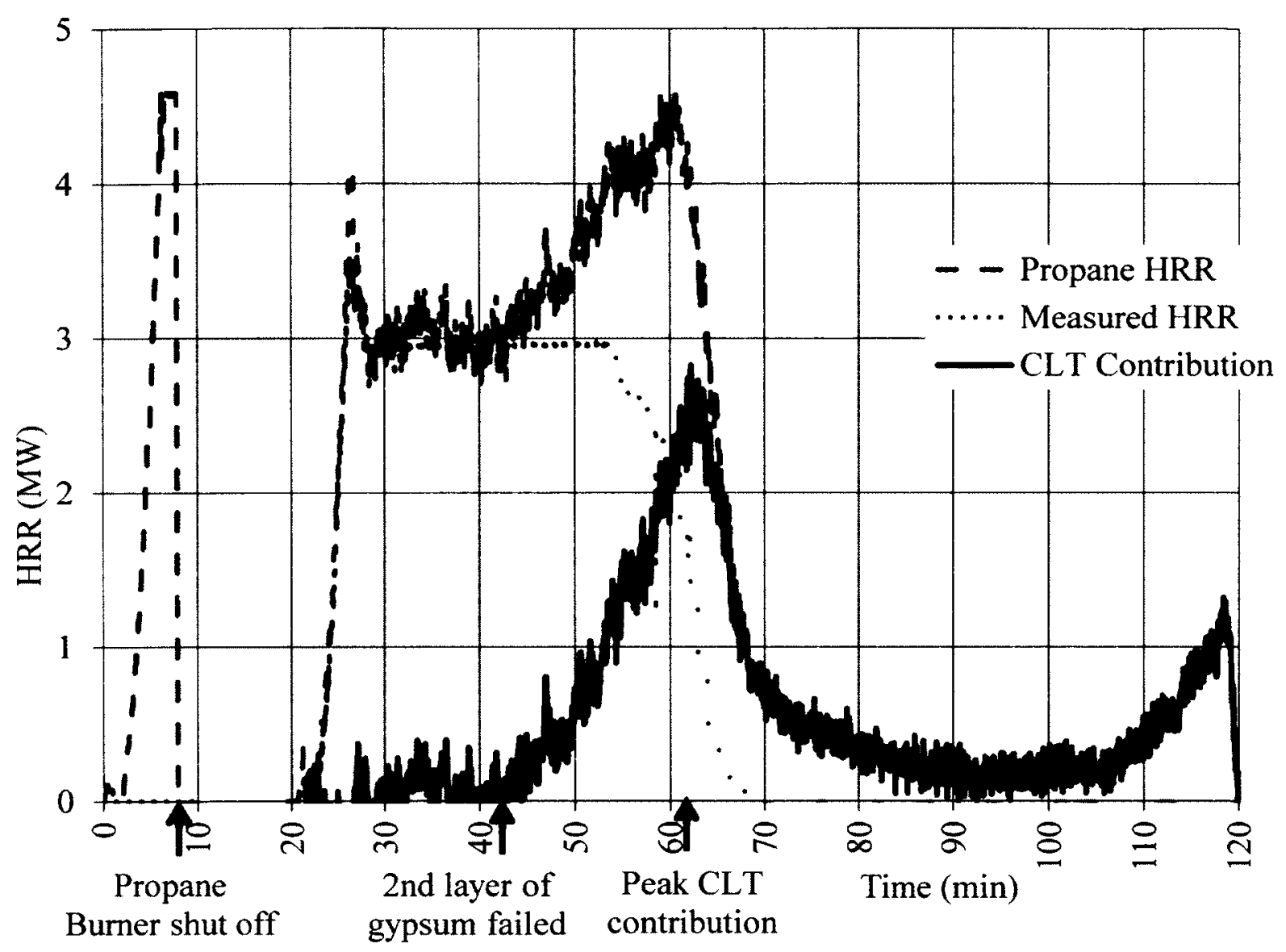

Figure 59 - Heat release rate - Test 1

The propane burners were ignited for a second start after 19:41 minutes. At 21:36 the propane flow was increased at a fast fire growth rate reaching a peak of $4 \mathrm{MW}$ at 26:23 minutes. Flaming and black smoke were observed outside the compartment, as seen in Figure 60, and the decision was made to reduce the flow rate of propane until most combustion was contained within the room, this occurred at $3 \mathrm{MW}$, much lower than the calculated peak HRR. Calculation of flow characteristics discussed in Section 2.6 give an air limited max HRR of 4.26 MW. 


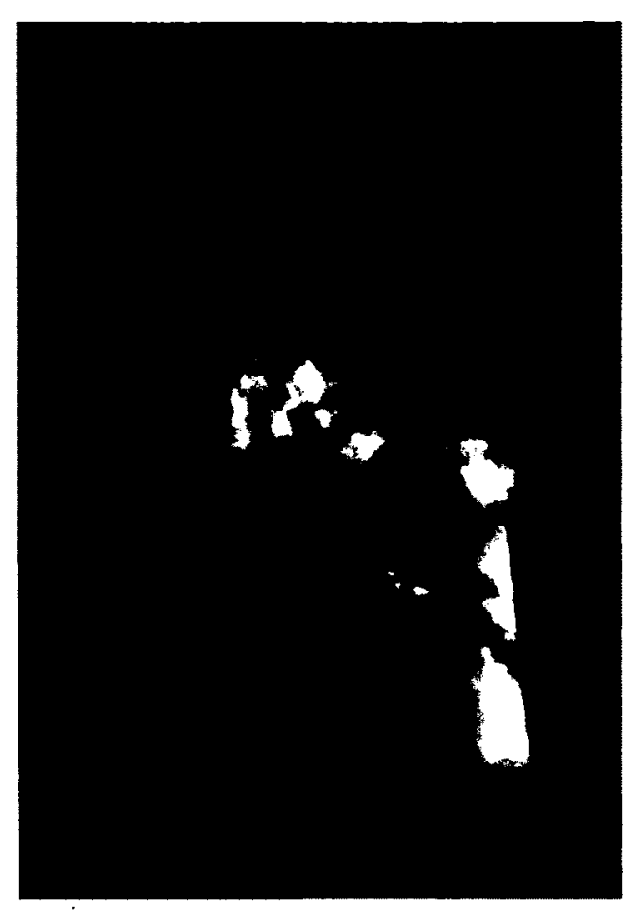

Figure 60 - Flaming and black smoke outside room - Test 1

After 36:26 minutes significant amounts of gases were observed escaping to the outside from numerous areas of the panel joints and, in some cases, from the individual CLT members as seen in Figure 61. This gas was not tested for composition, however condensation was observed in the immediate areas and the gas itself felt warm and moist indicating that it was steam being driven out of the panels. Discoloration at joints indicated that the gases likely contained some smoke and products of combustion.

At 20:29 failure of the first layer of gypsum board above the seat of the fire was indicated by a sharp increase in temperature at the measuring point beneath the layer and at approximately 23 minutes the measured HRR began to increase above the propane flow in the room indicating that the structure is becoming involved in the fire. 


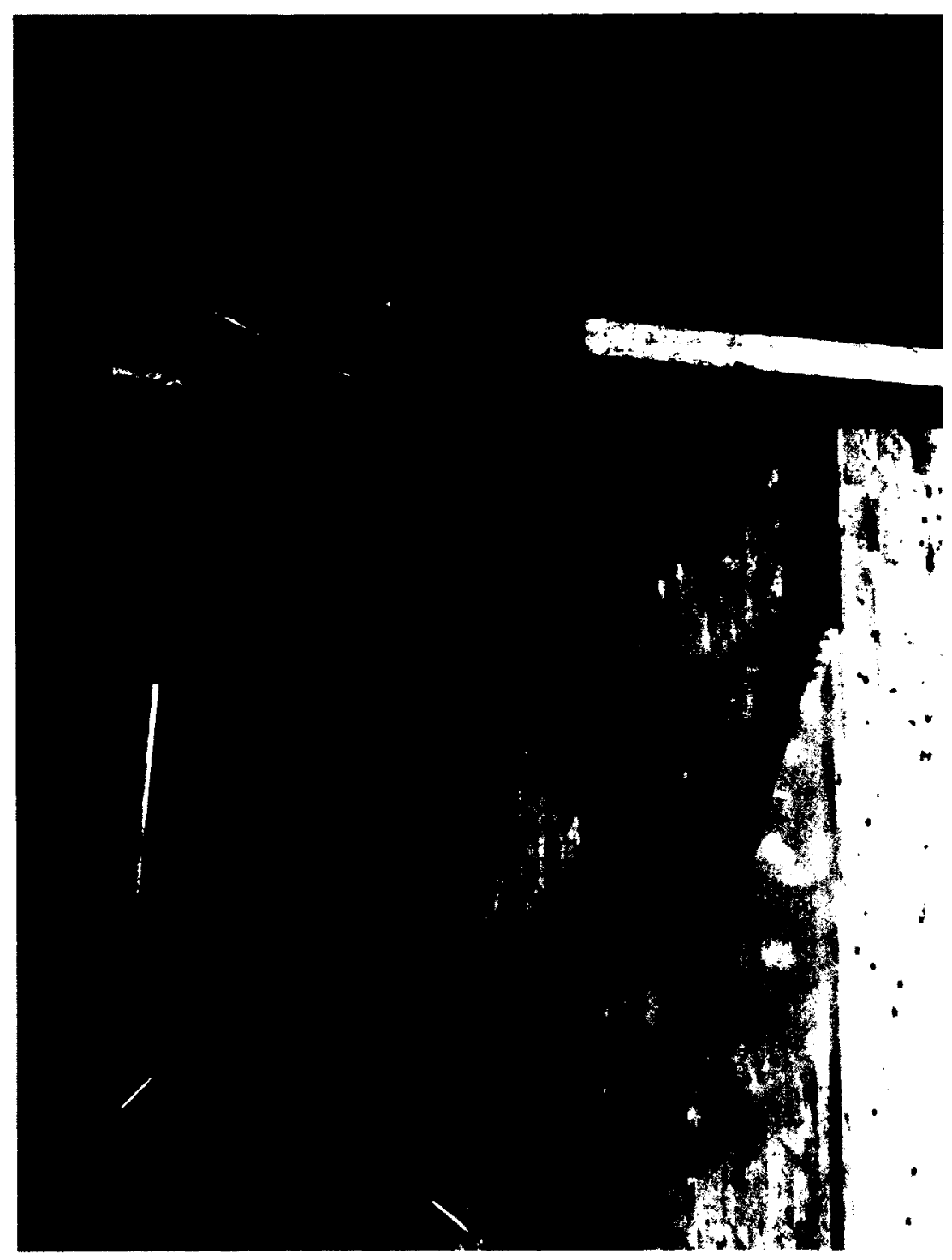

Figure 61 - Gases escaping through ceiling joint and walls - Test 1

The HRR continued to increase, and flaming and flow of black smoke increased outside the room. The reduction of the propane flow was initiated at 54:23 minutes after the HRR exceeded $4 \mathrm{MW}$, however the HRR continued to increase reaching a peak of 4.59 MW at $61: 21$ minutes before a sharp period of decay occurred. After the propane flow was shut off completely at 68:30 minutes, when the HRR at this point was approximately $0.75 \mathrm{MW}$, the rate of decay of the HRR slowed which can be seen in 
Figure 59. The HRR continued to drop slowly settling at approximately $200 \mathrm{~kW}$ at 70 minutes and glowing combustion could be seen on the exposed CLT panels.

Visibility in the compartment improved after the propane flow was reduced and flames could be seen coming from between the gypsum panels, shown in Figure 62, indicating that pyrolysis and charring was occurring behind the gypsum board. The second layer of gypsum on the rear and side walls nearest to the burner, and on the ceiling, were observed to have completely failed exposing the CLT panels.

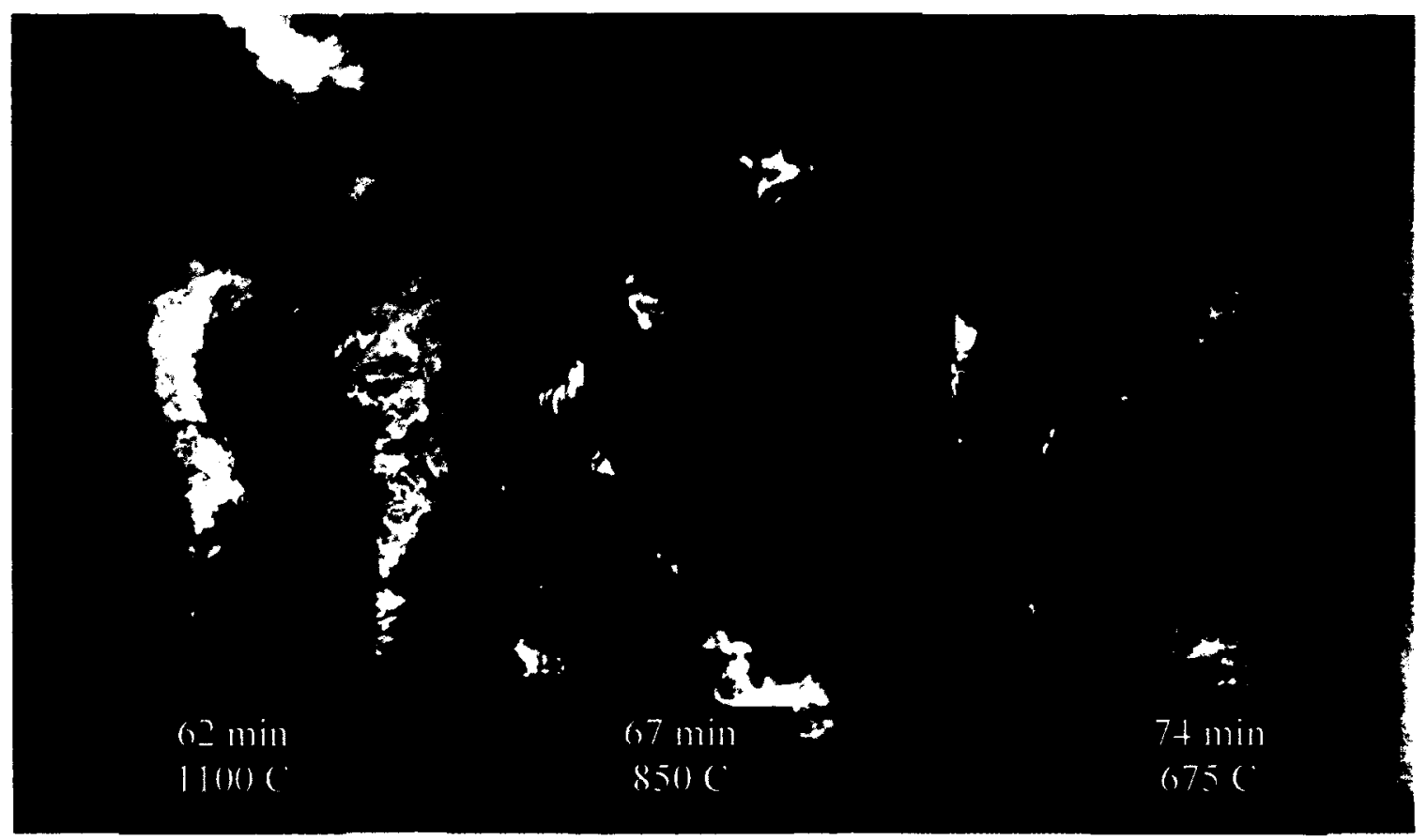

Figure 62 - Fire subsides after propane flow reduced - Test 1 At 105 minutes some delamination of the first layer of CLT began to occur exposing the second layer. Some of the delaminated members hang in place, seen in Figure 63, and ignite exposing the structure to flames. The fire grew as further delamination occurs and at 115 minutes the room began to re-enter flashover. 


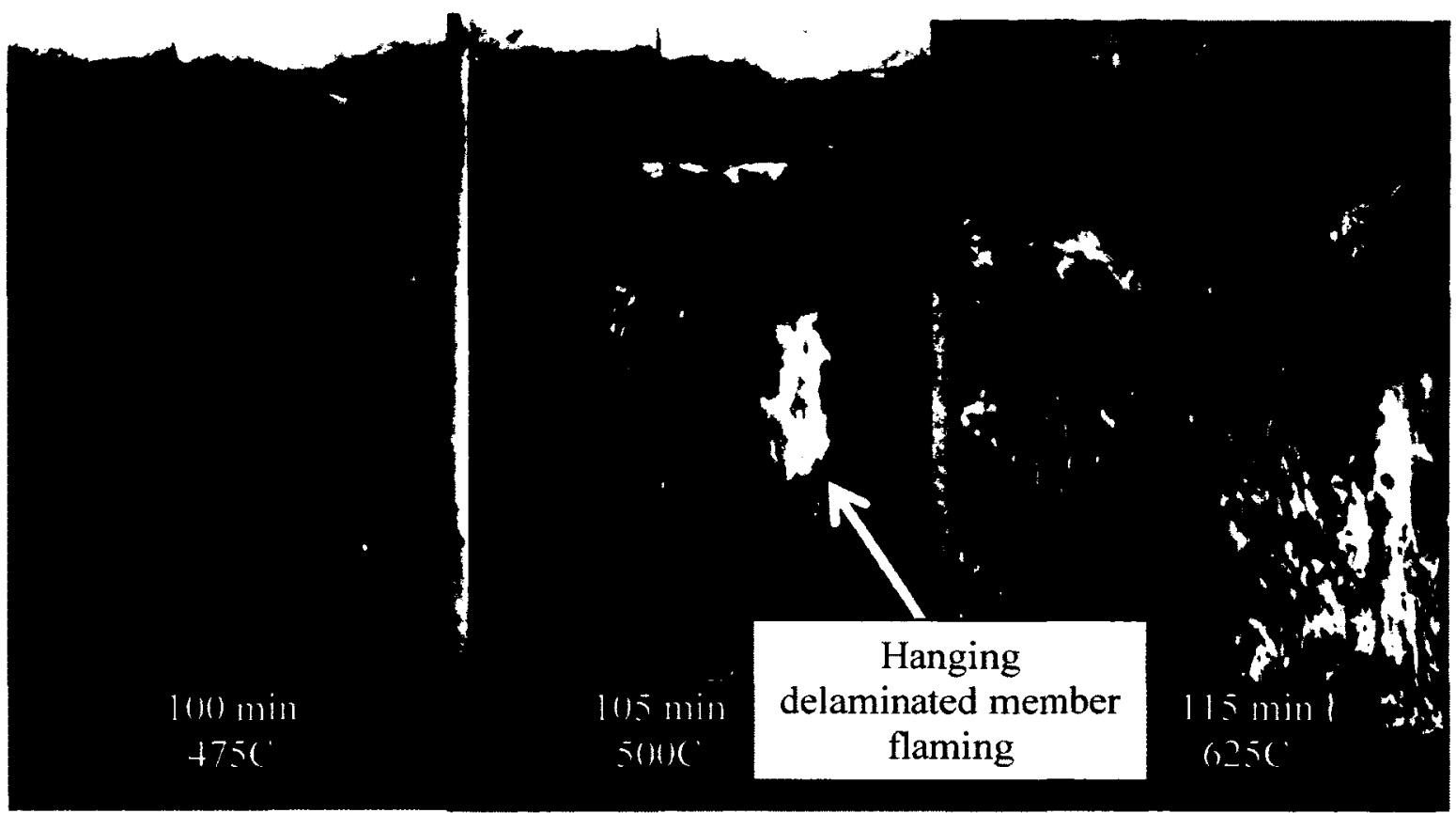

Figure 63- The fire reflashes as the CLT panels delaminates exposing unburned timber - Test 1

The fire was extinguished at 119 minutes after the flames started to exit the room as seen in Figure 64.

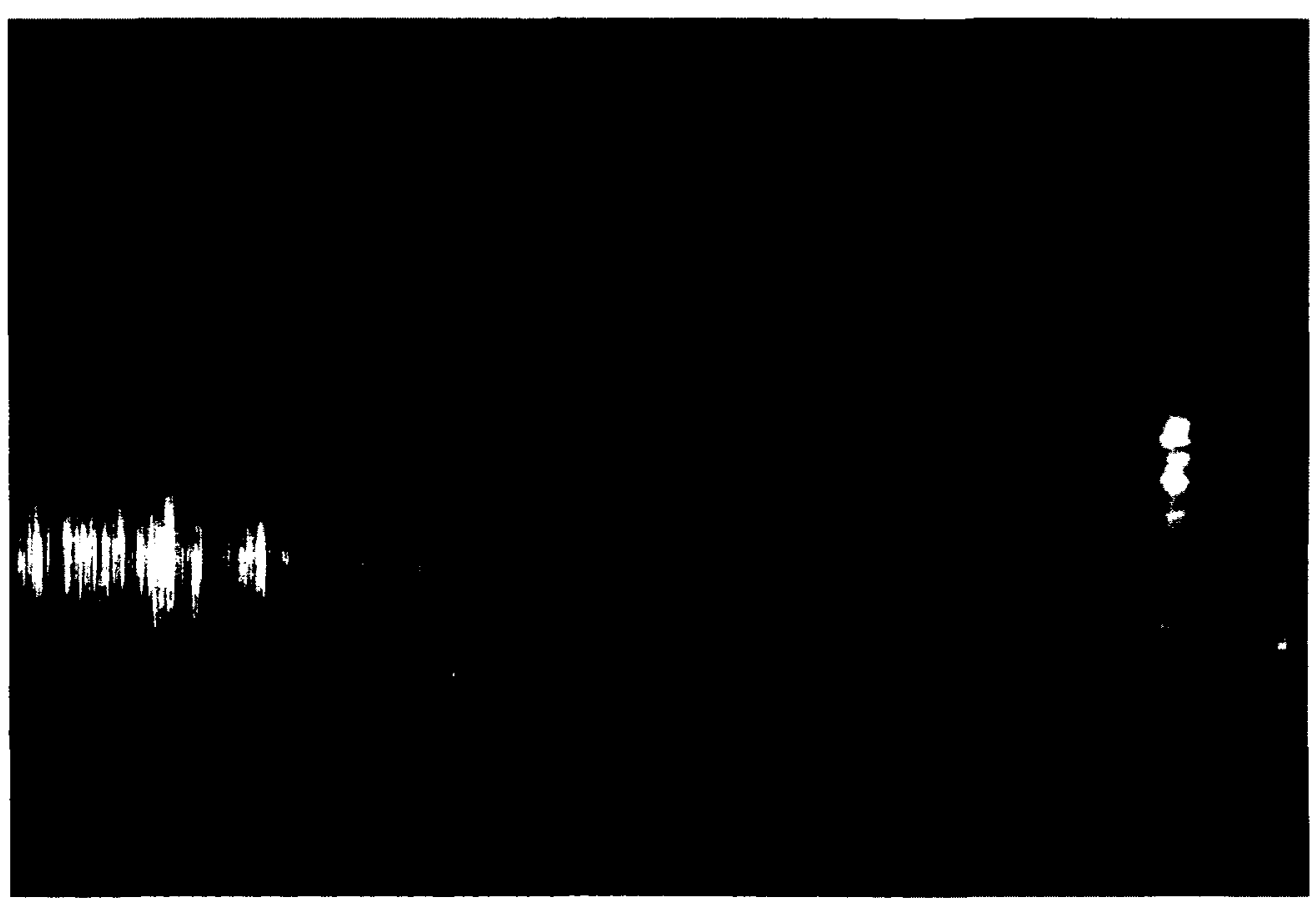

Figure 64 - Fire extinguished - Test 1 


\subsubsection{Localized Failure of Gypsum Protection}

Of particular note in Figure 62 and Figure 63 is the localised failure and falling off of both layers of the gypsum protection on the ceiling and the walls nearest the propane burners. The gypsum protection remained in place at all other locations on the walls throughout the test. An equivalent furniture fire load would have been more evenly distributed throughout the room and would not have burned as intensely as the propane fuel. For this scenario less extreme localised exposure would be expected and falling of the gypsum protection would be expected after a longer time and to a lesser degree, possible not at all. Given the delamination failure at such a late time and as a result of such extreme localised exposure, it is unlikely that delamination would have occurred in a furniture fire or that the room would have entered flashover a second time.

\subsubsection{Contribution of CLT panels to HRR}

The CLT contribution to HRR presented in Figure 59 commences at 43 minutes and grows steadily reaching a peak of $2.8 \mathrm{MW}$ at 64 minutes, after which the CLT contribution to HRR begins to decay rapidly similar to the overall HRR in the room. Smouldering and glowing combustion continued to occur in the room until the first layer of the CLT panels began to delaminate which caused a second growth to flashover.

A summary of energy released during the test is presented in Table 9 . The total was calculated using Eq 29. Energy released by the propane fire was $57 \mathrm{MJ} / \mathrm{m}^{2}$ for the first start $0: 00-0: 08$ minutes and $486 \mathrm{MJ} / \mathrm{m}^{2}$ overall. CLT contribution to the fire was calculated using Eq 30 and was equivalent $200 \mathrm{MJ} / \mathrm{m}^{2}$ overall.

$$
Q_{\text {Fire }}^{n}=\sum_{0}^{t_{\text {end }}} \frac{\dot{Q}_{t_{n}}+\dot{Q}_{t_{n-1}}}{2}\left(t_{n}-t_{n-1}\right) / A_{F}
$$


Where

$$
Q_{\text {Fire }}^{n}=\text { Total energy released per unit area }\left(m^{2}\right)
$$

$\dot{Q}_{1}=$ Measured HRR at time $t(M W)$

$t_{\text {end }}=$ time at end of test $(s)$

$$
Q_{(I t T}^{n}=Q_{\text {Fire }}^{n}-Q_{\text {fuel }}^{n}
$$

Where $\quad Q_{(L T}^{\prime \prime}=$ Total energy released per unit area $\left(\mathrm{MJ} / \mathrm{m}^{2}\right)$

$Q_{\text {mul }}^{\prime \prime}=$ Fuel energy released per unit area $\left(\mathrm{MJ} / \mathrm{m}^{2}\right)$

Table 9 - Energy released during test $\left(\mathrm{MJ} / \mathrm{m}^{2}\right)$

\begin{tabular}{|c|c|c|c|}
\cline { 2 - 4 } \multicolumn{1}{c|}{} & Propane & CLT & Total \\
\hline Test 1 & 486 & 200 & 686 \\
\hline
\end{tabular}

\subsubsection{Temperature}

In Figure 65 the average temperature of the thermocouple trees is compared to the plate thermometer readings, with the standard fire test and the HRR overlayed for reference. The temperatures quickly rise at flashover exceeding $1000^{\circ} \mathrm{C}$ before entering a much slower growth phase. The average room temperature stabilises near $1130^{\circ} \mathrm{C}$ $\left(1200^{\circ} \mathrm{C}\right.$ for the plate thermometer). There is a sharp decay whilst the HRR continues to drop and then a slower decay once the HRR stabilises. The temperature stabilises near $480^{\circ} \mathrm{C}\left(400^{\circ} \mathrm{C}\right.$ for the plate thermometer) whilst smouldering combustion continues in the compartment and again increases with the HRR as the room enters the second phase of flashover. 


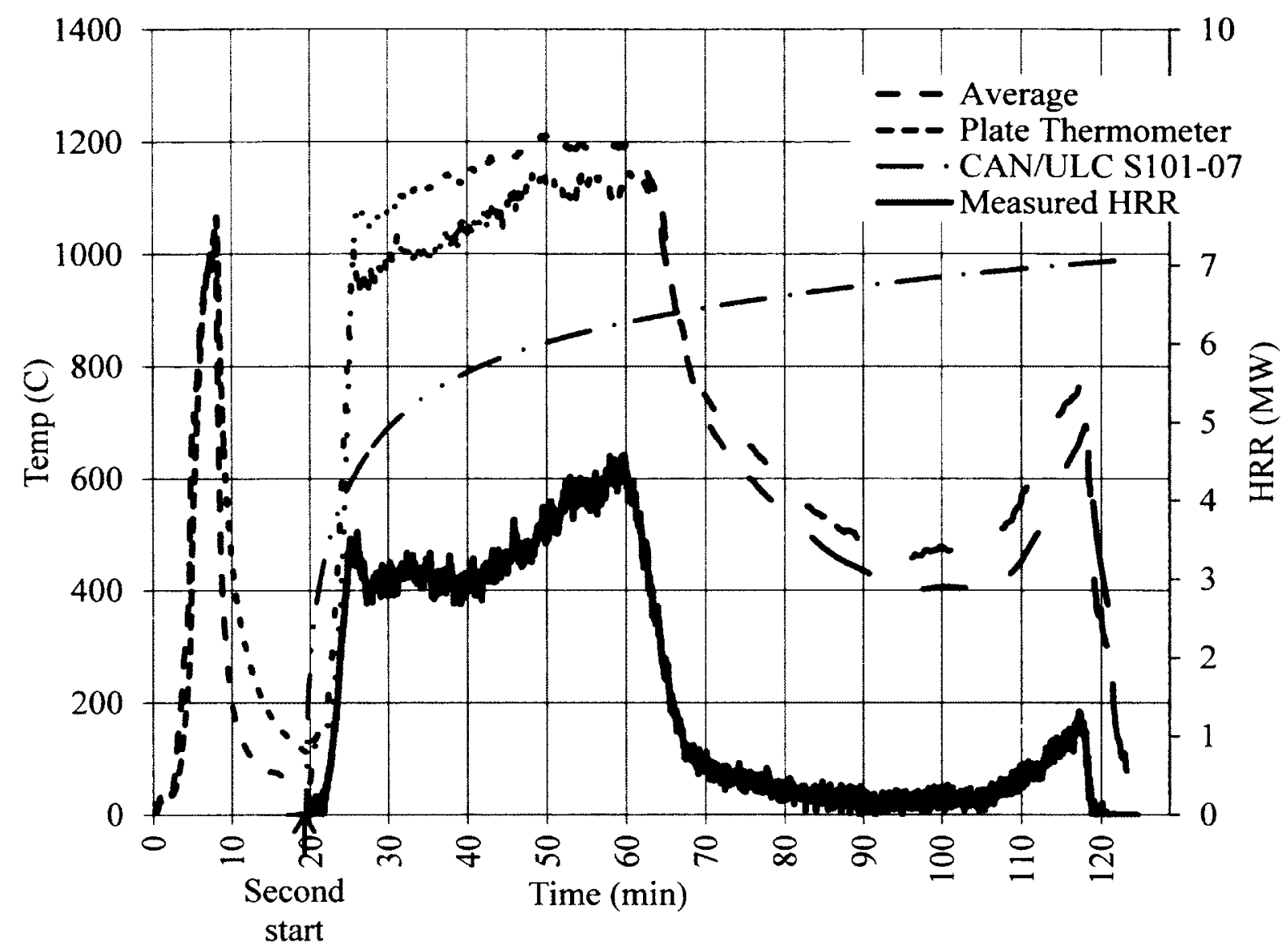

Figure 65 - Comparison of room temperatures and HRR - Test 1

The average temperature at each of the thermocouple trees is presented in Figure 66. The temperatures initially rise together rapidly at flashover for both starts, however higher peaks are experienced at positions 1 and 2 whilst the temperatures at positions 3 and 4 were very similar. After the rapid rise in temperature at flashover (second start) temperatures continued to rise slowly and appeared to stabilize after 50 minutes. 


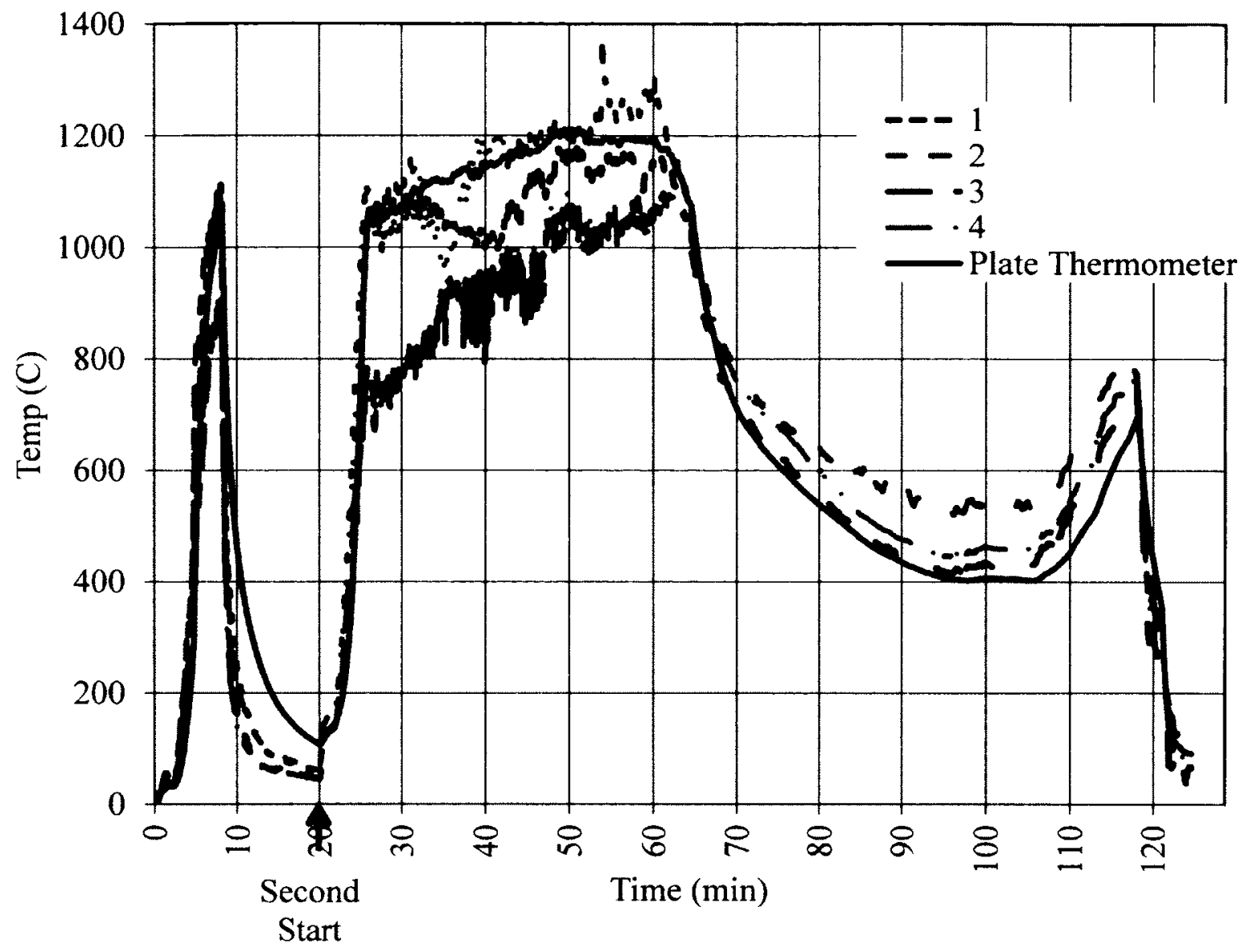

Figure 66 - Thermocouple tree average temperatures - Test 1

The highest temperatures are observed at position 2 closest to the seat of the fire,

which indicates that the thermocouple tree is exposed to the intense combustion occurring as the propane mixes with the incoming fresh air. The consistent difference in temperatures in this case indicates a uniform counterclockwise circular flow of gases in the room in the following order:

1. Fresh air mixes with hot gases in the doorway at position 3 ;

2. Mixture flows through position 4 to the seat of the fire;

3. Propane mixes with the gases with intense combustion occurring as it passes through position 2; 
4. Intensity of combustion decreases as oxygen in consumed and mixing with other gases occurs as it flows through position 1; and

5. Gases flow to position 3 where they exit the room or mix with incoming air and are recirculated in the room.

The variation in temperatures reduces after the propane fire is removed, however when the temperatures begin to stabilize after 90 minutes, TCT2 remains approximately $100^{\circ} \mathrm{C}$ higher than the other positions. At this time, the air movement in the room is greatly reduced and the temperatures are likely influenced more by radiative than convective heat transfer. TCT2, being closer to a corner, has a higher radiative view factor with respect to the boundaries, than the other positions, which may explain the higher temperatures after the propane fire is removed.

The highest temperatures were observed at TCT2 position at the rear of the room $\left(\mathrm{T}_{\max }=1304^{\circ} \mathrm{C} @\right.$ TCT2-16). Thermocouples 2-12 and 2-24 showed higher readings (2$24>1500$ and $2-12>2000$ ) however have been disregarded as spikes appear to indicate some interference. The temperatures measured at the TCT's are presented in Figure 67, Figure 68, Figure 69 and Figure 70. It is clear that the temperatures experienced at TCT2, which was nearest the fire, were higher than the other positions. 


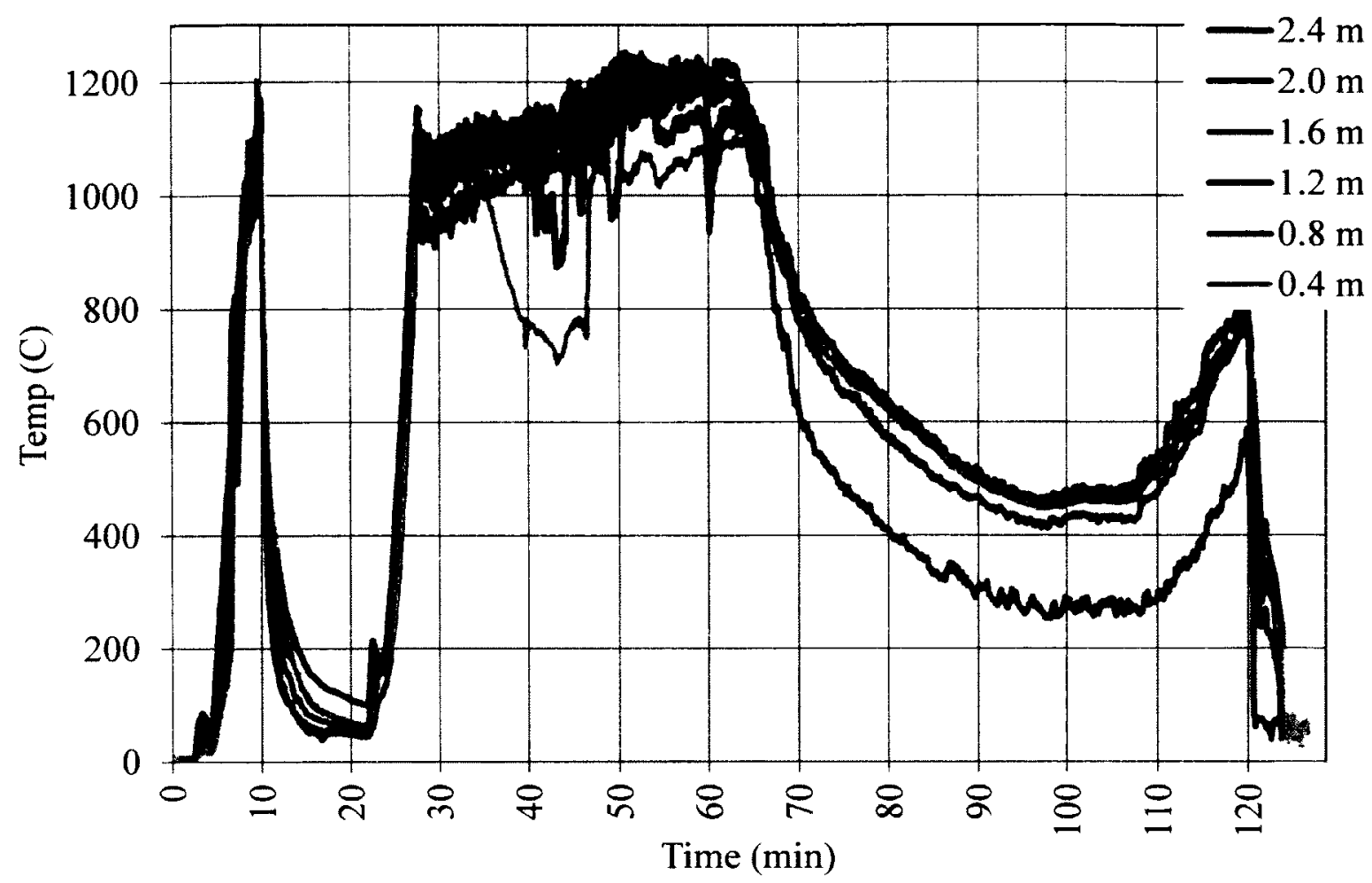

Figure 67 - Thermocouple Tree 1 temperatures - Test 1

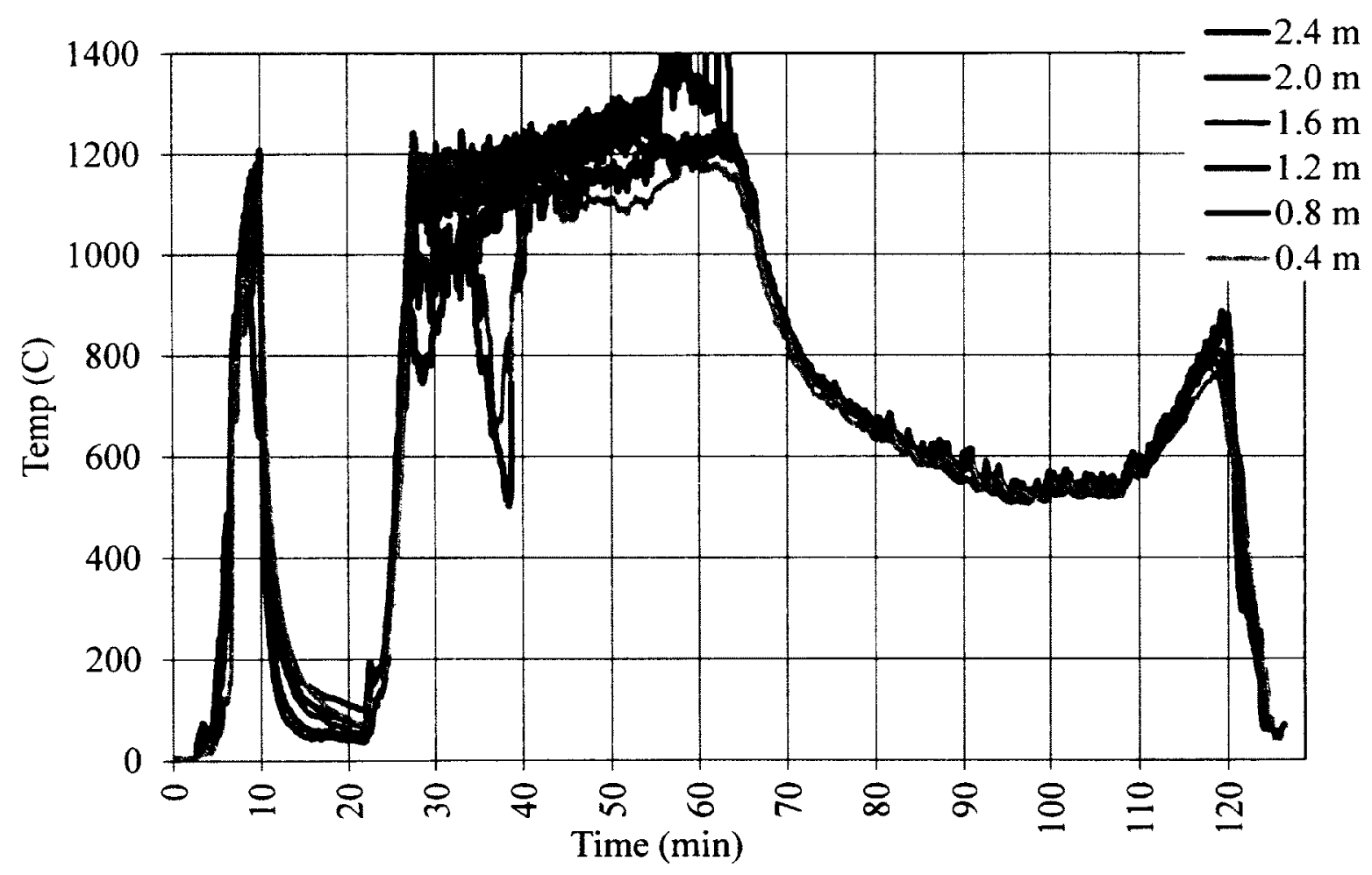

Figure 68 - Thermocouple Tree 2 temperatures - Test 1 


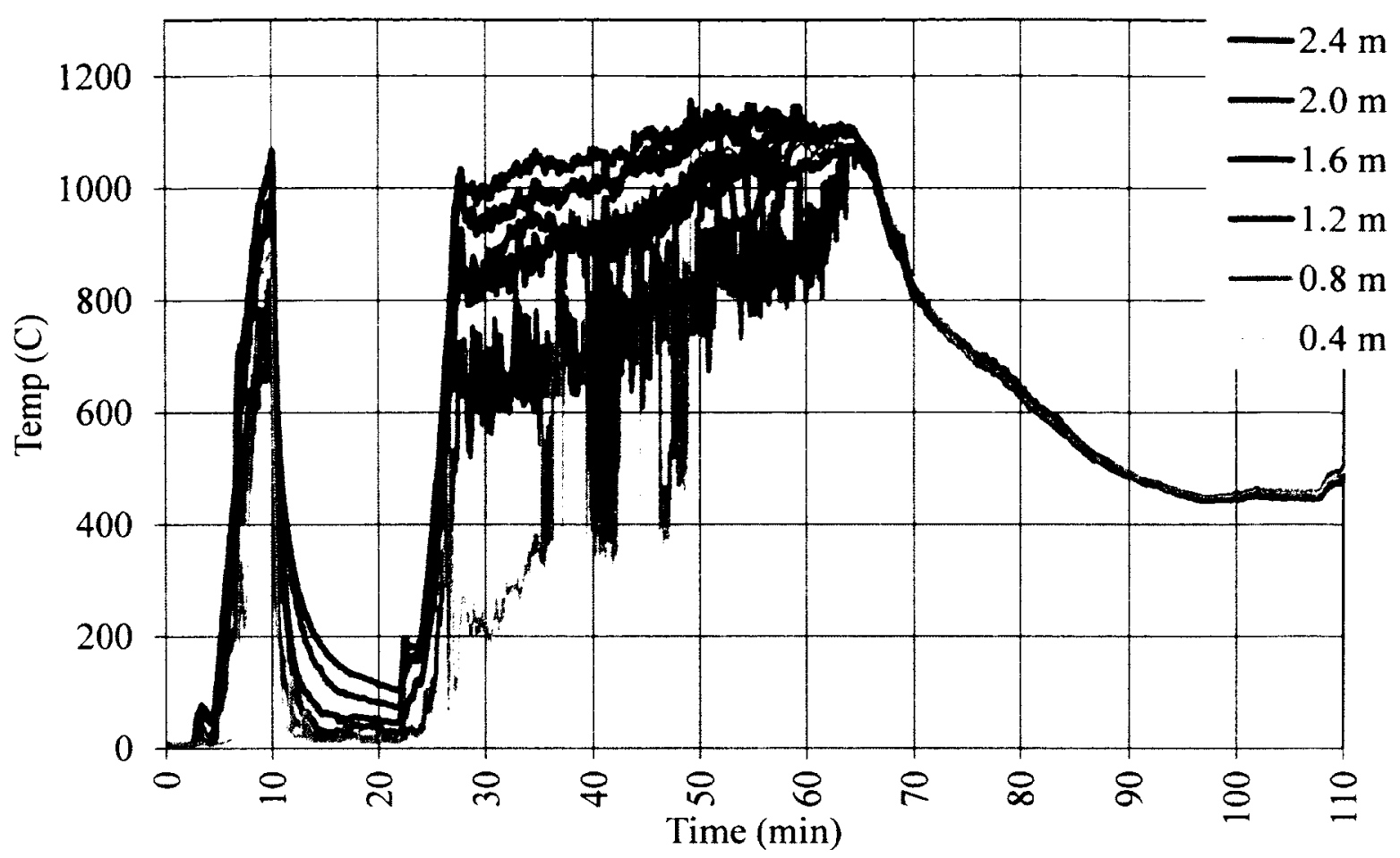

Figure 69 - Thermocouple Tree 3 temperatures - Test 1

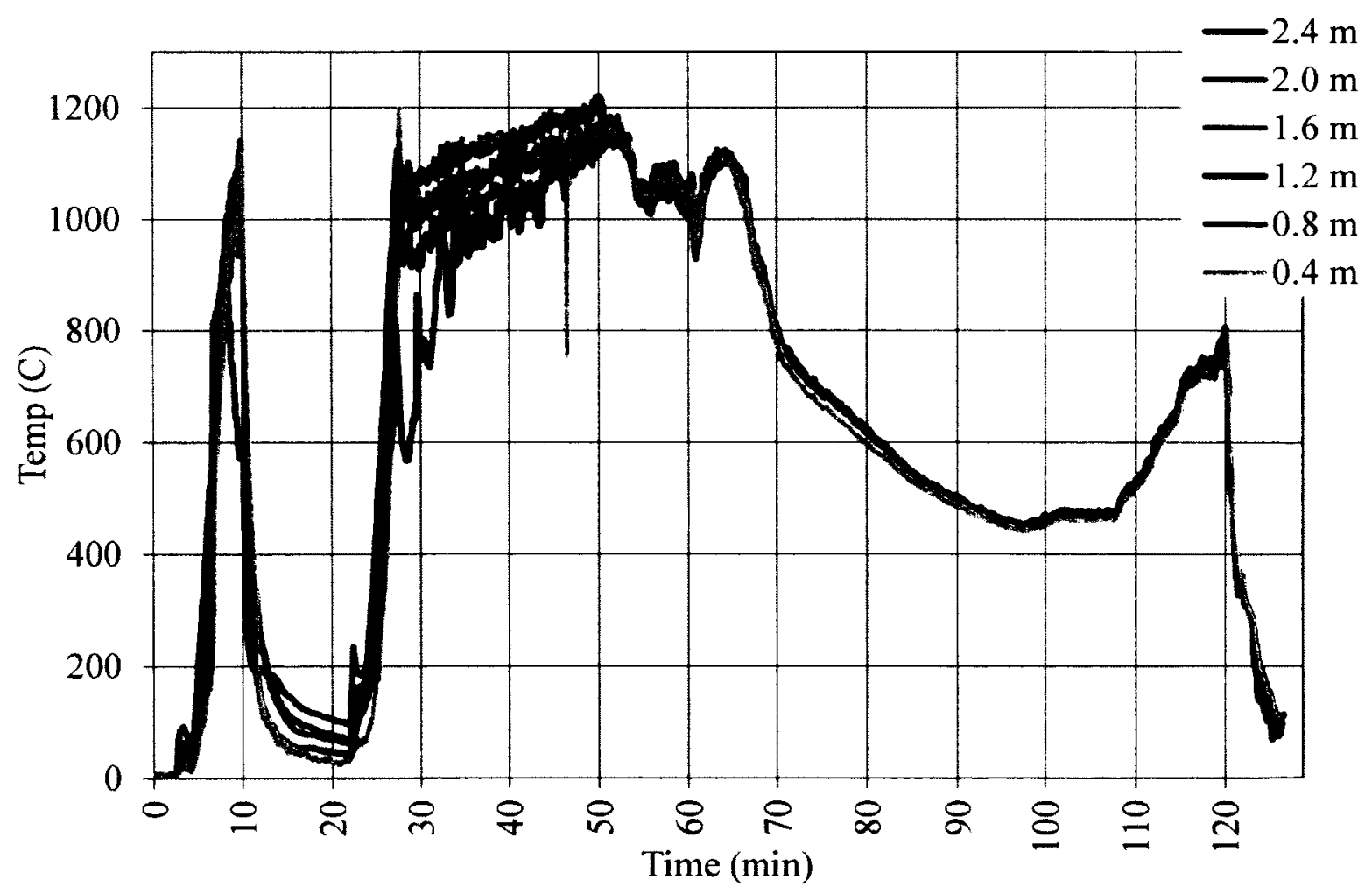

Figure 70 - Thermocouple Tree 4 temperatures - Test 1 


\subsubsection{CLT interface}

The temperatures measured at the interface of the gypsum board protection and the CLT panels are presented in Figure 71 along with the average room temperature. Sharp rises in temperature are observed between 31 and 36 minutes which plateau at approximately $100^{\circ} \mathrm{C}$ as chemically bound water is driven from the gypsum [48]. This occurs in the second layer after the first layer has already failed, first indicated at position $\mathrm{C} 2$, directly above the fire, at approximately 31 minutes. The temperature behind the gypsum begins to increase above $100^{\circ} \mathrm{C}$ once all of the water has been released. The first indication of this is at 41 mins at position $\mathrm{C} 2$.

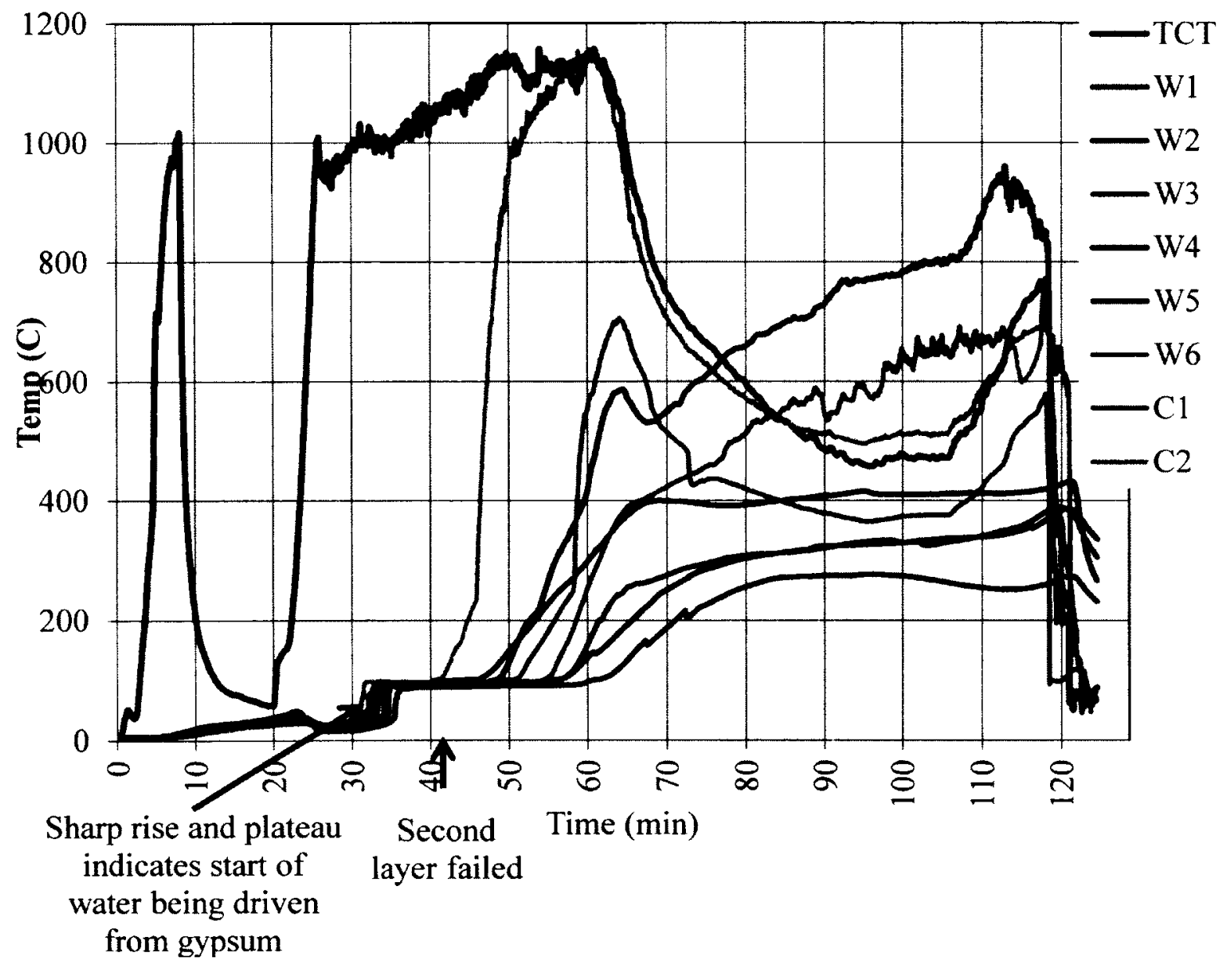

Figure 71-Temperatures at interface of gypsum board protection and CLT panels - Test 1 
After the decay period begins, the room temperature drops, most temperatures within the structure begin to stabilise, however some temperatures continue to increase as observed at positions W4 and W6. This is a result of pyrolysis and smouldering combustion occurring behind the gypsum board protection which remained in place despite having lost its chemically bound water. The effects of this can be seen in Figure 62 where the flames are emerging from the joints between the gypsum board panels and Figure 72 where smouldering combustion was exposed when the protection was removed more than 1 hour after the test was ended and the fire extinguished. This demonstrates that the fire can spread, and continue, behind the insulation which must be considered during the post fire period.

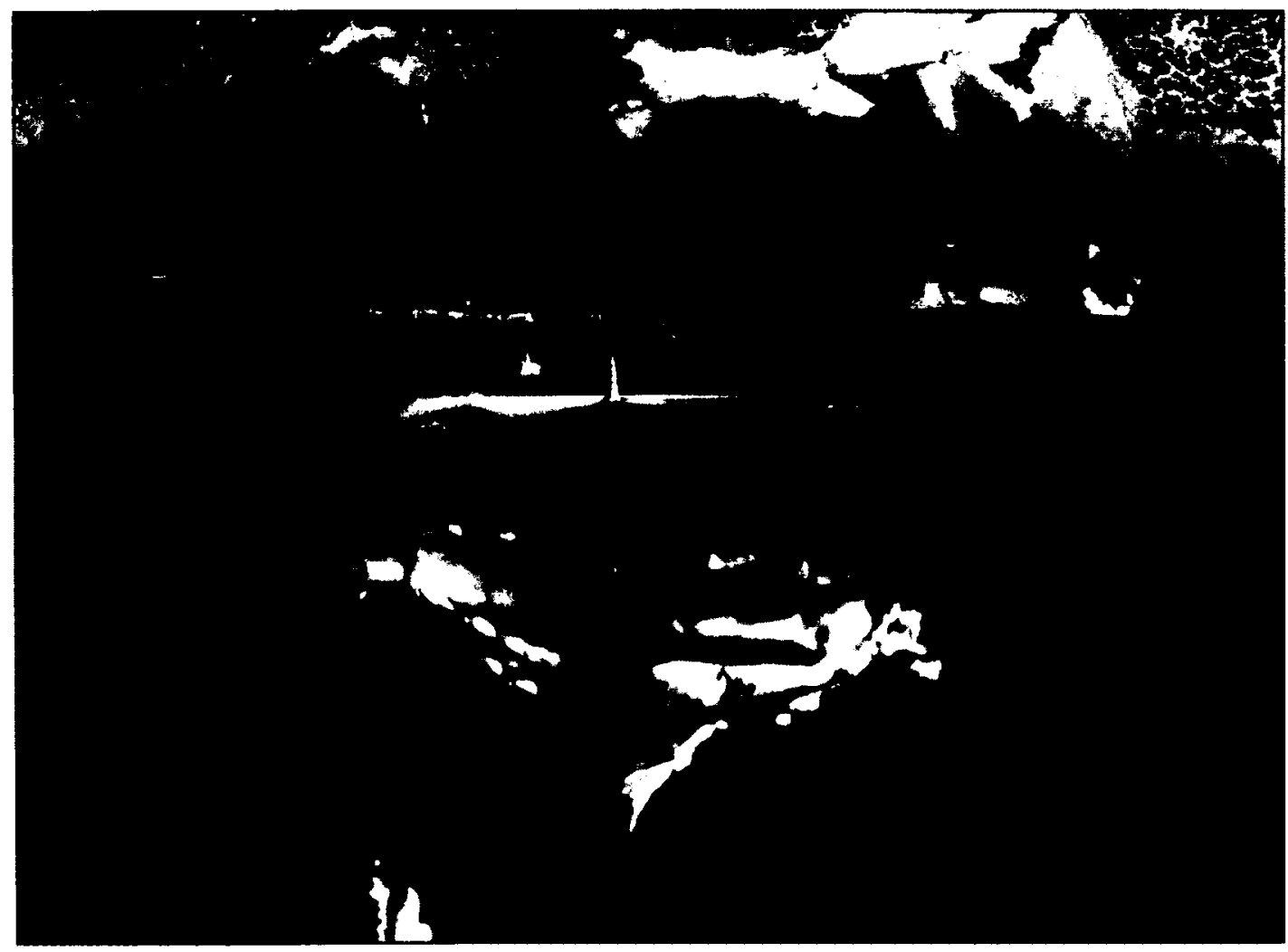

Figure 72 - Charring discovered when removing gypsum lining $>1 \mathrm{hr}$ after end of Test 1 


\subsubsection{Joint Temperatures}

Despite there being no sealant used in the test the joints temperatures presented in Figure 73 did not reach the level at which pyrolysis $\left(200^{\circ} \mathrm{C}\right)$ or charring begins $\left(300^{\circ} \mathrm{C}\right)$. The maximum temperatures were experienced at the rear and ceiling joints, the nearest to the fire, and were observed after the most intense period of the fire.

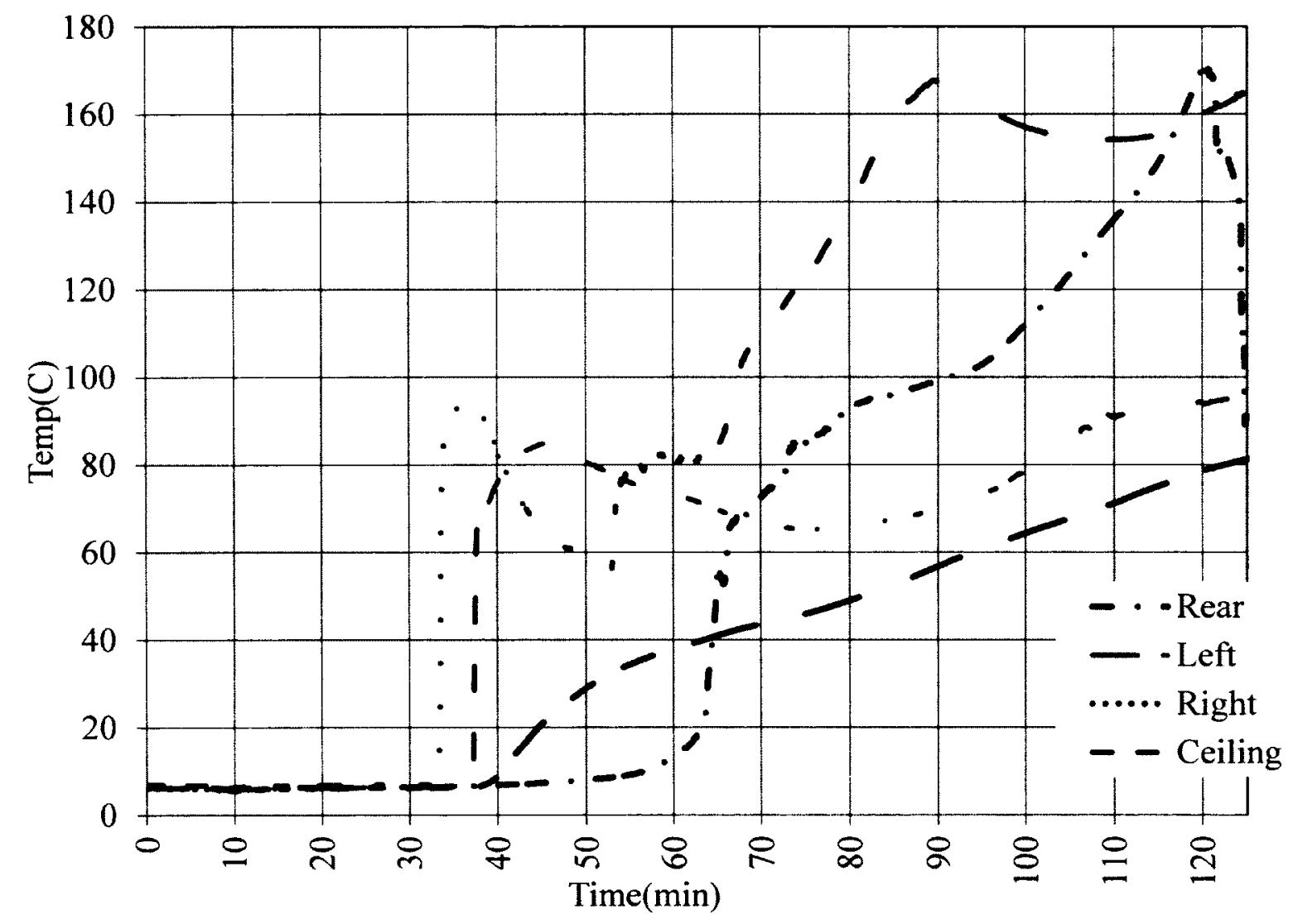

Figure 73 - Joint temperatures - Test 1

A record of events that took place is presented in Table 10, these observations are sourced from video, photographic and test records. 
Table $10-$ Record of events - Test 1

\begin{tabular}{|l|l|}
\hline & Event \\
\hline $00: 00$ & Fuel on all burners \\
\hline $02: 05$ & Propane flow 'fast' fire growth commenced \\
\hline $02: 10$ & Light smoke visible exiting door approx 25\% height \\
\hline $03: 09$ & Moderate smoke visible exiting door approx 50\% height \\
\hline $03: 40$ & $1.055 \mathrm{MW}$ propane flow reached \\
\hline $04: 57$ & Flames exiting door and room in flashover \\
\hline $08: 00$ & Fuel off - No HRR readings collected \\
\hline $19: 41$ & Test Restarts - Fuel on all burners \\
\hline $21: 36$ & Propane flow 'fast' fire growth commenced \\
\hline $23: 04$ & Dark smoke visible exiting door $~ 1 / 3$ height \\
\hline $24: 06$ & HRR exceeds $1.055 \mathrm{MW}$ \\
\hline $26: 23$ & Peak of 4MW reached, reduction to $3 \mathrm{MW}$ commenced \\
\hline $36: 26$ & Steam observed coming from wood and joints \\
\hline $40: 10$ & First layer fails above fire(indication) \\
\hline $43: 00$ & CLT panels begins to become involved in the fire \\
\hline $48: 16$ & Second layer fails above fire(indication) \\
\hline $54: 23$ & Propane flow reduction commences \\
\hline $61: 21$ & Peak HRR of 4.59 MW - HRR begins to decay \\
\hline $64: 27$ & Flames visible coming from between GB on walls.(1100C) \\
\hline $64: 27$ & Back wall lining visibly failed, CLT panel burning \\
\hline $64: 03$ & CLT contribution peak HRR(2.8MW) \\
\hline $68: 30$ & Fuel off \\
\hline $69: 07$ & Significant reduction in flaming (850C) \\
\hline $76: 34$ & Flaming mostly stopped (675C) \\
\hline $78: 30$ & HRR drops below 1.055 MW \\
\hline $102: 29$ & Smouldering combustion visible(475deg) \\
\hline $107: 29$ & Fire begins to grow with falling and hanging CLT elements(500C) \\
\hline $115: 00$ & Second flashover occurs with ceiling alight and flames exiting room (625C) \\
\hline $118: 00$ & HRR exceeds 1.055 MW \\
\hline $119: 00$ & Fire extinguished \\
\hline & \\
\hline
\end{tabular}




\subsection{Test 2 - Protected room with furniture fire}

Test 2 was conducted in the morning of 16 May 2012. The aim of the test was to observe the performance of the CLT panels in a protected room, the same protection as in Test 1, using furniture as the fire source.

The burner was ignited at 11:28 AM with an ambient temperature of $17.5^{\circ} \mathrm{C}$. After 1:27 minutes, the smoke detector activated, the visibility at this time was very good. The fire began to catch on the bedding and the burner was removed at 2:24 minutes when visibility was observed to be degrading to hazy. The fire began to grow across the pillows on the bed and flames can be seen in Figure 74 at approximately 0.5 metres in height, sparks were visible travelling upwards from the bed. At 4:06 minutes at which time the HRR was less than $0.2 \mathrm{MW}$, the sprinkler (set to activate at $60^{\circ} \mathrm{C}$ ) activated, releasing a small amount of pressurised water into the room. At that time the environment still appeared tolerable for escape and had the sprinkler been connected to a water supply, the fire would likely have been controlled at that time with no further growth. 


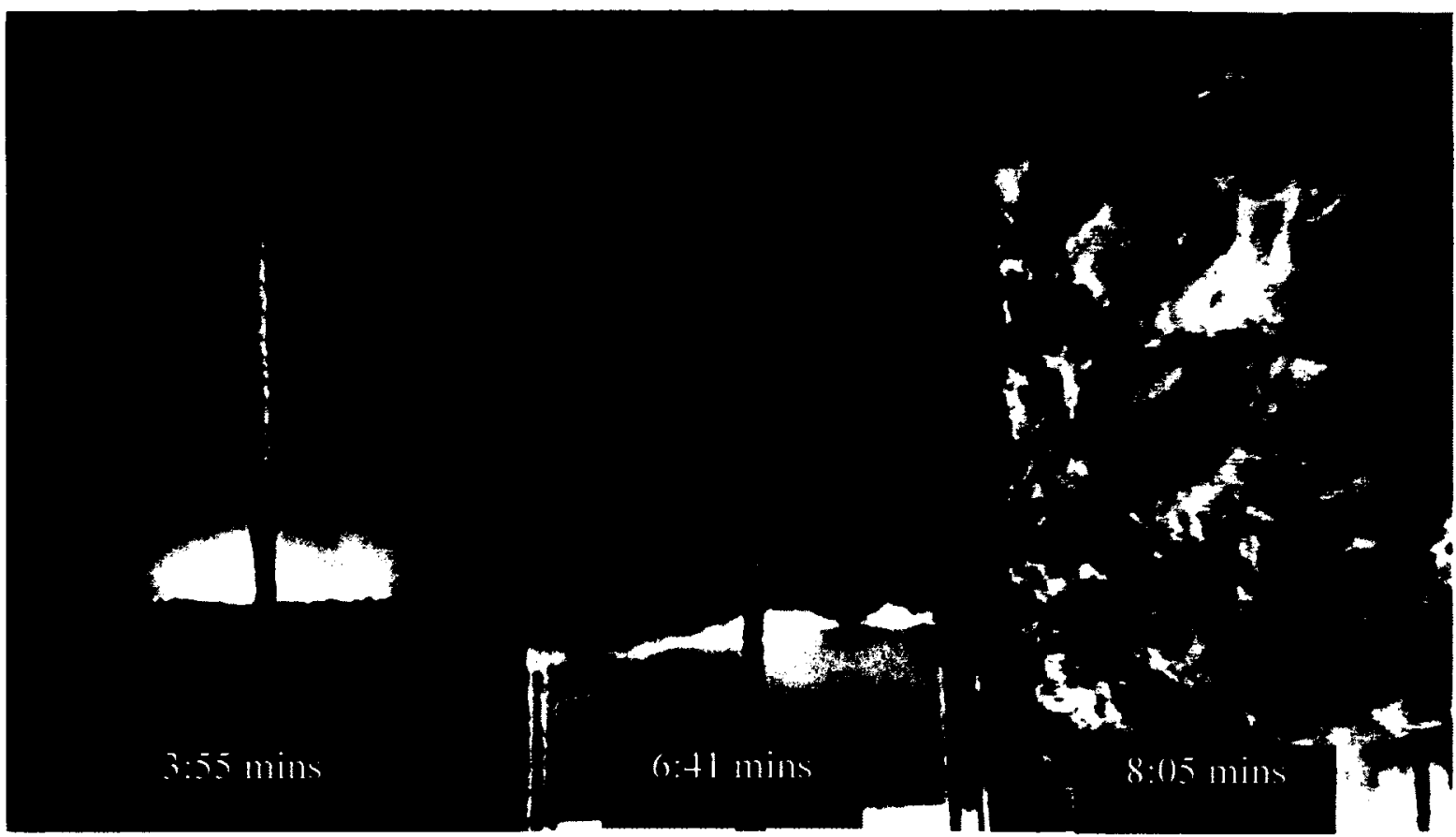

Figure 74 - Fire development in furniture fire - Test 2

A dark smoke layer began to develop reducing visibility and smoke started to exit the room at 4:53 minutes, at which time the flames on the bed were approximately 1 meter high. At 5:32 the fire had spread across most of the bed and the smoke layer, now thick and black with almost no visibility began to descend towards the bed. Flaming and melting material was seen dripping onto the hardwood floor at the head of the bed at $6: 10$ minutes and flames were observed exiting the room at 6:41, Figure 74 , as the smoke layer reached the bed. Flames crossed the surface of the footboard at $6: 59$ minutes and by $7: 30$ minutes all items in the room appeared to be involved in the fire with significant flaming and black smoke exiting the room. Sustained bright orange flaming was observed exiting the doorway at 8:05 minutes.

The HRR graph presented in Figure 75 shows a fire growth rate comparable to that of the ultra-fast $\mathrm{t}^{2}$ discussed in Chapter 2.6 which reaches $1.055 \mathrm{MW}$ at 5:48 minutes and continues to increase to a peak of $5.49 \mathrm{MW}$ at 8:06 minutes. At this point all items in 
the room appeared involved in the fire and intense flaming was observed outside the room. The fire burned intensely for a short period before reducing in intensity and then noticeably increased again when the bed collapsed. The fire entered the decay period after approximately 18 minutes. Early in the test and before flashover, thick black smoke was observed exiting the room. Once flashover occurred, the amount of smoke decreased, however a large amount of smoke was still observed, more so than in the propane fire in Test 1 which indicates a larger amount of incomplete combustion occurring.

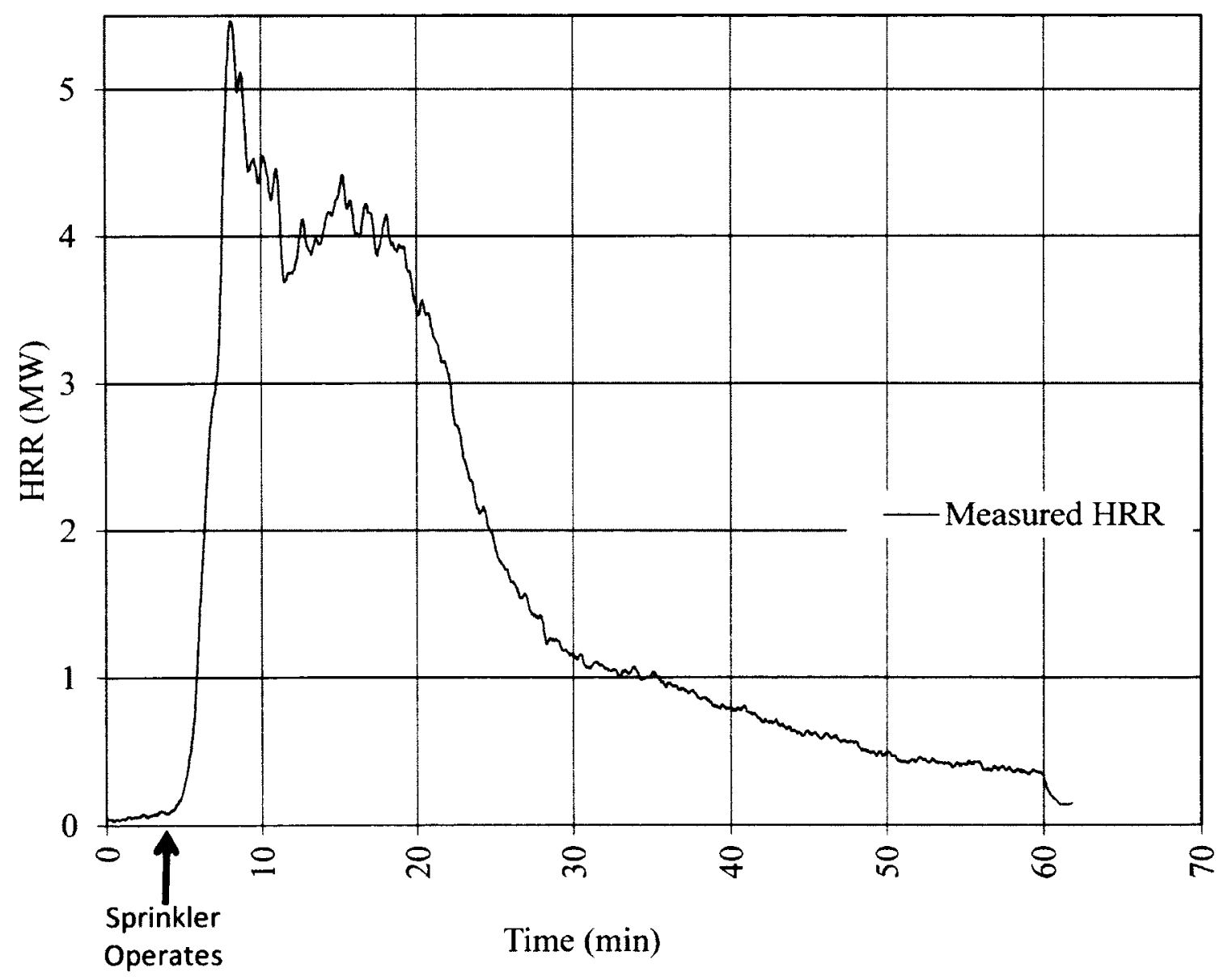

Figure 75 - Heat release rate - Test 2 
Figure 76 shows the room as the fire decays. At 22:45 minutes, most of the flaming is contained within the room and by $32: 45$ most of the flaming in the room is out. At this time the HRR also drops below $1.055 \mathrm{MW}$. The protection in the room remains largely in place with the exception of a panel above the location of the bed which failed at 37:20 minutes. The HRR continued to decay at a steady rate until the test ended and the room was cooled with water after 60 minutes.

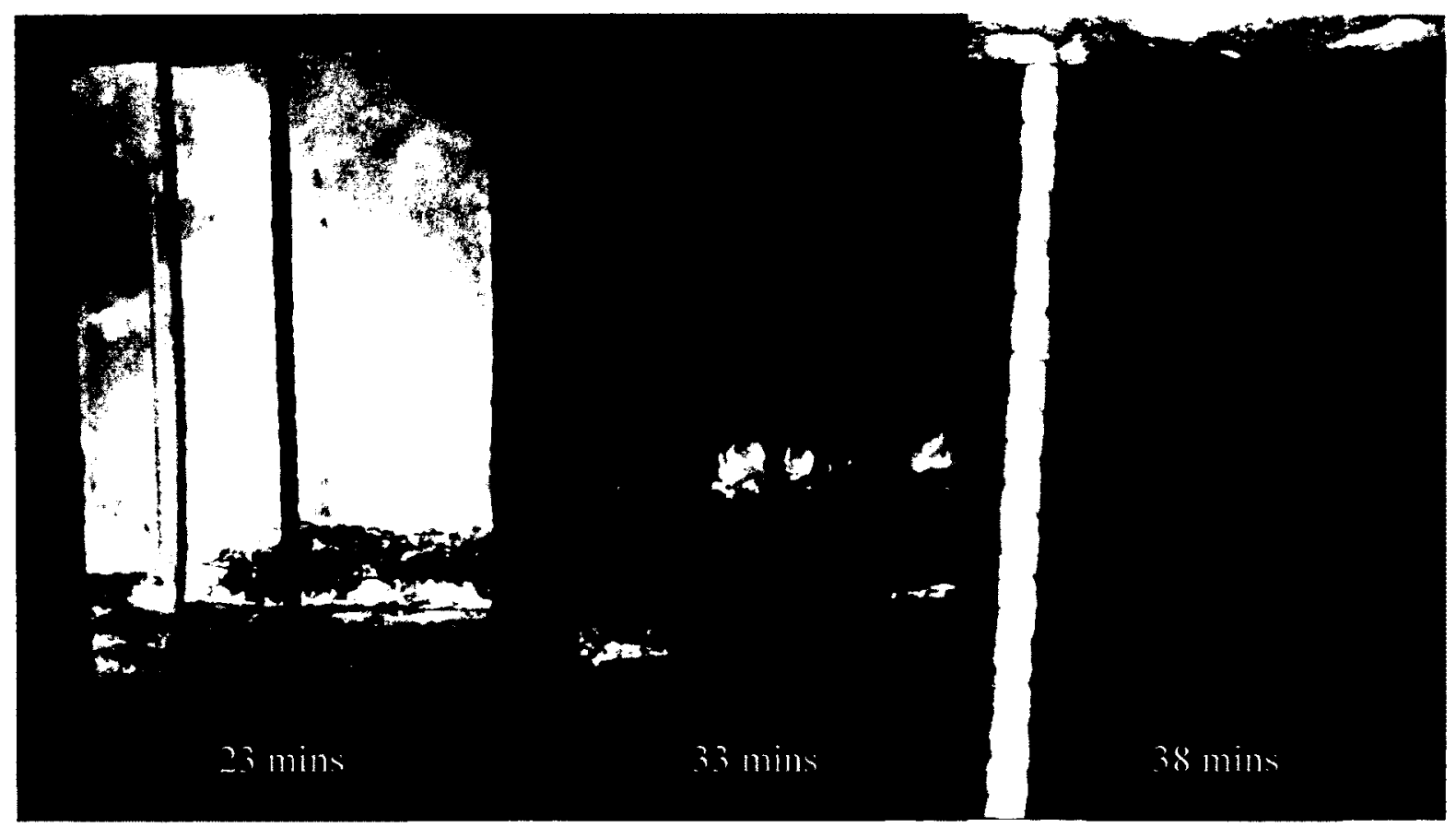

Figure 76 - Fire decay - Test 2

The gypsum board protection remained in place for the duration of the test. When removed after the test, no charring was observed at any point on the surface indicating that the CLT panels were not involved in the fire. The energy released by the fire was 379 $\mathrm{MJ} / \mathrm{m}^{2}$ for the period 0:00 to $60: 00$ minutes, equivalent to $69 \%$ of the estimated fuel load of the room contents. 


\subsubsection{Temperatures}

Temperature measurement data was lost in a system crash at the end of the test, however some observations were recorded. The peak plate thermometer temperature was observed at approximately $1100^{\circ} \mathrm{C}$ after 19 minutes. The peak temperatures observed at the CLT gypsum interface was $161^{\circ} \mathrm{C}$ at position $\mathrm{C} 2$ above the location of the bed and $122^{\circ} \mathrm{C}$ and $109^{\circ} \mathrm{C}$ at positions $\mathrm{W} 2$ and $\mathrm{W} 4$ respectively. The maximum joint temperature was measured at the ceiling panel joint at $72^{\circ} \mathrm{C}$. No visible gases were observed escaping from joints or the structure during Test 2 .

A record of events that took place is presented in Table 11, these observations are sourced from video, photographic and test records.

Table 11 - Record of events - Test 2

\begin{tabular}{|l|l|}
\hline & Event \\
\hline $00: 00$ & Test started, burner ignited \\
\hline $01: 27$ & Smoke detector activation 1:27 \\
\hline $02: 24$ & $\begin{array}{l}\text { Burner gas off. Visibility reducing, some smoke visible exiting } \\
\text { opening. }\end{array}$ \\
\hline $03: 55$ & Fire increasing, some airborne sparks visible, visibility hazy. \\
\hline $04: 06$ & Sprinkler activates \\
\hline $04: 53$ & Smoke layer visible, smoke exiting room, flames 1 m high \\
\hline $05: 32$ & Heavy black smoke layer. Fire over most of bed \\
\hline $05: 48$ & HRR exceeds 1.055 MW \\
\hline $06: 10$ & Flaming melted material visible under bed, smoke layer descending \\
\hline $06: 28$ & Flames visible in smoke layer at entrance \\
\hline $06: 41$ & Smoke layer at top of bed, flames exiting room \\
\hline $06: 59$ & Footboard surface ignites \\
\hline $07: 30$ & All items in room appear to be burning(Flashover?) \\
\hline $07: 34$ & First smoke ignition visible outside room \\
\hline $08: 05$ & Continuous flaming of gas flow observed outside room(Flashover?) \\
\hline $11: 18$ & Footboard again visible, intensity dropping \\
\hline $12: 16$ & Bed collapses, intense flaming observed again \\
\hline $17: 14$ & Fire intensity decreasing. Flaming visible on floor \\
\hline $21: 54$ & Ceiling visible \\
\hline
\end{tabular}




\begin{tabular}{|l|l|}
\hline $22: 45$ & Most flaming contained within room \\
\hline $32: 44$ & Most flaming out \\
\hline $32: 54$ & HRR drops below 1.055 MW \\
\hline $36: 00$ & Max Room Temp drops below 650C (min room temp 400C) \\
\hline $37: 10$ & Gypsum panel on ceiling falls \\
\hline $39: 30$ & Max Room Temp drops below 600C (min room temp 340C) \\
\hline 53:00 & Max Room Temp at 410C (min room temp 200C) \\
\hline
\end{tabular}

\subsection{Test 3 - Unprotected room with propane fire}

Test 3 was conducted in the morning of 8 of June 2012. The aim of the test was to observe the involvement of the exposed CLT panels in a room fire using a controlled propane fire.

The propane burners were ignited at 10:50 AM with an ambient temperature of $16^{\circ} \mathrm{C}$. At 1:05 minutes after the burners were ignited the propane flow, presented in Figure 77 , was increase at a fast fire growth rate to a peak of $3 \mathrm{MW}$, as used in Test 1. The measured HRR followed the fast fire growth rate until it reached $0.811 \mathrm{MW}$ at 4:25 after which the growth rate increased sharply above that of the propane flow, indicating that the CLT panels were becoming involved in the fire. 


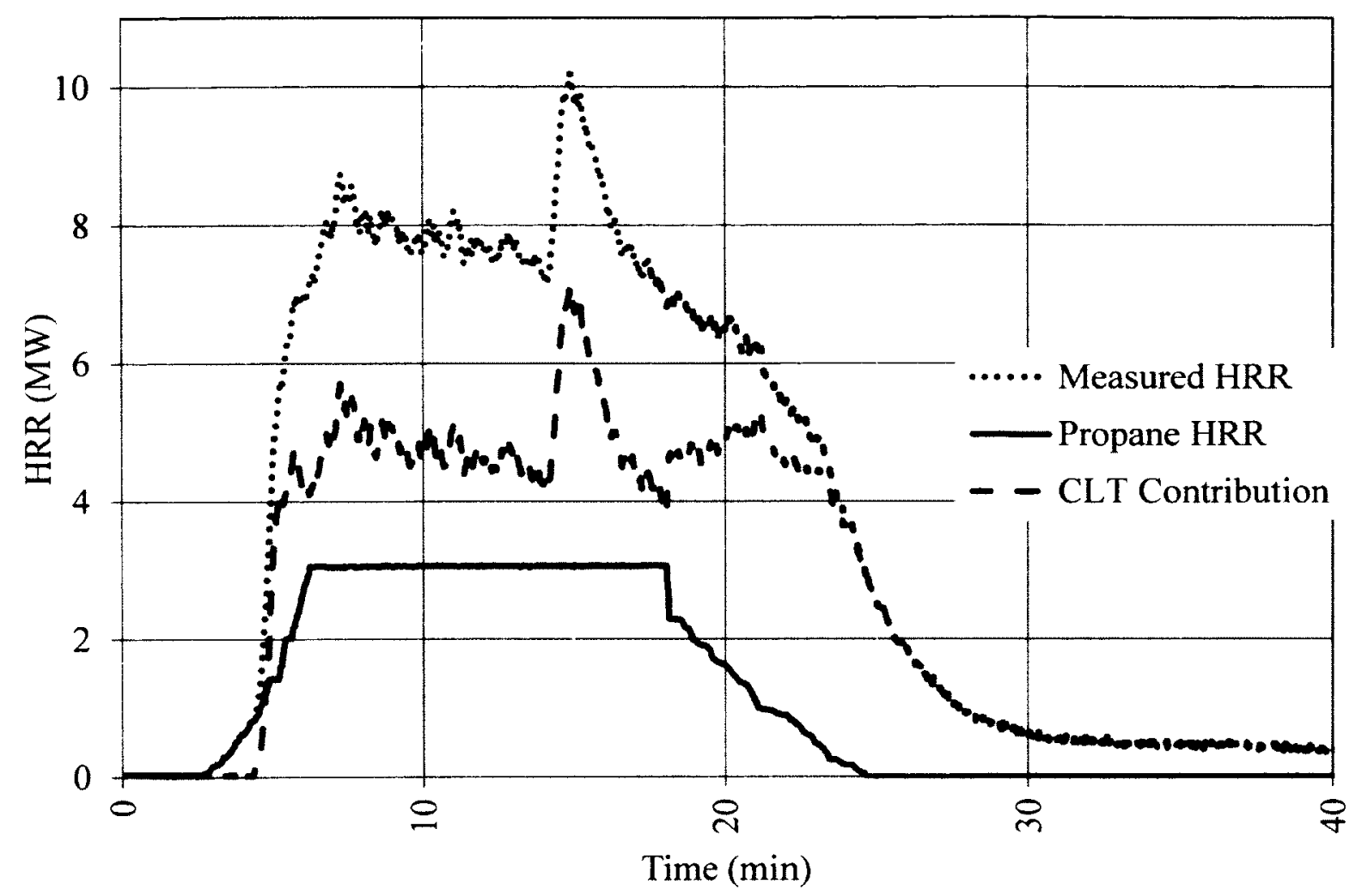

Figure 77 - Heat release rate - Test 3

The first flames were observed on the surface of the CLT panels in Figure 78 at 4:39 minutes, 11 seconds later all exposed CLT panels in the room appeared to be involved in the fire and a further seven seconds later the room was in full flashover with flames extending from the doorway. 


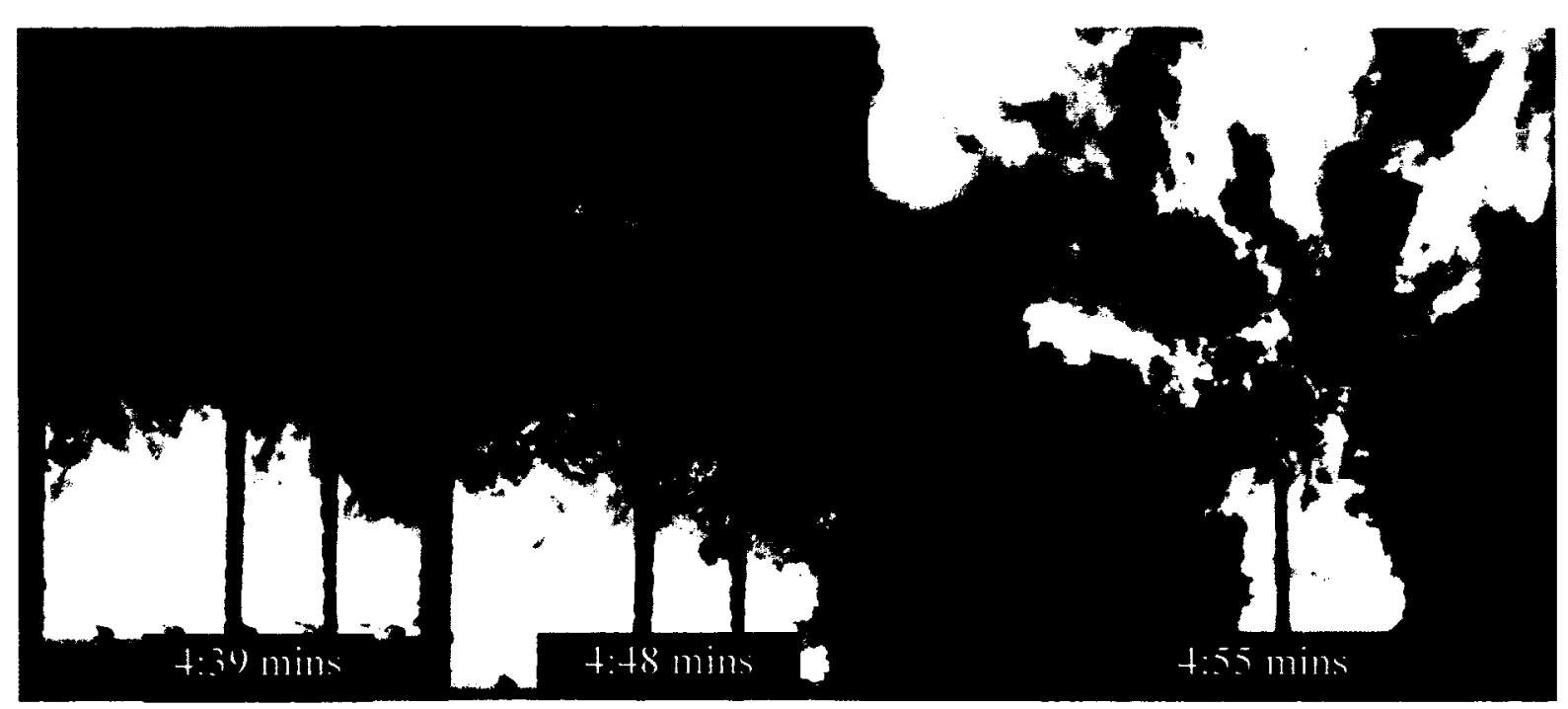

Figure 78-CLT panels became involved in the fire initiating flashover - Test 3

The HRR, as seen in Figure 77, exceeded the ventilation limit reached a peak of 8.75 MW, indicating that a large amount of combustion had occurred outside the room, and began a slow decay.

A large spike in HRR at approximately 15 minutes, shown in Figure 77 is the result of an increase in the speed of the extraction fans to remove a buildup of smoke in the tunnel upstream of the test. The higher flow rate and concentration of smoke passing the sensors whilst the buildup cleared resulted in a spike in the calculated HRR. The magnitude of the spike is disregarded for this test, however the total area under the graph is relevant for analysis as it represents the energy released (oxygen consumed) during the test.

At 17:00 minutes the propane decay was initiated. Despite a sharp drop, no significant change was noticed in the CLT contribution to HRR until 21:00 minutes when it entered a period of decay and the flaming outside the room began to subside. The propane was completely shut off at 24:50 minutes and the flaming continued to subside until only glowing combustion was observed in the room after 29:00 minutes. The 
glowing combustion is shown in Figure 79 and is notable near the floor and in the corners of the room. The cement board floor, having a higher radiative thermal mass than char, and the higher radiative configuration factors experienced in corners, resulting in higher incident radiation in these areas, would explain this observation. The effect of this can also be seen in Figure 80 where the thermocouple tree temperatures has an inverted gradient with the highest temperature at the lowest point during the decay period. HRR drops below 1.055 $\mathrm{MW}$ at 27:45 minutes and begins to stabilise settling at approximately 0.45 MW after 35:00 minutes.

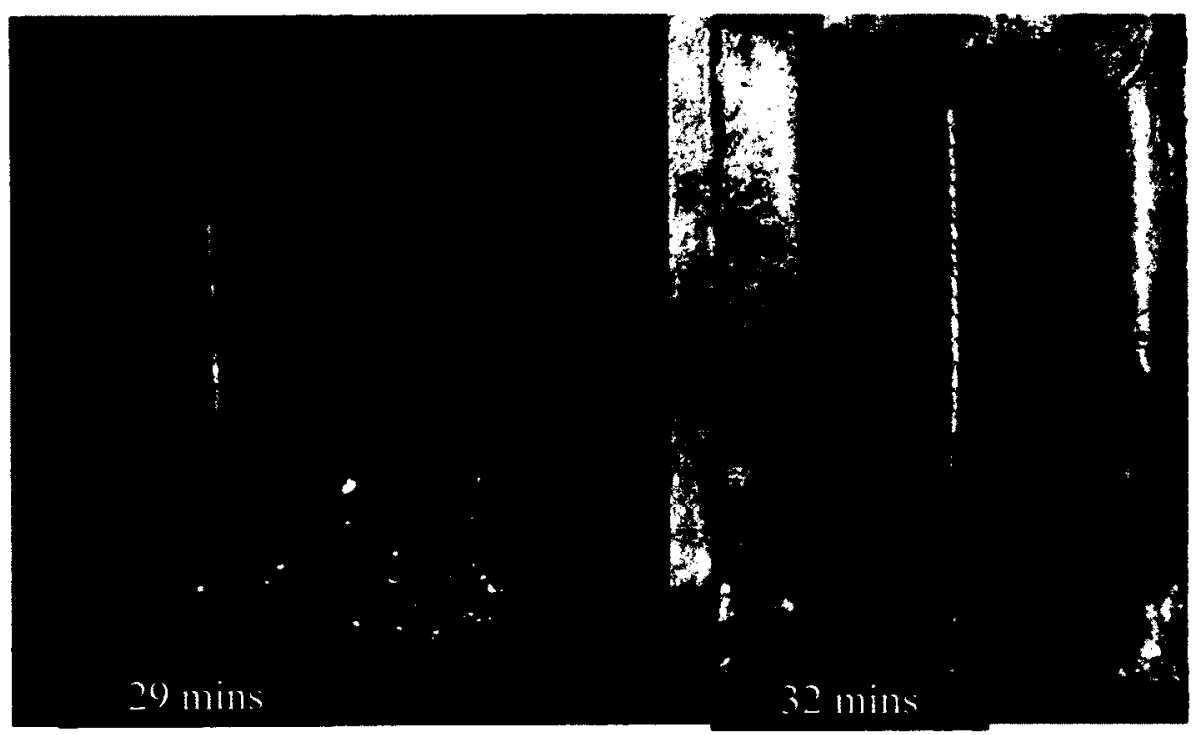

Figure 79 - Glowing combustion observed as flaming ends (left) and as the room cools (right) - Test 3 


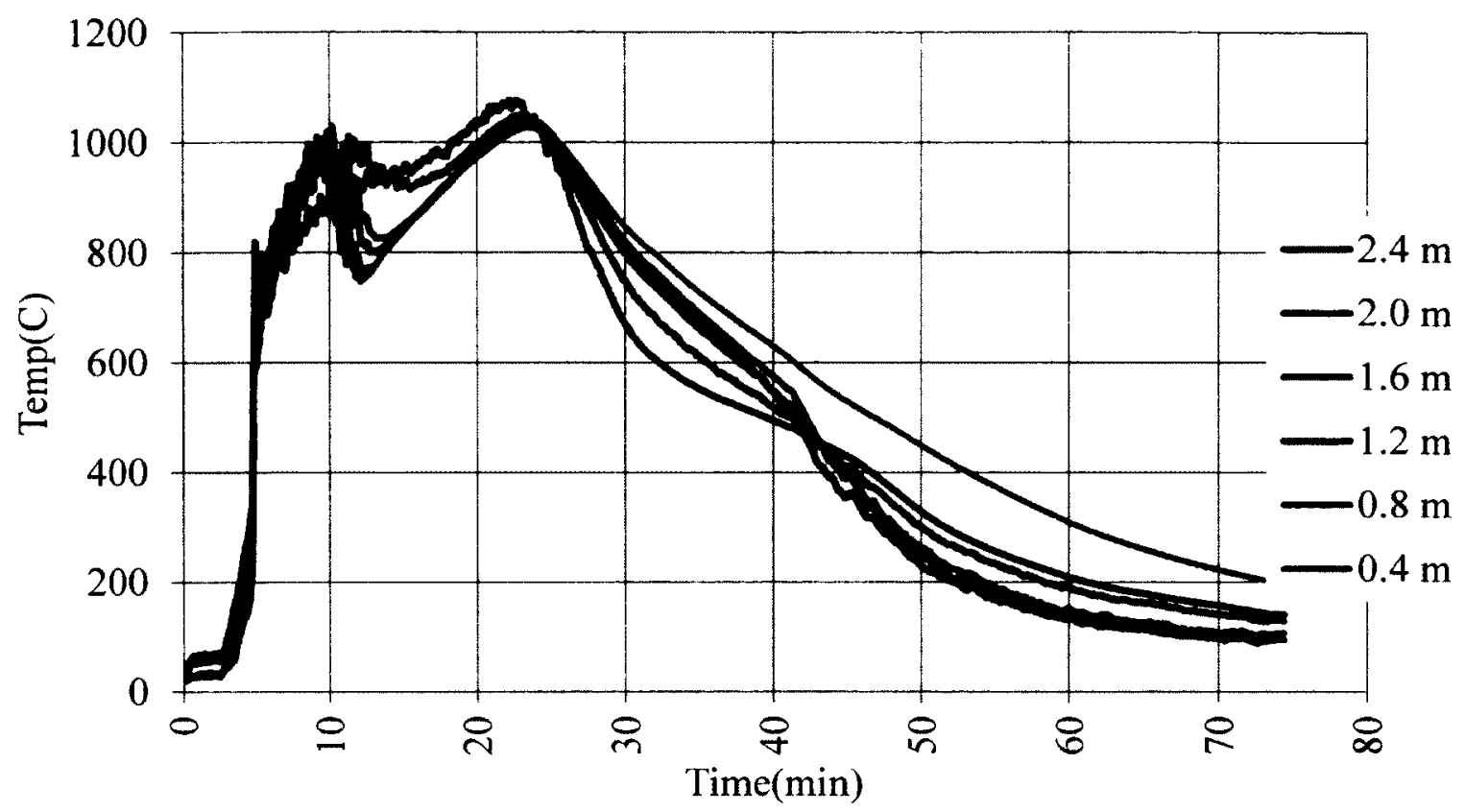

Figure 80 - Thermocouple Tree 1 temperatures - Test 3

Some localised flaming was observed at 58 minutes where some minor

delamination was observed, however this was sporadic and unsustained. The room was cooled with water after 60 minutes.

\subsubsection{CLT Contribution to HRR}

The CLT contribution to HRR shown in Figure 77 rises rapidly from 0 at 4:24 minutes to $4 \mathrm{MW}$ at 5:15 minutes after which the growth rate decreases and reaches a peak of $5.71 \mathrm{MW}$ at 7:20 minutes. The HRR then drops away settling at approximately 4.5 $\mathrm{MW}$, indicating uniform charring and pyrolysis of all the surfaces, until entering a decay period at 23:00 minutes at which point the decreasing propane HRR is at 0.48 MW.

A summary of the energy released during the test is presented in Table 12. The total energy released by the propane fire was $182 \mathrm{MJ} / \mathrm{m}^{2}$ and the CLT contribution was $408 \mathrm{MJ} / \mathrm{m}^{2}$. The CLT panels contributed more than twice as much energy in this case, 
most of which is unable to be released in the compartment posing a considerable hazard which may occur locally, or remotely through transport of the products.

Table 12 - Energy released during Test $3\left(\mathrm{MJ} / \mathrm{m}^{2}\right)$

\begin{tabular}{|c|c|c|c|}
\cline { 2 - 4 } \multicolumn{1}{c|}{} & Propane & CLT & Total \\
\hline Test 3 & 182 & 408 & 590 \\
\hline
\end{tabular}

\subsubsection{Temperature}

Similar to the Test 1 , the average room temperature shown in Figure 81 rises quickly at flashover, however the growth rate slows noticeably at $700^{\circ} \mathrm{C}, 300^{\circ} \mathrm{C}$ below that in Test 1 , before rising to a peak of $963^{\circ} \mathrm{C}$ at $09: 56$ minutes. This is followed by a drop in temperature, possibly due to poor ventilation, before increasing again to a peak of $982^{\circ} \mathrm{C}$ at $24: 06$ minutes. The plate thermometer peaks at $1140^{\circ} \mathrm{C}$ at $21: 00$ minutes and does not experience a drop in temperature, this may be due to the proximity of the measuring point to the room walls. 


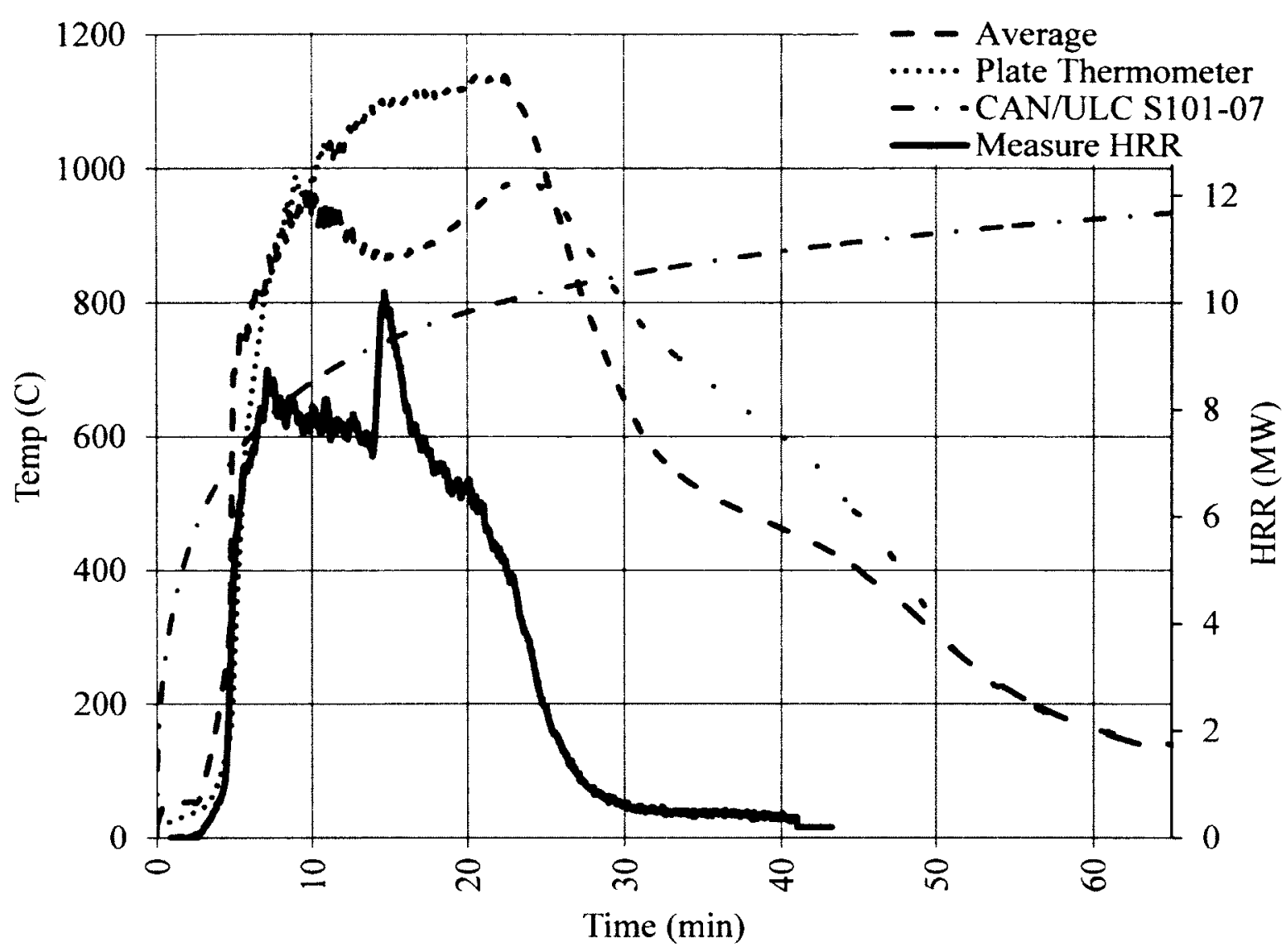

Figure 81 - Plate Thermometer and Average room temperatures showing HRR Test 3

The temperatures for each of the thermocouple tree measuring points are presented in Figure 80, Figure 82, Figure 83 and Figure 84. After flashover, the temperatures continue to rise, however they drop soon after most noticeably at points closest to the floor. These drops are not observed at the highest measuring points ( 2.4 metres) which, similar to the plate thermometer, may be related to the close proximity to the structure, which will be further discussed later in this section.

After the drops are observed, the temperatures at each location begin to group together at approximately the same time that HRR begins to decay. 


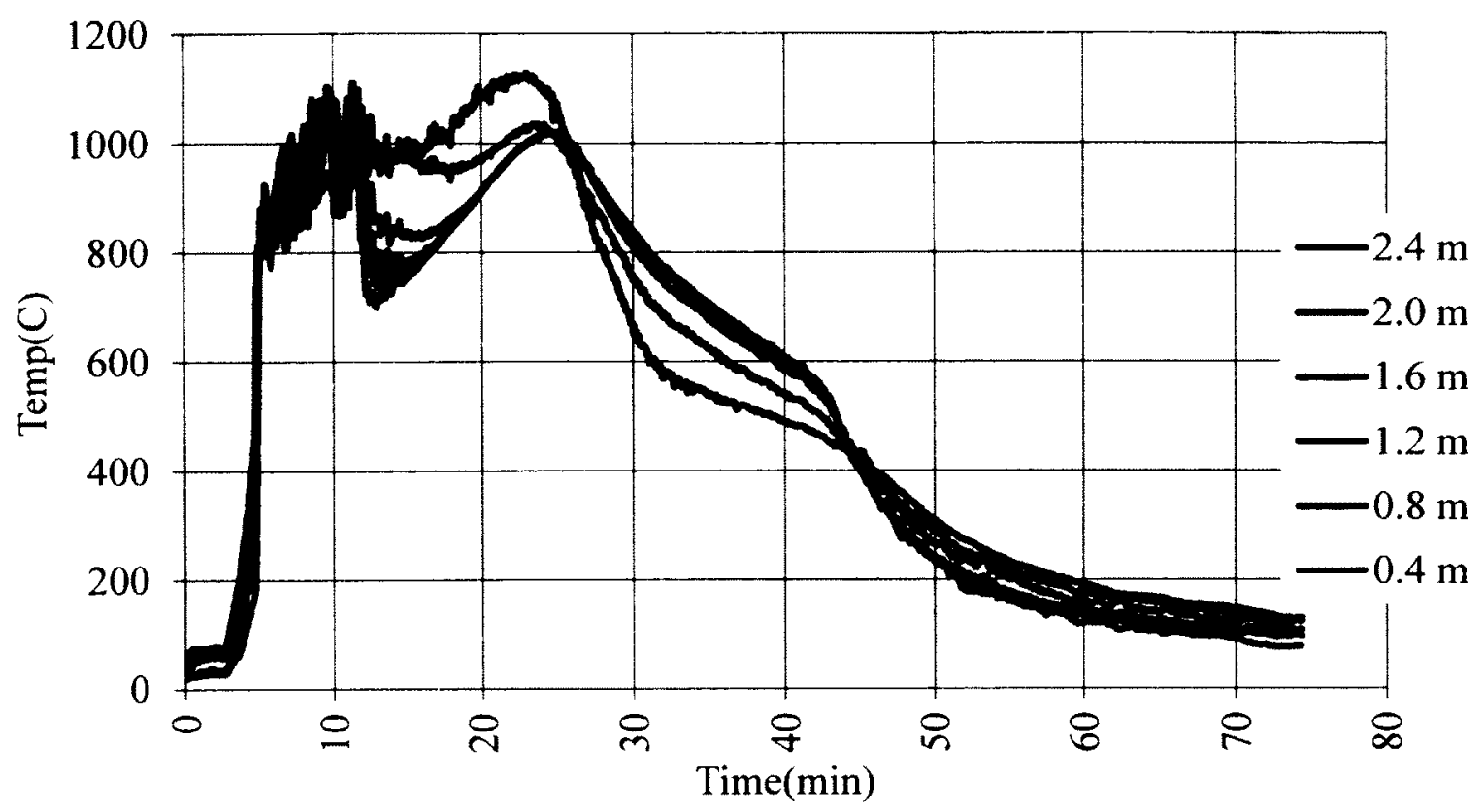

Figure 82 - Thermocouple Tree 2 temperatures - Test 3

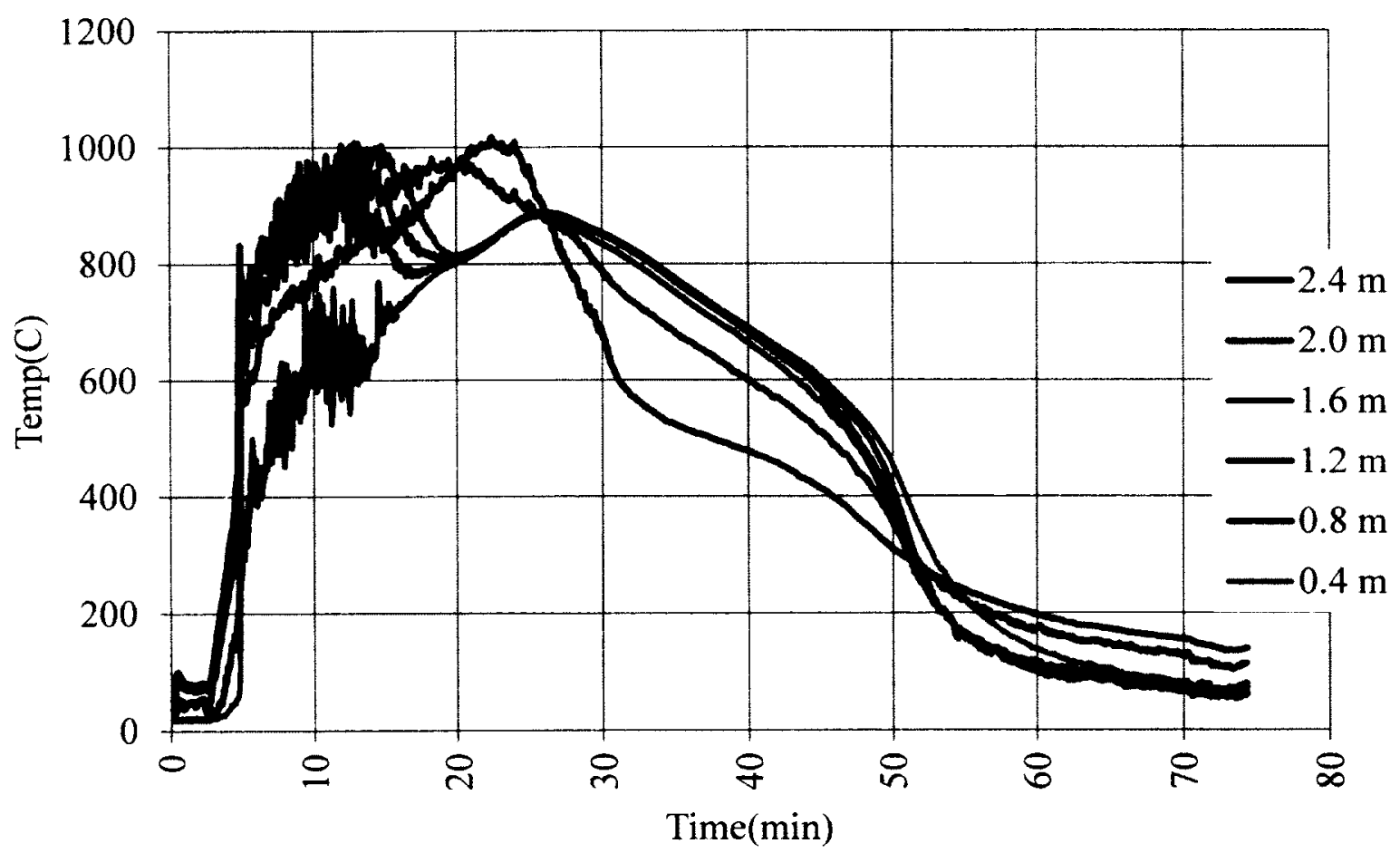

Figure 83 - Thermocouple Tree 3 temperatures - Test 3 


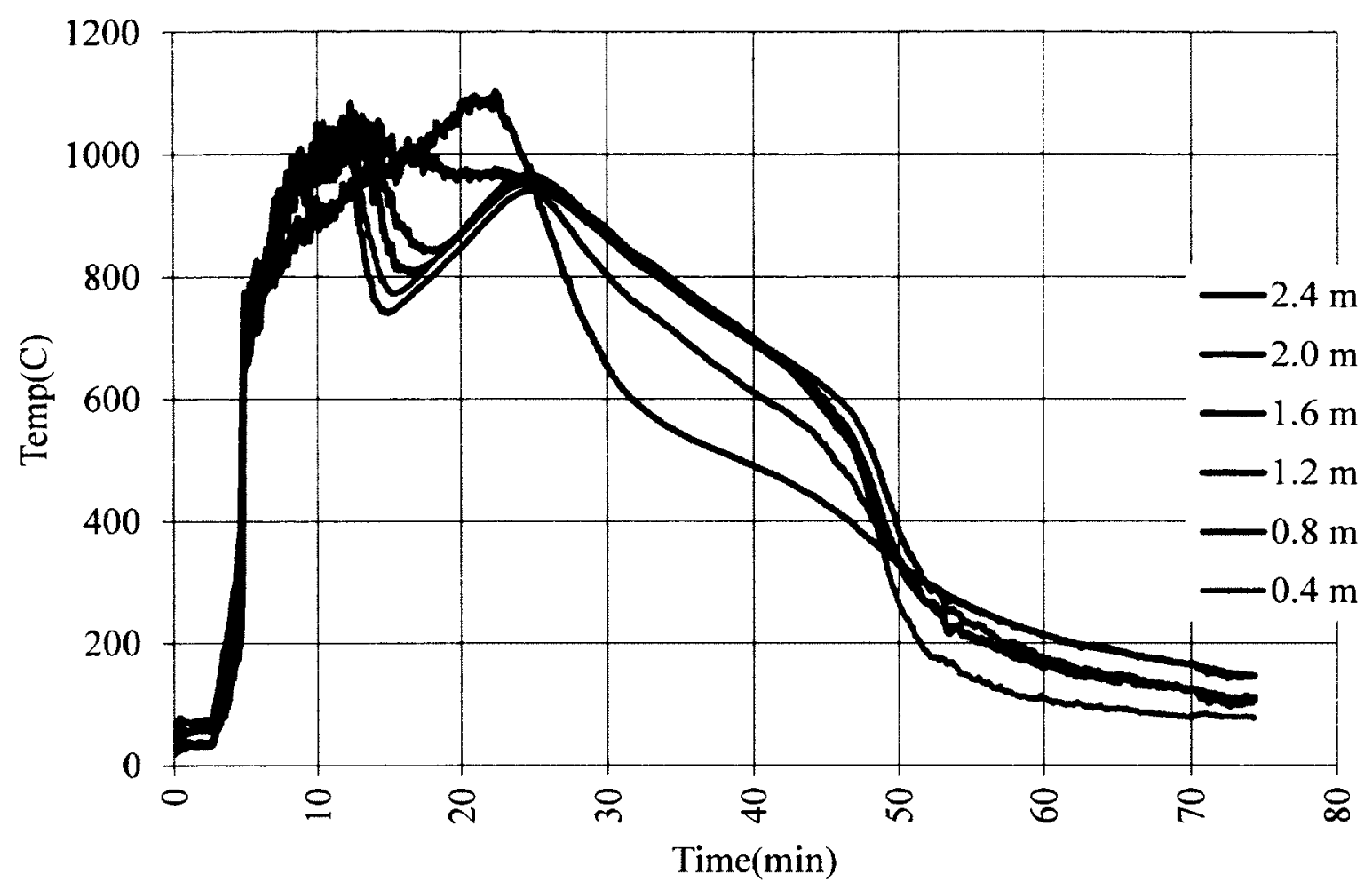

Figure 84 - Thermocouple Tree 4 temperatures - Test 3

By 28:00 minutes, almost all visible flaming has ceased in the room and glowing combustion is observed in Figure 79 on all surfaces. The HRR continues to decay and the glowing combustion begins to disappear as the temperatures in the room decrease. As with previous tests, the exterior faces of the walls did not experience any significant increase in temperature and remained safe to touch, demonstrated in Figure 85. 


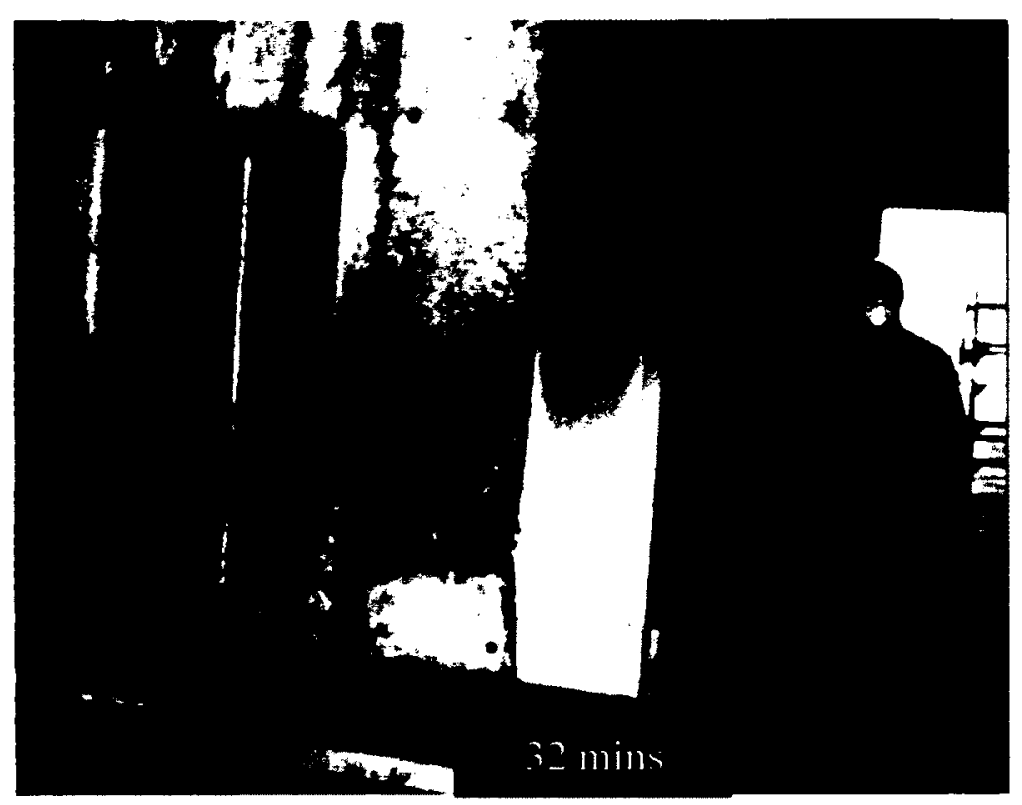

Figure 85 - Exterior faces of walls remained safe to touch throughout Test 3

The average temperatures at each thermocouple tree, presented in Figure 86, show drops in temperature occurring after 10 minutes. The temperatures begin to increase again peaking between 23-25 minutes before beginning to decay.

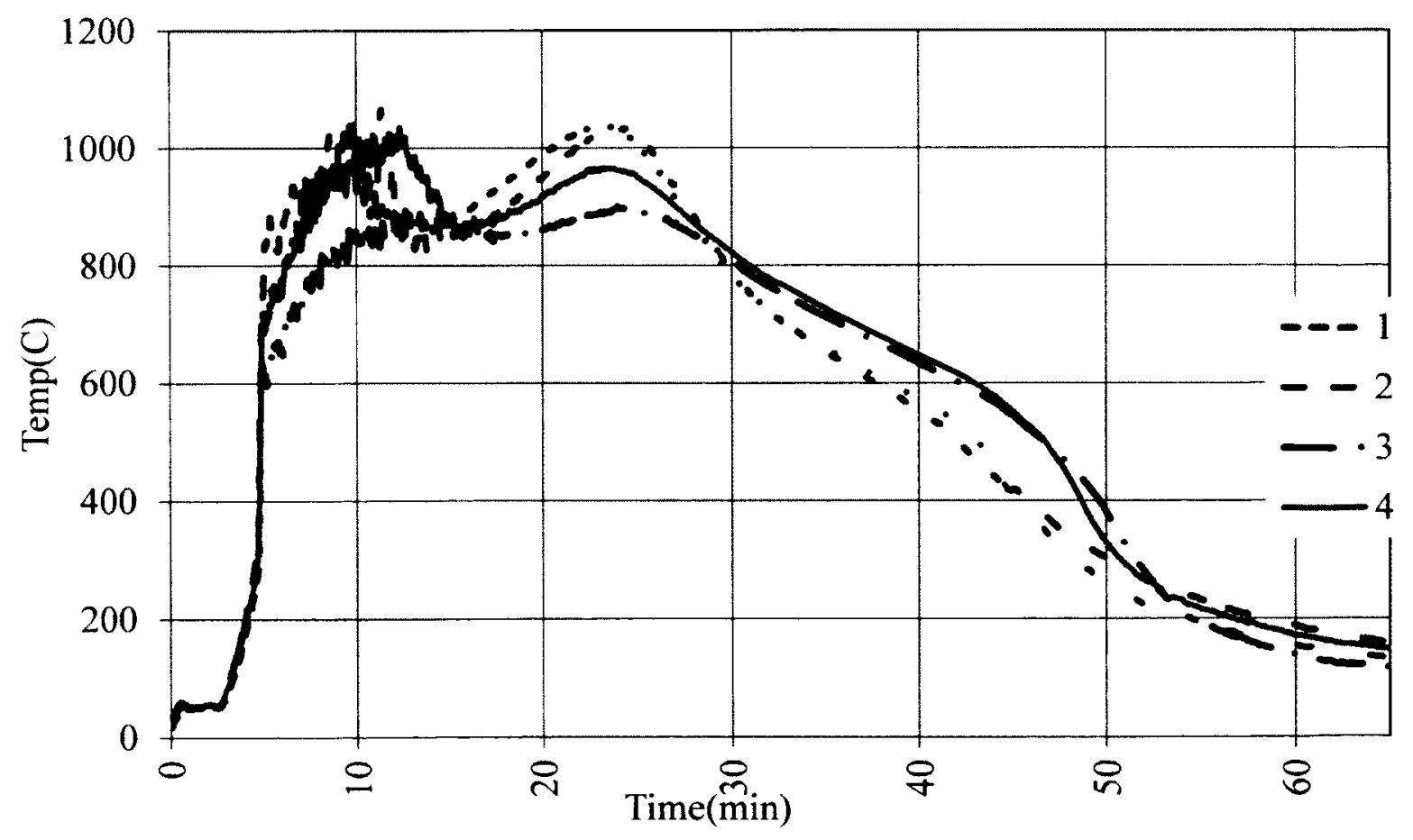

Figure 86 - Thermocouple tree average temperatures - Test 3 


\subsubsection{Joint Temperatures}

The joint temperatures presented in Figure 87 show increases which plateau above $90^{\circ} \mathrm{C}$. This likely indicates the transport of steam through the joints as it is driven from the wood as the char front advances. The temperature of the structure rises slower at a comparable depth of $54 \mathrm{~mm}$ at position $\mathrm{W} 4$, driven by conductive heat transfer within the structure.

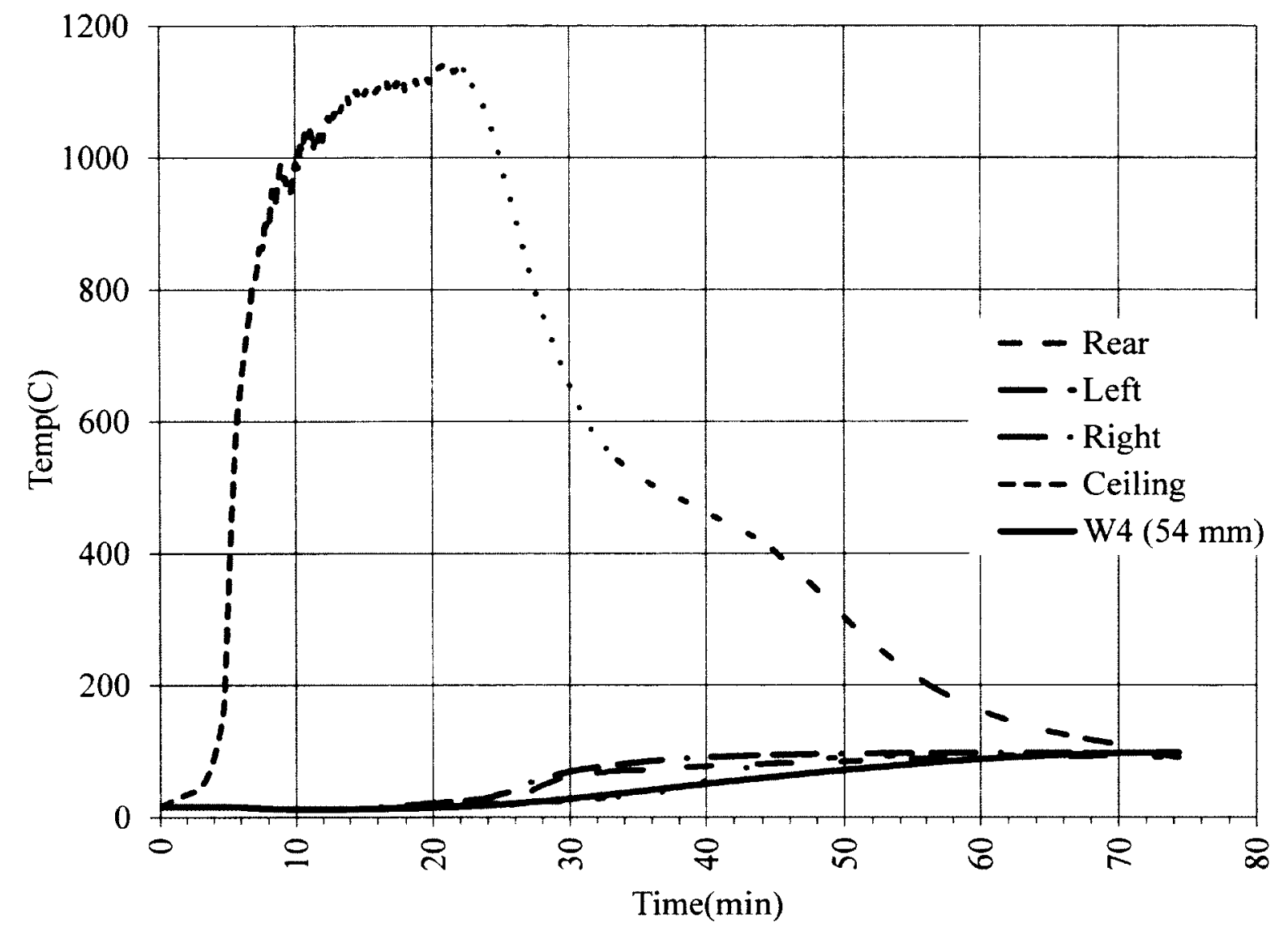

Figure 87 - Temperatures at joints and W4 measuring position - Test 3

A record of events that occurred are presented in Table 13 below, sourced from video, photographic and test records. 
Table 13 - Record of events - Test 3

\begin{tabular}{|l|l|}
\hline & Event \\
\hline $00: 00$ & Fuel on1 burner \\
\hline $01: 54$ & Fast' fire growth rate commenced \\
\hline $02: 32$ & Second burner ignited \\
\hline $02: 55$ & Light smoke visible exiting door approx $25 \%$ height \\
\hline $04: 10$ & Moderate smoke visible exiting door approx $50 \%$ height \\
\hline $04: 25$ & Measured HRR begins to exceed propane flow \\
\hline $04: 35$ & HRR exceeds 1.055 MW \\
\hline $04: 39$ & First flaming visible on ceiling \\
\hline $04: 48$ & Entire ceiling engulfed in flames and first flames exit door \\
\hline $04: 55$ & Room in flashover \\
\hline $13: 40$ & Front video camera fails \\
\hline $13: 56$ & Side video camera fails \\
\hline $14: 00$ & Exhaust fan speed increased from $50 \%$ to $75 \%$ \\
\hline $17: 00$ & Propane decay initiated \\
\hline $23: 29$ & Front video camera restarts, flames still exiting door. \\
\hline $27: 45$ & HRR drops below 1.055 MW \\
\hline $27: 59$ & Last flaming visible at door, some flames on structure \\
\hline $31: 00$ & Flaming stops, glowing combustion observed \\
\hline $58: 00$ & Test complete, room cooled \\
\hline
\end{tabular}

\subsection{Test 4-Protected room with furniture fire}

Test 4 was conducted in the morning of July 172012 . The aim of the test was to observe the performance of the CLT panels in a protected room, the same as Tests 1 and 2 , using furniture as the fire source. Test 4 was a repeat of Test 2 , for which the temperature data had been lost.

The burner was ignited at 11:00 AM with an ambient temperature of $27^{\circ} \mathrm{C}$. After 28 seconds the smoke detector activated, almost a minute earlier than observed in test 2 , at which time only a small amount of smoke was observed, mostly from the propane burner. At 2:23 minutes the burner was turned off as the bed coverings caught fire and some smoke was observed coming from the room. The fire began to spread across the 
head of the bed with visibility reducing and a defined smoke layer was visible at $4: 46$ minutes. By 6:48 minutes, the whole bed was alight melting and burning material from the mattress can be seen in Figure 88 dripping and pooling beneath the bed. Flames were first observed in the smoke layer at 8:25 minutes at which time the smoke layer had descended almost to the top of the bed. Flaming was observed exiting the room at 8:41 minutes and the HRR exceeded 1.055 MW at 9:07 minutes. The surface of the beds footboard ignited at 9:11 minutes and all items in the room appeared to be burning by 9:26 minutes, approximately 2 minutes later than observed in Test 2.

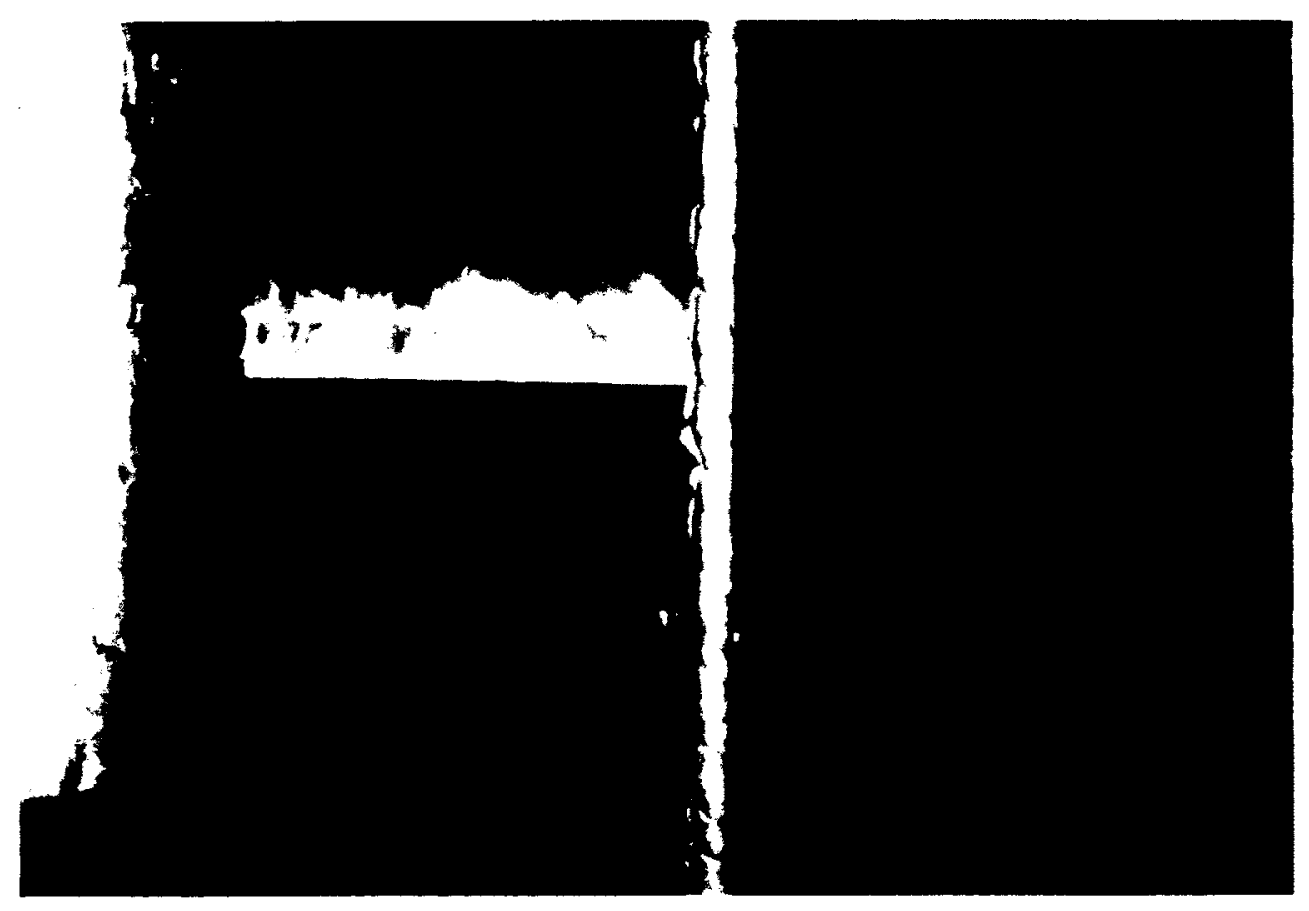

Figure 88 - Descending Smoke layer and burning material dripping from mattress - Test 4

The HRR curve presented in Figure 89 shows a longer incipient phase than Test 2 before entering a rapid fire growth period which exceeds that for an ultra-fast classification. For comparison the two graphs have been matched at the point where sustained fire growth at flashover occurs. A plateau is observed at $3 \mathrm{MW}$ which lasts for 
approximately 1 minute before the growth continues reaching a peak of $5.7 \mathrm{MW}$ at 11:58 minutes. At this time consistent bright orange flaming was observed extending from the door. The plateau is likely related to a longer time to involvement of the hardwood flooring which can be explained by its position at the bottom of the room and being largely sheltered from the hot upper layer and flames by the bed. Flaming on the hardwood flooring in the doorway was not observed until 10:08 minutes. Fire growth at the doorway is shown in Figure 90.

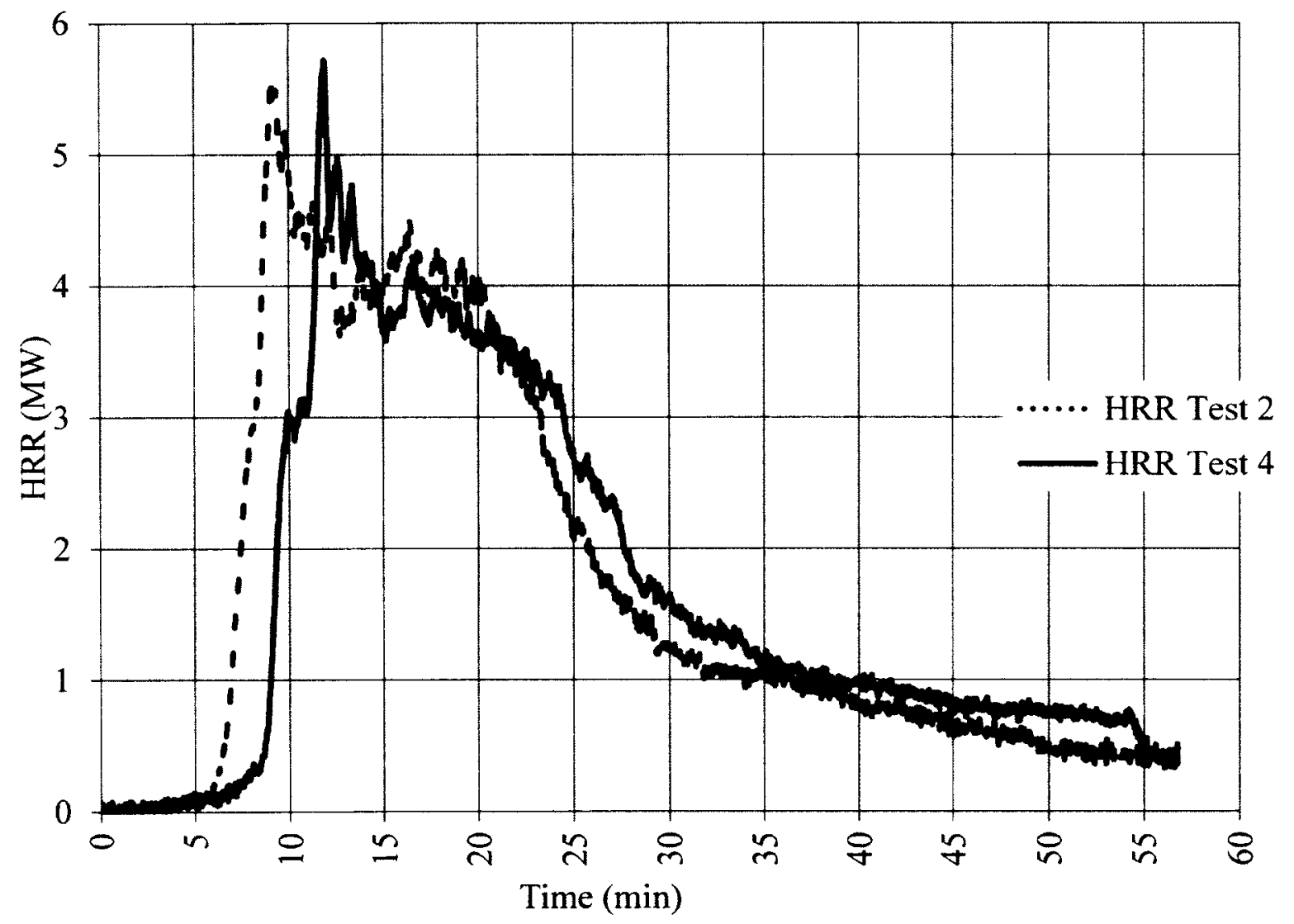

Figure 89 - Heat release rate - Test 2 and 4 


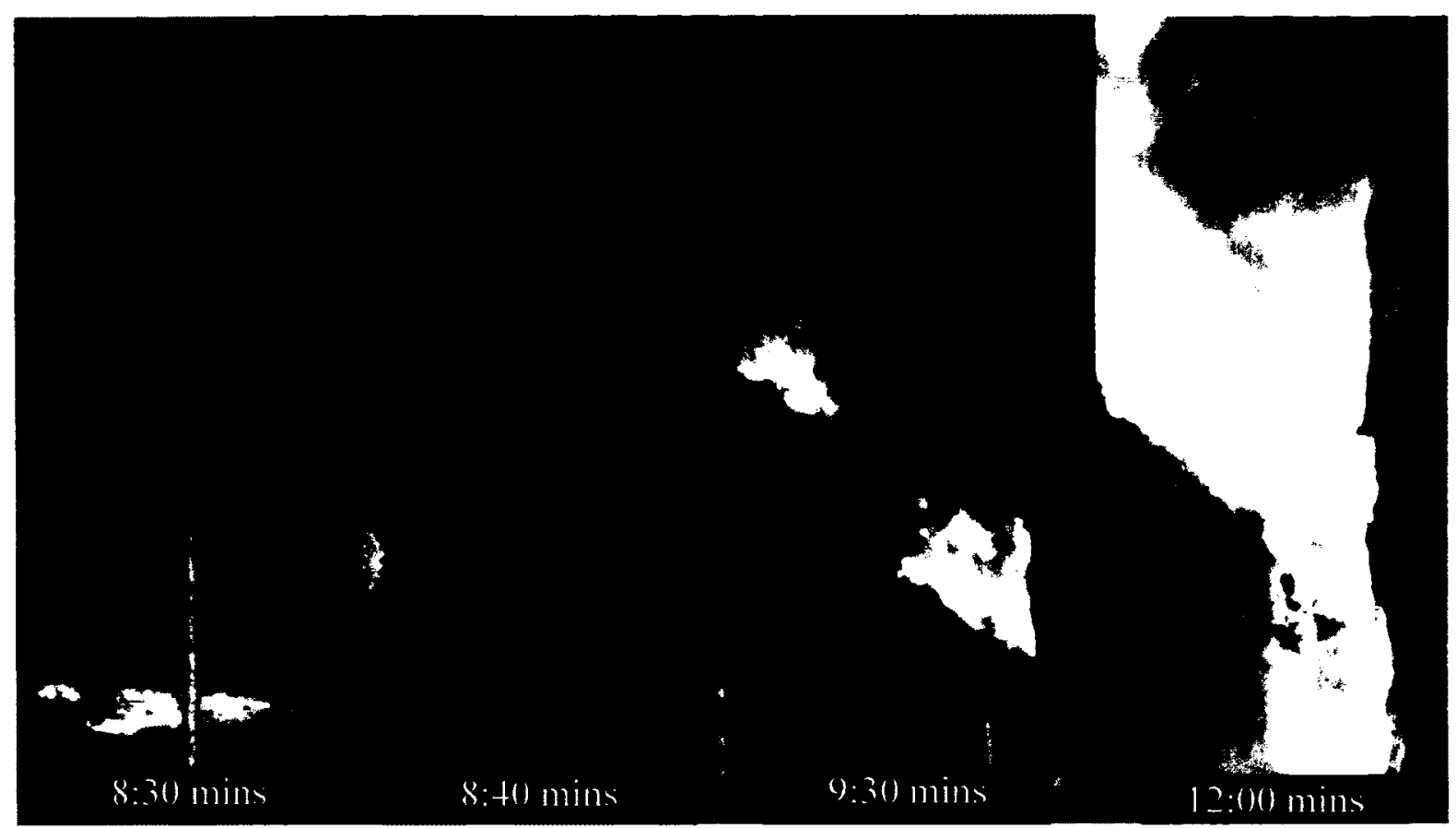

Figure 90 - Fire growth - Test 4

The visibility in the room began to improve with the footboard again visible at 14:45 minutes as the HRR decayed. It then deteriorated as the HRR increases again reaching 4.15 MW at 16:50 minutes., presumably as the bed collapsed as observed in Test 2 . HRR then began to decay slowly with the ceiling visible at $23: 23$ minutes. The fire then entered a sharp decay phase after approximately 24:00 minutes with most flaming contained within the room by 25 minutes and most flaming extinguishing after 30minutes as presented in Figure 91. The decay then slowed and the HRR dropped below 1.055 MW at 37:24 minutes. Smoke was observed coming from the joints similar to previous tests with a significant amount coming from the floor panels after 33 minutes. The floor panels had been reused and some charring occurred beneath the protection, this does not appear to have had a noticeable effect on the overall HRR. 


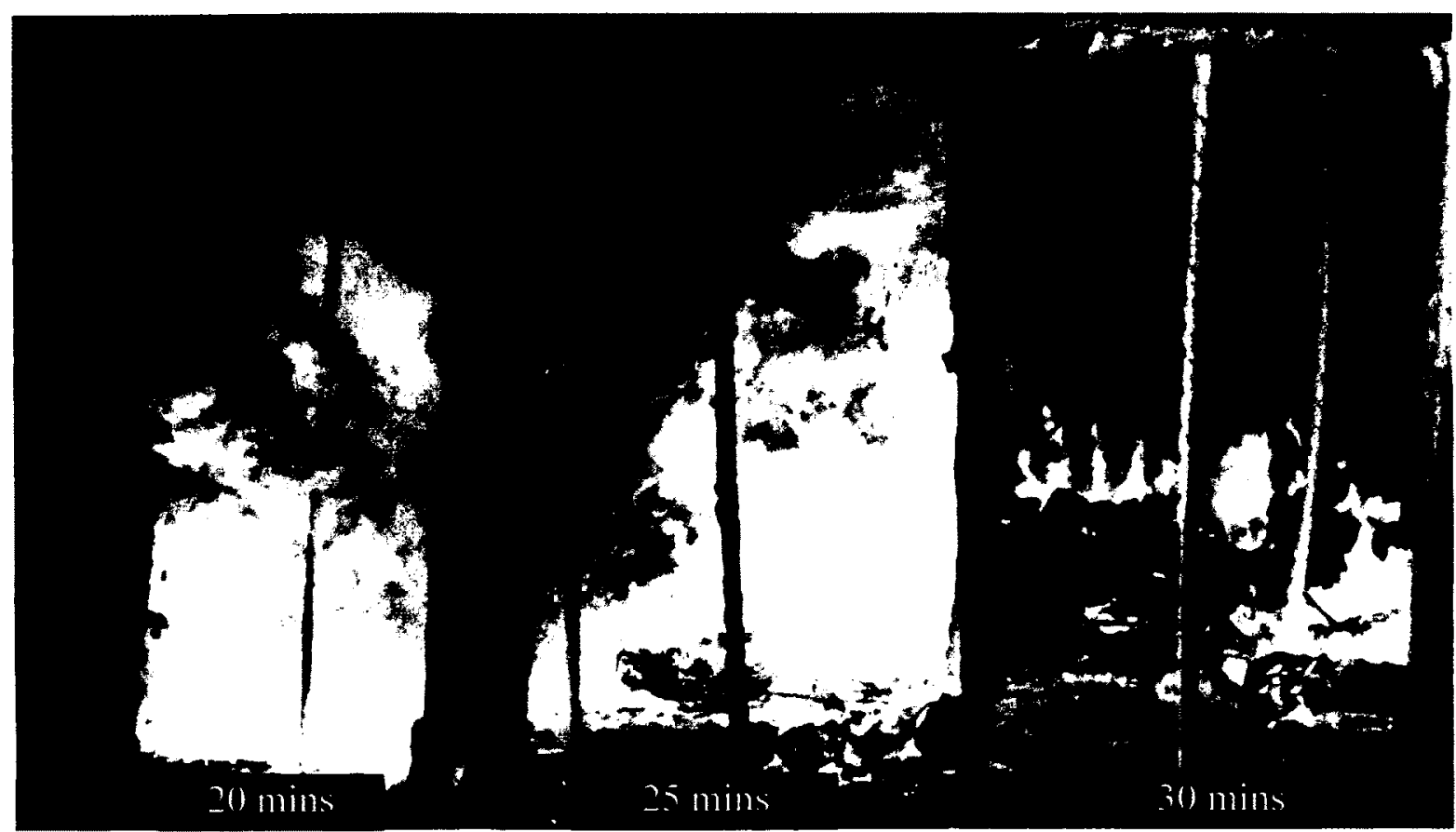

Figure 91 - Fire Decay - Test 4

Similar to Test 2, the majority of the gypsum board remained in place with a panel above the bed collapsing at 39:24 minutes. The fire was extinguished after 53:34 minutes.

\subsubsection{Temperature}

The room temperature, presented in Figure 92 rises rapidly at flashover, as seen in previous tests, with a noticeable decrease in growth rate observed at approximately $700^{\circ} \mathrm{C}$, similar to Test 3 , before rising to a peak of $998^{\circ} \mathrm{C}$ at $16: 01$ minutes. Similar to Test 3, a significant drop in temperature is observed before increasing again to a peak of $1002^{\circ} \mathrm{C}$ at $25: 20$ minutes. The plate thermometer shows a smaller drop in temperature, not observed in Test 3, which then recovers and continues to increase reaching a peak of $1109^{\circ} \mathrm{C}$ at $23: 15$. Following the peaks, the temperatures begin to decay along with the HRR. 


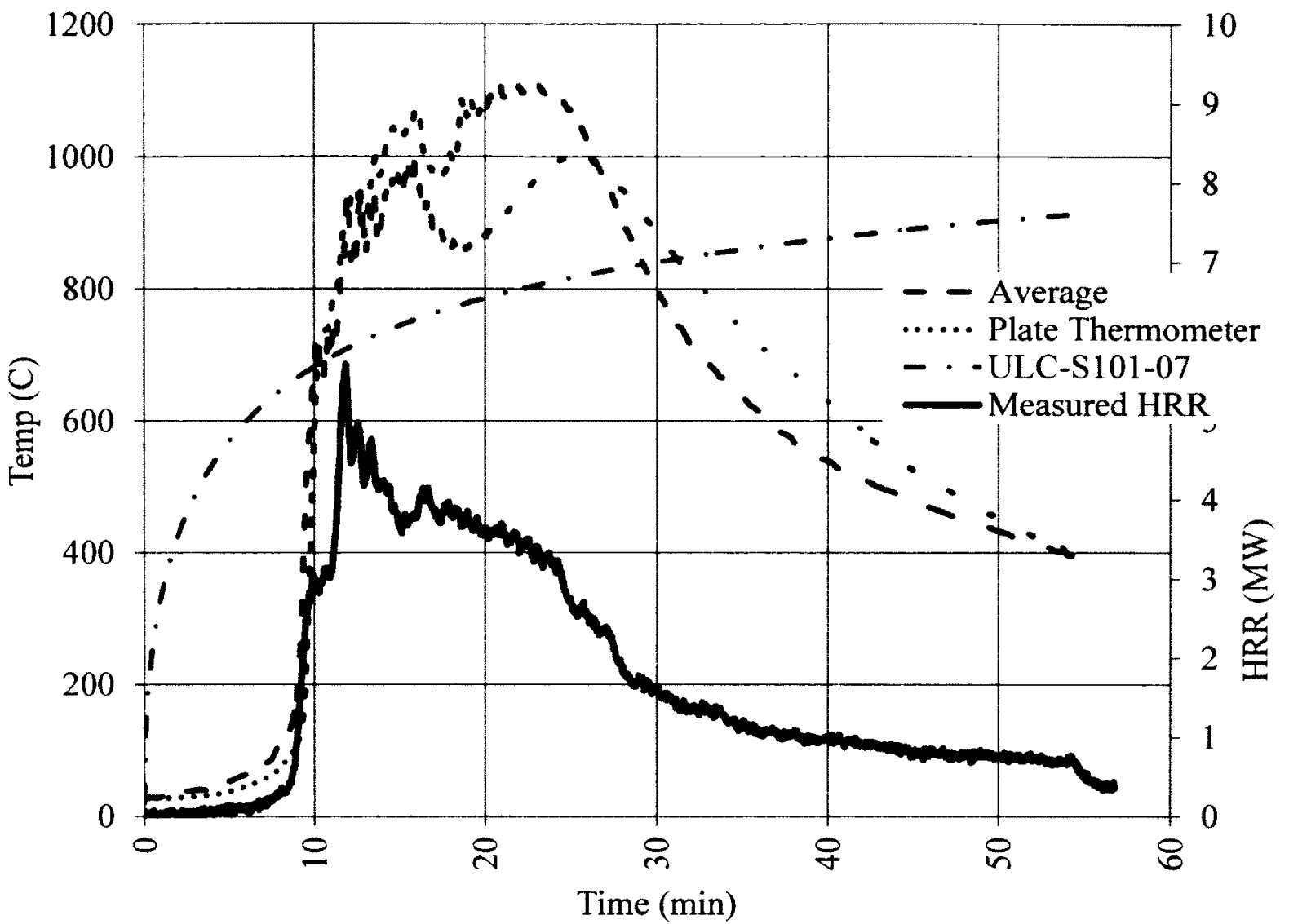

Figure 92- Plate thermometer and Average room temperatures showing HRR Test 4

Similar to Test 3, drops are observed in Figure 93, Figure 94, Figure 95 and Figure 96 at locations nearest to the floor following the initial peak after which the temperatures group together as the HRR begins to decay. Like Test 3, the temperatures at the highest points in the room are noticeably different, which is likely an effect of the proximity to the structure. The maximum temperature of $1154^{\circ} \mathrm{C}$ was measured at thermocouple tree two at 2.4 metres. 


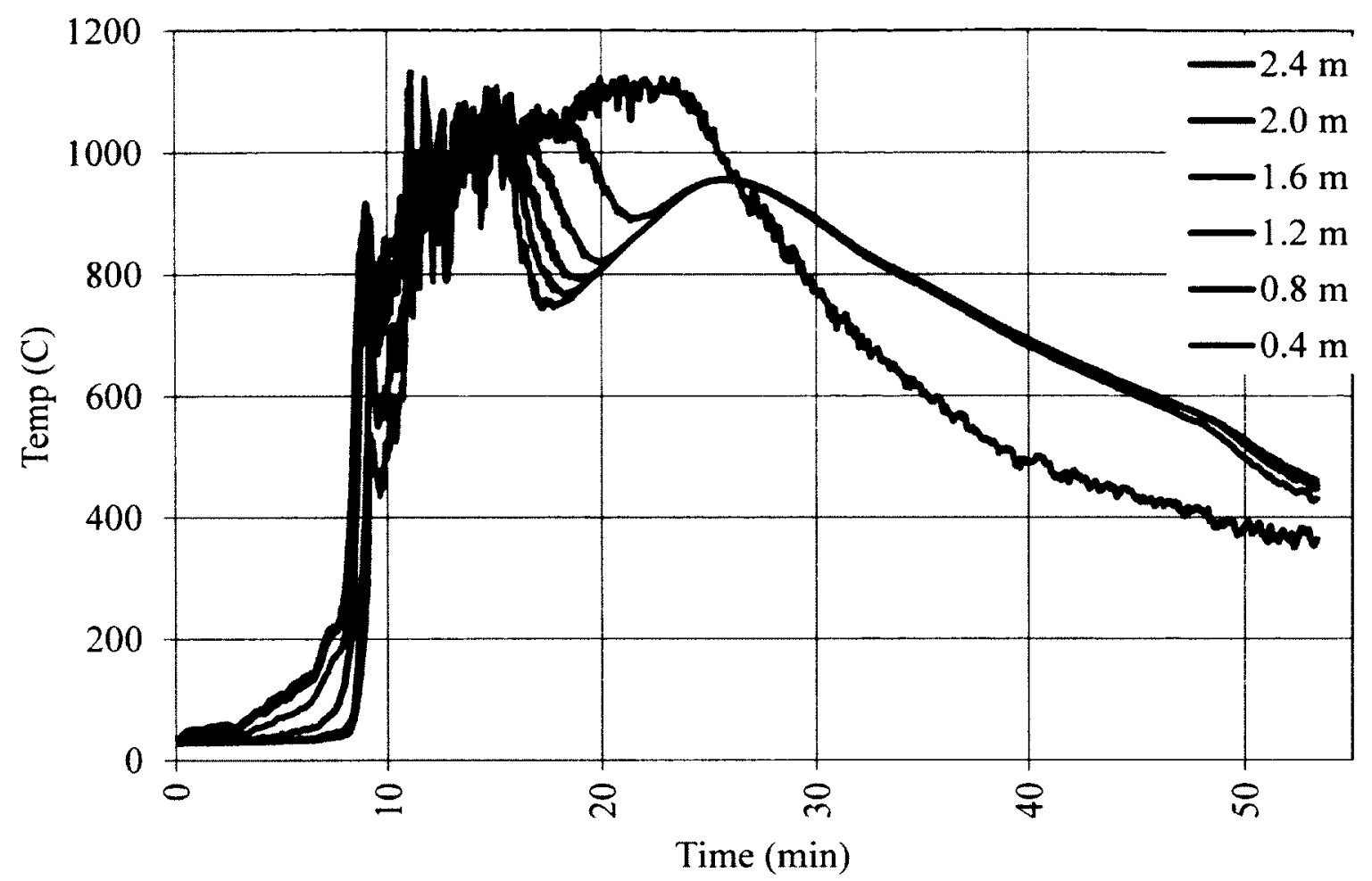

Figure 93 - Thermocouple Tree 1 temperatures - Test 4

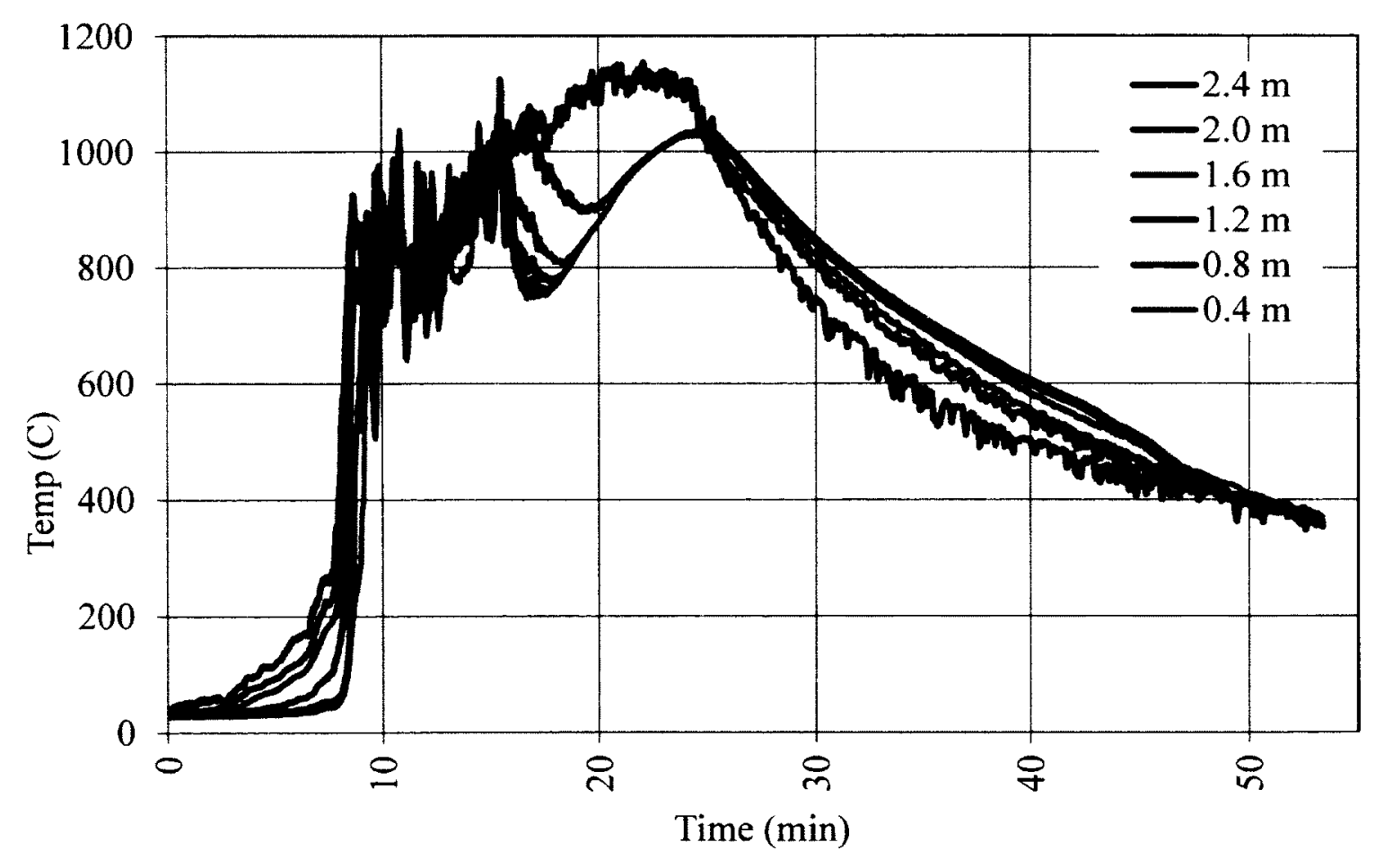

Figure 94 - Thermocouple Tree 2 temperatures - Test 4 


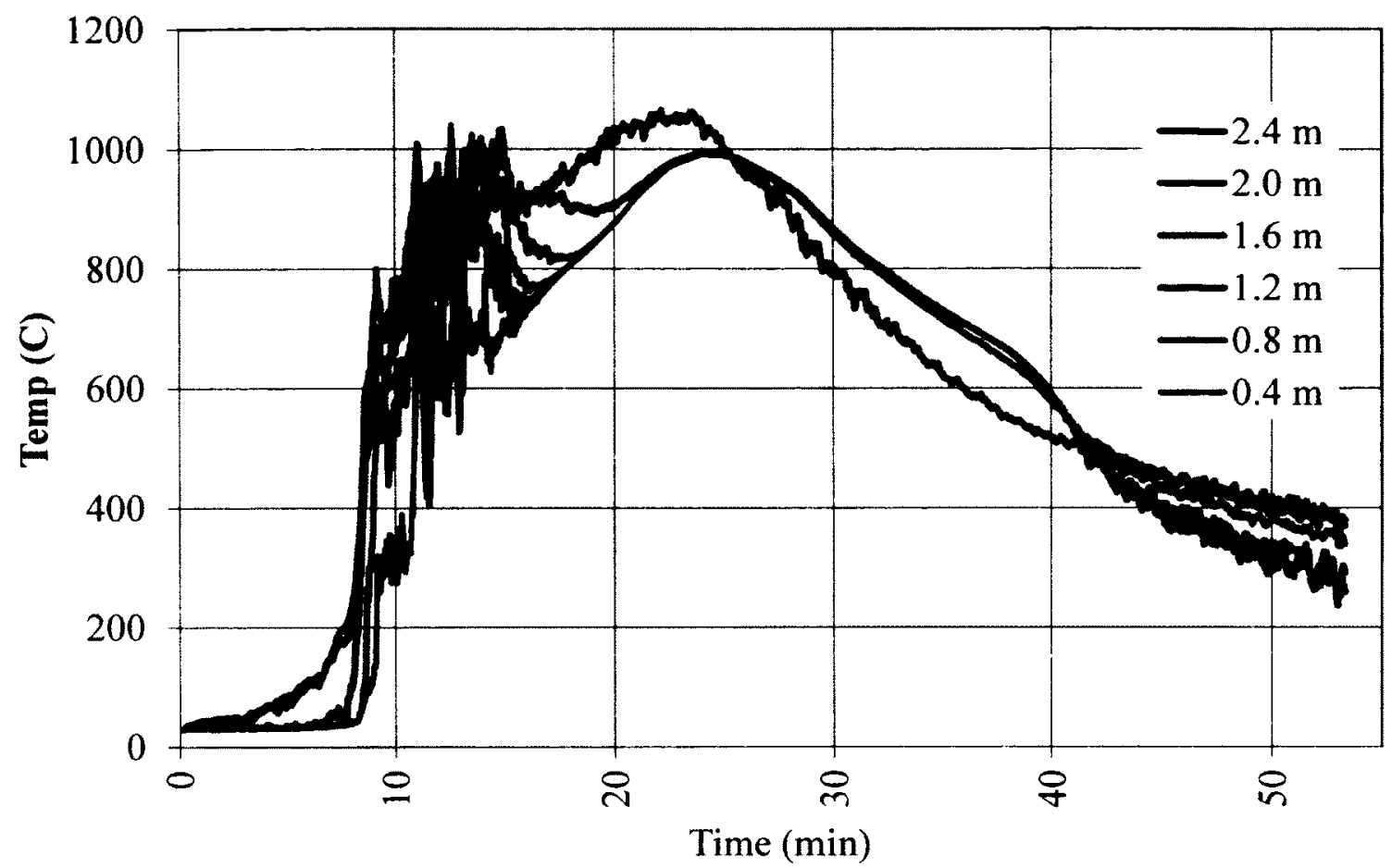

Figure 95- Thermocouple Tree 3 temperatures - Test 4

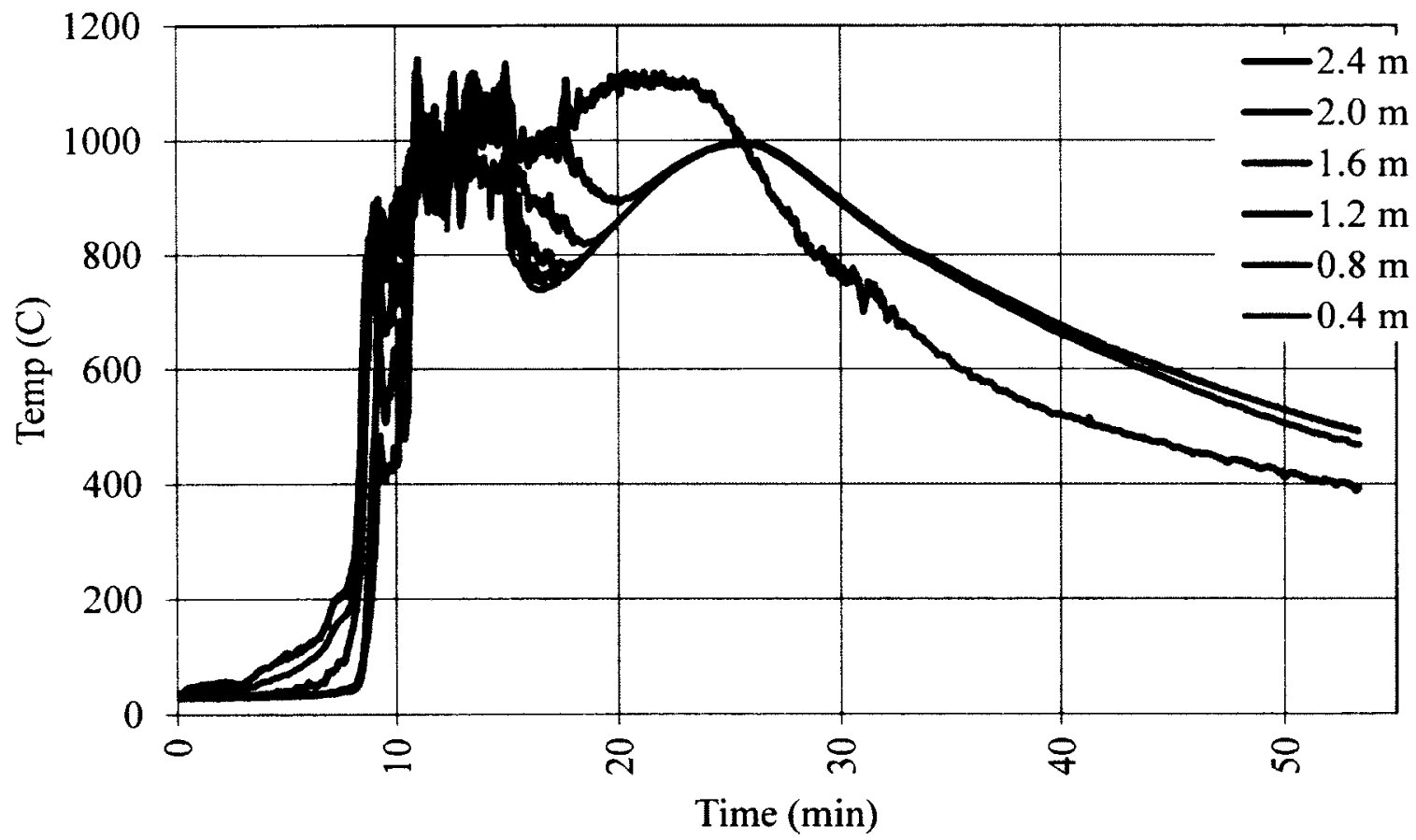

Figure 96- Thermocouple Tree 4 temperatures - Test 4 
The average temperatures at each location are presented in Figure 97. The highest temperatures are experienced at the rear of the room during the initial fire growth phase. Immediately following this the rear of the room experiences lower temperatures, likely an effect of limited ventilation.

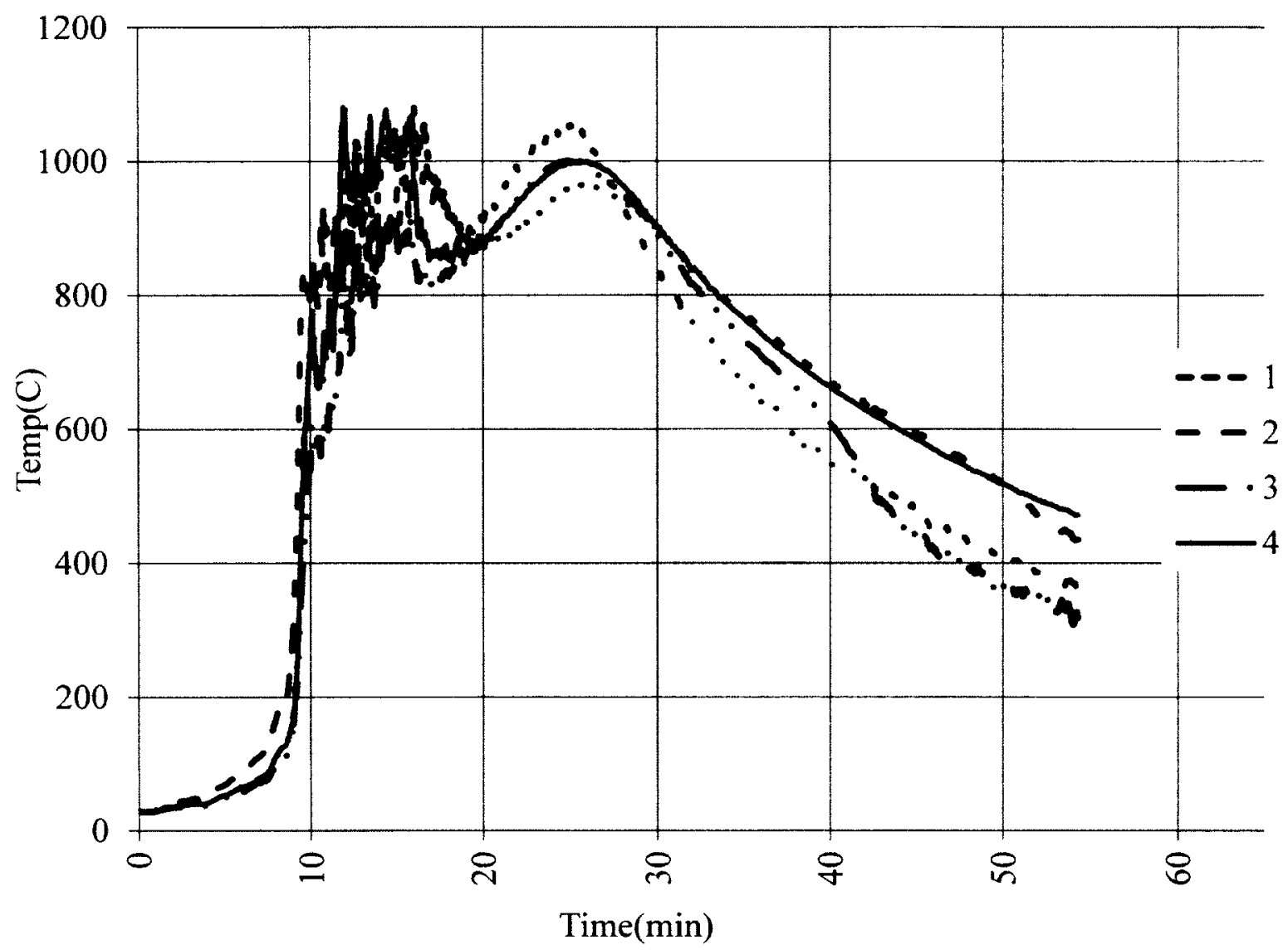

Figure 97 - Average thermocouple tree temperatures - Test 4

Like Test 2 , the lining remained in place for the duration of the test, consequently the CLT panels did not become involved in the fire and did not experience any charring. The temperatures at the CLT/Gypsum board interface are presented in Figure 98 which show the failure of the first layer of gypsum board after approximately 21 minutes and the first indication of failure of the second layer after 43 minutes. The maximum temperature measured at the CLT/gypsum board interface was $133^{\circ} \mathrm{C}$. 


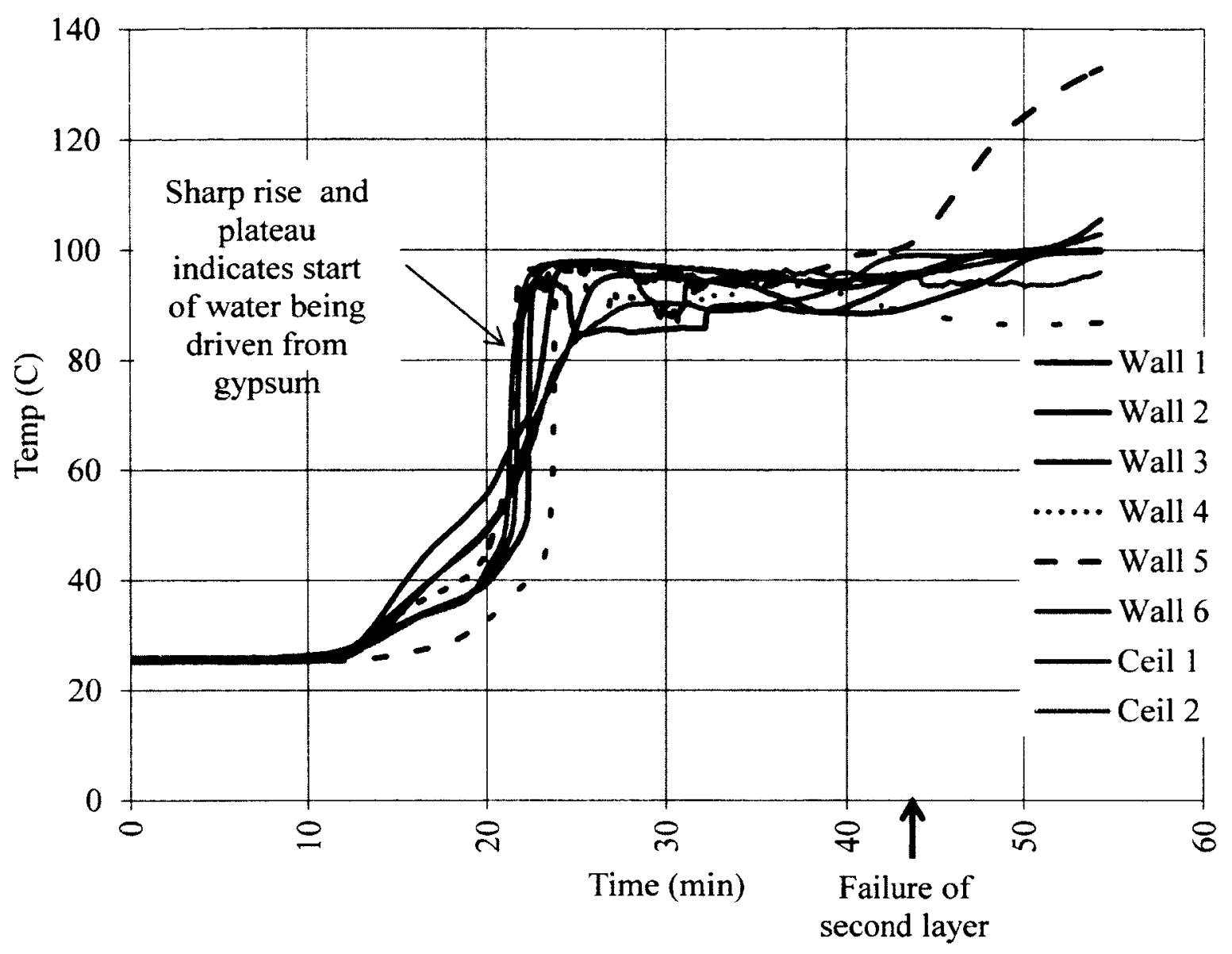

Figure 98 - Temperatures at interface of CLT panels and Gypsum Board insulation - Test 4

The temperatures of the joints are presented in Figure 99. The temperature at the ceiling joint rises towards $100^{\circ} \mathrm{C}$ after 22 minutes indicating the transport of the chemically bound water being released from the gypsum board after the first layer of gypsum board fails. The temperatures then show a decrease after $40 \mathrm{mins}$, as the room cools (but still remain above $400^{\circ} \mathrm{C}$ ) and at that time most of the chemically bound water in the second layer of gypsum board would have been released. A thermocouple embedded in the structure at position $\mathrm{C} 2,24 \mathrm{~mm}$ from the surface, shows a much slower temperature increase than that of the joints. 


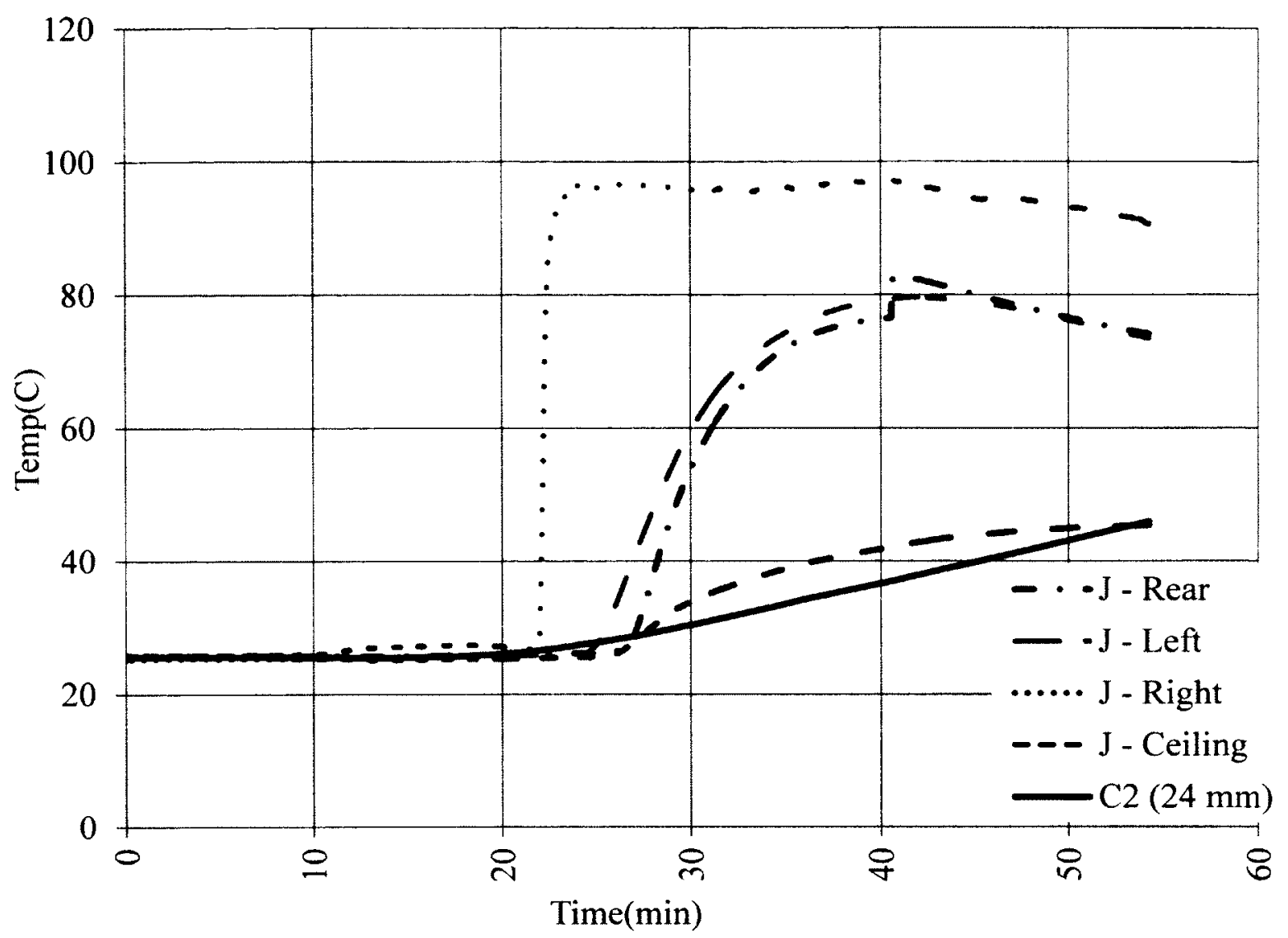

Figure 99 - Temperatures at the joints and embedded $24 \mathrm{~mm}$ from surface at position $\mathrm{C} 2-$ Test 4

The energy released during the fire was $364 \mathrm{MJ} / \mathrm{m}^{2}, 64 \%$ of the estimated fire load present in the room.

A record of events that occurred is presented in Table 14 below, sourced from video, photographic and test records.

Table 14 - Record of events - Test 4

\begin{tabular}{|l|l|}
\hline & Event \\
\hline $00: 00$ & Test started, burner ignited - bedding \\
\hline $00: 28$ & Smoke detector Activation 1:27 \\
\hline $02: 23$ & Burner gas off. Visibility reducing, some smoke visible exiting opening. \\
\hline $03: 56$ & Fire increasing, some airborne sparks visible, visibility hazy. \\
\hline $04: 46$ & Fire spread across head of bed, smoke layer defined \\
\hline
\end{tabular}




\begin{tabular}{|l|l|}
\hline $06: 48$ & Smoke detector stops, flames across most of bed \\
\hline $06: 48$ & Flaming melted material visible under bed \\
\hline $08: 25$ & First flaming visible in smoke layer above bed \\
\hline $08: 41$ & Smoke layer at top of bed, flames exiting room, burning smoke detector falls \\
\hline $09: 07$ & HRR exceeds 1.055 MW \\
\hline $09: 11$ & Footboard surface ignites \\
\hline $09: 26$ & All items in room appear to be burning \\
\hline $09: 30$ & First smoke ignition visible outside room \\
\hline 10:00 & Solid red flaming exiting door \\
\hline 10:08 & Floor burning \\
\hline 10:56 & Continuous flaming of gas flow observed outside room \\
\hline $12: 26$ & Uniform flow flaming begins in top half of door \\
\hline $14: 45$ & Footboard again visible sporadically \\
\hline $18: 55$ & Flaming outside room decreasing \\
\hline $23: 23$ & Ceiling visible \\
\hline $24: 56$ & Most flaming contained within room \\
\hline $27: 56$ & Flaming reduced significantly \\
\hline $29: 56$ & Most flaming out \\
\hline $33: 00$ & Smoke coming from floor joint \\
\hline $37: 24$ & HRR drops below 1.055 MW \\
\hline $39: 34$ & Gypsum panel on ceiling falls \\
\hline $53: 34$ & Fire Extinguished \\
\hline
\end{tabular}

\subsection{Test 5 - Unprotected room with furniture fire}

Test 5 was conducted in the morning of 25 of July 2012. The aim of the test was to observe the performance of the CLT panels in an unprotected room, the same as Test 3 , by using furniture as a fuel.

The ignition burner was ignited at 10:00 $\mathrm{AM}$ with an ambient temperature of $21^{\circ} \mathrm{C}$. The smoke detector activated after 20 seconds as the bedding caught alight. The burner was turned off and removed after 1:21 minutes. The fire spread across the bed with flames growing in height. At 3:00 minutes, the flames began to touch the wall behind the bed and the smoke layer was defined. Flaming was visible on the walls at 3:34 
minutes and the smoke had descended to a height of approximately 1.4 metres from the floor. The fire continued to grow with flames visible in the smoke layer at 4:04 minutes shown in Figure 100.

Flames in smoke

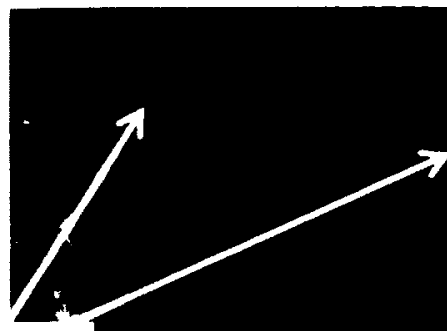
layer

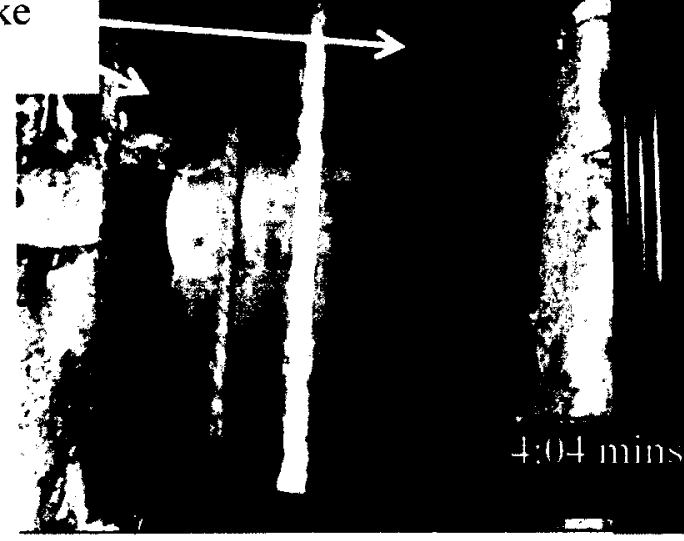

Figure 100 - Flaming in smoke layer - Test 5

At approximately 5 minutes the flames spread up the walls at the rear of the room above the bed and across the ceiling with the flames first extending from the doorway at 5:20. The fire grew rapidly, as shown in Figure 101, with all items in the room becoming fully involved in the fire at 5:55 minutes when the floorboards in the doorway ignited. 


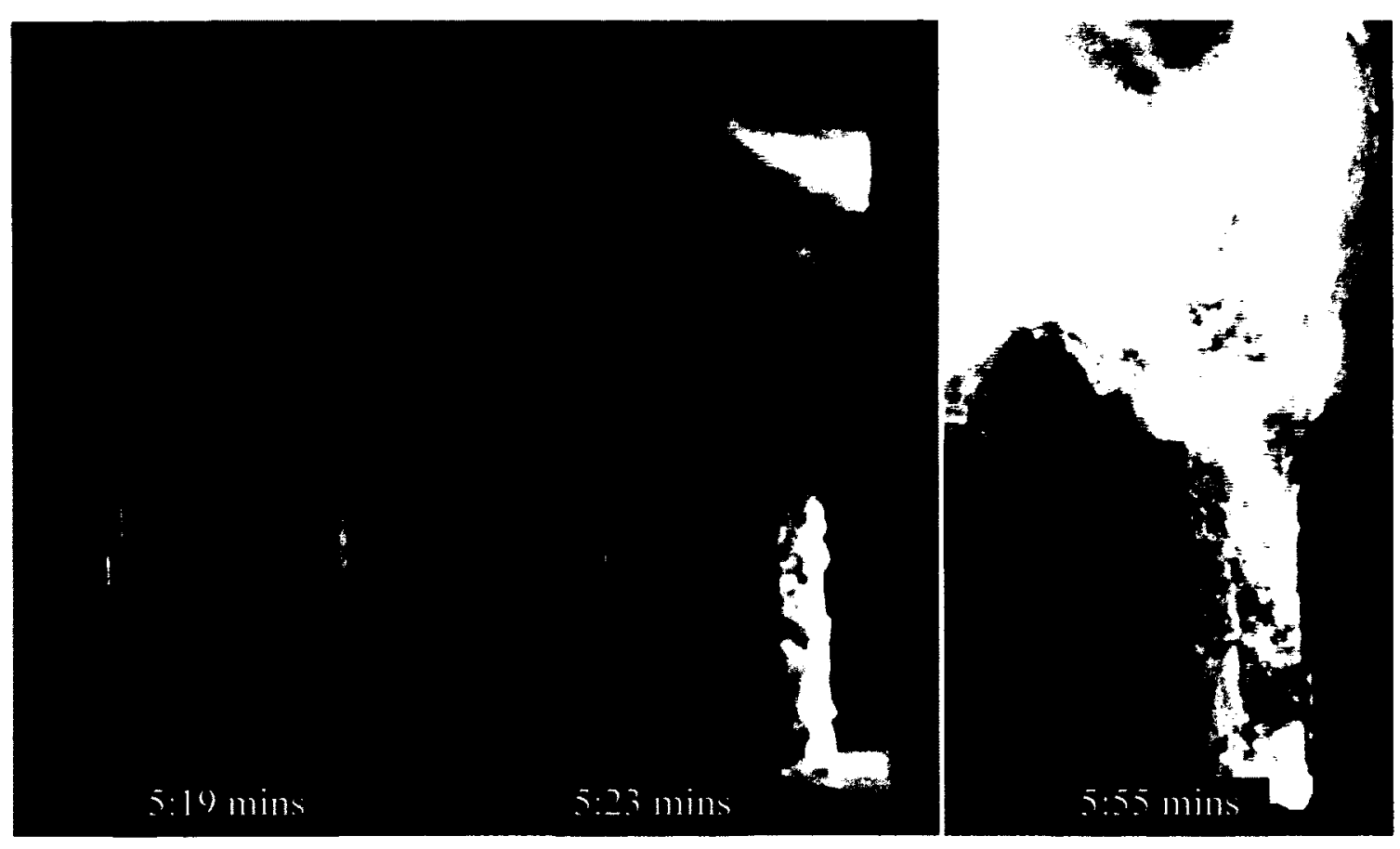

Figure 101 - Fire Growth - Test 5

At 5:19 minutes the HRR, presented in Figure 102, exceeds 1.055 MW. The HRR continues to rise reaching a peak of 7.64 MW at 7:00 minutes with the fire burning at approximately $7 \mathrm{MW}$ for 20 minutes before entering a decay period at 27 minutes. The decay occurs as the estimated contribution from the furniture and hardwood floor drops below approximately $1.5 \mathrm{MW}$. 


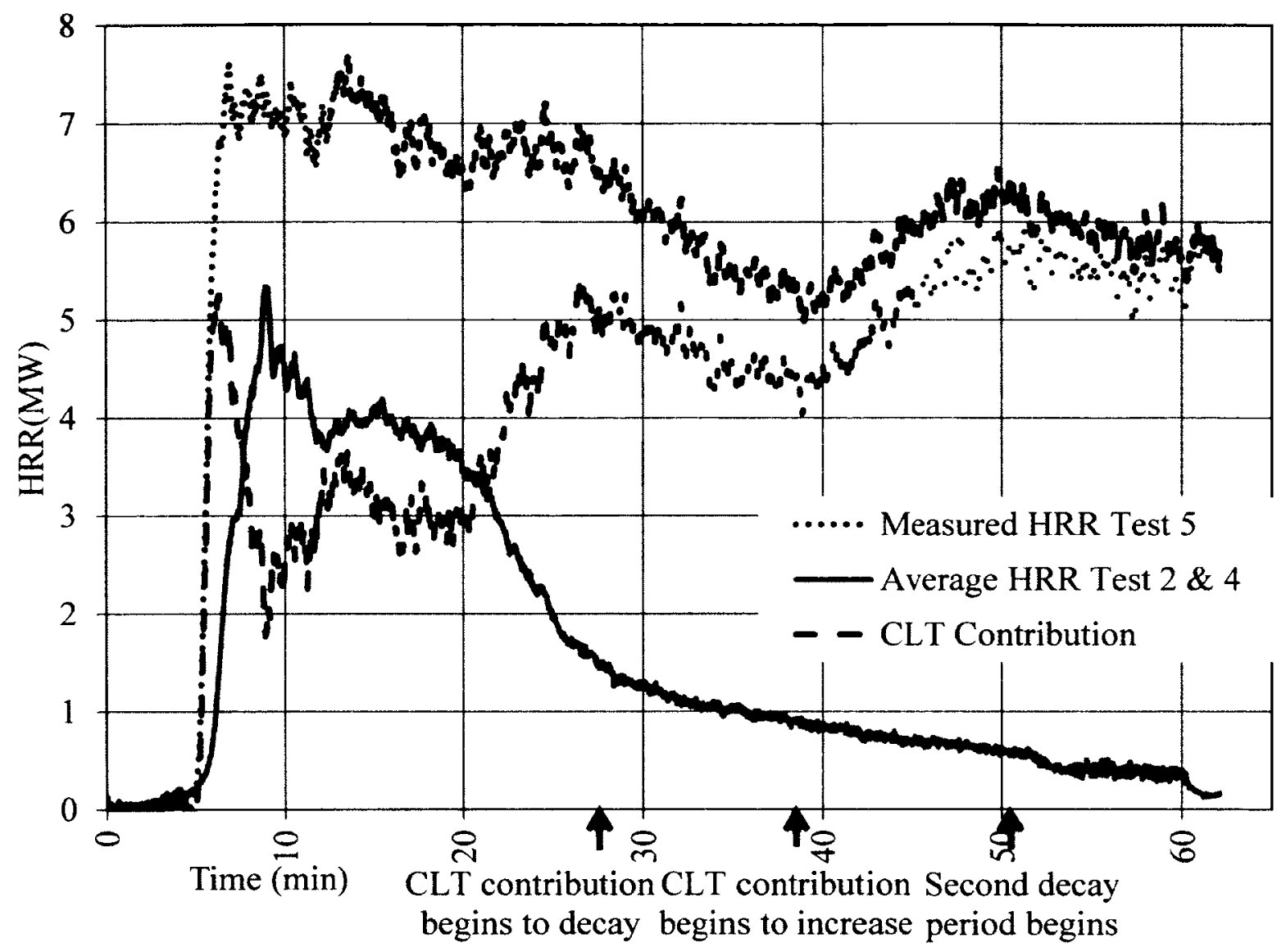

Figure 102- Heat release rate showing estimated contributions from CLT panels and furniture - Test 5

Figure 103 shows the room at 35 minutes, where the structure is seen burning and the furniture and hardwood floor have been mostly consumed. At 39 minutes, the HRR begins to rise again entering a second growth phase, at which time the pieces of the first CLT layer were observed delaminating and falling off. Similar to Test 1 , this delamination contributed to the fire load in the room and exposed unburned wood that caused the fire to grow. A second peak of $6.6 \mathrm{MW}$ is reached at 50 minutes after which the HRR begins a gradual decay. The HRR appears to stabilise at approximately $5.7 \mathrm{MW}$ after 57 minutes and the test was stopped at 63 minutes to protect the integrity of the structure. 


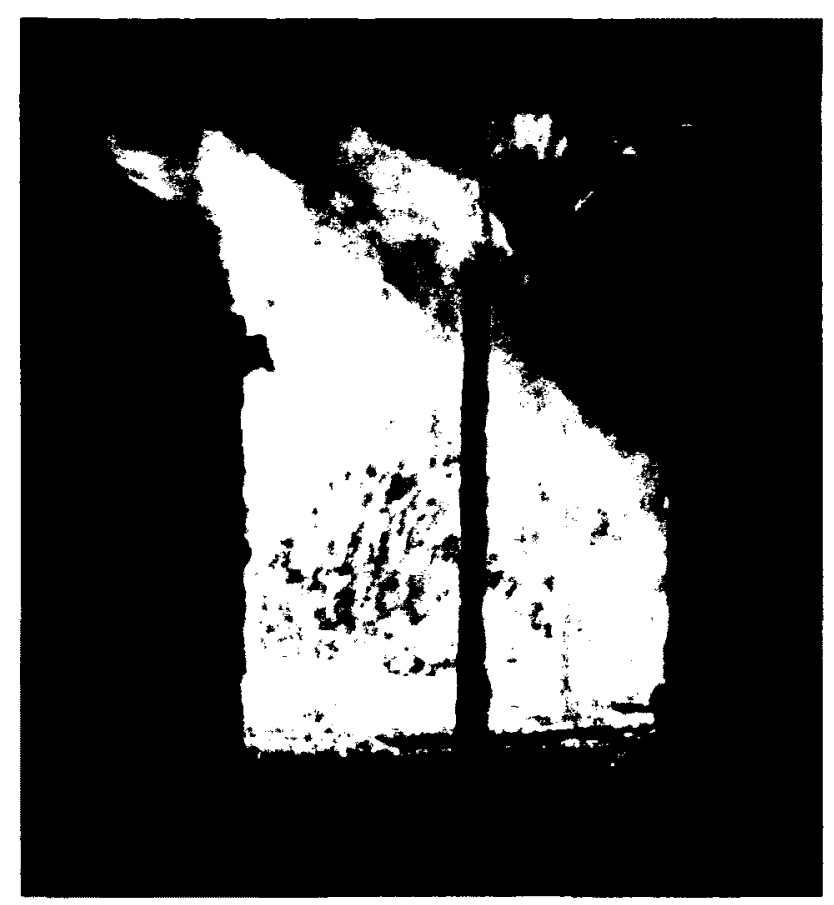

Figure 103 - Structure burning after most of furniture and hardwood flooring consumed - Test 5

\subsubsection{CLT contribution to HRR}

Similar to Test 3, Figure 102 shows a rapid rise in the CLT contribution to HRR at flashover as the structure becomes involved in the fire. This increases the growth rate of the HRR putting the room into flashover earlier than observed in the protected rooms of Tests 2 and 4 . The contribution from CLT is $5 \mathrm{MW}$ during the early stage of the fire increasing to up to $6 \mathrm{MW}$ when the first layer starts to delaminate. The period between 6 and 27 minutes suggests a decrease in contribution to HRR from the CLT, however this is unlikely as a constant rate of charring is expected. It is likely that the overall HRR is limited by the environment and a large proportion of volatiles released are transported away and not combusted.

A summary of energy released during the test is presented in Table 15 . The total energy is estimated by calculating the area under the graph using equation 1 . 
Table 15 - Energy released during test $5\left(\mathrm{MJ} / \mathrm{m}^{2}\right)$

\begin{tabular}{|c|c|c|c|}
\cline { 2 - 4 } \multicolumn{1}{c|}{} & Furniture & $\mathrm{CLT}$ & Total \\
\hline T5 & 366 & 612 & 978 \\
\hline
\end{tabular}

The CLT contribution is estimated using equation 2 by subtracting the average from Tests 2 and $4\left(366 \mathrm{MJ} / \mathrm{m}^{2}\right)$ from the total energy released giving a value of 612 $\mathrm{MJ} / \mathrm{m}^{2}$. This represents a $167 \%$ increase in contribution to HRR from the unprotected CLT panels.

\subsubsection{Temperature}

The average room temperature, presented in Figure 104, rises rapidly at flashover, as seen in previous tests, with a decrease in growth rate occurring at $825^{\circ} \mathrm{C}$ before rising to $980^{\circ} \mathrm{C}$ and stabilising. A drop is observed after 16 minutes, similar to that observed in Tests 3 and 4 , with the temperature stabilising at approximately $1000^{\circ} \mathrm{C}$ after 30 minutes. The plate thermometer rises to approximately $1000^{\circ} \mathrm{C}$, experiencing a dip after 13 minutes, before rising to approximately $1170^{\circ} \mathrm{C}$ at 24 minutes where it stabilises. 


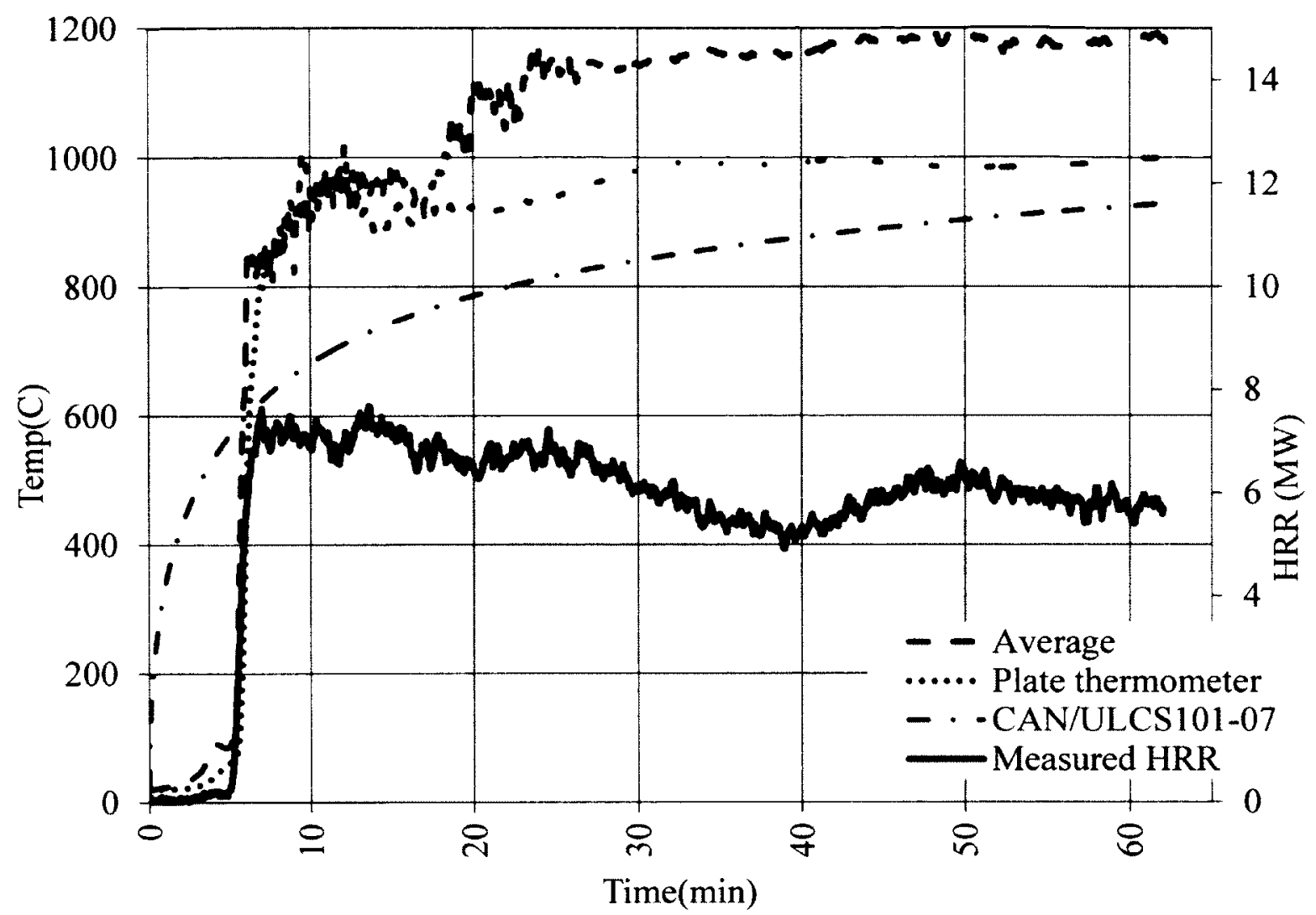

Figure 104 - Plate thermometer and Average room temperatures showing HRR Test 5

The temperature at the rear of the room reaches a lower peak than the centre and doorway which is likely an effect of limited ventilation as a large amount of volatiles are released in the room. This spikes to approximately $1100^{\circ} \mathrm{C}$ after 13 minutes nearing the peak temperatures reached at positions 1 and 4 in the centre of the room. The spike is likely due to an improvement in ventilation resulting from a decrease in volatiles production in the room, which can be expected as the initial peak for the furniture would have passed at this time. Drops in temperatures are observed in Figure 105 at all positions, similar to previous tests, before the temperatures throughout the room stabilise at approximately $1000^{\circ} \mathrm{C}$. 


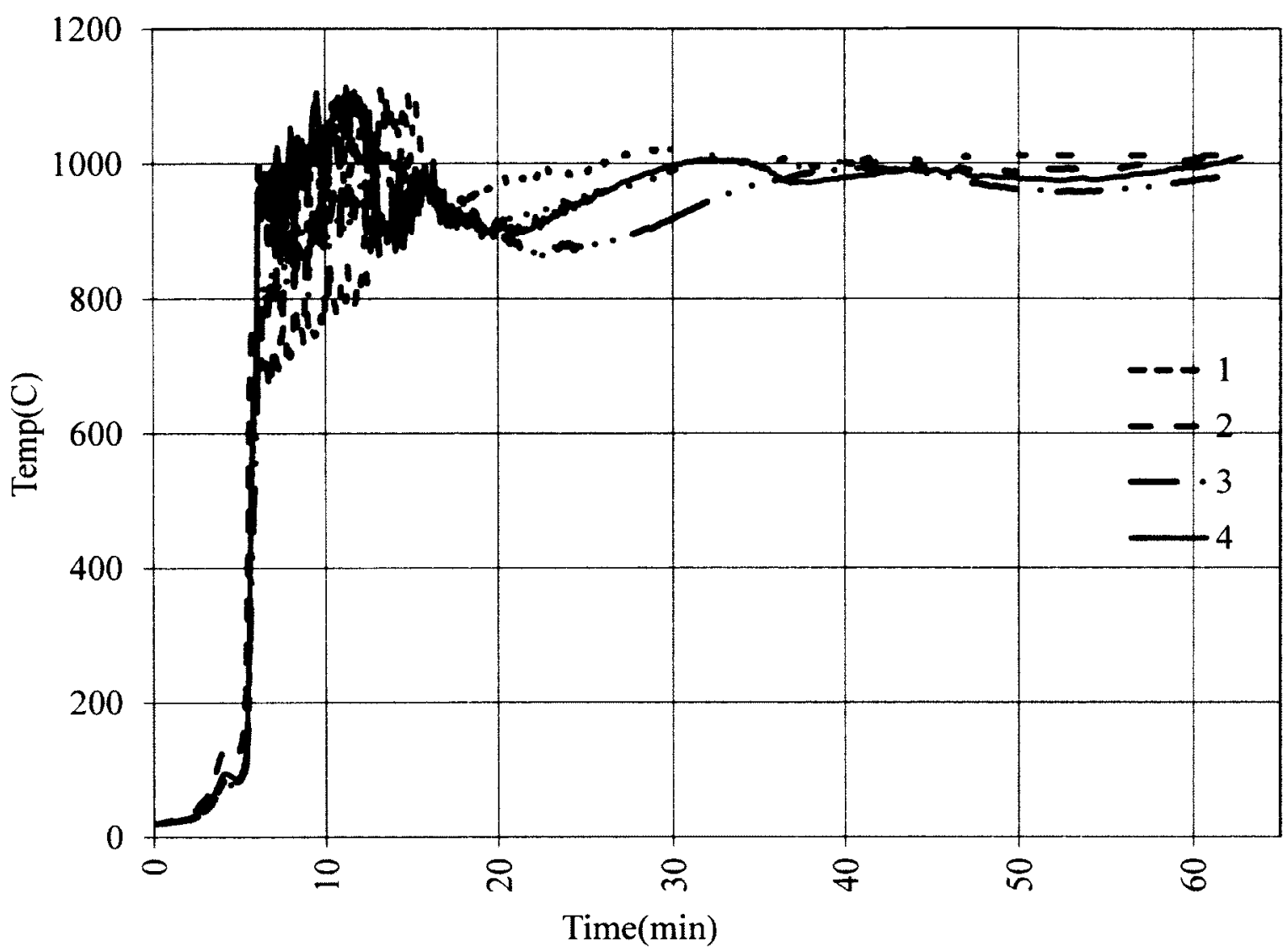

Figure 105 - Average temperatures at thermocouple tree positions - Test 5

The lower early temperatures at position 2 can be seen in Figure 106, Figure 107, Figure 108 and Figure 109 as well as the grouping at all positions as the temperatures stabilise after approximately 25 minutes. After 50 minutes the thermocouple tree collapsed at position 2 exposing the thermocouple wires to the flame and allowing flame and gases to exit through the penetration. An increase in temperature is noted in all points on the thermocouple tree indicating that all the readings have been affected. The temperatures approach that of the plate thermometer which showed consistently higher temperatures. For calculation of the average room temperature, presented in Figure 104 above, these increases have been disregarded. 


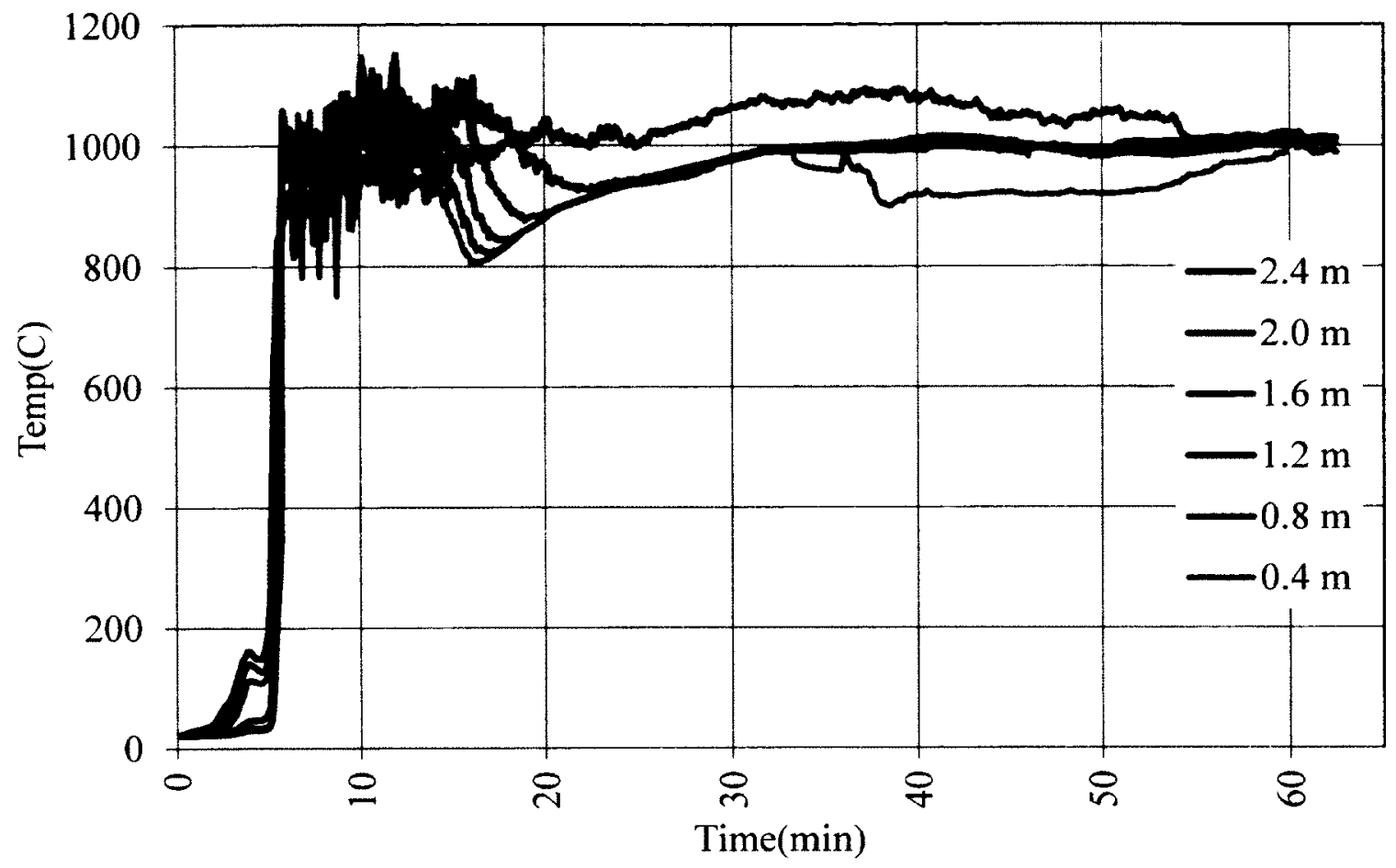

Figure 106 - Thermocouple Tree 1 temperatures - Test 5

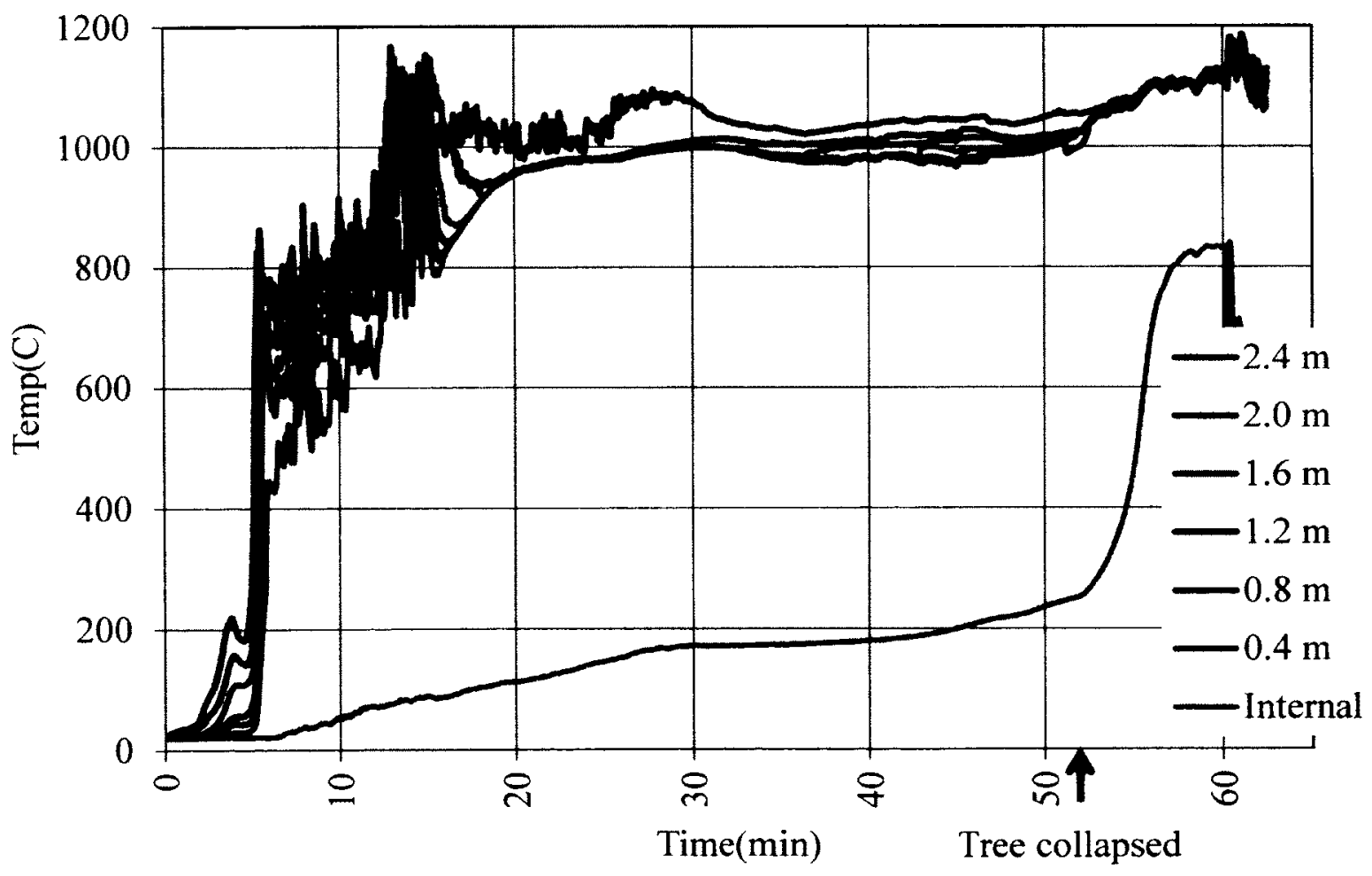

Figure 107 - Thermocouple Tree 2 temperatures - Test 5 


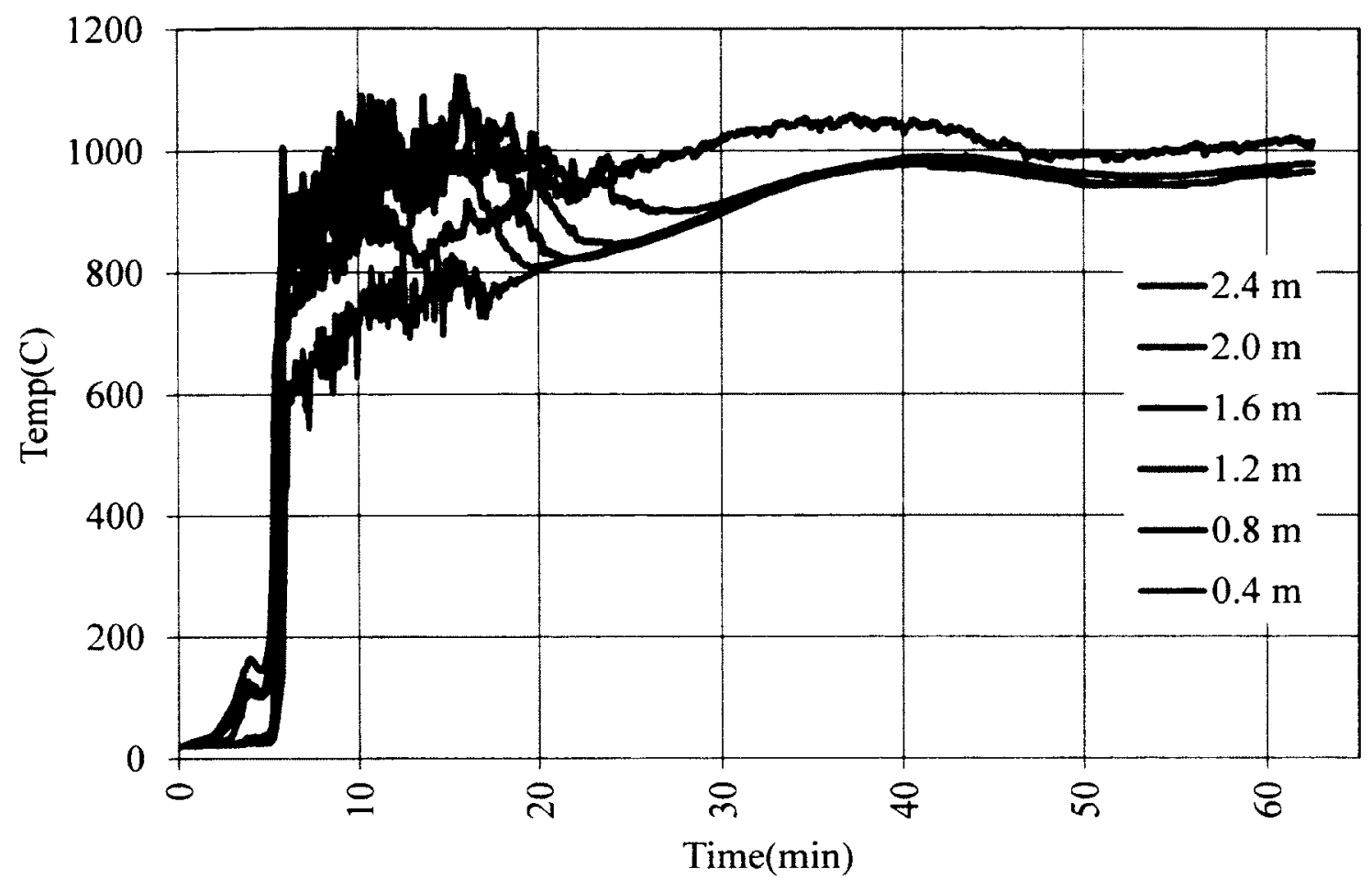

Figure 108- Thermocouple Tree 3 temperatures - Test 5

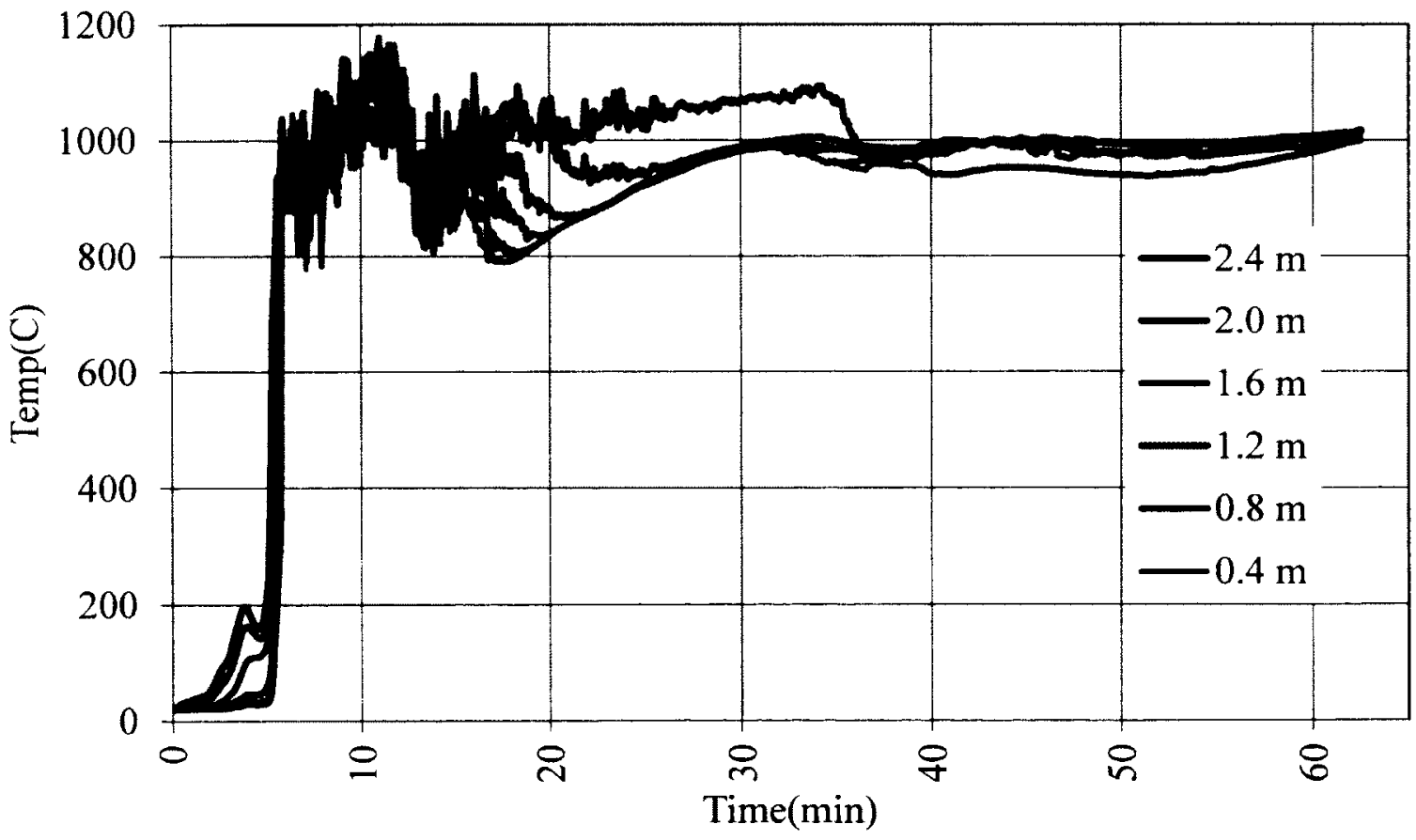

Figure 109- Thermocouple Tree 4 temperatures - Test 5 
Figure 110 shows glowing combustion observed through the joint at the rear wall at 50 minutes indicating that charring depth had advanced through to half the thickness of the CLT panels $(54 \mathrm{~mm}$ ) and that the lap joint had failed. This created a flow path allowing air into the room, likely increasing the intensity of the fire inside the room in the vicinity of the joint. This could also have acted as a path for the fire to spread. A temporary repair was applied covering the gap with a non-flammable panel which resulted in charring on the unexposed exterior rear wall shown in Figure 110.

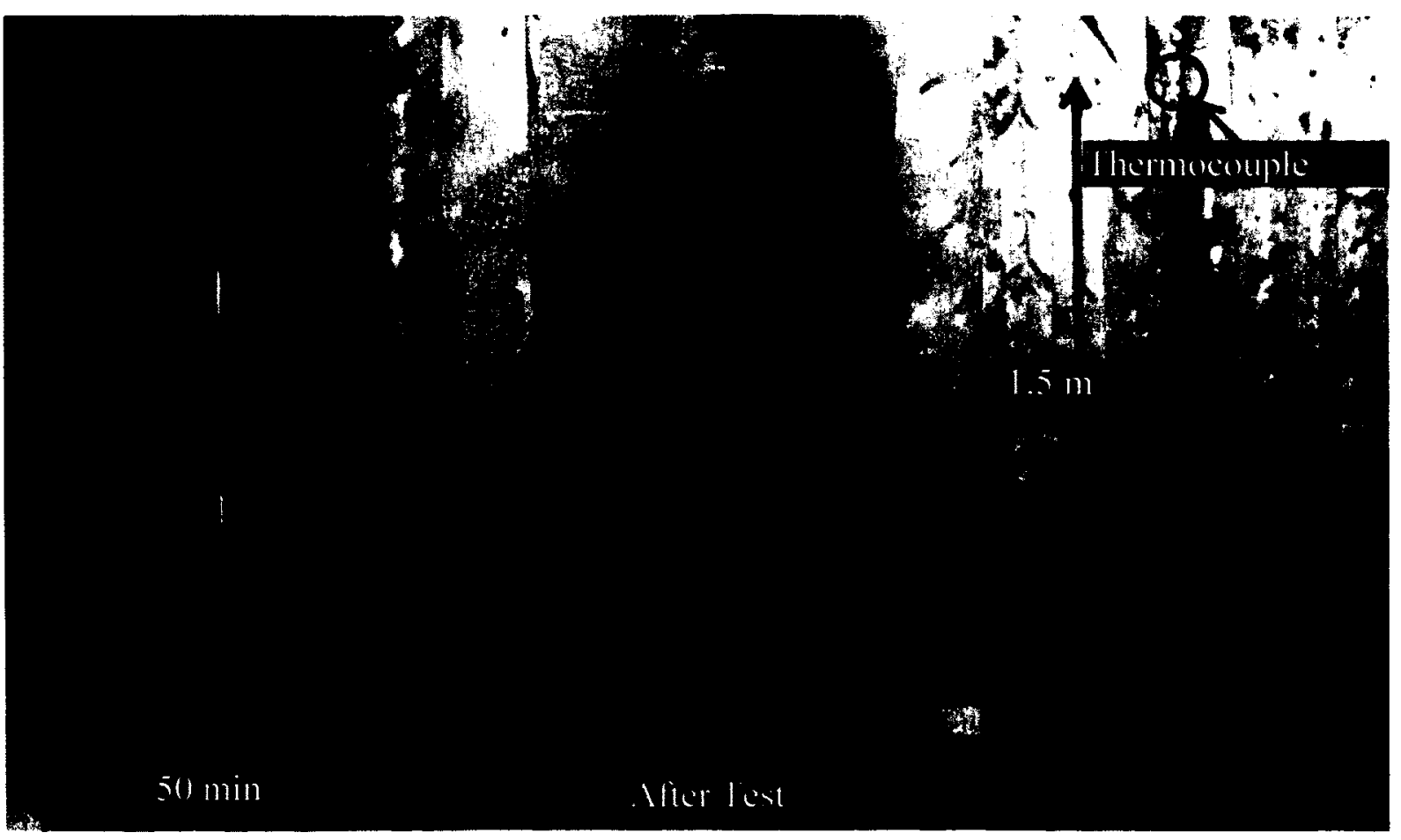

Figure 110 - Rear Joint failure - Test 5

The joint temperatures presented in Figure 111 show failure of the ceiling joint early on in the test, this was also observed by gases escaping as seen in Figure 112. The drop in temperature at 50 minutes occurred when water was sprayed on the roof which provided cooling for a short time. The temperatures of the other joints exhibit rises much 
later as a result of the pyrolysis and char fronts progressing through the structure. Despite the rear joint failing at 50 minutes near the floor, as seen in Figure 110, the measuring point does not indicating that the char rate at the two locations differ. This is likely due to a misalignment in the panel resulting in some separation at the base of the joint.

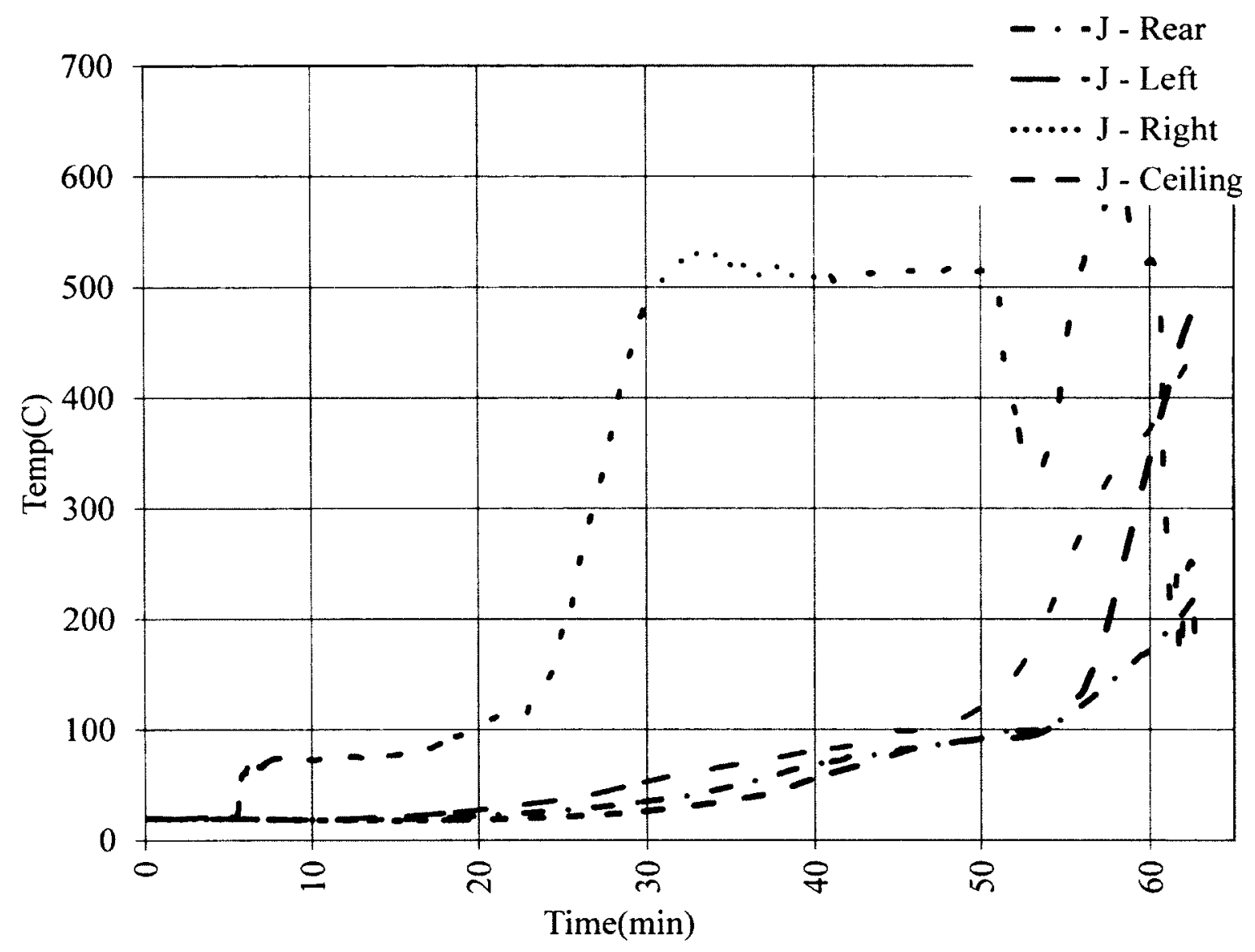

Figure 111 - Joint temperatures - Test 5

Insufficient sealing of existing penetrations can result in paths for fire spread.

Figure 112 shows flames that were observed from an insufficiently sealed lifting hole at 54 minutes. Gases can also be seen escaping from the ceiling joint. At approximately 58 minutes gases escaping from the rear right ceiling corner joint ignited with continuous flaming observed outside the room, this was extinguished with a garden hose but reignited several times. 


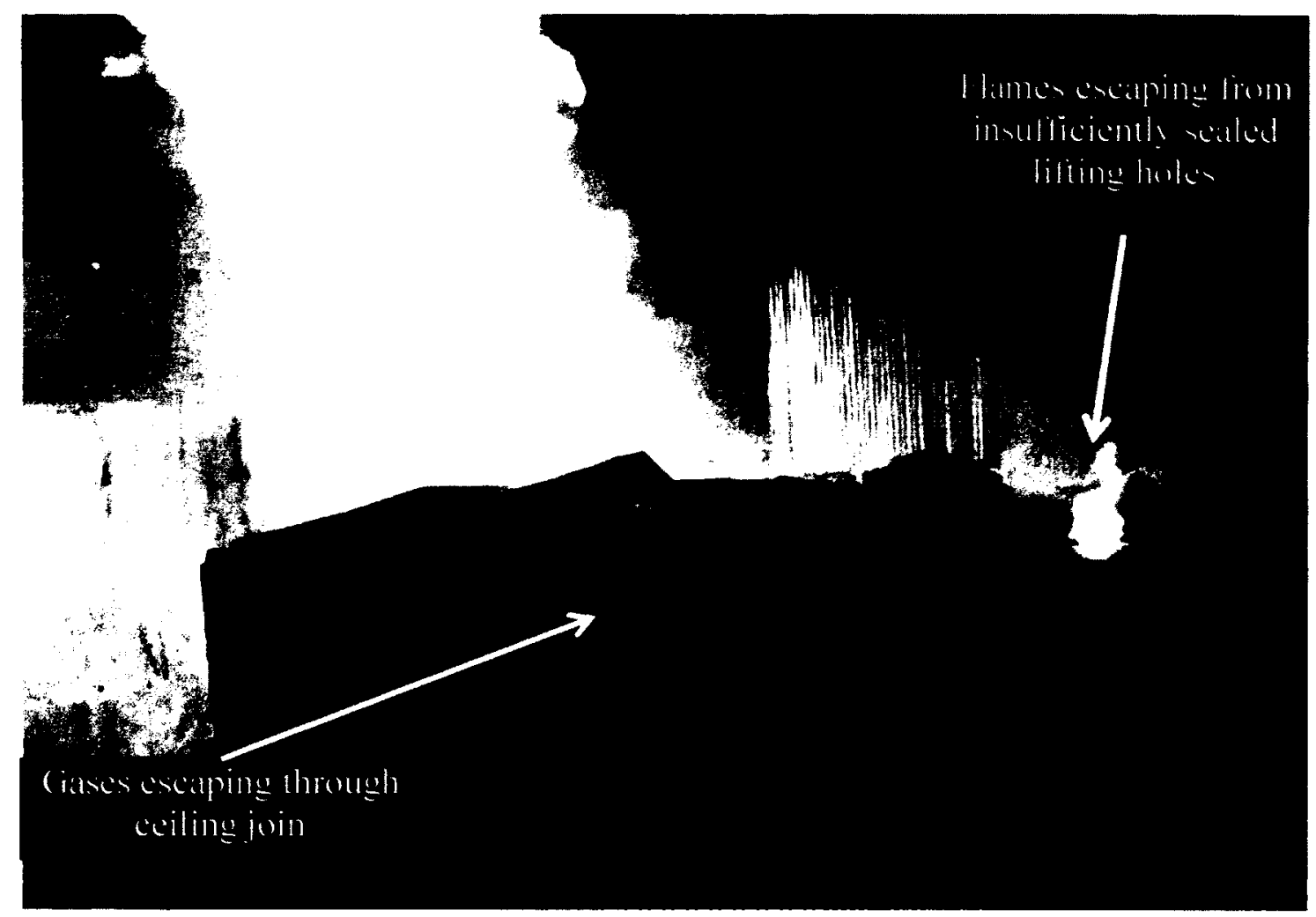

Figure 112 - Flaming from insufficiently sealed penetrations and gases escaping through ceiling joint.

A record of events that occurred is presented in Table 16 below, sourced from video, photographic and test records.

Table 16 - Table of events - Test 5

\begin{tabular}{|l|l|}
\hline & Event \\
\hline $00: 00$ & Test started, burner ignited - bedding \\
\hline $00: 20$ & Smoke detector activation \\
\hline $01: 21$ & Burner gas off. \\
\hline $02: 11$ & Fire increasing, airborne sparks visible, visibility hazy, smoke exiting door \\
\hline $03: 00$ & Flames touching wall behind bed, smoke layer defined \\
\hline $03: 34$ & Some flaming on walls - front camera fails - smoke layer 1/3 of door \\
\hline $03: 34$ & Flaming melted material visible under bed \\
\hline $04: 04$ & Flaming in smoke layer throughout room \\
\hline $05: 00$ & Flaming spread up walls and across ceiling \\
\hline $05: 19$ & HRR exceeds $1.055 \mathrm{MW}$, first flames exit room \\
\hline $05: 33$ & Continuous flaming of gas flow observed outside room \\
\hline
\end{tabular}




\begin{tabular}{|l|l|} 
05:55 & Floorboard surface ignites \\
\hline $07: 00$ & Peak HRR of 7.64 MW reached \\
\hline $27: 00$ & HRR begins to decay \\
\hline $35: 00$ & Most of floorboard consumed, walls burning \\
\hline $39: 00$ & HRR stops decaying and start to increase again \\
\hline $50: 00$ & HRR begins to decay for second time \\
\hline $50: 00$ & Thermocouple tree 2 partially collapses \\
\hline $55: 00$ & Glowing embers visible through rear joint, smoke coming from west joint \\
\hline $58: 00$ & Flaming externally from top right rear corner. \\
\hline 1:03:00 & Fire extinguished \\
\hline
\end{tabular}




\section{Chapter 5 : Discussion}

The observations are discussed collectively in this section to investigate the effects of CLT panels. The protected tests provide references against which the unprotected tests are compared and in many figures the data have been time corrected to allow direct comparison, which is specified.

Corrections applied to data in this section address a delay between the readings of propane and measured HRR that occurred due to the travel time of the products of combustion from the room to reach the measurement area of the chamber. Ko [21] measured these delays at 35 and 10 seconds for fan speeds between $25 \%$ and $100 \%$ respectively and also specified an additional 45 second delay time due to the gas analysis system. The observed delays in the calibration test for this setup were approximately 150 and 60 seconds at fan speeds of $25 \%$ and $75 \%$ respectively as seen in Figure 49 . To account for this, graphs have been adjusted to accurately predict the contribution of CLT panels in each of the tests. Graphs in this section have been overlaid to enable comparison of the growth rates once the fire took hold and may not represent the actual start times.

\subsection{Heat Release Rate}

\subsubsection{Propane Fires}

Figure 113 compares the measured flow of propane and the measured HRR from oxygen calorimetry in Tests 1 and 3 . A correction of -10 seconds is applied to Test 1 to align for comparison with Test 3 as detailed in Table 17. A large increase in fire growth rate is observed in Test 3 at approximately $1 \mathrm{MW}$ as the CLT panels become involved in the fire. The fire growth rate increased from fast $\left(0.0469 \mathrm{MJ} / \mathrm{s}^{2}\right)$ to $1.3 \mathrm{MJ} / \mathrm{s}^{2}$, exceeding 
the ultra-fast classification $\left(0.1896 \mathrm{MJ} / \mathrm{s}^{2}\right)$ as a result of the involvement of the CLT panels in the fire. The peak HRR of $8.75 \mathrm{MW}$ in Test 3 indicates a peak CLT contribution of approximately $5.75 \mathrm{MW}$ after 7 minutes as seen in Figure 77, almost twice the $3 \mathrm{MW}$ observed before combustion occurred outside the room.

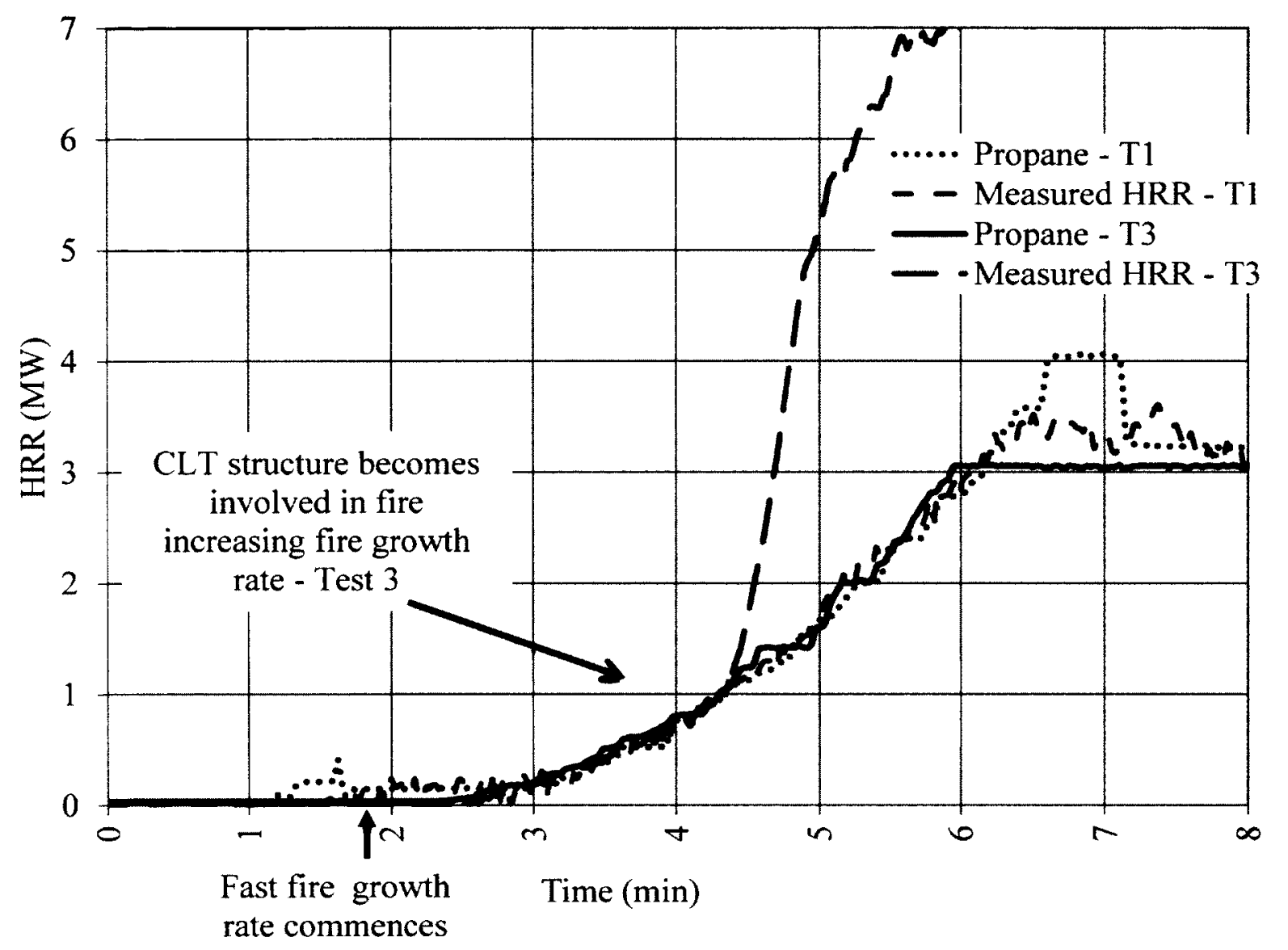

Figure 113 - Comparison of HRR growth rates for propane tests 
Table 17-Observed heat release rate development phase and corrections applied

\begin{tabular}{|c|c|c|c|c|c|c|}
\cline { 2 - 7 } \multicolumn{1}{c|}{} & \multicolumn{2}{|c|}{$\begin{array}{c}\mathrm{t}^{2} \text { Growth Rate } \\
\left(\mathrm{MJ} / \mathrm{s}^{2}\right)\end{array}$} & $\begin{array}{c}\text { Time to } \\
1.055 \mathrm{MW} \\
(\text { seconds })\end{array}$ & $\begin{array}{c}\text { Peak } \\
\text { HRR } \\
(\mathrm{MW})\end{array}$ & $\begin{array}{c}\text { Time }>1.055 \\
\mathrm{MW}(\mathrm{min})\end{array}$ & $\begin{array}{c}\text { Correction } \\
\text { applied } \\
(\text { seconds })\end{array}$ \\
\hline Test 1 & 0.0469 & Fast & 275 & 4.59 & $0: 44: 15$ & -10 \\
\hline Test 2 & 0.1876 & Ultra-fast & 348 & 5.60 & $0: 25: 02$ & -81 \\
\hline Test 3 & 1.3 & >Ultra-fast & 265 & 8.75 & $0: 23: 11$ & 0 \\
\hline Test 4 & 0.4 & > Ultra-fast & 547 & 5.72 & $0: 27: 55$ & -266 \\
\hline Test 5 & 1.3 & > Ultra-fast & 319 & 7.69 & $0: 57: 14$ & -93 \\
\hline
\end{tabular}

\subsubsection{Furniture Fires}

Figure 114 presents the growth rates observed in the Tests 2,4 and 5 with the furniture fuel source and hardwood flooring. The curves have been corrected and matched at $0.25 \mathrm{MW}$ for comparison. Corrections applied to each of the tests are detailed in Table 17. The growth rates in the protected tests were $0.1876 \mathrm{MJ} / \mathrm{s}^{2}$ and $0.4 \mathrm{MJ} / \mathrm{s}^{2}$ for tests 2 and 4 respectively, similar to the ultra-fast classification $\left(0.1896 \mathrm{MJ} / \mathrm{s}^{2}\right)$ and faster than the values of $0.055 \mathrm{MJ} / \mathrm{s}^{2}$ and $0.06 \mathrm{MJ} / \mathrm{s}^{2}$ observed for each of Chen's [40] tests. The faster growth rates between these and Chen's [40] tests may be related to the higher fire loads in these tests.

In Tests 2 and 4 a short plateau was observed as the HRR reached approximately $3 \mathrm{MW}$. This plateau likely represented the peak involvement of portable fire load in the room, whereas the further increase likely represented the hardwood floor becoming involved in the fire. The involvement of the hardwood floor likely to occurred later than other items in the room for the following reasons:

1. It was lower in the room where it was cooler for longer,

2. It was partially shielded from radiation from the hot layer, and 
3. It would have had a longer ignition time than the furniture in the room as it was made of denser and thicker wood.

In Test 5 the HRR began to rise rapidly at $0.4 \mathrm{MW}$ with a fire growth rate of 1.3 $\mathrm{MJ} / \mathrm{s}^{2}$ similar to that observed in Test 3 and much faster than Tests 2 and 4 . The lower value of $0.4 \mathrm{MW}$ in comparison to $1 \mathrm{MW}$ in Test 3 , was likely due to the effects of the furniture in the room vs a largely empty room for Test 3 and the elevated seat of the fire on top of the bed exposing the ceiling to direct flames earlier. The fire reaches 1.055 MW approximately 30 seconds earlier than Test 2 and continues to rise to a peak of 7.69 MW. The calculations of contribution of CLT panels to the fire indicate approximately 5 MW, as seen in Figure 102, similar to that from Test 3.

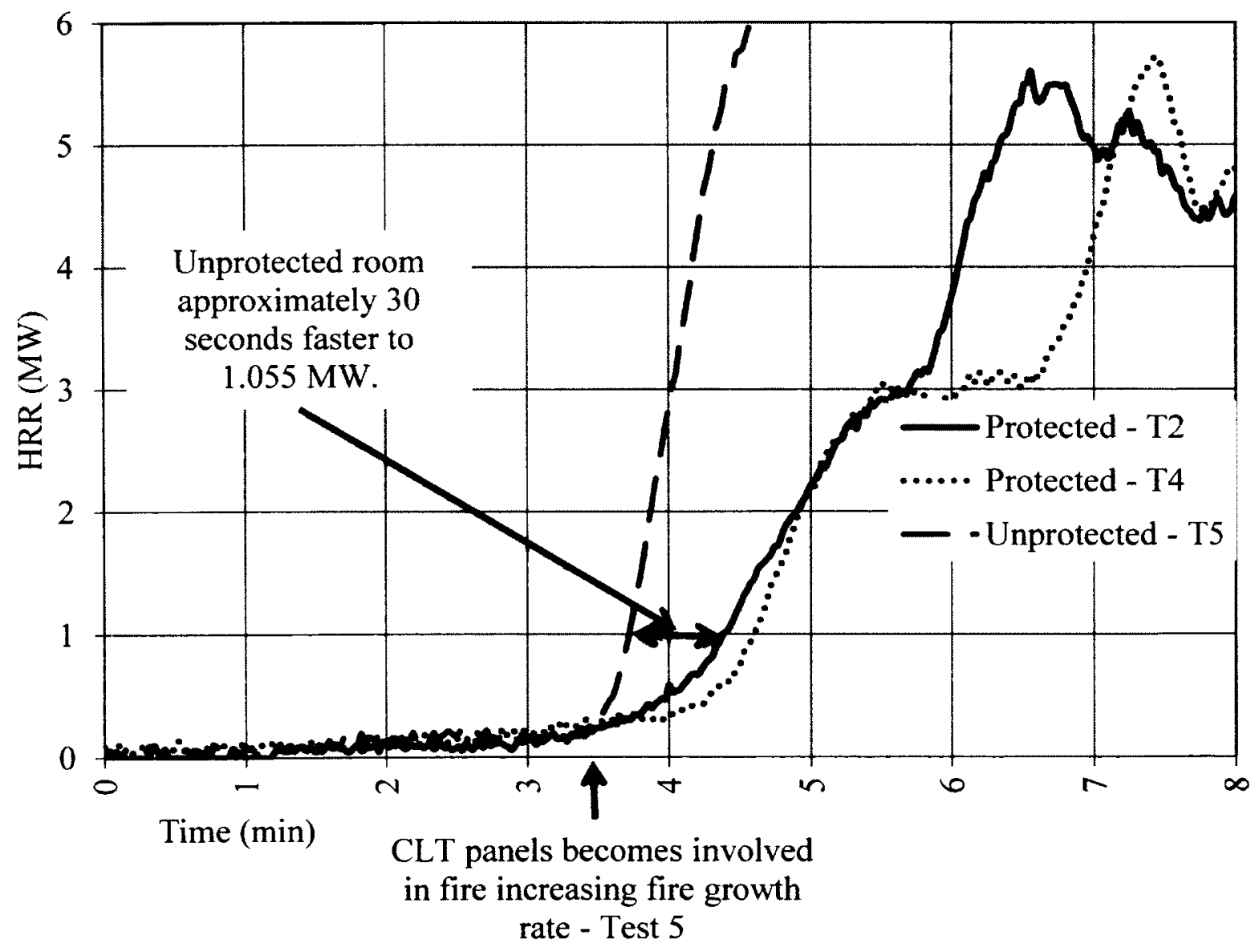

Figure 114 - Comparison of HRR growth phase of furniture tests 
Table 17 presents a summary of heat release rate during the development stage of each of the fires. These results show that exposed CLT panels increases the fire growth rates and peak heat release rates in room fires when compared to rooms with gypsum board protection.

\subsection{Temperatures}

A number of differences were observed during tests in relation to the temperatures recorded at different positions or with different equipment. Whilst these phenomena are interesting and may warrant further investigation to identify their source, there are of little significance to the major observations of this series of tests. The differences are discussed below.

\subsubsection{Minor internal temperature drops within CLT panels}

At the beginning of Tests 1 and 3, slight drops in temperature were observed at measuring points embedded in the panels. The temperatures drops ranged from $0.8^{\circ} \mathrm{C}$ to $6.9^{\circ} \mathrm{C}$ with the most significant drops shown in Figure 115 from Test 3 . Test 4 did not exhibit this phenomenon and there is no information available for Test 2.

It is suspected that this is a result of evaporation of moisture in the wood at the measuring position before heating occurred. This evaporation may have been driven by drying of the wood closer to the fire or a drop in pressure at the location related to the fire conditions in the room. The minimum temperatures observed in the structure for each of the tests remains above the wet bulb temperature of the ambient conditions, calculated using the psychrometric chart in Figure 116, which represents the minimum temperature to which air can be cooled through evaporation of water only. 


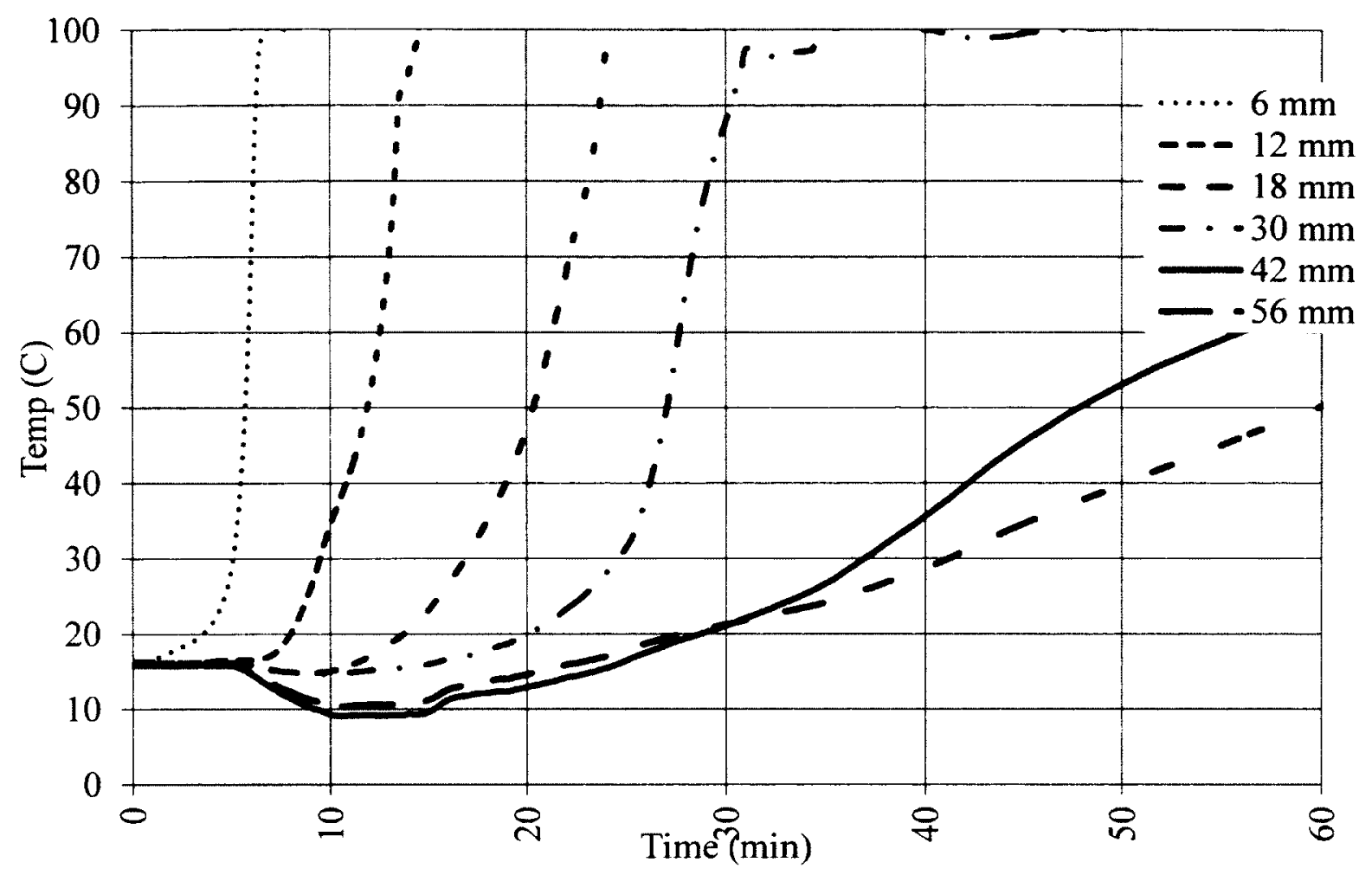

Figure 115 - Temperatures of embedded thermocouples at position W2 showing the temperature drops - Test 3

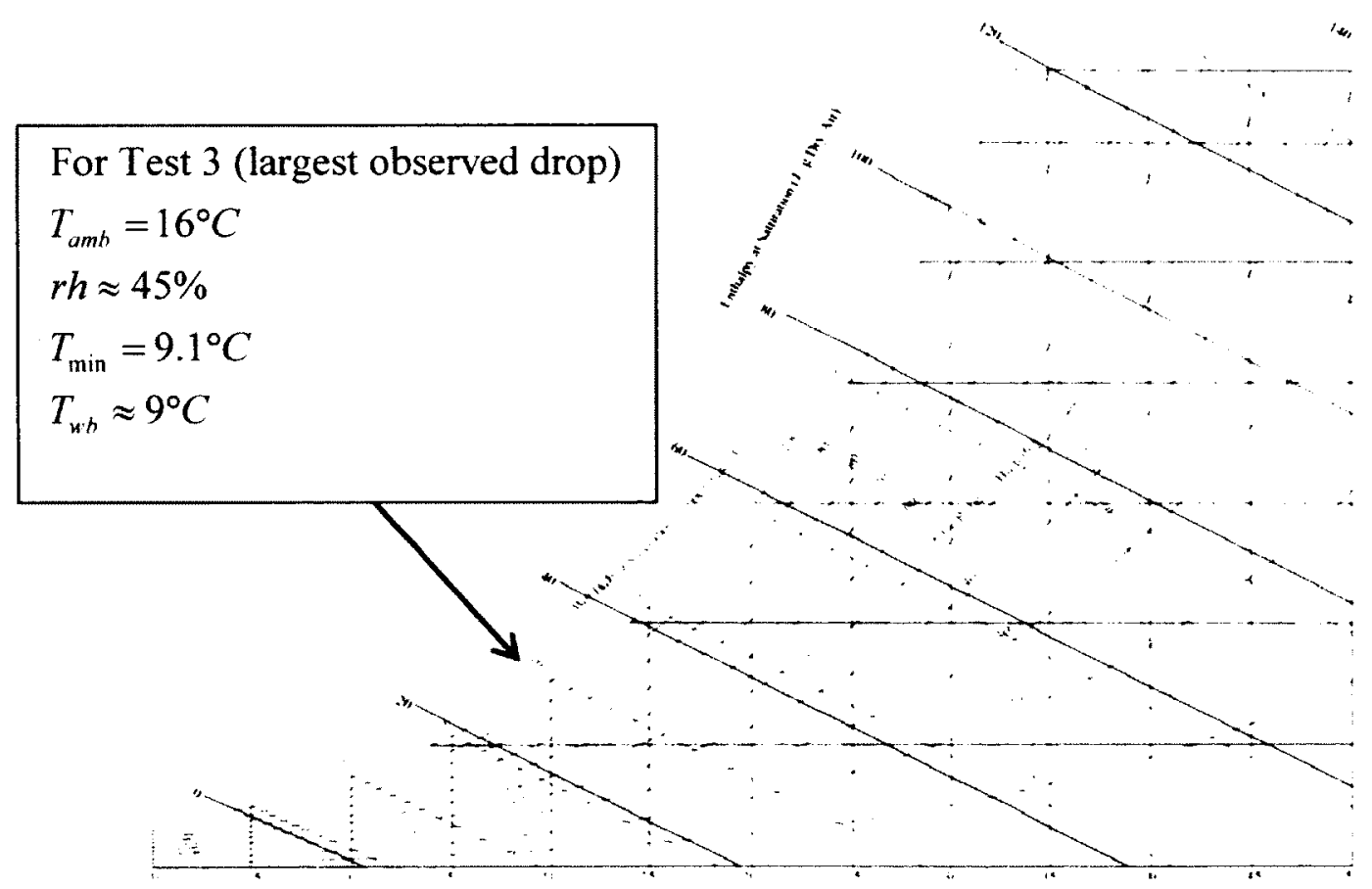

Figure 116 - Psychrometric chart showing wet and dry bulb temperatures [49] 


\subsubsection{Drops in room temperature following flashover}

Drops in temperature discussed in the observations for Tests 3,4 and 5 were observed at nearly all points inside the rooms for each of these tests after flashover. The temperatures later recovered however in most cases the temperatures at each thermocouple tree converged showing little or no difference in relation to height. The convergence of the temperatures indicates that the dominating mode of heat transfer was transitioning from convective to radiative. The original drops in temperature were likely related to changes in the environment due to poor ventilation, this is supported by the observation that positions lower in the room, where initial mixing of incoming air occurred, experienced the largest drops.

More pronounced effects can be observed in Hakkarainen's [38] heavy timber test and the Tsukuba [39] test where lower temperatures were observed early before gradual growth to peak temperatures which can be attributed to initial poor ventilation. It is likely that similar fire growth characteristics would be observed in fires with exposed CLT panels and limited initial ventilation.

\subsubsection{Plate thermometer and thermocouple tree points at $2.4 \mathrm{~m}$ height.}

In general the plate thermometer and thermocouples at $2.4 \mathrm{~m}$ displayed higher peak temperatures and were less affected by the drops in temperatures that were observed at other locations. It is likely that the differences observed are related to the proximity of the measuring points to the structure, $200 \mathrm{~mm}$, compared to $400+\mathrm{mm}$ for the other locations that would experience greater effects of convective heat transfer and mixing. It is also likely that these two locations would be exposed to more consistent flaming as the volatiles are released from the CLT panels and combustion occurring close the surface 
which explains the higher temperatures. Noting these observations, when considering the exposure of the CLT panels, it would be prudent to use the plate thermometer readings as this is representative of the localised environment at the boundaries. When considering the fire environment away from the boundaries of the room, considering life safety early in the test for example, the average temperatures are more relevant.

\subsubsection{Propane Tests}

Figure 117 presents the average room temperatures observed during the growth and flashover stages for Tests 1 and 3. Both graphs show similar features after transition from incipient to sustained growth occurs, with an increase in rate of temperature rise observed after reaching $300^{\circ} \mathrm{C}$ for the unprotected room and $400^{\circ} \mathrm{C}$ for the protected room. The higher peak in the protected room may be a result of the cleaner burning propane vs the mixture of propane and volatiles generated from the CLT panels. 


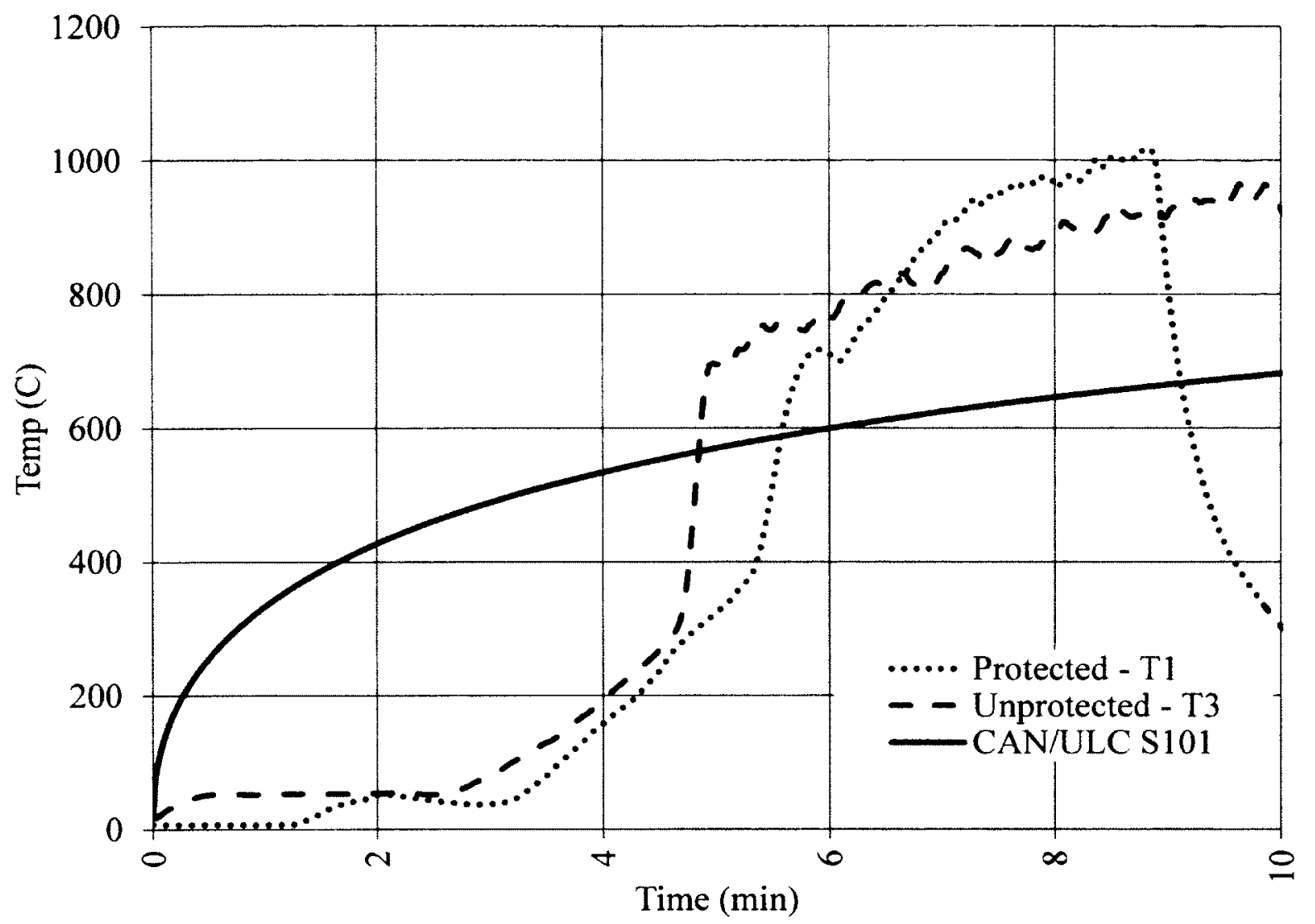

Figure 117 - Temperature increases observed in propane fires - Tests 1 and 3

\subsubsection{Furniture Tests}

Figure 118 presents the average room temperatures observed during the growth and flashover stages for Tests 4 and 5. Rates of temperature rise for both rooms are similar following transition from incipient to sustained growth and transition to slower rate of rise at approximately $650^{\circ} \mathrm{C}$ and $850^{\circ} \mathrm{C}$ for Test 4 and 5 respectively. This difference may be due to the composition of the fire environment, however it occurs at conditions well above those considered tolerable and is of little significance when considering life safety. 
Ultimately the two rooms reach a similar peak temperature which approaches $1000^{\circ} \mathrm{C}$.

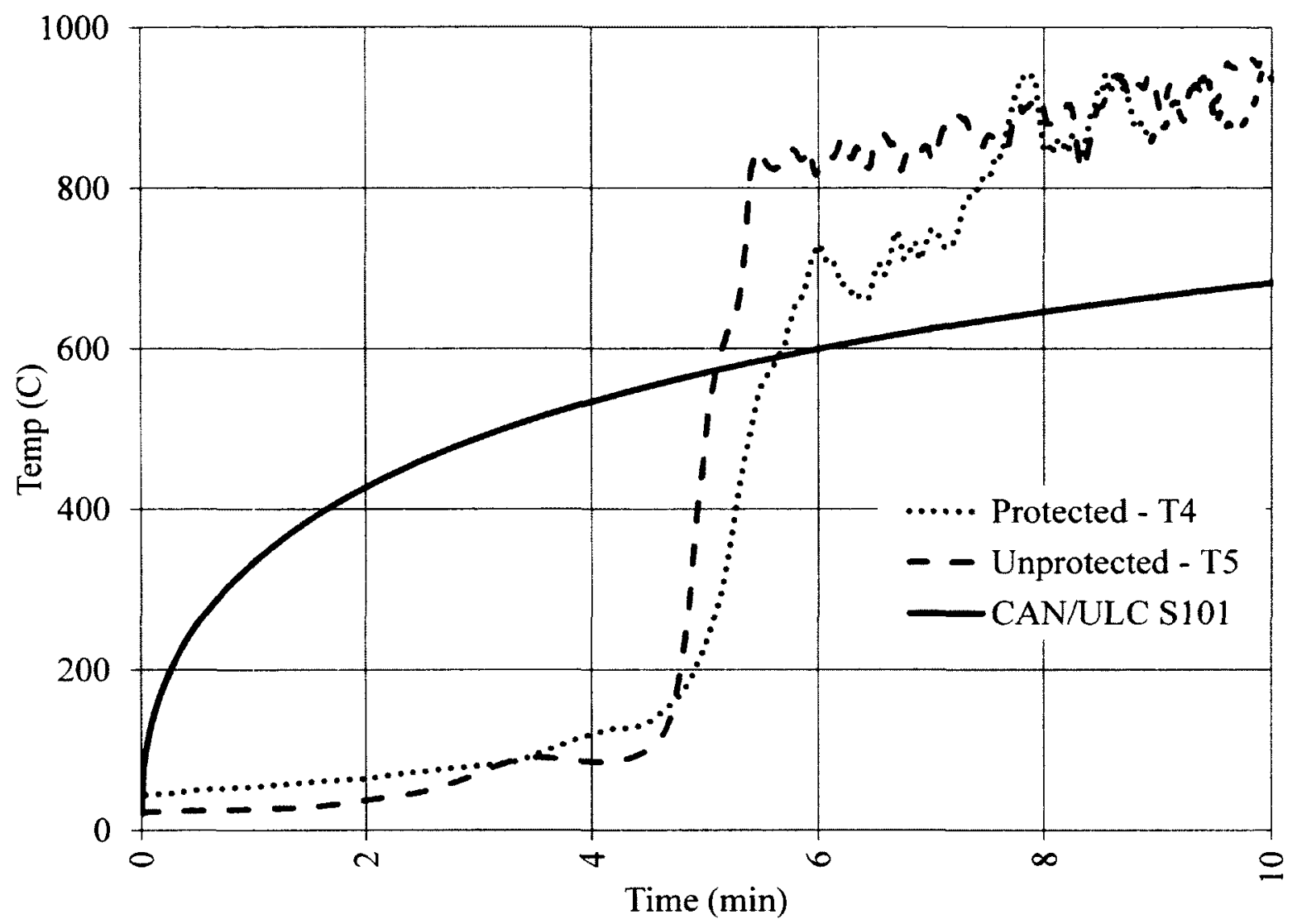

Figure 118-Temperature growth rates of furniture fires - Tests 4 and 5

\subsubsection{Average Room Temperatures}

The average room temperatures for Tests 1, 3, 4 and 5 are presented in Figure 119. Rooms experience a rapid temperature rise at flashover before transitioning to a phase of slower rate of rise. The protected room with propane fire in Test 1 yields noticeably higher temperatures which is likely a result of cleaner burning propane and less observed smoke than the other fires which involve furniture and the structure. The sustained temperature increases occurring at flashover are more rapid with higher peaks than those of the CAN/ULC test fire however they quickly decrease once the fuel is consumed. For the unprotected room in Test 5 however, delamination occurred, 
prolonging the duration of the fire and maintaining higher temperatures for an extended period resulting in higher severity than the standard test.

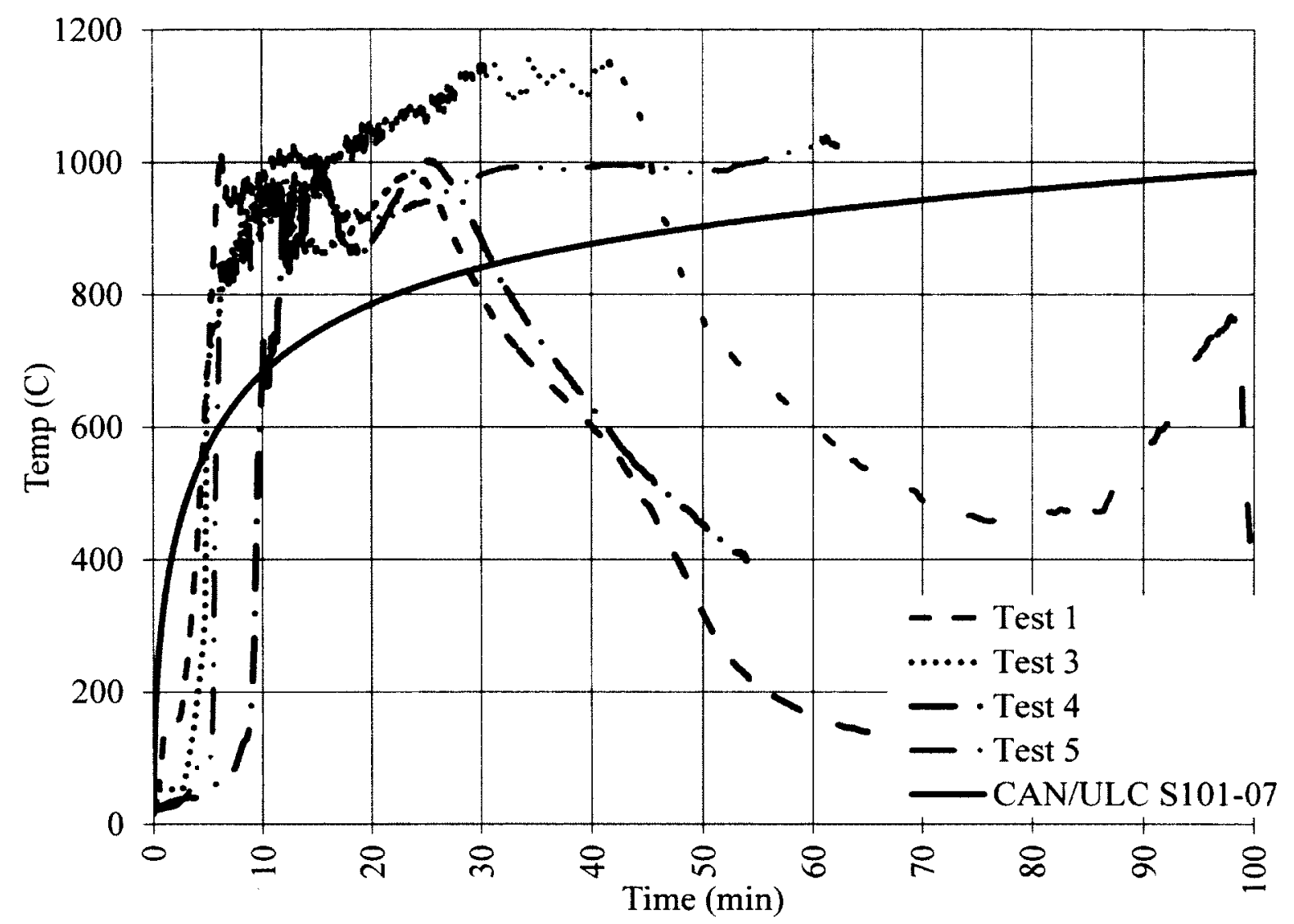

Figure 119 - Comparison of Average TCT room temperatures (second start only for Test 1)

The localised and average peak temperatures for the tests are presented in Table

18.

Table 18 - Peak temperatures observed in tests $\left({ }^{\circ} \mathrm{C}\right)$

\begin{tabular}{|c|c|c|c|c|}
\hline Test & $\begin{array}{c}\text { Plate } \\
\text { Thermometer }\end{array}$ & Average & Localised & $\begin{array}{c}\text { Thermocouple Tree } \\
\text { position }\end{array}$ \\
\hline 1 & $1212^{\circ} \mathrm{C}$ & $1157^{\circ} \mathrm{C}$ & $1304^{\circ} \mathrm{C}$ & $2-1.6$ \\
\hline 3 & $1140^{\circ} \mathrm{C}$ & $982^{\circ} \mathrm{C}$ & $1128^{\circ} \mathrm{C}$ & $2-2.4$ \\
\hline 4 & $1109^{\circ} \mathrm{C}$ & $1081^{\circ} \mathrm{C}$ & $1154^{\circ} \mathrm{C}$ & $2-2.4$ \\
\hline 5 & $1192^{\circ} \mathrm{C}$ & $1039^{\circ} \mathrm{C}$ & $1187^{\circ} \mathrm{C}$ & $2-2.4$ \\
\hline
\end{tabular}




\subsection{Fire load and energy released}

Table 19 presents the fire load and energy release information for each of the tests. The HRR measurement system showed accurate alignment with the measured propane heat release rate in Tests 1 and 3, which allowed accurate measurement of the contribution from the CLT panels. For Tests 2 and 4, protected rooms with furniture fires and no observed contribution of the CLT panels, the measured energy released averaged $68 \%$ of the estimated fire load in each of the rooms $\left(Q_{t r r}^{n}=0.68 Q_{t u m}^{n}\right)$. To provide a comparison between the different fuel types, this value was used to estimate equivalent fire load densities of the propane fires, using Eq 31 giving values of $710 \mathrm{MJ} / \mathrm{m}^{2}$ and 266 $\mathrm{MJ} / \mathrm{m}^{2}$ for Tests 1 and 3 respectively.

$$
Q_{\text {cquiv }}^{n}=\frac{Q_{\text {l.um }}^{n}}{0.68}
$$

In the unprotected configurations, Tests 3 and 5, the involvement of the CLT panels increased the energy release by $153 \%$ and $167 \%$ respectively, demonstrating the potential for the structure to contribute to the fire load. Test 5 had to be extinguished demonstrating that the potential contribution could have been much higher. The implications for fire protection arrangements may be significant if considering the CLT panels in the fire load densities at design. 
Table 19 - Test fire loads and measured energy released $\left(\mathrm{MJ} / \mathrm{m}^{2}\right)$

\begin{tabular}{|c|c|c|c|c|c|c|}
\hline & \multicolumn{2}{|c|}{ Propane } & \multicolumn{2}{|c|}{ Furniture } & \multirow{2}{*}{$\begin{array}{c}\text { CLT } \\
\text { Calculated } \\
\text { Heat } \\
\text { Released } \\
\left(\mathrm{MJ} / \mathrm{m}^{2}\right)\end{array}$} & \multirow[b]{2}{*}{$\begin{array}{c}\text { Total } \\
\text { Heat } \\
\text { Release } \\
\left(\mathrm{MJ} / \mathrm{m}^{2}\right)\end{array}$} \\
\hline & $\begin{array}{c}\text { Actual } \\
\text { Heat } \\
\text { released } \\
\left(\mathrm{MJ} / \mathrm{m}^{2}\right)\end{array}$ & $\begin{array}{c}\text { Furniture } \\
\text { equivalent } \\
\left(\mathrm{MJ} / \mathrm{m}^{2}\right)\end{array}$ & $\begin{array}{c}\text { Measured } \\
\text { Heat } \\
\text { released } \\
\left(\mathrm{MJ} / \mathrm{m}^{2}\right)\end{array}$ & $\begin{array}{l}\text { Estimated } \\
\text { Fire Load } \\
\left(\mathrm{MJ} / \mathrm{m}^{2}\right)\end{array}$ & & \\
\hline Test 1 & 486 & 710 & - & - & 200 & 686 \\
\hline Test 2 & - & - & 379 & 533 & - & 379 \\
\hline Test 3 & 182 & 266 & - & - & 408 & 590 \\
\hline Test 4 & - & - & 364 & 553 & - & 364 \\
\hline Test 5 & - & - & 366 & 529 & 612 & 978 \\
\hline
\end{tabular}

Figure 120 presents the total energy released during each of the tests with corrections to align with the fast propane fire so that HRR values for each test pass through $1.055 \mathrm{MW}$ at 150 seconds. The corrections used are presented in Table 20. In the unprotected configurations, Tests 3 and 5 , the energy is released at approximately twice $(\sim 7.15 \mathrm{MW})$ the rate of the protected configurations, Tests 1,2 and $4(\sim 3.5 \mathrm{MW})$, which also corresponds to twice the amount of volatiles and gases released. The increase in fire load associated with the CLT panels is accompanied with an increase in fuel surface area (walls and ceiling) that increases the production rate of volatiles as the fire develops. The increased rate in generation of volatiles increases the risk of fire spread locally when combustion occurs, however can also present a remote hazard through the transport of combustible gases in cases of low ventilation. The corresponding increase in generation of gases and smoke significantly increases the associated life safety hazards. 


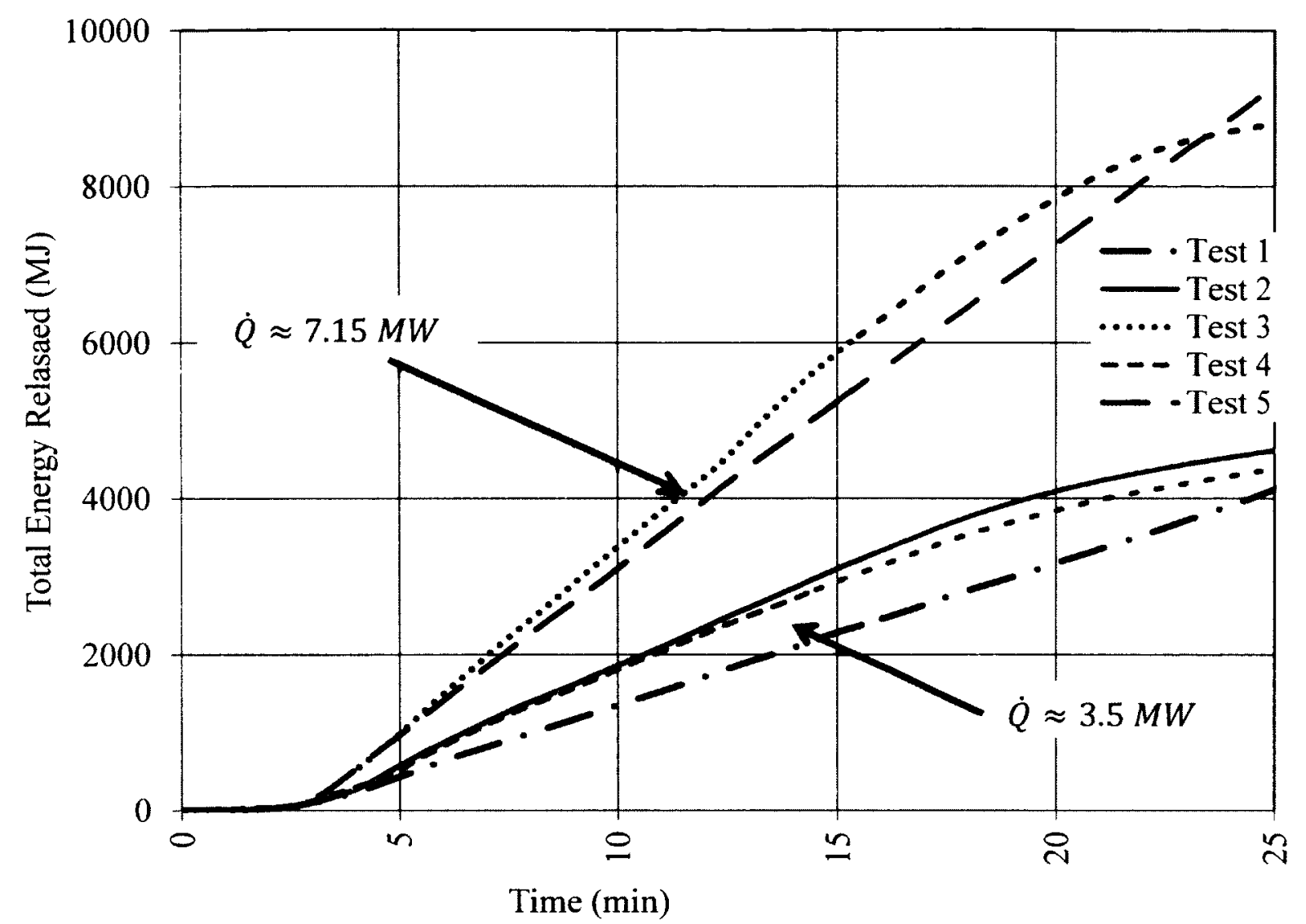

Figure 120 - Comparison of total energy released for all tests (corrected to 1.055 MW at 150 seconds)

Table 20 - Original times and corrections applied to match energy release curves to $1.055 \mathrm{MW}$ at 150 seconds

\begin{tabular}{|c|c|c|}
\cline { 2 - 3 } \multicolumn{1}{c|}{} & $\begin{array}{c}\text { Time to } 1.055 \mathrm{MW} \\
\text { (seconds) }\end{array}$ & $\begin{array}{c}\text { Correction applied } \\
\text { (seconds) }\end{array}$ \\
\hline Test 1 & 275 & -125 \\
\hline Test 2 & 348 & -198 \\
\hline Test 3 & 265 & -115 \\
\hline Test 4 & 547 & -397 \\
\hline Test 5 & 319 & -169 \\
\hline
\end{tabular}

Whilst gypsum board protection was in place, the CLT panels did not contribute to the HRR in the room, however once the protection failed, the structure became involved which was observed in Test 1. 
The observations from Tests 1 and 3 indicate that flaming of the CLT panels will self-extinguish after the fuel source is removed, similar to a thick slab of wood [9], before delamination occurs. If charring continues, the polyurethane at the interface between the CLT layers fails due to heat and delamination occurs [50] contributing to the fire in two ways

1. The delaminated layer members fall creating piles of partially burned timber which continues to burn, effectively increasing the fuel load in the room; and

2. Delamination exposes the uncharred next layer, shown in Figure 121 which rapidly contributes combustible gases into the environment. Charring, and the release of volatiles, is expected to occur at up to twice the normal rate on the newly exposed surface after delamination occurs, similar to that reported in Eurocode 5 [13] for early failure of protected timber following failure of protective linings.

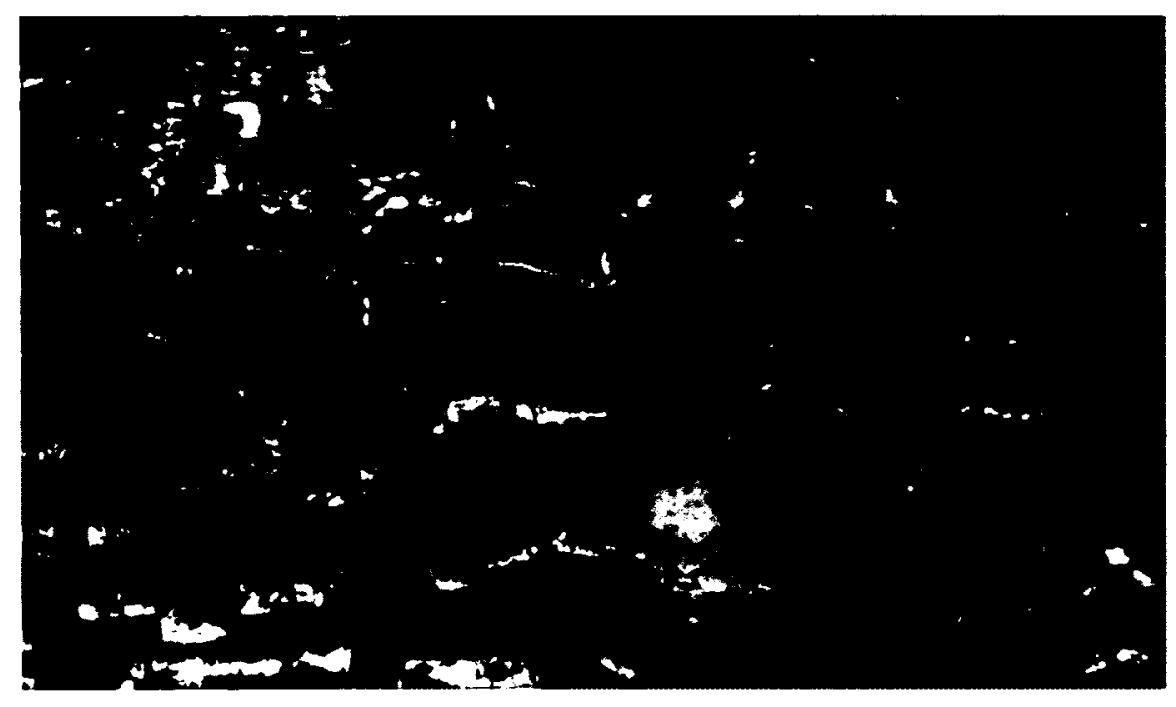

Figure 121 - Newly exposed layer following delamination

Delamination was observed in Test 1 where the room returned to flashover approximately 40 minutes after the propane fire had been shut off completely, this was 
also observed in Test 5 where delamination reversed the decay of the HRR in the room after the fire load should have been largely consumed.

These results show that exposed CLT panels can have a significant effect on the generation rate of volatiles increasing the fire size and products of combustion as well as extending the duration through delamination of layers.

\subsection{Joint temperatures}

No sealant was used for the joints in Test 1 during which gases were observed escaping from the joints in many places. A fire rated silicon was used in the remaining tests to seal the joints which was more effective, however gases were observed escaping from joints to some degree in all tests.

Increases in temperature at the joints were observed earlier than at equivalent depth in the panels indicating leakage. In most cases the temperatures approached $100^{\circ} \mathrm{C}$ indicating that the leakage was likely made up of water vapor being driven from either the gypsum board or the panels.

The center layer of the 3-ply panels contains gaps between individual members which have not been glued along the edges as shown in Figure 122. These gaps act as channels for the flow of gases to the joints where the gases escape.

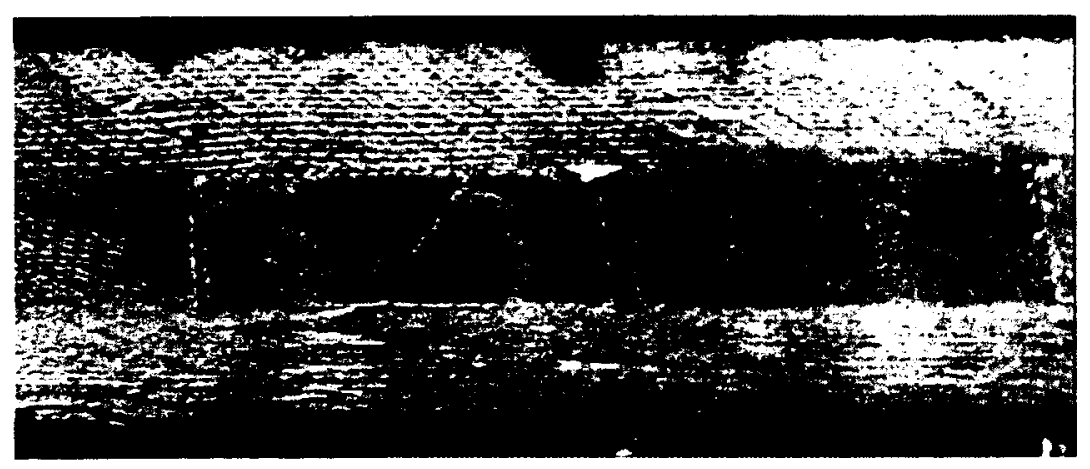

Figure 122 - Gaps between non-structural middle layer members 
The most significant failure of the ceiling joint was observed in Test 5 which resulted in much higher temperatures indicating transport of gases from the fire. Glowing combustion was also observed through part of the rear joint once charring reached the depth of the lap joint.

\subsection{Gypsum-CLT Interface}

Two layers of $12.7 \mathrm{~mm}$ fire rated gypsum board were used for the protected tests. Gypsum board is an effective method of protection and its use in these tests has shown that each layer delays the onset of charring by at least 20 minutes. Until failure, the temperature at the interface of the gypsum and CLT is maintained at or below $100^{\circ} \mathrm{C}$ whilst chemically bound water [48] is driven from the gypsum board. Once the gypsum loses the chemically bound water it may fall off, however in many places during the tests, the gypsum remained in place providing protection resulting in lower temperatures than experienced in the room. Gypsum board was also shown to act as an insulator permitting charring after the fire had been extinguished. This was observed up to several hours after the fire was extinguished.

\subsection{Charring}

Charring of the CLT panels was not observed in Tests 2 and 4, with maximum temperatures at the gypsum/CLT interface observed at $161^{\circ} \mathrm{C}$ and $132^{\circ} \mathrm{C}$ respectively. Charring rates were calculated using thermocouples embedded in the structure at different depths from the exposed surface to track the progress of the char front, indicated by the $300^{\circ} \mathrm{C}$ isotherm. To measure the final char depth, a wire brush was used to remove the char from each section of CLT panels leaving solid timber exposed as shown in Figure 123. 


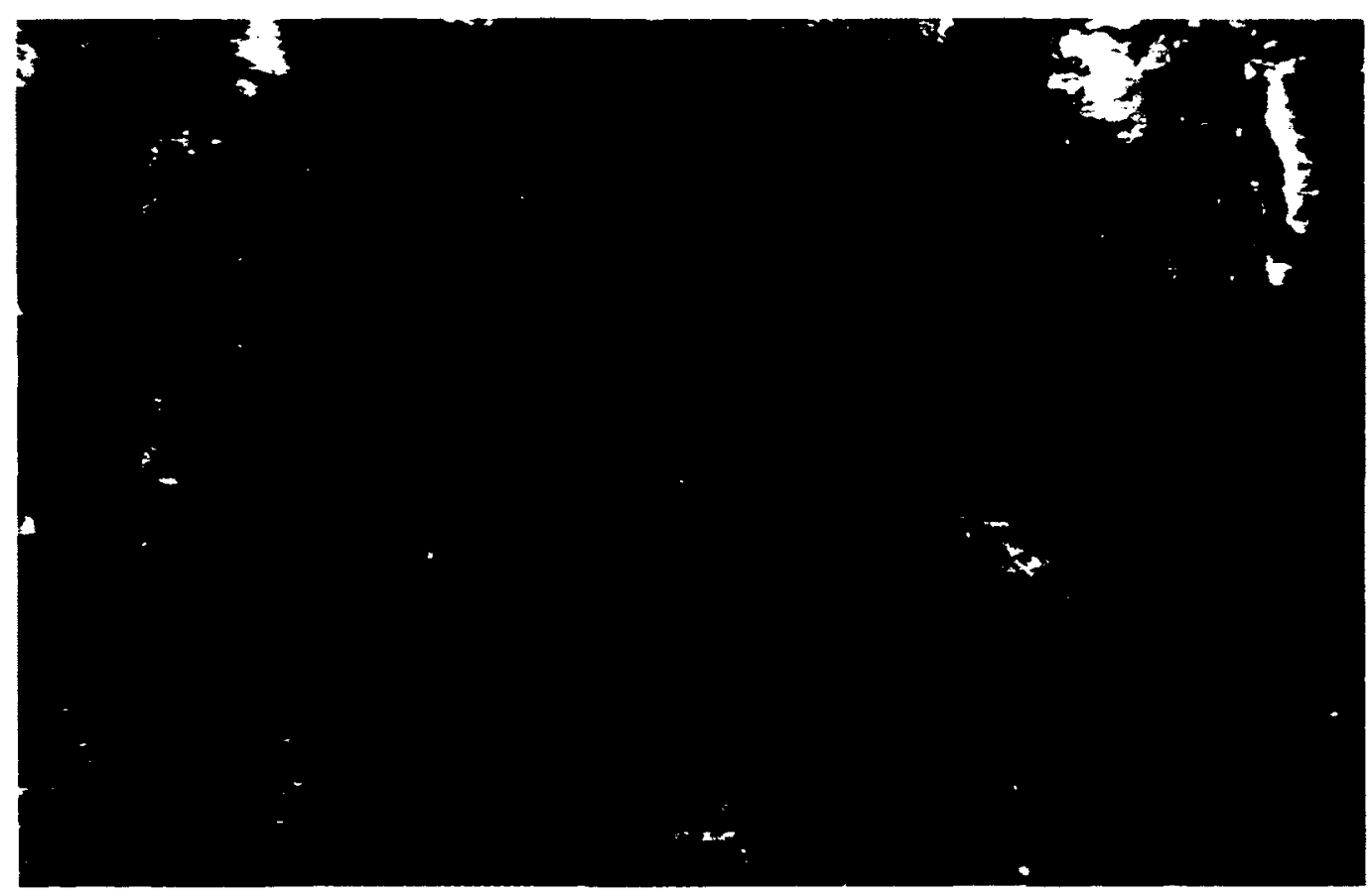

Figure 123 - Example of prepared char test measurement position

\subsubsection{Test 1 - Protected room with propane fire}

The charring depths observed in Test 1 are presented in Figure 124. Charring starts at different times for each of the measuring points commencing when the gypsum board protection had failed. Very high average charring rates of $1.27 \mathrm{~mm} / \mathrm{min}$ and 1.67 $\mathrm{mm} / \mathrm{min}$ were observed at ceiling positions $\mathrm{Cl}$ and $\mathrm{C} 2$ respectively after the gypsum was observed falling off. These rates are approximately twice that normally expected, however consistent with increased rates of charring following failure of protective system recommended in Eurocode 5 [13].The lower charring rates experienced at the wall positions can be explained by the gradual failure of the degraded gypsum vs the sudden falling off of entire sheets at the ceiling. Charring continued at wall position W4 well after the propane fire had been turned off. This is an area of the wall where the gypsum fell off and near the position where delamination occurred initiating a second flashover. 


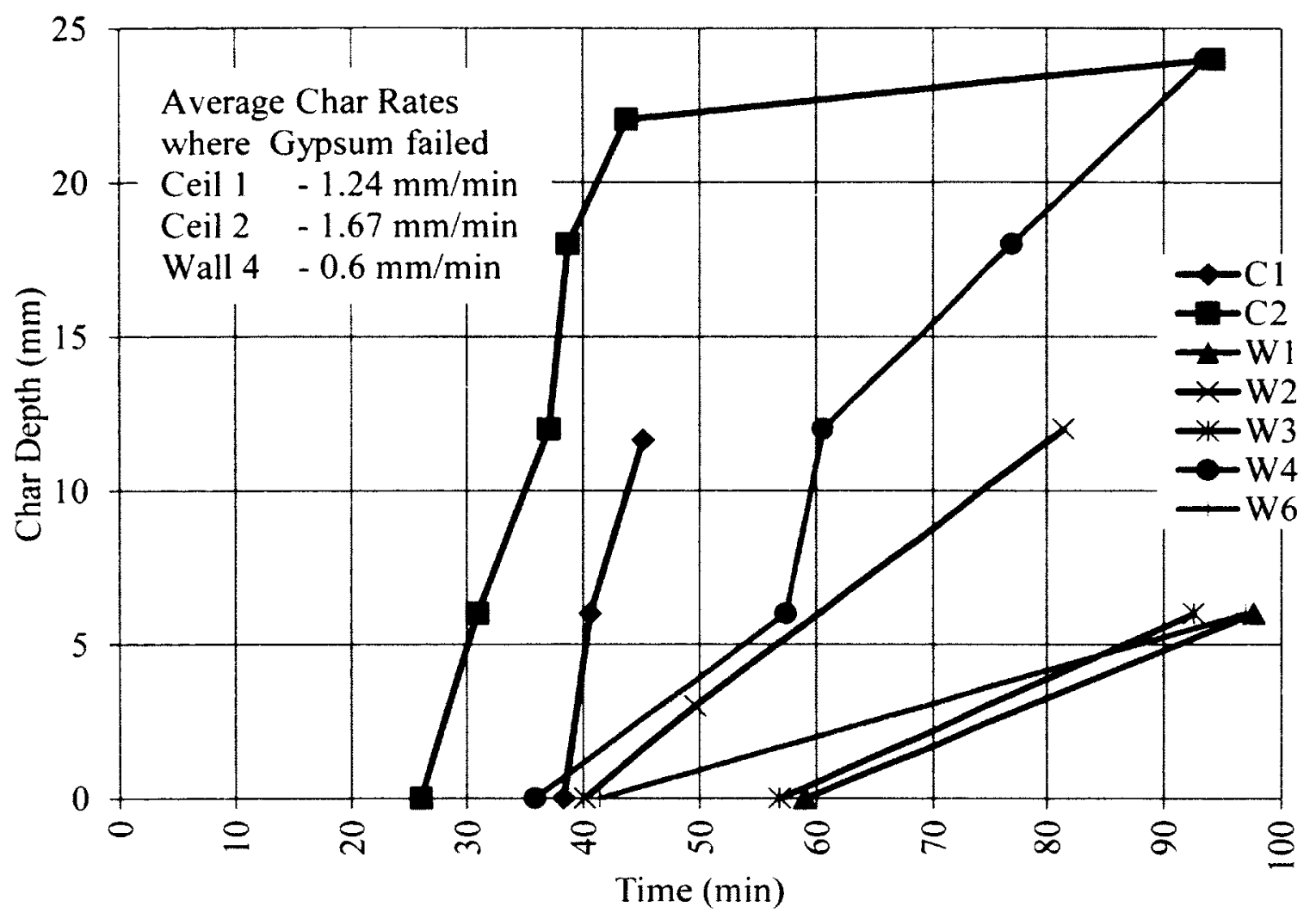

Figure 124 - Charring of CLT panels - Test 1

Extensive charring occurred in Test 1 after the gypsum board protection failed.

The most extreme charring occurred where the gypsum board fell away from the structure completely which was mainly on the ceilings and the walls nearest to the seat of fire. The gypsum remained in place in other locations, however charring and pyrolysis occurred extensively behind the gypsum with volatiles escaping at the joints resulting in flaming as shown in Figure 125. 


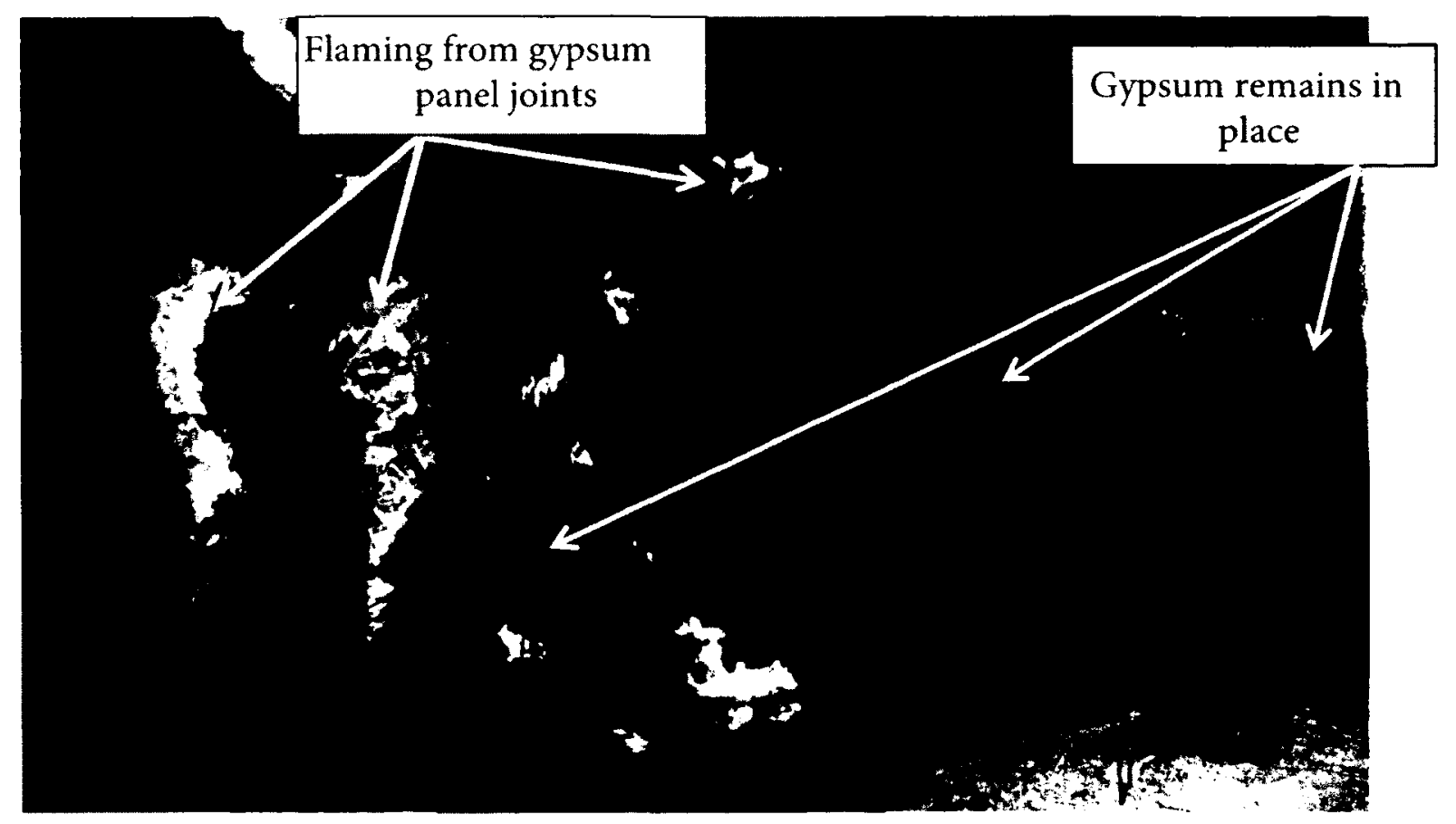

Figure 125 - Gypsum panels remaining in place following release of chemically bound water - Test 1

After the fire was extinguished, charring continued at the gypsum/CLT interface where gypsum remained. Figure 126 shows charring discovered behind the gypsum board when it was removed 1 hour after the fire was extinguished.

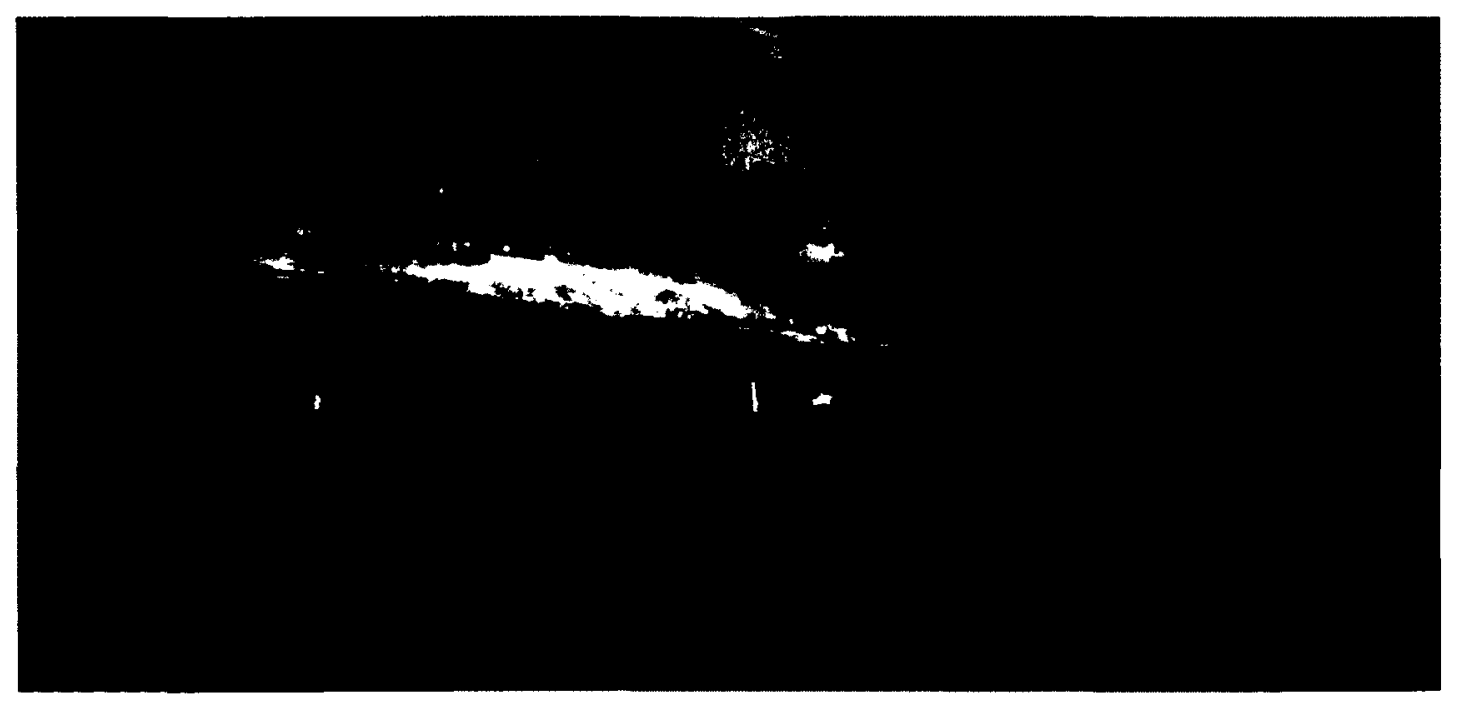

Figure 126 - Charring at the gypsum/CLT interface 1 hour after fire extinguished - Test 1 
Figure 127 shows the total char depths experienced by the structure for Test 1 . The most severe charring occurred on the rear wall near the seat of the fire and directly above the fire on the ceiling, the positions where the gypsum failures were observed.

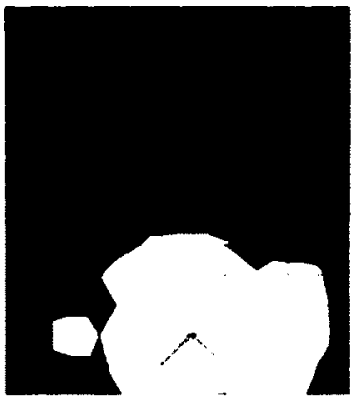

$50 \mathrm{~mm}-60 \mathrm{~mm}$ $\square 40 \mathrm{~mm}-50 \mathrm{~mm}$ $30 \mathrm{~mm}-40 \mathrm{~mm}$ $20 \mathrm{~mm}-30 \mathrm{~mm}$ $10 \mathrm{~mm}-20 \mathrm{~mm}$ $0 \mathrm{~mm}-10 \mathrm{~mm}$
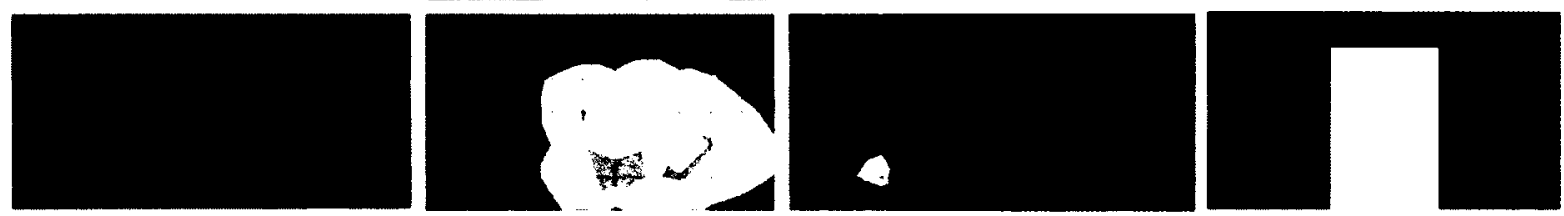

Figure 127 - Final Char Depths (mm) - Test 1

\subsubsection{Test 3 - Unprotected room with propane fire}

The charring depths observed in Test 3 are presented in Figure 128. Charring occured at all positions after 5 minutes at which time the room entered flashover and all surfaces became involved in the fire. Rates of charring up to $6 \mathrm{~mm}$ in depth are an average of $0.81 \mathrm{~mm} / \mathrm{min}$ and reduced to $0.51 \mathrm{~mm} / \mathrm{min}$ over the second $6 \mathrm{~mm}$, likely a result of the char layer developing which acts as an insulator. The overall average charring rate was $0.63 \mathrm{~mm} / \mathrm{min}$ which is consistent with the Eurocode 5 [13] charring rate of $0.65 \mathrm{~mm} / \mathrm{min}$. All charring stopped soon after the propane fire was removed at 25 minutes, similar to what would have been expected from a thick slab of wood [9]. 


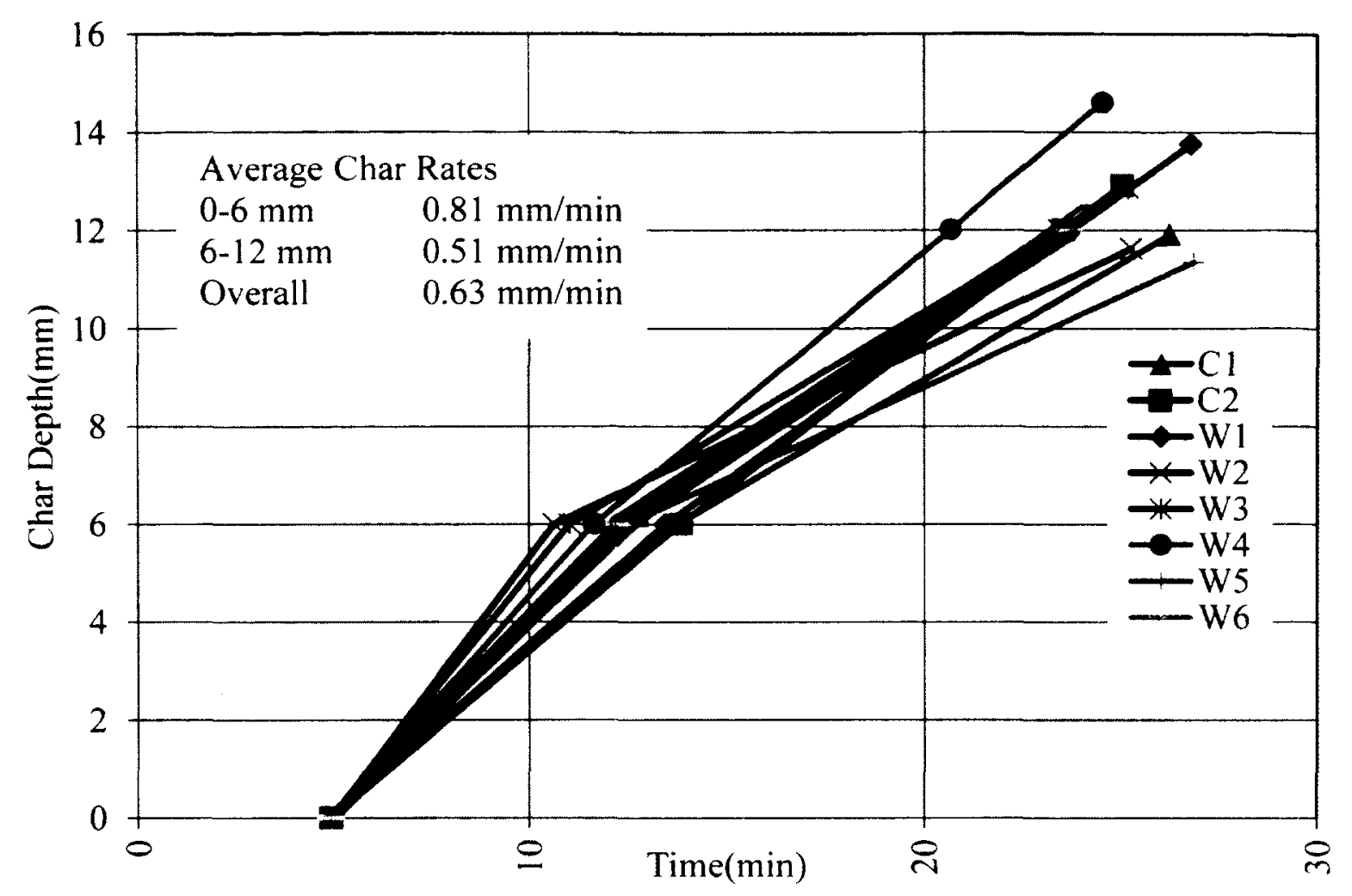

Figure 128 - Charring of CLT panels - Test 3

Final char depth measurements are presented in Figure 129 showing relatively uniform charring throughout the compartment. The deepest charring measurements are observed near the seat of the fire at the rear of the compartment.

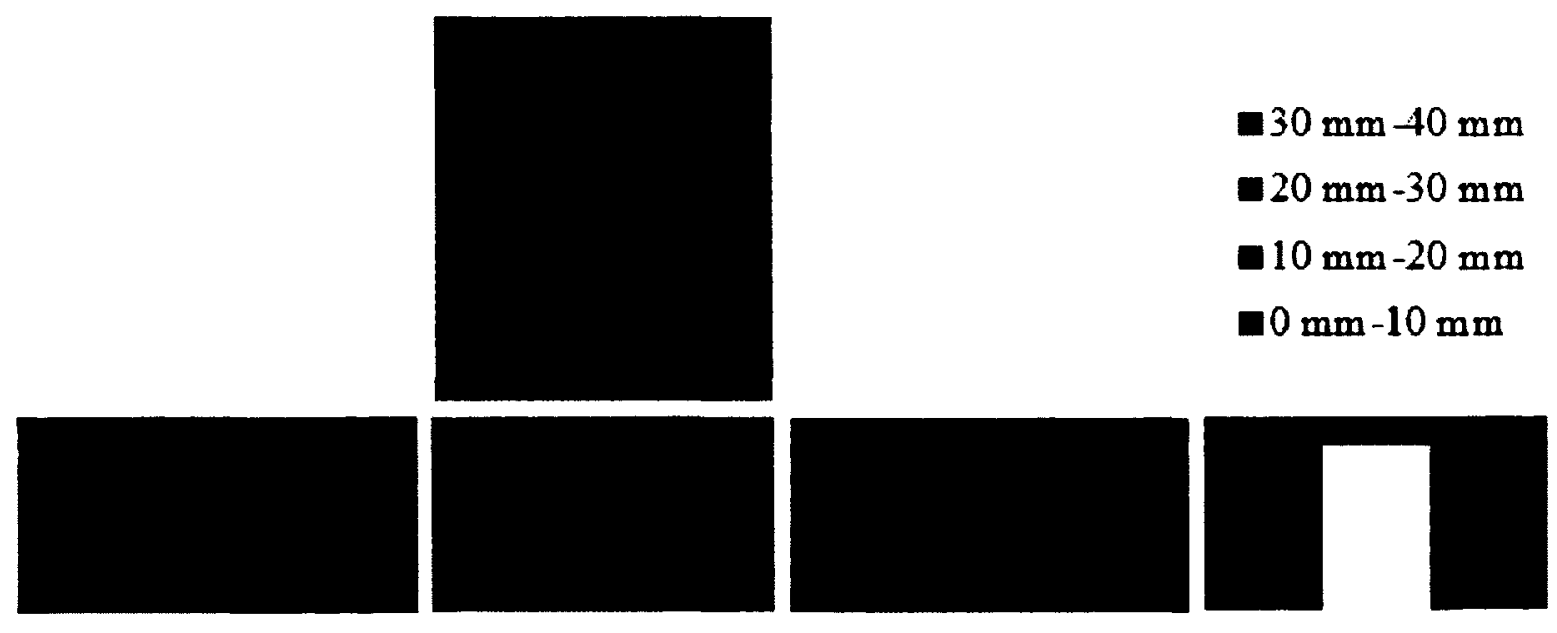

Figure 129 - Final Char Depths (mm) - Test 3 


\subsubsection{Test 5 - Unprotected room with furniture fire}

The charring depths observed in Test 5, presented in Figure 130, were measured up to depths of $24 \mathrm{~mm}$. Charring at all positions is observed at 5 minutes when the room enters flashover. Average char rates over the first $6 \mathrm{~mm}$ were $0.52 \mathrm{~mm} / \mathrm{min}$ increasing to $1.08 \mathrm{~mm} / \mathrm{min}$ up to the depth of $24 \mathrm{~mm}$. This indicates an increase in charring as depth increases which is unlikely, indicating that the depth of the thermocouples may have been incorrect. The overall average of $0.85 \mathrm{~mm} / \mathrm{min}$ is higher than the Eurocode 5 [13] charring rate of $0.65 \mathrm{~mm} / \mathrm{min}$.

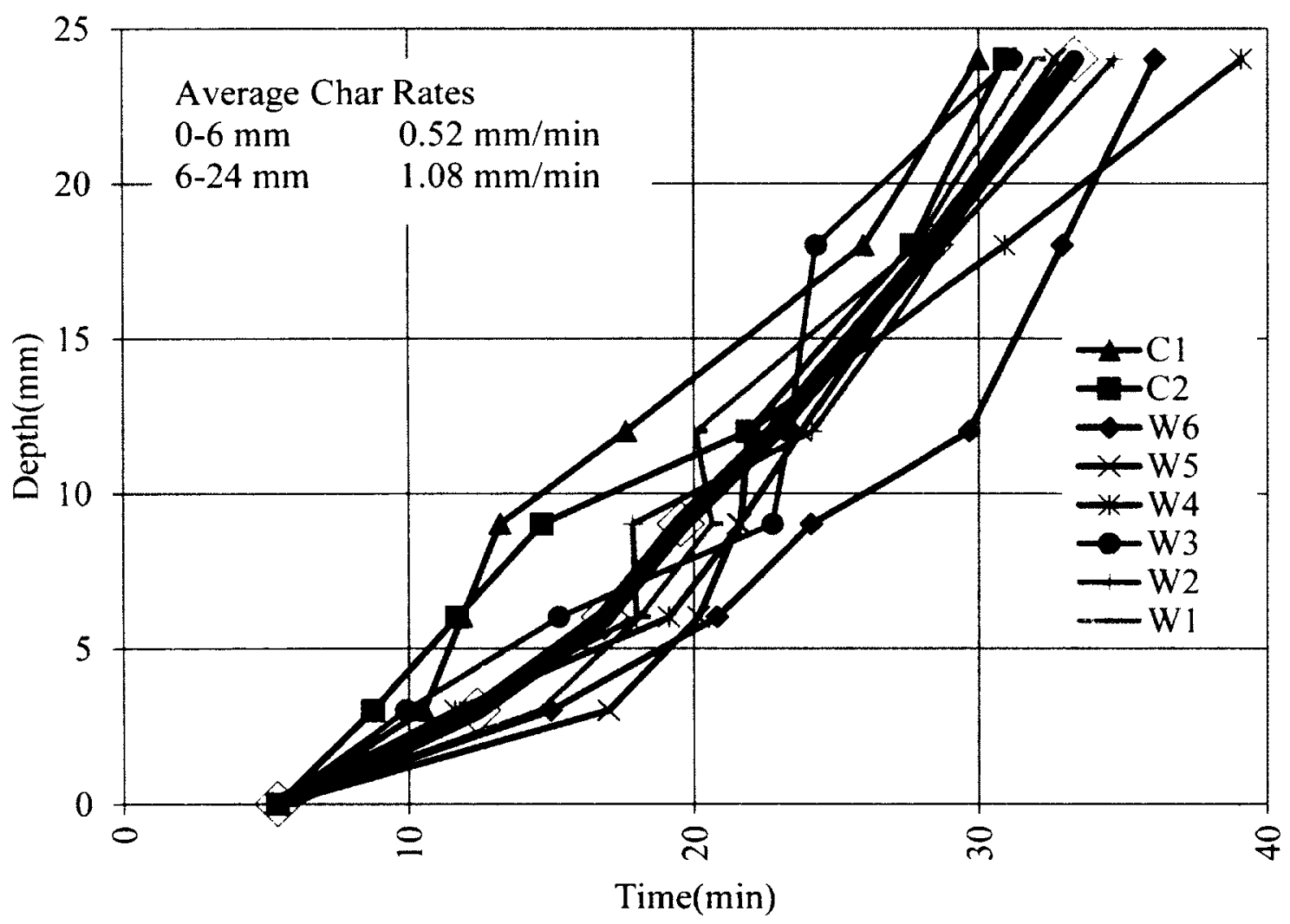

Figure 130 - Charring rates observed in Test 5

Final char depths are presented in Figure 131. The most extreme charring occurred on the ceiling where most convection and highest temperatures would have been expected. Based on a burning time of approximately 60 mins, these measurements 
indicate overall charring rates of approximately $1 \mathrm{~mm} / \mathrm{min}$, higher than the expected values from Eurocode 5 [13]. This increased charring rate overall is due to delamination.

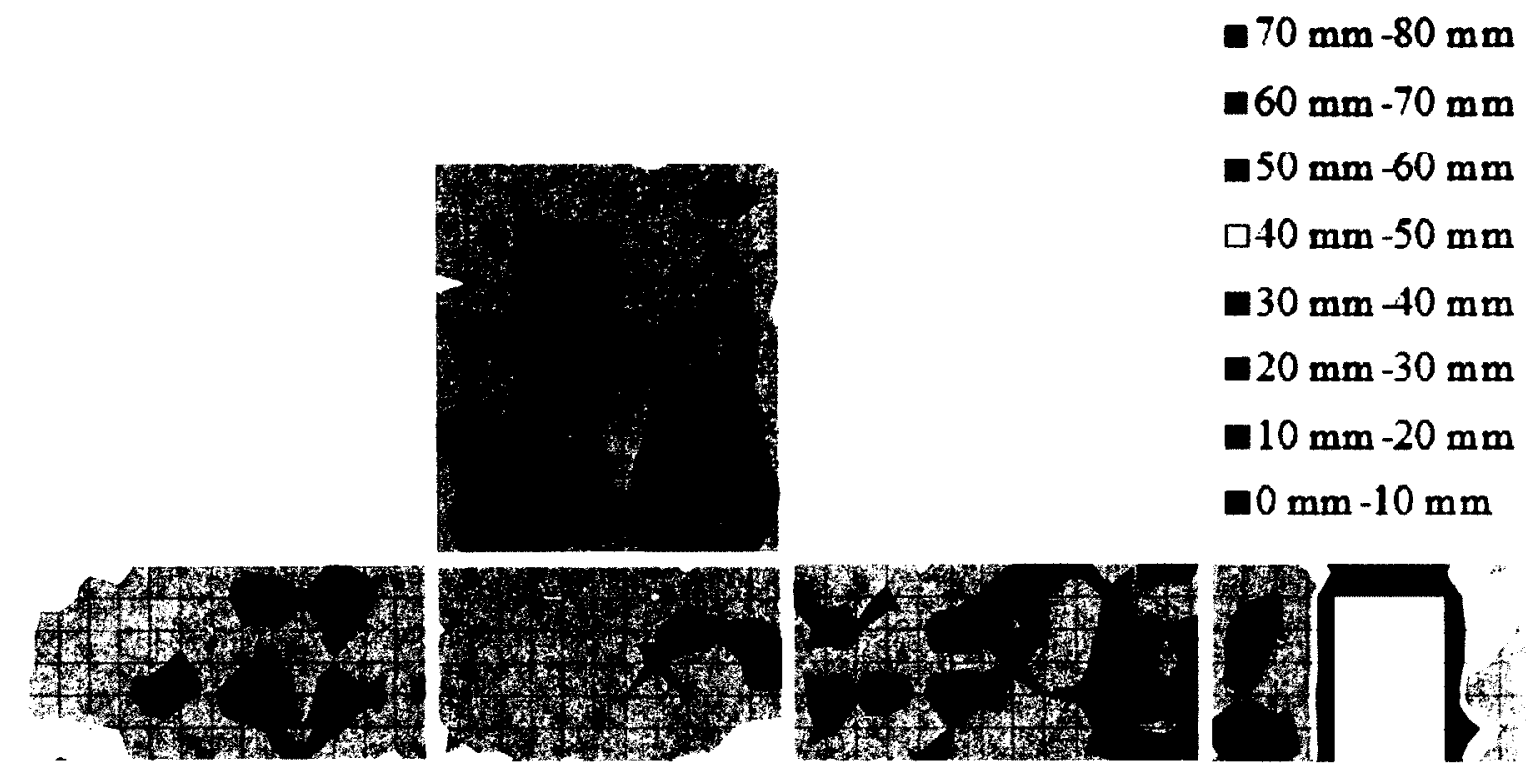

Figure 131 - Final char depths (mm) - Test 5

Figure 132 shows the charring observed following Test 5.

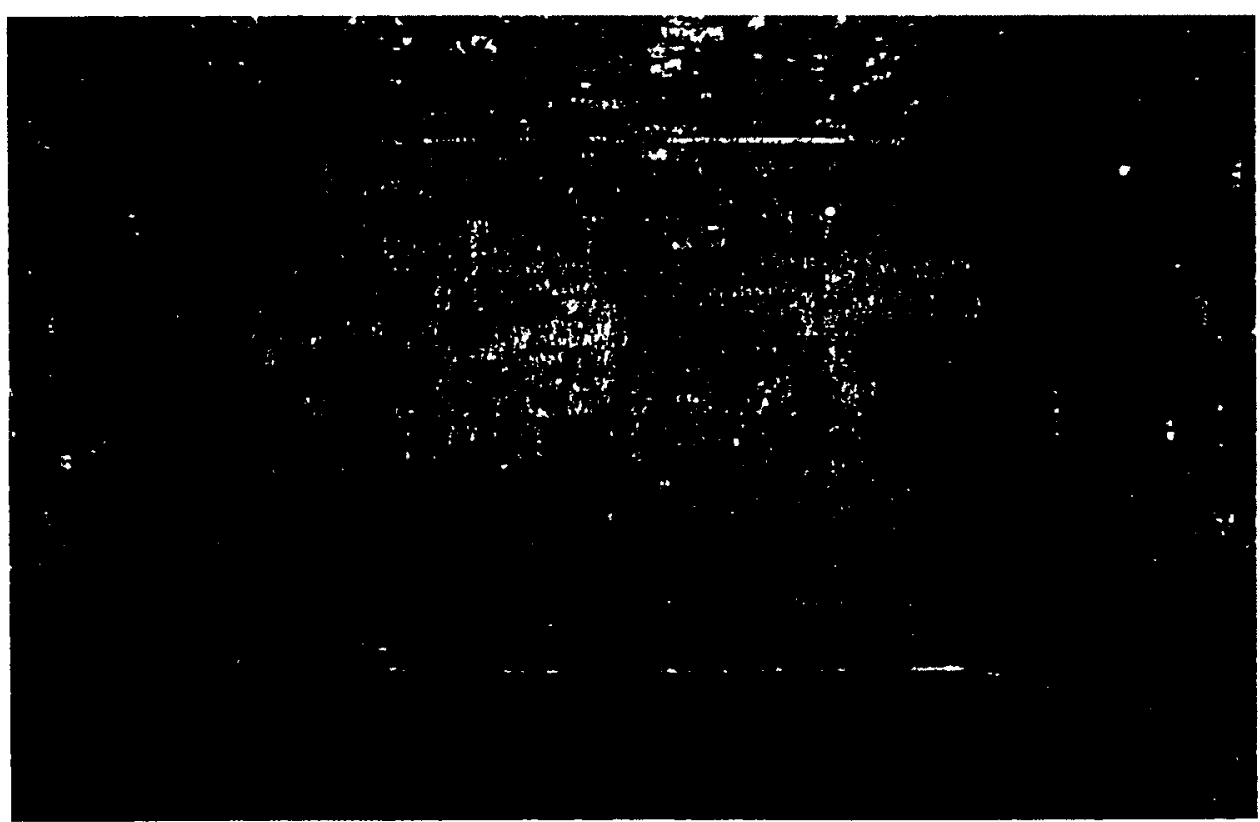

Figure 132 - Charring of CLT panels following Test 5 


\subsection{Fire Detection and Protection}

\subsubsection{Smoke Detectors}

Standard residential smoke detectors were used in the three furniture fires.

Activation occurred during the incipient phases for each fire at times between 20 seconds to 1:27 minutes following ignition of the burners. The indicates that the fire detection would occur well before significant fire growth or involvement of exposed CLT panels.

\subsubsection{Sprinklers}

Sprinkler activation was investigated in Test 2 using a sprinkler head set at $60^{\circ} \mathrm{C}$. Sprinkler activation occurred very early in the growth phase and would likely have controlled the fire before conditions became intolerable or involvement of CLT panels. This indicates that sprinklers should provide adequate protection in situations where CLT panels are used. NBCC [1] requires sprinklers in most buildings above 3 stories and all buildings above 6 stories which should provide adequate protection for structures made from CLT structures.

\subsubsection{Gypsum Protection}

In the protected room with the propane fire, localized failure and falling off of the gypsum panels was only observed close to the fire source. Delamination of the CLT, a phenomenon that was shown to extend the duration of the fire did not occur until after 90 minutes into the fire, long after response would be expected. In the protected rooms with furniture fires, the fire load was consumed before falling off of the protection occurred and in both tests, the CLT panels remained undamaged following the fire. These results indicate that gypsum board protection can provide excellent protection for CLT panels in room fires over an extended period of time 


\section{Summary}

The objective of this research was to conduct room tests to study the contribution of CLT panels to the growth, duration and intensity of room fires. This research contributes to the body of knowledge for fire performance of CLT panels and will be used to develop guidelines for use of CLT panels in mid-rise construction and develop fire modelling tools to predict its fire performance.

5 full scale fire tests were conducted between 18 April 2012 and 25 Jul 2012 at the Carleton University Fire Research Laboratory using rooms constructed from $105 \mathrm{~mm}$ 3-ply CLT panels with propane or furniture as fuel. Tests were conducted for each fuel with the CLT panels in protected (2 layers of $12.7 \mathrm{~mm}$ fire rated gypsum) and unprotected configurations.

Data was collected on HRR, temperature and charring of the CLT panels using a permanent oxygen calorimetry installation and thermocouples installed in the room and within the structure. LabVIEW software was used to record and display the information in real time. Estimated fuel loads for the 2 protected and 1 unprotected furniture fires were 533,553 and $529 \mathrm{MJ} / \mathrm{m}^{2}$ of which an average of $68 \%$ of the energy was released. Based on those observations, the equivalent fuel loads of the protected and unprotected propane fires were estimated at $710 \mathrm{MJ} / \mathrm{m}^{2}$ and $266 \mathrm{MJ} / \mathrm{m}^{2}$ respectively. 


\section{Conclusions}

From the results of the tests that were conducted, the following conclusions could be drawn:

1. In protected room tests using furniture as the fuel, the fires self-extinguished when all combustibles were consumed and the CLT panels remained unaffected by the fire with no noticeable contribution to the growth, duration or intensity of the fire was observed.

2. In the protected room tests with propane as the fuel, once gypsum board protection began to fail, CLT panels contributed to the fire, increasing the energy release and production of smoke.

3. Increased fire growth rates were observed in rooms where CLT panels were unprotected, which reduced time to flashover.

4. Sprinklers can provide protection against fire growth for construction using CLT panels as sprinkler activation is expected to occur before significant fire growth and fire involvement of exposed CLT panels. Sprinklers are recommended where exposed CLT panels are used.

5. Increased rates of energy release were observed where CLT panels were unprotected, approximately twofold in these tests.

6. Where charring caused delamination of the CLT panels, energy release rates increased extending the duration of the room fire. This indicates that the CLT panels can contribute significantly to the fire load in a room and delamination could eventually lead to structural failure. 
7. Delamination of the CLT panels provides fuel to the fire as it uncovers unburnt wood, which could lead to room flashover. Delamination occurred following failure of the gypsum boards in the protected room with propane fire test as a result of extensive charring over a long period which the room temperature remained above $400^{\circ} \mathrm{C}$. This caused the room to flashover for a second time.

8. The peak heat release rate in the unprotected room fire with furniture reached values that were considerably higher than the ventilation controlled peak indicating that combustion was taking place outside the room.

9. This research highlights fire hazards associated with construction using CLT panels in situations where no active fire protection is provided and over extended periods without response. In reality, for mid-rise applications that are the target for this research, the NBCC already includes active fire protection requirements that should prevent any contribution from CLT panels to the growth, duration and intensity of room fires. 


\section{Future Research}

This research featured CLT panels in fully protected and unprotected configurations with a single opening only. To ensure that the results of this research can be used practically for assessing the performance of CLT panels in room fires, further tests should be conducted using common construction methods such as light frame timber or steel. In reality there are many possible options for configuration of protection and ventilation in a room.

In future research it would be beneficial to understand the effects of partial protection to gain an understanding of the contributions and behaviour of the CLT panels when smaller areas of the room and specific orientation are exposed.

Tests should also be conducted with CLT panels constructed with different adhesives, such as thermosets, which may minimize delamination, and panels with different CLT ply thicknesses.

Due to the unique phenomenon of delamination identified with CLT in advanced stages of fire, it is recommended that the fire service be included in the distribution of CLT fire performance literature in the interests of firefighter safety. 


\section{References}

1. National Building Code of Canada., N.R.C.o.C. Issued by the Canadian Commission on Building and Fire Codes, Editor 2005.

2. Popovski, M.M.S.G.E.K.M., Innovative Mid-rise Timber Structures Offer New Opportunities for Designers, in SEAOC 2011.

3. Gagnon, P.C.S., Cross Laminated Timber: a Primer, 2010, FPInnovations.

4. Wheeldon, D., World's tallest timber building 'tops out' in Melbourne, in Architecture and Design2012: Australia.

5. Harris, M., Wooden high-rise buildings, in Engineerign and Technology Magazine 2012.

6. Spearpoint, M., Fire engineering design guide2008: New Zealand Centre for Advanced Engineering.

7. Ohlemiller, T.J., Smoldering Combustion. SFPE Handbook of Fire Protection Engineering, 1995: p. 1-229.

8. Buchanan, A.H., Structural Design for Fire Safety2006.

9. Drysdale, D., An introduction to fire dynamics2011: Wiley.

10. Tewarson, A. and R. Pion, Flammability of plastics-1. Burning intensity. Combustion and Flame, 1976. 26: p. 85-103.

11. Petrella, R., The mass burning rate of polymers, wood and organic liquids. Journal of Fire and Flammability, 1980. 11.

12. Frangi, A. and M. Fontana, Charring rates and temperature profiles of wood sections. Fire and Materials, 2003. 27(2): p. 91-102.

13. EN 1995-1-2:2004. Eurocode 5: Design of Timber Structures, Part 1-2: GeneralStructural Fire Design.

14. V. Babrauskas, a.R.D.P., Heat Release rate: The Single Most Important Variable in Fire Hazard. Fire Safety Journal, 1992. 18: p. 255-272.

15. Babrauskas, V., Heat Release Rates, in The SFPE Handbook of Fire Protection Engineering2008, National Fire Protection Association.

16. Quintiere, B.K.a.J.G., Enclosure Fire Dynamics2000: CRC Press LLC.

17. Thornton, W., The relation of oxygen to the heat of combustion of organic compounds. Philosophical Magazine and Journal of Science, 1917. 33: p. 196-203.

18. Huggett, C., Estimation of the Rate of Heat Release by Means of Oxygen Consumption. Journal of Fire and Flammability, 1980. 12: p. 61-65.

19. Janssens, M.L., Measuring rate of heat release by oxygen consumption. Fire Technology, 1991. 27(3): p. 234-249.

20. Ko, Y., R. Michels, and G. Hadjisophocleous, Instrumentation Design for HRR Measurements in a Large-Scale Fire Facility. Fire Technology, 2011. 47(4): p. 1047-1061.

21. Ko, Y.J., A Study of the Heat Release Rate of Tunnel Fires and the Interaction between Suppression and Longitudinal Air Flows in Tunnels, in Department of Civil and Environmental Engineering2011, Carleton University.

22. Shannon, K. and B. Butler. A review of error associated with thermocouple temperature measurement in fire environments. in Proceedings of the 2nd Fire Ecology Congress. 2003.

23. Omega Engineering Inc. Thermocouples - An Introduction. 2012; Available from: http://www.omega.com/thermocouples.html.

24. Wickström, U., The plate thermometer - a simple instrument for reaching harmonized fire resistance tests. Fire Technology, 1994. 30(2): p. 195-208. 
25. Quintiere, J.G. and J. Wiley, Fundamentals of fire phenomena2006: John Wiley England.

26. Walton, W.D. and P.H. Thomas, Estimating temperatures in compartment fires. SFPE Handbook of Fire Protection Engineering, 1995: p. 3-198.

27. Bwalya, A., An Overview of Design Fires for Building Compartments. Fire Technology, 2008. 44(2): p. 167-184.

28. Heskestad, G., Engineering relations for fire plumes. Fire Safety Journal, 1984. 7(1): p. 25-32.

29. NFPA, N., 204M-Guide for Smoke and Heat Venting. National Fire Protection Association, 1995.

30. Bwalya, A.C., N. Benichou, and M. Sultan, Literature review on design fires2003: Institute for Research in Construction, National Research Council Canada.

31. Waterman, T., Room flashover-Criteria and synthesis. Fire Technology, 1968. 4(1): p. 25-31.

32. Francis, J. and A. Chen, Observable characteristics of flashover. Fire Safety Journal, 2012. 51: p. 42-52.

33. McCaffrey, B., J. Quintiere, and M. Harkleroad, Estimating room temperatures and the likelihood of flashover using fire test data correlations. Fire Technology, 1981. 17(2): p. 98-119.

34. EN 1991-2-2: 1995E. Eurocode 1: Basis of Design and Actions on Structures, Part 2-2: Actions on Structures Exposed to Fire.

35. Magnusson, S.E. and S. Thelandersson, Temperature-time curves of complete process of fire development: Theoretical study of wood fuel fires in enclosed spaces1970: Royal Swedish Academy of Engineering Sciences.

36. Harmathy, T. and J.R. Mehaffey, Post-Flashover compartment fires. Fire and Materials, 1983. 7(2): p. 49-61.

37. Hazewinkel, M., Encyclopaedia of Mathematics, Supplement III. Vol. 3. 2001: Springer.

38. Hakkarainen, T., Post Flashover Fires in Light and Heavy Timber Construction Compartments. Fire Sciences, 2002. 20.

39. Frangi, A., et al. Natural full-scale fire test on a 3 storey XLam timber building. in World Conference on Timber Engineering. 2008.

40. Chen, Z., Design Fires for Motels and Hotels, in Civil Engineering2008, Carleton University: Ottawa.

41. NIST, Fire Dynamics Simulator 5.2.0, 2008.

42. Bois, N.S., CROSS-LAMINATED TIMBER PANELS - LAYUPS FOR 3, 5, ET 7 PLYS, DS01_E_Dimensions.pdf, Editor 2011.

43. Structures, N.W., Erection Plan, U.-F.t.D. PLAN_(2012-02-12_rO.pdf, Editor 2012.

44. Bois, N.S., CROSS-LAMINATED TIMBER PANEL CONNECTIONS, DS02_e_Connection_Details.pdf, Editor 2010.

45. National_Instruments, LabVIEW 11, 2011.

46. Bwalya, A., et al., Survey Results of Combustible Contents and Floor Areas in Canadian Multi-Family Dwellings. Fire Technology, 2011. 47(4): p. 1121-1140.

47. State of California Department of Consumer Affairs, N.H., CA., California Technical Bulletin 133 Flammability Test Procedure for Seating Furniture for Use in Public Occupancies.

48. Craft, S., CUWoodFrame - A Heat and Mass Transfer Model for Light-frame Wood Floors Exposed to Fire, in Ottawa-Carleton Institute of Civil and Environmental Engineering2009, Carleton University. 
49. Ogawa, A., Psychrometric Chart, 2009: Wikipedia. p. Psychrometric Chart for Sea-level pressure using SI units.

50. Frangi, A., et al., Experimental analysis of cross-laminated timber panels in fire. Fire Safety Journal, 2009. 44(8): p. 1078-1087.

51. Roberts, A.F., Calorific Values of partially decomposed wood samples. Combustion and Flame, 1964.

52. Roberts, A.F., Ultimate analysis of partially decomposed wood samples. Combustion and Flame, 1964. 


\section{Appendix A - Preliminary Calculations}

\section{A.1 Combustion of wood and its products of pyrolysis}

During combustion wood releases energy by two methods, the combustion of volatiles produced during gasification, and the smouldering combustion of the char that remains. Smouldering combustion requires oxygen to be present at the char location whereas the volatiles produced from gasification can combust remotely. Low levels of oxygen would thus promote a buildup of the char layer. The volatiles and char have different values for heat of combustion, examples for European beech [51, 52] are presented in Table 21 which were used in the analysis and prediction fire performance of the room in this section.

Table 21 - Combustion properties of European beech [51]

\begin{tabular}{|l|c|c|c|}
\hline & Wood & Volatiles & Char \\
\hline Gross Heat of Combustion $\Delta H_{c}\left(k J g^{-1}\right)$ & 19.5 & 16.6 & 34.3 \\
\hline Mean Molecular Formula & $\mathrm{CH}_{1.5} \mathrm{O}_{0.7}$ & $\mathrm{CH}_{2} \mathrm{O}$ & $\mathrm{CH}_{02} \mathrm{O}_{002}$ \\
\hline Theoretical Air Requirements $\left(g_{a r} / g_{\text {fuel }}\right)$ & 5.7 & 4.6 & 11.2 \\
\hline Yield by weight & & $83 \%$ & $17 \%$ \\
\hline
\end{tabular}

\section{A.2 Maximum Room Temperatures}

Two methods were used to estimate the max room temperatures for the tests, the method of Law, Eq 19, and Eurocode (modified by Buchanan), Eq 20.

$$
\begin{array}{ll}
\text { Method of Law: } & T_{\max }=1127^{\circ} \mathrm{C} \\
\text { Eurocode: } & T_{g}=1241^{\circ} \mathrm{C}
\end{array}
$$




\section{A.3 Self-sustaining combustion}

A particular interest in this research was to assess whether rooms with CLT panels will support combustion once the fuel load had been consumed. It is known that heavy timber will not support combustion as the losses due to radiation, convection and degradation exceed that of the combustion of the products. In a room environment, the losses are reduced as they are directed back into the room and it is feasible that selfsustaining combustion may occur. To assess this for the test room, an energy balance was conducted for the room using Eq 32 unprotected CLT panels.

$$
\dot{Q}_{R(x) m}=\dot{Q}_{c}-\dot{Q}_{l}
$$

Where

$$
\begin{aligned}
& \dot{Q}_{C}=\text { HRR occurring in room } \\
& \dot{Q}_{l}=\text { Losses from room }
\end{aligned}
$$

This was calculated by assessing the potential released during degradation of structure and then assessing the HRR as a function of air flow into the room. For this calculation, only the structure is considered with respect to burning in the compartment.

The mass flow rate is derived from $\mathrm{Eq} 33$ assuming that all of products are released at the estimated charring rate.

$$
\dot{m}_{w:}=\frac{A_{s} \beta_{c s s} \rho}{1000 \times 60} g \cdot s^{-1}
$$

Where $\quad \beta_{c s t}=$ estimated charring rate $=0.8 \mathrm{~mm} \cdot \mathrm{min}^{-1}$

$$
A_{\mathrm{s}}=53.6 \mathrm{~m}^{2}
$$

Eq 34 is used to estimate the max possible contribution of CLT panels to the fire.

$$
\dot{Q}_{\max . C l . T}=\dot{m}_{w} \Delta h_{c}
$$


Where $\quad \Delta h_{c}=\Delta H_{c}-L_{\mathrm{v}}=16.36 \mathrm{~kJ} \cdot \mathrm{g}^{-1}$

$$
L_{\mathrm{v}}=2.64 \mathrm{~kJ} \cdot \mathrm{g}^{-1}=\text { Heat of gasification for Douglas Fir [19] }
$$

The maximum potential contribution from the CLT panels in the room using the equations above is $6.75 \mathrm{MW}$, and can be considered at $4.64 \mathrm{MW}$ if only assessing the combustion of the volatiles, assuming that the char is not combusted.

Table 22 - Maximum potential contribution from CLT in fire

\begin{tabular}{|l|l|l|l|}
\hline$\dot{m}_{w}$ & 400 & ${\mathrm{~g} . \mathrm{s}^{-1}}^{-1}$ & estimated max mass flow of volatiles from CLT \\
\hline$\dot{\mathrm{Q}}_{\max (I T}$ & 6.75 & $\mathrm{MW}$ & max contribution \\
\hline$\dot{\mathrm{Q}}_{\max , V}$ & 4.64 & $\mathrm{MW}$ & Volatiles only (assuming no char is burned) \\
\hline
\end{tabular}

To estimate the max HRR in the room in more detail than Table 22 it is calculated from the amount of air entering the room through analysis of vent flows. Iteration of Eq 13 and Eq 14, as discussed in Chapter 2.6, are used to identify the neutral plane $\left(h_{l}\right)$ which is used to assess the inflow of air. This is conducted for the maximum temperatures estimated by Law and those observed in Hakkarainen's [38] unprotected heavy timber test.

The HRR in the room is then determined using Eq 6 assuming all oxygen entering the compartment is consumed. The trend in HRR, presented in Table 23 shows that an increase in temperature reduces the amount of air entering the room, which in turn reduces the amount of combustion occurring in the room. The max HRR for air entering the room is also lower than the potential HRR from the CLT panels already discussed, which means that flaming outside the compartment will be expected.

\section{A.4 Losses}

The losses in the room are then estimated to determine the overall energy balance. 


$$
\dot{Q}_{I}=\dot{q}_{l}+\dot{q}_{H}+\dot{q}_{R}+\dot{q}_{B}
$$

Where

$$
\begin{aligned}
& \dot{q}_{l}=\text { convective heat losses }(M W) \\
& \dot{q}_{u}=\text { internal conductive losses }(M W)
\end{aligned}
$$$$
\dot{q}_{R}=\text { radiative losses }(M W)
$$$$
\dot{q}_{B}=\text { energy storage losses }(M W)
$$

a. Convective heat losses for air entering the compartment

$$
\dot{q}_{l}=\dot{m}_{u} c_{p} \Delta T
$$

b. Pettersen et al uses Eq 37 to represent the internal conductive heat losses to the boundaries which tends to 0 as the surface temperature of the boundary approaches that of the room.

$$
\dot{q}_{w}=\left(A_{t}-A_{O}\right) \frac{1}{\pi} \sqrt{\frac{k \rho c}{t}}\left(T_{g}-T_{a}\right)
$$

Where $\quad t<t_{p}$

The CLT boundaries are degrading into volatiles and char however, so this eqn is replaced with an expression using the heat of gasification assuming steady state charring in Eq 38

$$
\begin{aligned}
\dot{q}_{W^{\prime}} & =A_{C I T} \rho_{C L T} \beta L_{v} & & \text { for steady state charring } \\
& =1.015 \mathrm{MW} & & \text { @ } 0.8 \mathrm{~mm} \cdot \mathrm{min}^{-1}
\end{aligned}
$$

c. Radiative losses from the opening are determined using Eq 39:

$$
\dot{q}_{R}=A_{o} \varepsilon_{f} \sigma\left(T_{y}^{4}-T_{u}^{4}\right)
$$

d. Assume $\dot{q}_{B}$, energy storage, is minor and generally considered to be negligible. 
The energy balance calculations are presented in Table 23 and have been determined using the room temperatures for Hakkarainen (unprotected heavy timber), LAW and Eurocode. These show that the losses increase as the room temperature increases and that the room will likely lose more energy than is being released within the room at higher temperatures.

Table 23 - HRR (MW) - Total and air limited

\begin{tabular}{|l|c|c|c|}
\cline { 2 - 4 } \multicolumn{1}{c|}{} & \multicolumn{3}{c|}{ Max Temp } \\
\cline { 2 - 4 } \multicolumn{1}{c|}{} & 800 & 1127 & 1241 \\
\hline$\dot{m}_{a}\left(\mathrm{~kg} . \mathrm{s}^{-1}\right)$ & 1.31 & 1.25 & 1.23 \\
\hline$h_{l}(\mathrm{~m})$ & 0.71 & 0.67 & 0.66 \\
\hline$\dot{Q}_{\text {max }, a r r}(M W)$ & 3.94 & 3.75 & 3.68 \\
\hline$\dot{Q}_{l .}(M W)$ & 2.84 & 3.76 & 4.13 \\
\hline$\dot{Q}_{\text {Roxm }}(M W)$ & 1.10 & -0.01 & -0.45 \\
\hline
\end{tabular}

Whilst the calculations also show that the net HRR for the room is positive at the lower temperature of $800^{\circ} \mathrm{C}$, indicating that the room combustion will be self-sustaining, a few points are worth considering:

- Char does not always burn as it requires oxygen at the interface, even where oxygen is present in the room, the gasification products may displace it as they are released through the char increasing the thickness of the char layer.

- Decreases in $\dot{m}_{x}$ are likely as the char layer builds up as it will produce an insulating effect to the CLT which reduces the char rate/rate of gasification and fuel to the fire. 
- The calculations above consider combustion in the room at $100 \%$ efficiency, which is unlikely, and the HRR values are likely to be lower further reducing the probability of self-sustaining combustion.

Based on the calculations above, it is unlikely that the CLT panels will be able to sustain combustion without an additional fuel source in the room. 